\title{
Three Essays on Gender and Education in Canada
}

by

Susan M. Bennet

A thesis submitted to the Faculty of Graduate and Postdoctoral Affairs in partial fulfillment of the requirements for the degree of

\section{Doctor of Philosophy}

in

\section{Economics}

Carleton University

Ottawa, Canada

(C) 2017, Susan M. Bennet 


\section{Abstract}

In the first chapter of this dissertation, I examine the gender gap in primary school academic performance. While boys and girls have similar cognitive abilities, they are systematically assigned to different performance categories. Hypothesizing that this may be due to differences in non-cognitive skills, I construct a measure of these skills based on self-regulation and hyperactivity. Boys are reported to have lower levels of these skills, by both parents and teachers. Notably, I find that even when I have controlled for all skills, both cognitive and non-cognitive, boys are still more likely to be assigned to a lower performance category than girls.

In the second chapter, I estimate a production function for grade outcomes in the senior year of high school, where boys continue to lag girls.. The focus of this essay is on the contribution of differences in non-cognitive skills in explaining this gap in grade outcomes. This research finds that, even controlling for the lower level of non-cognitive skills possessed by boys, gender still plays an important role in determining the overall grade in the senior year of high school. By examining the production functions for girls and boys separately, it becomes apparent that much of the difference in grade outcomes can be attributed to the difference in the likelihood of academic advancement associated with increases in skills, particularly cognitive skills.

The participation rate of boys in post-secondary education lags that of girls substantially. One important factor in explaining this gender gap is high school performance, where there is a significant gender gap. However, there is substantial heterogeneity by gender in PSE participation within high school grade categories. The final chapter of this dissertation examines the interplay of gender, aspirations and skills in determining participation in post-secondary education, at ages 19 and 25, conditional on academic achievement in high school. The results of this research indicate that gender influences post-secondary education participation through a number of channels beyond high school grade. Notably, even after accounting for skills, aspirations, and high school grades, this research finds that there remains a significant role for gender. 


\section{Acknowledgements}

Thank you to my supervisor Marcel Voia, who believed in me unfailingly, even when I did not. Thank you also to my co-supervisor Chris Worswick for providing calm and thoughtful guidance. I am especially grateful to Lynda Khalaf, who provided support and encouragement at every step of the way, from the first class right through to the thesis defence.

My manager at ESDC, Tomasz Gluszynski, provided me with endless support in the final year of my thesis writing, helping me through many rough spots. Thank you Tom.

I am grateful to my daughters, Rachael and Emma, for their enthusiastic support. My son, Ian, worked right alongside me for many years, and always knew I'd succeed, even when I was sure I would not. Thank you, Ian, for your patience.

A whole community of friends supported me throughout my studies, stepping in to keep my life running while I was studying for comps, going to classes, or writing my thesis. Thank you Alex Robison, Lisa Creskey, Stephanie Sewell, Doris Nabert, Sylvie Bourassa, and James Drevniok.

Thank you to my father, David, and my sister, Tracy, for being a very persistent cheerleading squad. Finally, this thesis is dedicated to the memory of my mother, Michaeline Bennet, whose brave decision to go back to finish high school as an adult taught me the value of persistence, and inspired me to always keep learning. 


\section{Table of Contents}

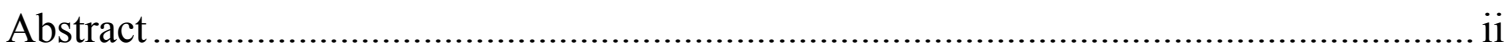

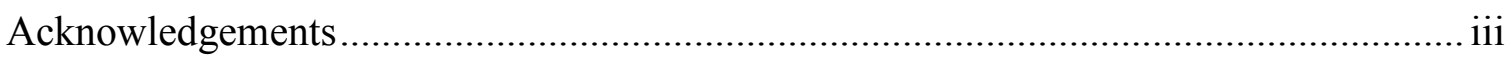

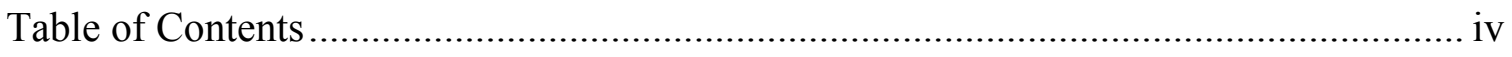

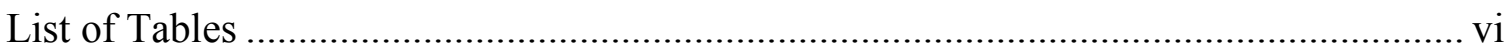

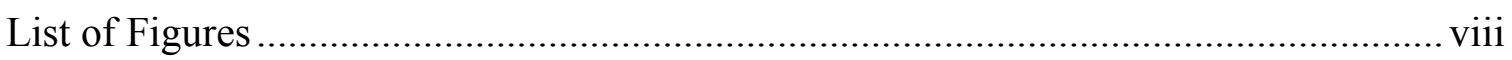

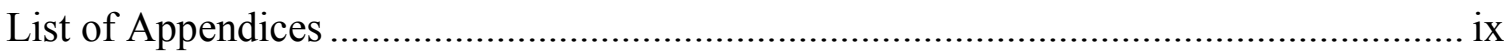

1 Chapter: Gender and Skills in the Determination of Primary School Performance ...... 10

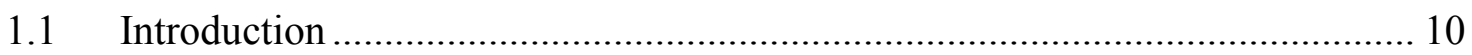

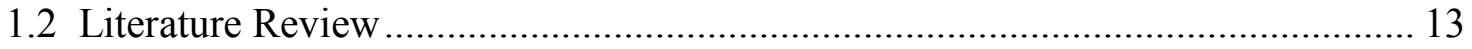

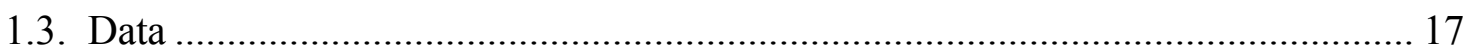

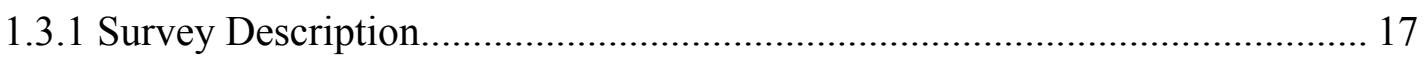

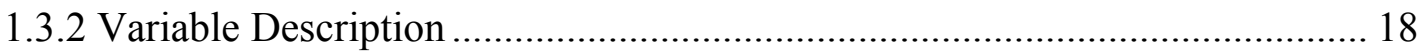

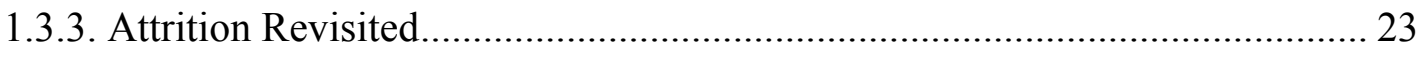



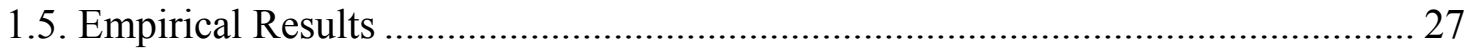

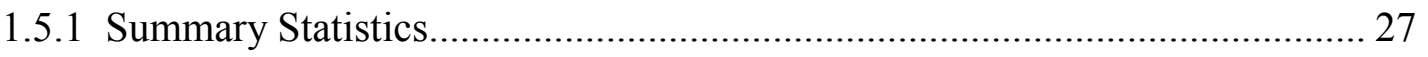

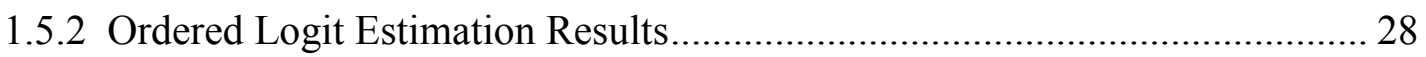

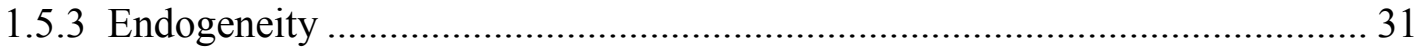

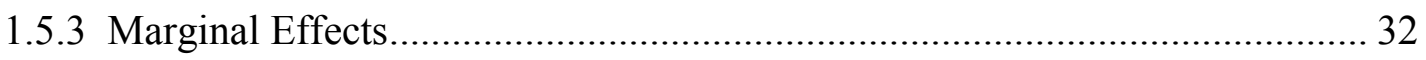

1.5.4. Marginal Effects Along the Skills Distributions............................................ 33

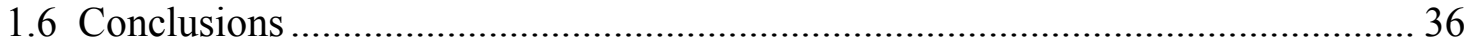



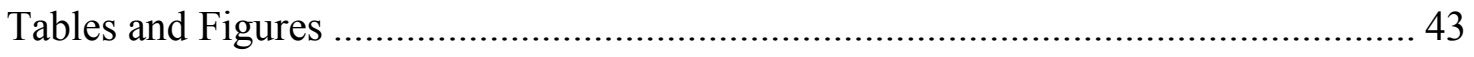

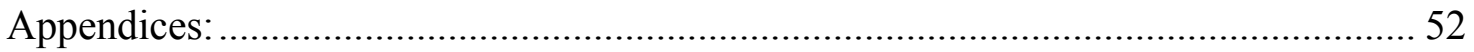

2 Chapter: Gender and Skills in the Production of High School Grades......................... 53



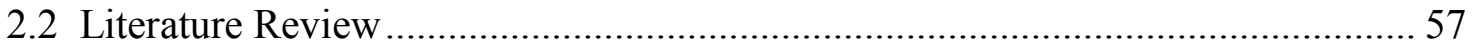

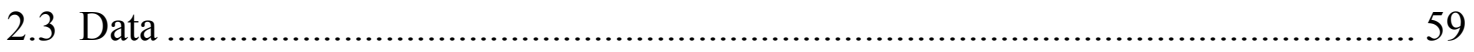

2.3.1 Youth in Transition Survey ………............................................................. 59

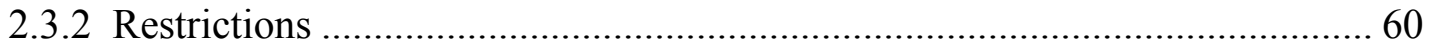

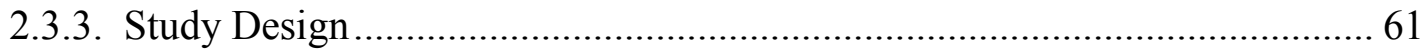




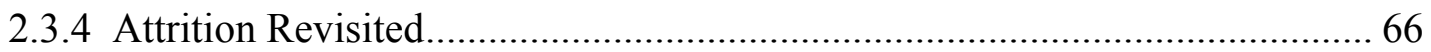

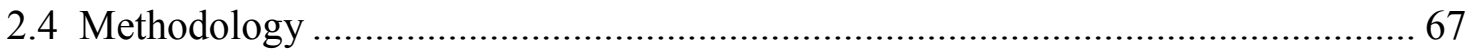

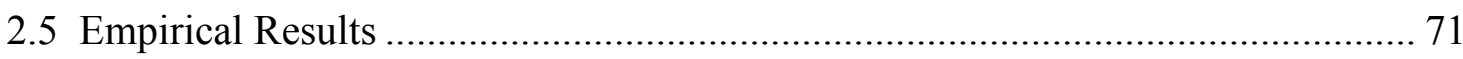

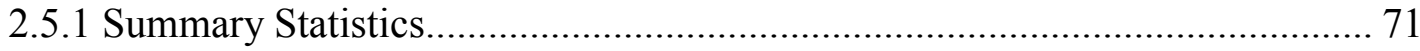

2.5.2 Regression Analysis - Ordered Logit ......................................................... 73

2.5.3 Marginal Effects of Gender and Other Covariates in the Full Model............. 75

2.5.4 Robustness Check - Generalized Ordered Logit........................................... 76

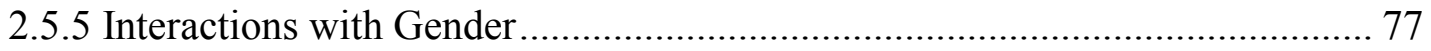



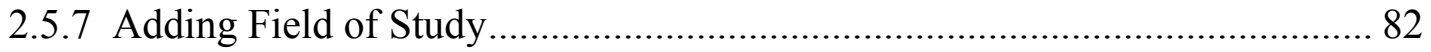



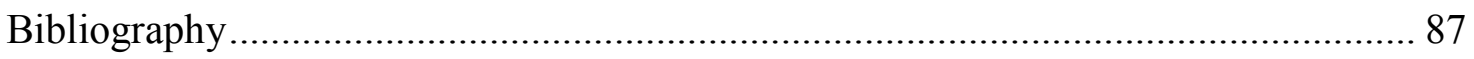



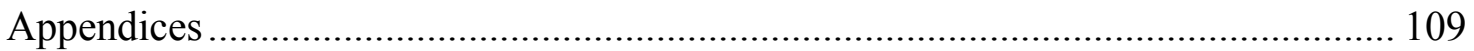

3 Chapter: The Role of Gender in PSE Participation in Canada .................................. 121

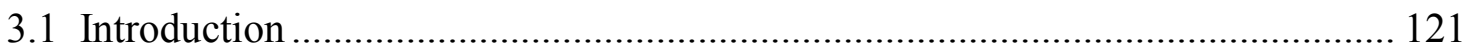

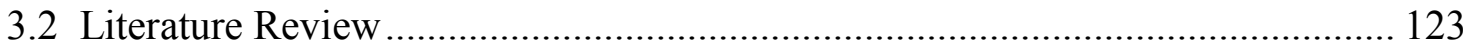

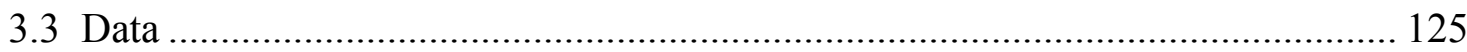

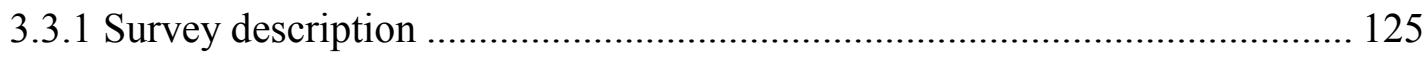

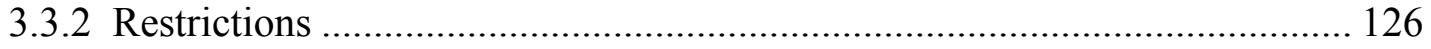

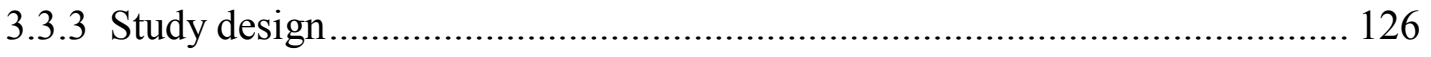

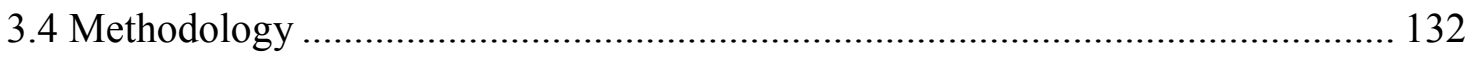

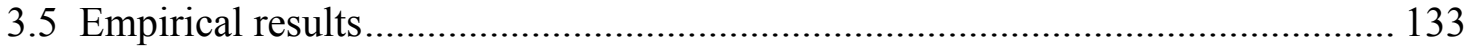

3.5.1 Short-run determinants of PSE participation: Cycle 3 analysis.................... 133

3.5.2 Longer-run determinants of PSE participation - Cycle 6 analysis ................ 143

3.5.3 Discussion of Results: The Residual Effect of Gender................................... 145

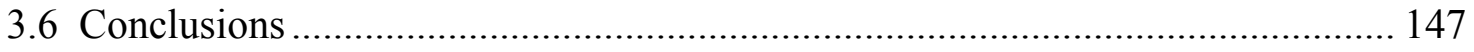

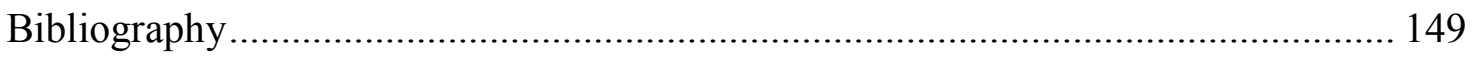

Tables and Figures …………………................................................................ 153

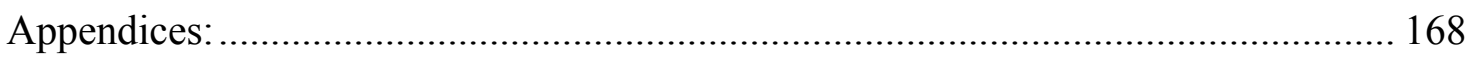

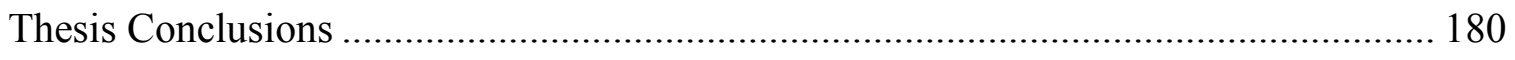




\section{List of Tables}

Table 1.1 Distributions of Teacher-Assessed Performance by Gender, Cycle 2 ............ 43

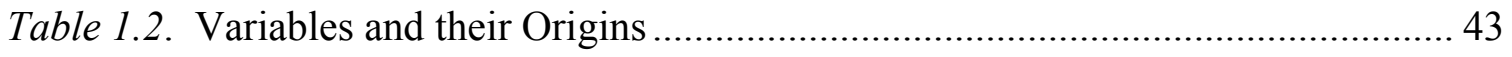

Table 1.3. Average Student Characteristics over Cycles 1 and 2 ............................... 43

Table 1.4. Average Characteristics - Survey Leavers vs. Continuing Respondents ........ 44

Table 1.5. Average Characteristics of the $\mathrm{C} 2$ Populations by Teacher Responses........... 44

Table 1.6. Summary Statistics by Gender (Cycle 2 population)..................................... 44

Table 1.7. Ordered Logit Regression Results. .......................................................... 45

Table 1.8a. AME of Gender, Cognitive Skills Only.................................................... 45

Table 1.8b. AME of Gender: PMK-Assessed Non-Cognitive Skills............................... 46

Table 1.8c. AME of Gender: Teacher-Assessed Non-Cognitive Skills.......................... 46

Table 1.9a. Defining Non-Cognitive Skills Levels .................................................... 46

Table 1.9b. Distribution of Non-Cognitive Skills Levels ........................................... 46

Table 1.10a. MER of Gender: LOW Non-Cognitive Skills Levels, PMK ..................... 47

Table 1.10b. MER of Gender: LOW Non-Cognitive Skills Levels: Teacher................. 47

Table 1.11a. MER of Gender: HIGH Non-Cognitive Skills Levels: PMK.................... 47

Table 1.11b. MER of Gender: HIGH Non-Cognitive Skills Levels: Teacher............... 48

Table 1.12a. Summary of MER of Gender (Boy-Girl): PMK ....................................... 48

Table 1.12b. Summary of MER of Gender (Boy-Girl): Teacher.................................... 48

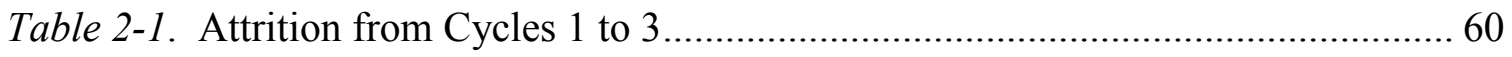

Table 2-2. Grade in final year of high school as of 2004 (Age 19) by gender ............... 61

Table 2-11b - Selected Marginal Effects with Interactions Included............................ 78

Table 2.3. Summary and Origin of Variables Used in Analysis.................................. 92

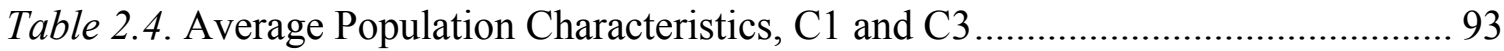

Table 2.5. Summary Statistics of Explanatory Variables by Gender. ............................. 94

Table 2.6. Aspirations (measured at age 17) by Gender.............................................. 94

Table 2.7a. Distribution of Overall Grade for High Performers in Reading. .................. 95

Table 2.7b. Distribution of Overall Grade for Student with High Learning Skills. ........ 95

Table 2.7c. Distribution of Overall Grades for Students with High Aspirations (>BA). 95

Table 2.8. Ordered Logit Coefficients for Models (A) - (F)..................................... 96

Table 2.9. Average Marginal Effect Using Ordered Logit, for Model (E) ..................... 97

Table 2.10. AME, Ordered Logit vs Generalized Ordered Logit for Model (E) ............. 98

Table 2.11: Model (E) with Interactions ...................................................................... 99

Table 2.12. Average Marginal Effects, by Gender (Ordered Logit)............................ 100

Table 2.13. Decomposition Results Using Oaxaca, Blinder and Neumark approaches 101

Table 2.14. CIP Primary Groupings with Their Constituent Series and Subseries ........ 102

Table 2.15. Field of Study by Primary Groupings and Gender. ................................. 104 
Table 2.16. Ordered Logit Results Controlling for Field of Study ……....................... 105

Table 2.17. Average Marginal Effect of Gender, with/without Field of Study ............. 106

Table 3.1. Tabulation of Highest Education Taken, by Cycle 3 and Cycle 6............... 153

Table 3.2. Summary and Origin of Variables Used in Empirical Analyses ................... 154

Table 3.3. Highest Education Taken (C3) by Grade, Boys vs Girls ............................. 155

Table 3.4. Average Characteristics by Gender ........................................................ 156

Table 3.5. Coefficients from Ordered Logit Regressions, Cycle 3............................... 157

Table 3.6. AME using Ordered Logit (Model E)....................................................... 158

Table 3.7a. AME from the Generalized Ordered Logit Estimation (Model E) ............. 159

Table 3.7b. AMEs from Ordered Logit vs. Generalized Ordered Logit Estimations ..... 160

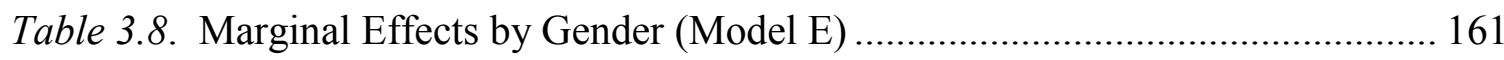

Table 3.9. Highest Education Taken (C6) by Grade and Gender................................ 162

Table 3.10. Average Characteristics by Highest Education Taken, C3 and C6. ........... 163

Table 3.11. AMEs, Short-Term (C3) vs. Longer-Term (C6)....................................... 164

Table 3.12. CIP by Gender and Senior Year Grade, University Participants (C3)....... 165 


\section{List of Figures}

Figure 1.1a. PMK-Assessed Non-cognitive Skills by Gender...................................... 49

Figure 1.1b. Teacher-Assessed Non-cognitive Skills by Gender .................................. 49

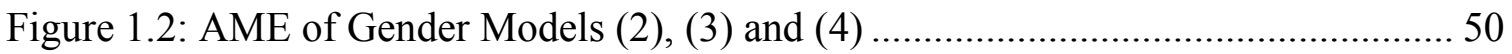

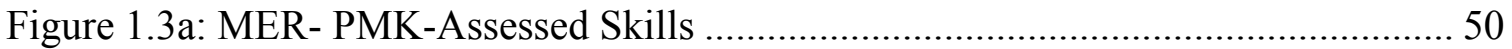

Figure 1.3b: MER - Teacher-Assessed Skills ............................................................. 51

Figure 2.1. U.S. College Graduation Rates by Gender: Cohorts born 1876-1975 ........ 107

Figure 2-2. Participation by Gender at Canadian Universities ................................... 108

Figure 2-3. Field of Study by Gender, Canadian Universities, 2014/15...................... 108

Figure 3-1. Rates of Participation in PSE from Cycle 3 to Cycle 6.............................. 166

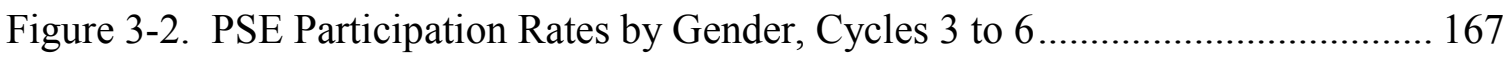




\section{List of Appendices}

Appendix 1.A: Coefficients from Regressions Using Non-Cognitive Skills Levels........ 52

Appendix 2.A. Sample Restrictions and Attrition Analysis ......................................... 109

Appendix 2.B: Using Math Scores in Addition to Reading Scores.............................. 113

Appendix 2.C: Factor Analysis to Identify Latent Factors:.......................................... 117

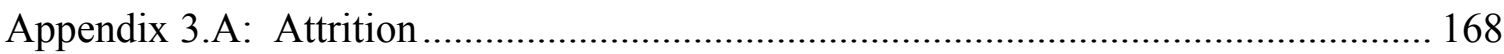

Appendix 3.B: Construction of the Outcome Variable "Highest Education Taken" .... 173

Appendix 3.C: Examining the Subsample with Less Than a High School Diploma .... 175 


\section{Chapter: Gender and Skills in the Determination of Primary School Performance}

\subsection{Introduction}

The gender gap that exists between men and women in university education is now welldocumented. In 2014/15, for example, only $42 \%$ of students attending university in Canada were men (Statistics Canada). Though less well-recognized, this gender gap is present throughout the education system: in rates of high school completion, where boys are much less likely to graduate than girls (Lefebvre and Merrigan, 2010); in the superior performance of women at the senior high school level as in Cho (2007), Drewes (2010) and Buchmann and DiPrete (2006); in French immersion, where the participation rate of boys lags that of girls (Worswick, 2003); in grade retention rates, which show that boys are more likely to be held back a year than girls; and in gender differences in Ritalin use and school engagement measures (Turcotte, 2011). This gender gap extends to include the academic expectations that both students and their parents hold. Fortin et al. (2015) find that that there are gender-based differences in students' post-secondary expectations as early as eighth grade. Turcotte (2011) finds that even in primary school there exist gender-based differences in parental expectations, such that girls are expected to go further in their education than boys.

What is driving this pervasive educational gender gap? That is the question on which this paper attempts to shed light. Inspired by recent work by Cunha, Heckman, Lochner and Masterov (2006), Cameron and Heckman (2001), and Cunha and Heckman (2007), I approach this question from a lifecycle point of view. According to this view, skills are accumulated over a lifetime. Gaps that exist later in life have their genesis in the early years. Thus, in explaining the gender gap in university participation, high school graduation rates and throughout the education system, we need to look to the very beginning of the formal education process. Accordingly, this paper looks at the academic outcomes for boys and girls in early primary school. Using the National Longitudinal Survey of Children and Youth (NLSCY) from Statistics Canada, I examine the teacherassessed performance of children in grades 1 and 2. Interestingly, there exists even at this early point in formal schooling a gender gap in performance outcomes.

The balance of this paper attempts to explain this emergent gap by giving consideration to the roles of both cognitive and non-cognitive skills, as well as the interplay between skills and gender, in determining academic performance. While it is common to study the influences of cognitive abilities on educational outcomes (Murnane, Willett and Levy, 
1995; Hernstein and Murray, 1994), the inclusion of non-cognitive abilities is still in its infancy. At first glance this is puzzling. The idea that non-cognitive skills - which are sometimes referred to as social skills or, more generally, personality traits - are important in determining life success is intuitively appealing. In non-academic circles, the relationship between non-cognitive skills and academic outcomes is widely acknowledged (Tyre, 2008; Whitmore, 2011; Sax, 2009).

Including non-cognitive skills in academic research, however, is challenging for a number of reasons. One problem is that the surveys generally used for research in economics do not often include measures of non-cognitive abilities, or questions pertaining to personality or social skills. Variables relating to cognitive skills (intelligence tests, school grades, test scores), wages and unemployment are readily available in the data, and are well-understood by economists; variables relating to perseverance, creativity or self-concept are not. The survey used in this paper, the NLSCY, is fortunately rich in these unusual measures.

Another challenge in including non-cognitive skills in our research is that these skills are difficult to measure. They are complex, multi-dimensional, and often uncorrelated, a reflection of the complexity of personality. Unlike cognitive abilities, which are thought to be captured by one underlying factor, $g$, and are routinely measured by tests such as the Armed Forces Qualifying Test (AFQT), there is no single measure of non-cognitive skills on which to rely in our estimations. ${ }^{1}$ Researchers have borrowed a variety of measures from other disciplines - measures such as self-esteem or personal traits - to try and capture these skills.

In the face of such measurement difficulties, some researchers find ways to reverse engineer, or impute, non-cognitive skills. In some cases this has been fruitful, as in Heckman and Rubinstein (2001), who find that the GED is a signal of non-cognitive abilities. $^{2}$ However, the imputation of non-cognitive skills should be approached with caution. Because non-cognitive skills often differ by gender, direct measurement of these skills is important if we are to disentangle the effects of skills versus gender on the outcomes of interest. For example, if boys lag in the acquisition of non-cognitive skills, it would not be surprising to see them lagging in early schooling outcomes. However, if we simply use the difference in school outcomes to infer differences in non-cognitive skills (Jacob, 2002; Frenette and Zeman, 2008), there is the possibility that we are confounding gender-based biases in grading (Lavy, 2008) with differences in skills.

\footnotetext{
${ }^{1}$ The $\mathrm{g}$ factor is a construct that summarizes positive correlations among different cognitive tasks. Originally proposed by English psychologist Charles Spearman [Spearman (1904)], the g factor stands for a single general ability factor.

${ }^{2}$ The GED, which stands for General Educational Development, is a set of tests which, when passed, provide certification that the test taker has American or Canadian high school-level academic skills. Passing the GED test gives those who do not complete high school the opportunity to earn their high school equivalency credential.
} 
In this paper, I directly measure non-cognitive skills. Following Heckman, Stixrud and Urzua (2006), and Cunha and Heckman (2007), I focus on a subset of non-cognitive skills that are particularly relevant to the study of early schooling outcomes. Specifically, I measure attention-related abilities, which are captured by a series of questions in the NLSCY which pertain to a child's ability to focus, to engage in tasks for extended periods, and to control the need to fidget, all important abilities for children in early primary.

Finally, the inclusion of non-cognitive abilities in explaining socioeconomic outcomes is often limited by problems of endogeneity, as discussed in Groves (2005) and Cornwell, Mustard and Van Parys (2013). For example, when considering the importance of selfesteem in determining grades, one must acknowledge the possibility of simultaneity problems - while self-esteem may play a role in determining grades, past grades may also contribute to the formation of self-esteem. The longer one has been in school, the more complicated this problem can become, as there are layers upon layers of feedback; early academic outcomes inform our growing sense of self, which then influences later grades, feeding back again into our perceptions of self and abilities. I argue that my use of data from the very early years of schooling largely circumvents these problems.

This paper is then built upon two main ideas. First, as suggested by the lifecycle literature, later life outcomes are determined by skills acquisitions made very early in life, thus demanding that we look toward early schooling experiences to explain later educational attainment. Second, this paper argues that both cognitive and non-cognitive skills play an important role in determining education outcomes. Despite the difficulties inherent in the measurement of these skills, direct measures are necessary as we examine their role in the production of academic outcomes.

The paper then proceeds as follows. Controlling for cognitive abilities, which are measured just prior to school entry, I examine performance outcomes, and observe that boys and girls of similar cognitive abilities are systematically assigned to different performance categories. Hypothesizing that this may be due to differences in noncognitive abilities, specifically with respect to the ability to regulate one's classroom behaviour, I construct a measure of non-cognitive skill that is based on parental and teacher responses to questions about attention skills and hyperactivity. Boys are reported to have lower levels of these skills, by both parents and teachers, although there is significant divergence between these reported measures. Notably, I find that even when I have controlled for all skills, both cognitive and non-cognitive, boys are still more likely to be assigned to a lower performance category than girls. 


\subsection{Literature Review}

This paper contributes to a growing literature that acknowledges the importance of noncognitive skills in understanding the educational gender gap. The bulk of this literature has focused on the relationship between non-cognitive skills and participation in postsecondary education, as opposed to performance in earlier grades. However, the lessons learned from these papers are widely applicable, including to primary outcomes, which are the focus of this paper.

Goldin, Katz and Kuziemko (2006), one of the most widely cited papers in this literature, examined many possible contributors to the decreased relative participation of men. After considering numerous factors such as changes in the culture surrounding women's labour force participation, marriage, and child bearing, the authors were left with the following observation:

A more level and wider playing field for girls enabled them to blossom. At the same time, the slower social development and more serious behavioral problems of boys remained and allowed girls to leapfrog over boys in the race to college. (p. 24)

Jacob (2002) also highlights the importance of non-cognitive skills in explaining the gender gap in post-secondary participation. In providing a context for the discussion of non-cognitive skills, he describes an educational environment where girls and boys score roughly equivalently on measures of cognitive abilities, but where boys receive lower grades, are retained in grade at a higher rate, have less engagement in the learning process, and have more disciplinary problems than girls. He notes that these difficulties have been attributed to the lower level of non-cognitive skills among boys, and describes this deficit of skills as "the inability to pay attention in class, to work with others, to organize and keep track of homework or class materials and to seek help from others."(p. 590)

He suggests that low non-cognitive skills might reduce university attendance through two channels: first, this skill deficit may reduce an individual's high school grades, or even lead to dropping out of high school; in addition, low non-cognitive skills may increase the non-pecuniary costs of attending university, decreasing the likelihood of attending.

Using the National Educational Longitudinal Study (NELS), an American survey of junior high school students, Jacob tests this hypothesis by constructing a measure of noncognitive abilities based on four components: grade retention; a composite measure of disciplinary incidents; hours spent on homework; and middle school grades ("achievement in school"). He finds that among students with similar family 
backgrounds, cognitive and non-cognitive skills, there is no statistically significant difference in post-secondary attendance rates between males and females. Thus, the gender-gap in university participation is thought to be driven by a deficit in non-cognitive skills on the part of boys.

Other papers use this approach to measuring non-cognitive abilities, including Frenette and Zeman (2008). The use of hours of homework and behavioral incidents is questionable, however, as a proxy for non-cognitive skills, especially if these are measured contemporaneously with the academic outcome of interest. As argued by Bishop (2005), the amount of effort put into schoolwork and one's behaviour are chosen, and are arguably influenced by past experiences in school, which suggests the possibility of significant endogeneity (dynamic simultaneity) issues. One might "check out" of the formal education process because of past low grades; behaviour and effort may be measures of discouragement or feelings of disenfranchisement, rather than truly exogenous factors in the school performance production function.

It is also important to note how achievement in school contributes to Jacob's measure of non-cognitive skills. He writes that "[t]he idea here is that, conditional on cognitive ability, school achievement is determined by a variety of non-cognitive skills such as the ability to follow directions, work in groups, pay attention in class, and organize material". (p. 591) So, students whose cognitive abilities are high, as measured by reading and math tests, but who perform poorly in school, are deemed to have low non-cognitive abilities. This is then a backdoor way of accounting for non-cognitive abilities without actually going out and measuring them. This approach is also followed by Frenette and Zeman (2008), who use the Youth in Transition (YITS) data to examine the gender gap in university participation in a Canadian context. These authors use the students' selfreported overall grade (mark) in school, conditional on standardized test performance, as their measure of non-cognitive ability. ${ }^{3}$

It is unclear, however, that the difference between test scores and overall school grade is entirely driven by a deficit in non-cognitive abilities. Perhaps what is being attributed to a non-cognitive skills gap is in fact caused, at least in part, by something else which is also related to gender. One possibility is that there exists a systemic gender bias in grading, as discussed in Lavy (2008) and Cornwell, Mustard and Van Parys (2013). Alternatively, the gap between measured cognitive ability and grade outcomes may be in part measuring biases in curriculum that favour girls over boys, as discussed in Lai (2010). These possibilities strongly suggest the need to use a direct measure of noncognitive skills.

\footnotetext{
${ }^{3}$ The standardized tests comes from the PISA 2000 survey (reading), administered at the same time as the YITS baseline survey.
} 
My paper departs from this backdoor approach, and directly measures one facet of noncognitive abilities. Specifically, I consider a set of questions that ask both teachers and parents to assess their children's attention-related skills - the ability to focus, stay engaged, and sit still in class. Claessens, Duncan and Engel (2009), and Duncan et al. (2007) find that, among the many facets of non-cognitive skills that they measure, including socioemotional and social skills, attention-related skills measured in Kindergarten were the only significant predictors of achievement in fifth grade. Lefebvre and Merrigan (2010b) also find that, among the many non-cognitive skills measured in their research, attention-related skills were the only consistently significant predictor of later outcomes (post-secondary participation).

This research also departs from the bulk of the literature in that it considers primary school outcomes rather than senior high school grades or participation in post-secondary education. This departure is motivated by two considerations. The first consideration is that, in later years of schooling, there is the possibility of significant endogeneity (simultaneity) between performance and skills, particularly non-cognitive skills. Bishop (2005), in his study of student incentives to study and learn, noted that time devoted to homework, and engagement in learning activities, are choice variables. He suggests that learning only occurs when an individual is ready and able to learn, is offered an opportunity to learn, and, critically, makes the effort to learn. Effort may vary depending on one's history in school - earlier poor performance may be the cause of low effort, and not visa-versa. This is circumvented to a large extent by looking at very early experiences in school, when it can still be argued that "effort" belongs on the right hand side of the equation.

Another compelling reason for focusing on early school experiences comes from the literature on lifecycle learning. In their seminal article, Cunha, Heckman, Lochner and Masterov (2006) look at early intervention (preschool) programs to examine the influences of childhood skills acquisitions on lifetime outcomes. In their model, skills are multi-dimensional, are acquired over time, and are complementary in nature. Skill deficits in early periods are carried forward into the future, and make the acquisition of complementary skills difficult or impossible. With this approach, the authors opened the door to research focusing on non-cognitive abilities and early family investments in human capital as primary contributors to later life outcomes. Their conclusion, that the skills and abilities formed during the early period of a child's life cycle are crucial for explaining later inequalities, is fundamental to my paper.

Cameron and Heckman (2001) study the differences in college participation rates across family income classes in each year, looking at Black, Hispanic and White males in the US in order to comment on tuition policy. Their conclusion, summarized in Cunha et al. (2006), is that "it is the influences of family factors present from birth through adolescence that accumulate to produce college readiness. By the time individuals finish 
high school and their scholastic ability is largely determined, the scope of tuition policy for promoting attendance is greatly diminished."(p. 733). To explain any skills gap that exists in high or middle school, you need to look back to primary school influences.

Other research such as Cunha and Heckman (2007), and Heckman and Masterov (2007) lend further weight to the lifecycle approach, and reiterate this take-away: skills are accumulated over a lifetime, and gaps that exist later in life have their genesis in the early years.

The only papers to my knowledge in the extant literature that combine examination of early schooling outcomes with direct measure of non-cognitive skills are Cornwell, Mustard and Van Parys (2013) and Golsteyn and Schils (2014). Using the Early Childhood Longitudinal Study - Kindergarten (ECLS-K), an American Survey of primary school children, Cornwell, Mustard and Van Parys (2013) focus on a series of questions asked of the child's teacher that are associated with approaches to learning. Their measure of non-cognitive abilities included scores relating to the child's ability to sit for long periods of time, his or her participation in the classroom, and the effort he or she supplied on assignments and homework. The authors find that girls are consistently rated as having higher non-cognitive abilities than boys, and that once non-cognitive abilities are controlled for, boys and girls are for the most part graded similarly.

Golsteyn and Schils (2014) also construct a measure of non-cognitive skills using survey questions. In this case, Dutch children in grade 6 were asked questions about social and instrumental skills as well as questions about personality traits (for example, extroversion and agreeableness). Using a Oaxaca-Blinder decomposition to examine the effects of both cognitive and non-cognitive skills, the authors find that gender-based differences in non-cognitive skills can explain part of the difference in performance that they observe. However, contrary to the findings of Cornwell, Mustard and Van Parys (2013), they find that a large part of the gender gap is unexplained by IQ and non-cognitive factors. 


\subsection{Data}

\subsubsection{Survey Description}

The data used in this research are from the National Longitudinal Survey of Children and Youth (NLSCY), a Canadian survey which began in 1994 with an initial cohort of 22,831 children aged 0-11. These children were randomly selected from the noninstitutionalized civilian population using the sample design of the Labour Force Survey (LFS). Every two years this sample of children was contacted for re-interview, from 1994 until 2008. Thus, the survey spans 14 years and includes eight cycles of interviews.

The unit of observation for the NLSCY is the child. Information about the child comes from three sources: the Person Most Knowledgeable (PMK) about the child, usually the mother; the child's teacher once the child is old enough to attend school; and the child him- or herself, in the form of a self-completed questionnaire provided to children aged 10 and older. The purpose of the survey is to provide a dynamic picture of the health and development of Canadian children from birth to early adulthood. Questions are asked regarding family dynamics, school experiences, childhood behaviour, and attitudes toward school and friends. ${ }^{4}$

Although the original cohort consists of children aged 0-11, I restrict my sample to children who are 4 and 5 years olds in Cycle 1. I choose this sub-cohort because children of this age are administered a test, which I will discuss in detail below, that provides an important benchmark measure of cognitive abilities (intelligence) prior to entering the school system. Once I implement the necessary restrictions, I am left with a sample of 3,728 Cycle 1 children. I then use information from Cycle 2 of the survey, from both the PMK and the child's teacher, to examine the impact of skills and gender on school performance in early primary.

There is a significant reduction in sample size in moving from Cycle 1 to Cycle 2. Of the original 3728 respondents in Cycle 1, only 2426 remain in Cycle 2, representing 65\% of the original sample. This decline has two sources. First, there was the usual attrition of respondents that characterizes all longitudinal surveys, associated with respondent mobility and lack of interest in remaining in the survey. In addition, and unique to this survey, there were significant funding cutbacks after Cycle 1, so that the scope of the survey was scaled back by Statistics Canada in Cycle 2.

\footnotetext{
${ }^{4}$ Alternative data sets have been used to study the relationship between non-cognitive abilities and school outcome in Canada, most commonly the Youth in Transition Survey (YITS) (e.g., Frenette and Zeman, 2008). The YITS, however, does not provide information about the early school experiences of youth, but rather focuses on the transition years of age 15 and beyond. For the purposes of this research, the wealth of primary school information in the NLSCY makes it the preferred data set.
} 
Teachers are another source of attrition. In 488 cases, the child remained in the survey for Cycle 2 (that is, the PMK responded to the survey) but the teacher did not complete their accompanying section of the survey (notable, there are not instances of the reverse). Once we take into account this teacher non-response, there are only 1938 records remaining in Cycle 2, representing 52\% of the original sample of 4 and 5 year olds from Cycle 1. A discussion of sample characteristics follows at the end of this section, after variables of interest have been defined.

I use the NLSCY weights, as provided by Statistics Canada, for each cycle to produce a nationally representative sample. Because the original cohort is never topped up to reflect changes in the population over time, it is truly longitudinal; inferences can only be made regarding the population of children in 1994.

\subsubsection{Variable Description}

\section{Dependent Variable: School Performance Measure}

Academic outcomes can be measured in a number of ways. In the NLSCY, the overall grade, either as a percentage or a letter, was not available. However, there is a class rank available, which is provided by the teacher. This assessment of performance is a categorical variable, $\mathrm{Y}_{\mathrm{i}}$, taken from Cycle 2 when the children are 6 or 7 years old (grades 1 or 2). To construct this variable, I look at the question posed to the child's teacher: "How would you rate this student's current academic achievement across all areas?" Categories have been re-labelled, so that better performance corresponds to a higher category number, i.e.

$$
\mathrm{Y}_{\mathrm{i}}=\left\{\begin{array}{l}
1=\text { at or near bottom of class } \\
2=\text { below middle, but not at the bottom } \\
3=\text { in the middle of the class } \\
4=\text { above the middle, but not at the top } \\
5=\text { at or near the top of the class }
\end{array}\right.
$$

Table 1.1 shows the distribution of teacher-assessed performance by gender. It is clear from this distribution that boys are over-represented in the lower performance categories $\left(\mathrm{Y}_{\mathrm{i}}=\right.$ "Bottom" and $\mathrm{Y}_{\mathrm{i}}=$ "Below Average"), but under-represented at the top of the class. Less than 5 percent of girls are assessed as being at the bottom of the class, compared to almost 10 percent of boys. On the other hand, while just over 15 percent of boys are assessed as being at the top of the class, almost 30 percent of girls are placed in this highest performance category. 
Explaining this distribution of performance outcomes - which differs so dramatically between boys and girls - is the focus of this paper. The literature, as discussed above, points to gaps in skills, both cognitive and non-cognitive, as primary drivers of this difference. The construction of variables to capture these skills is discussed below.

\section{Independent Variables}

Cognitive Skills Measure: PPVT

I consider the performance of boys versus girls on a cognitive skills test called the Peabody Picture Vocabulary Test (PPVT) which is administered to all children in the sample in the year prior to their entry into school, or during their first year of school. The PPVT that is administered to children at ages 4 and 5 (Cycle 1) is a widely used predictor of intelligence in both children and adults. In this case, the children in the study were asked to look at a set of pictures. Then, for each set, the examiner says a word and the child responds by selecting the picture that best illustrates that word's meaning.

Because of its ease of administration and its limited time demands, the PPVT score is routinely used as a broad measure of intelligence. This is not entirely without controversy. The PPVT measures only one facet of intelligence (verbal ability), and is not intended as a measure of general intellectual ability. For this reason, the psychology literature indicates that it should be best viewed as a screening instrument (Domino and Domino, 2006). Further, there is some evidence to suggest that PPVT scores are lower than those obtained using other standard IQ tests in the case of minority children, but are higher for children that come from well-educated and verbally articulated families (Domino and Domino, 2006). ${ }^{5}$

However, correlation of the PPVT score with other standard tests of intelligence is reasonably high (Strauss et al., 2006). Further, in my research, I am using the PPVT score to establish a benchmark for cognitive abilities prior to entering school in order to compare outcomes between girls and boys. There is no evidence to suggest that the PPVT test favours one gender over the other. Therefore, for the purposes of this research I argue that the use of the PPVT score as a cognitive abilities benchmark is reasonable.

The raw PPVT score is derived from the number of correct answers below the ceiling. The ceiling is determined when a child incorrectly identifies six of eight consecutive items on the test. The raw score is then standardized, so that the mean is 100 and the

\footnotetext{
${ }^{5}$ Widely accepted standard IQ tests include the Stanford-Binet test, the Wechsler Intelligence Scales for Children (WISC) Full Scale IQ test, or the WAIS-Doppelt test.
} 
standard deviation is 15 . This standardization takes into account age, as older children would be expected to achieve, on average, a higher score on the test. ${ }^{6}$

\section{Non-Cognitive Skills}

Boys and girls may differ significantly in other aspects which are important in determining school outcomes. As in Heckman and Rubinstein (2001) I call these other aspects "non-cognitive skills". In the literature, researchers have referred to noncognitive skills in a variety of ways: perseverance, dependability, self-esteem, locus of control, motivation, self-discipline, pro-social behaviour, and hyperactivity/inattention. The term "social skills" is sometimes used interchangeably with non-cognitive skills, as in Carneiro, Crawford and Goodman (2007), while others suggest that non-cognitive skills are embodiment of personality as in Borghans, Duckworth, Heckman and ter Weel (2008).

In this paper, non-cognitive skills are modeled as aspects of behavior that mediate the transmission of cognitive abilities into school grades. In the context of early primary school, these are skills such as the ability to sit still long enough to hear the teacher's instructions, or the ability to control one's boisterous behavior even in the face of sometimes tedious work. This measure of non-cognitive skills is supported by the research of Claessens, Duncan and Engel (2009) and Duncan et al. (2007), who found that, among the many facets of non-cognitive skills they considered, attention-related skills were the only significant predictors of later (fifth grade) achievement. Lefebvre and Merrigan (2010b) also considered a number of facets of non-cognitive skills, and found that the only measure that was consistently significant in predicting later outcomes was the measure of hyperactivity-inattention.

Specifically, I use a series of seven questions, asked of both the child's teacher and parent-respondent (PMK) during Cycle 2, to construct my measure of non-cognitive abilities. This measure is based on information collected contemporaneously with the teacher's assessment of the child's academic achievement.

The PMK/ teacher were asked to rate how often the child...

1) ...can't sit still, is restless or hyperactive;

2) ....is distractible, has trouble sticking to any activity;

3) ...can't concentrate, can't pay attention for long;

4) ....is inattentive;

5) ...can't settle to anything for more than a few moments;

\footnotetext{
${ }^{6}$ For a complete discussion of the standardization procedure, see https://www.nlsinfo.org/content/cohorts/nlsy79-children/topical-guide/assessments/peabody-picturevocabulary-test-revised
} 
6) ...fidgets;

7) ... is impulsive.

In each case the respondent is asked to provide a rating from 1 to 3 , where

$1=$ never,

$2=$ sometimes,

$3=$ often.

To construct the scale score I simply add up the responses from each question. Thus the lowest possible score possible is 7 (where the response to each question was a $1=$ never) and the highest 21 . This measure of non-cognitive ability is very closely related to the scale score for measuring hyperactivity-inattention that was derived in the NLSCY by the analysts at Statistics Canada. ${ }^{7}$ For the teacher-assessed score in Cycle 2, the correlation between the proxy that I have constructed and the survey's derived scale score is 0.9933 ; for the PMK-assessed score, the correlation is 0.9861. My construction allows me to more easily categorize non-cognitive abilities, a point to which I will return later in the paper.

Note that the higher the hyperactivity-inattention score, the lower the measure of noncognitive abilities. A student who sits still and pays attention all the time will receive a very low score, while a student who cannot stay on task and disrupts the class with their fidgeting and antics will receive a very high score. In order to make this measure of noncognitive skills increasing in skills, I transform it by simply subtracting the score from 21. Thus, a child with a high hyperactivity-inattention score will have a score of zero on this new scale, and a child who sits still and listens all the time will have a score of 14 . This is the measure that will be used for the rest of the paper, with a minimum of zero, corresponding to low non-cognitive (attention-related) skills, and a maximum of 14, corresponding to very high attention-related skills.

Is this a reasonable measure of non-cognitive abilities? I argue that my construct is a reasonable measure of the skill required to turn innate intelligence into marks in early primary school. At this point, no one is skipping school, homework is not really an issue, drugs and alcohol are not in the picture, and the biggest problem for most children is just sitting still and following instructions. Even bright kids who cannot pay attention or sit still are more likely to miss details, misunderstand a lesson, or annoy the teacher. In this

\footnotetext{
${ }^{7}$ See the Statistics Canada Microdata User Guide for the Cycle data at http://www23.statcan.gc.ca/imdbbmdi/document/4450_D4 T9 V2-eng.pdf
} 
context and at this point in the education system, these attention-related skills are important mediators in the process of transforming intelligence into grades.

In the context of this data, respondent-reliability also needs to be taken into account. Who is assessing the students' non-cognitive abilities? In this survey, information about non-cognitive abilities is supplied by both teachers and parents. If there is a significant difference between the two, this will raise some important issues. One issue would be the reason for differences in parental- versus teacher-assessment of skills, which will be discussed shortly. More pressing is the question of which measure to use. In moving forward, I consider both of these measures of non-cognitive skills.

\section{Socio-Economic Status}

I use Socio-Economic Status (SES) as an exogenous control variable. SES is a derived variable, calculated by Statistics Canada using five sources of survey questions: the level of education of the PMK, the level of education of the spouse/partner, the prestige of the PMK's occupation, the prestige of the occupation of the spouse/partner, and household income. This variable is taken from the first cycle. It has been standardized in the data with a mean of 0 and standard deviation of 1 .

\section{Family Status}

Bertrand and Pan (2013) suggest that differences in non-cognitive skills may be explained, to some extent, by differences in home environment. I include a family status variable as a control. Family status comes from a Cycle 1 variable, and falls into one of three possible categories: "intact family," meaning a married or common law family where all children are the natural offspring or adopted children of both members; "census family," where the child in not a member of an intact family, but is in a couple census family; and "other," where the child lives with a single parent, or is a foster child.

\section{Gender}

Gender is also taken from the first cycle. The reference group is girls. Ultimately, this paper is concerned with examining the effect of gender on teacher-reported performance when everything else is taken into account. In principle, if all skills-related variables that are correlated with gender have been taken into account (so that gender is "as if" randomly assigned) then gender should not play a statistically significant role in determining outcomes.

\section{Summary of Variables Used and their Origins}

Table 1.2 summarizes the variables used in this paper, and their cycle of origin. Socioeconomic status, family background and gender are all reported by the PMK in 
Cycle 1. The PPVT score also comes from Cycle 1, and is derived from a test administered by the interviewer. Information about school performance (rank) and noncognitive skills are collected contemporaneously in Cycle 2. Both the PMK and the teacher provide information about non-cognitive skills. Class rank is as reported by the teacher.

\subsubsection{Attrition Revisited}

Table 1.3 illustrates the average characteristics of the sample in each cycle. As noted above, attrition stems from two sources - PMK attrition and teacher attrition. Based on the average characteristics of the three samples - labelled as samples A, B, and C in the first column of Table 1.3 - one might argue that, while the attrition is large in absolute terms, it does appear to be random. The Cycle 2 samples (with only PMK attrition, and with both PMK and teacher attrition considered) have mean values of PPVT scores and SES which are not are not statistically different from the mean scores observed in Cycle 1. The composition of the Cycle 1 and Cycle 2 samples do not differ significantly by gender. The Cycle 2 sample with only PMK attrition has a statistically different composition by family status $(\mathrm{p}=0.0773)$, with fewer intact families, but this difference disappears when teacher attrition is considered. The age distribution of students in Cycle differs from Cycle 1 only when both teacher and PMK attrition are considered, with the average age of the Cycle sample being slightly higher $(\mathrm{p}=0.0322)$

One way to consider the two sources of attrition is to consider their characteristics separately. Table 1.4 considers PMK attrition. This table illustrates the average characteristics of children whose PMK left the survey after Cycle 1 ("Leavers") compared to the average characteristics of children whose PMKs chose to remain with the survey into Cycle 2 ("Continuers"). While the changes in PPVT score and SES are on average small, these differences are nonetheless statistically significant. Evidently, those who remain in the sample have slightly higher cognitive abilities, but slightly lower socio-economic status. In addition, there is a slightly larger population of boys in the survey leavers than in the continuers, although this difference is not statistically significant $(\mathrm{p}=0.2444)$. The tabulation of the family status variable shows that leavers have a larger population of children from intact families; $75 \%$ of children from the leavers group come from an intact family while only $73 \%$ of children who remained in the survey in Cycle 2 were from intact families. ${ }^{8}$ Again, this difference is not statistically significant $(\mathrm{p}=0.1824)$. Finally, the children in the leaver sample tend to be younger, a difference which is statistically significant at the $5 \%$ confidence level. In sum, the differences between Leavers and Continuers are small, even when statistically significant.

\footnotetext{
${ }^{8}$ The second and third categories of family status have been combined for the purposes of calculating summary statistics, but are not combined for the regression analysis
} 
The teacher survey introduced another source of attrition. There were 448 teachers who participated in the survey in Cycle 1, but who did not submit a survey in Cycle 2. In addition, 173 teachers filled out a Cycle 2 survey, but did not respond to the question regarding class rank, which is the outcome variable of interest in this paper. Thus, we can look at attrition in Cycle 2 in this way: of the 2426 Cycle 2 surveys completed by the PMK, 1765 also had complete teacher records, 448 had no teacher survey, and 173 had an incomplete survey, with the class rank variable missing. Table 1.5 shows the average characteristics of each of these populations.

One important dimension over which these populations differ is age. The children are all 4 and 5 years old in Cycle 1. In both the complete record population and the population with no teacher survey, the average age is 4.57 and 4.5 , respectively, as of Cycle 1 about half of the children in each age group. However, for the population where the teacher responded but did not provide a class rank, the average age is 4.07 . Over $90 \%$ of the children in this group were 4 years old in Cycle 1 (6 years old in Cycle 2). This group also had a higher fraction of children from intact families than from the other two groups. There are also small differences over the other dimensions, particularly PPVT. It is not clear what is behind the age differences.

Observations with either missing teacher surveys or missing class-rank responses were dropped from the analysis. Of course, families that left the survey after Cycle 1 (Leavers) are also excluded from further analysis. In the end, the sample has 1765 remaining respondents with complete PMK and teacher records. The characteristics of this final population are summarized in the first row of Table 1.5.

\subsection{Methodology}

The outcome variable of interest in this research is the academic outcome for each student, assigned by the teacher and expressed as an ordinal class ranking, $\mathrm{Y}_{\mathrm{i}}=$ $(1,2, \ldots, 5)$. These outcomes are determined by skills, both cognitive and non-cognitive, along with gender and family background, which is captured through the socio-economic status variable. These contained the vector of explanatory variables $\mathbf{X}_{\mathrm{i}}$.

There are a number of possible methodological approaches to estimating this model. One possibility is to use a linear regression model, which assumes that $y$ is a linear function of the regressors, so that the model can be written as

$$
Y_{i}=\boldsymbol{X}_{i}^{\prime} \beta+u_{i}
$$


This involves numbering the dependent categories sequentially, and using standard ordinary least squares techniques. However, this involves the assumption that the distances between categories are equal. If this assumption is violated, a likely event in this instance, then estimation results may be misleading, as discussed in Winship and Mare (1984).

An alternative is to use ordered regression models, in this case ordered logit. ${ }^{9}$ The ordered logit model can be motivated in two ways. ${ }^{10}$ One way is to think of the observed categories, $\mathrm{y}_{\mathrm{i}}$, as being related to an unobserved latent variable, $\mathrm{y}_{\mathrm{i}}{ }^{*}$, such that

$$
\mathrm{Y}_{\mathrm{i}}=\mathrm{k} \text { if } \mathrm{T}_{\mathrm{j}-1}<=\mathrm{y}_{\mathrm{i}} * \mathrm{~T}_{\mathrm{j}},
$$

where the T's are thresholds, or cut-points, which are unknown. Specifically, in this paper $\mathrm{y}_{\mathrm{i}}{ }^{*}$ is student $\mathrm{i}$ 's actual grade (performance) in the class, while $\mathrm{Y}_{\mathrm{i}}$ is one of five categories of class rank as reported by the teacher. Using the continuous outcome variable, $\mathrm{y}_{\mathrm{i}}{ }^{*}$, the model is then written as

$$
y_{i}^{*}=\boldsymbol{X}_{i}^{\prime} \beta+u_{i}
$$

While the underlying latent variable can be expressed as a linear function of the explanatory variables, the relationship between the categorical variable and the covariates is potentially non-linear, and is therefore estimated using maximum likelihood algorithms. The coefficients are estimated using the following relationships:

$$
\begin{aligned}
\operatorname{prob}\left(\mathrm{Y}_{\mathrm{i}}=\mathrm{j} \mid \mathbf{x}_{\mathrm{i}}\right) & =\operatorname{prob}\left(\mathrm{T}_{\mathrm{j}-1}<=\mathrm{y}_{\mathrm{i}}{ }^{*}<\mathrm{T}_{\mathrm{j}}\right) \\
& =\operatorname{prob}\left(\mathrm{T}_{\mathrm{j}-1}<=\mathbf{X}_{\mathrm{i}}{ }^{\prime} \beta+\mu_{\mathrm{i}}<\mathrm{T}_{\mathrm{j}}\right) \\
& =\operatorname{prob}\left(\mathrm{T}_{\mathrm{j}-1}-\mathbf{X}_{\mathrm{i}}{ }^{\prime} \beta<=\mu_{\mathrm{i}}<\mathrm{T}_{\mathrm{j}}-\mathbf{X}_{\mathrm{i}}{ }^{\prime} \beta\right) .
\end{aligned}
$$

Ordered logit estimation assumes that the error term has a logistic distribution, so that equation (4) can be rewritten as

$$
\operatorname{prob}\left(\mathrm{Y}_{\mathrm{i}}=\mathrm{j} \mid \mathbf{X}_{\mathrm{i}}\right)=\Lambda\left(\mathrm{T}_{\mathrm{j}-1}-\mathbf{X}_{\mathrm{i}}{ }^{\prime} \beta\right)-\Lambda\left(\mathrm{T}_{\mathrm{j}}-\mathbf{X}_{\mathrm{i}}{ }^{\prime} \beta\right),
$$

where $\Lambda$ is the cumulative density function for the logistic distribution, expressed as

\footnotetext{
9 Ordered regression models are either ordered probit or ordered logit. The ordered logit model assumes that the error terms follow a logistic distribution while the ordered probit assumes a normal distribution for the error terms. The ordered logit is the preferred model here as it allows for the use of a generalized ordered logit model as a robustness test, an option not possible using ordered probit.

${ }^{10}$ This discussion is taken in part from Long (1997).
} 


$$
\Lambda(*)=\frac{1}{1+e^{-(*)}}
$$

The likelihood function for individual $i$ is then

$$
L^{i}=\prod_{j=0}^{J} \operatorname{prob}\left(Y_{i}=j \mid X_{i}\right)^{I\left(Y_{i}=j\right)}
$$

The coefficients returned from the solution to this problem are in the form of ordered log odds. ${ }^{11}$ It should be noted that only one set of coefficients (one for each covariate) is returned from the estimation algorithm. ${ }^{12}$ This is a result of the underlying assumption that the relationship between each pair of outcome groups is the same. Ordered logitistic regression assumes that the coefficients that describe the relationship between the lowest versus all higher categories of the response variable are the same as those that describe the relationship between the next lowest categories and all higher categories, etc. This is called the parallel regression assumption.

Alternatively, the ordered logit model can be interpreted without reference to a latent variable, but instead derived in terms of odd ratios for cumulative probabilities. The odds that $\mathrm{Y}_{\mathrm{i}}$ is less than or equal to outcome $k$ versus greater than $k$ (for $k=1$ to J-1) given $\mathbf{X}_{\mathrm{i}}$, can be written as

$$
\Omega_{k}\left(X_{i}\right)=\frac{\operatorname{prob}\left(Y_{i} \leq k \mid \boldsymbol{X}_{\boldsymbol{i}}\right)}{1-\operatorname{prob}\left(Y_{i} \leq k \mid \boldsymbol{X}_{\boldsymbol{i}}\right)}=\frac{\operatorname{prob}\left(Y_{i} \leq k \mid \boldsymbol{X}_{\boldsymbol{i}}\right)}{\operatorname{prob}\left(Y_{i}>k \mid \boldsymbol{X}_{\boldsymbol{i}}\right)}
$$

where

$$
\begin{gathered}
\operatorname{prob}\left(Y_{i} \leq k \mid \boldsymbol{X}_{\boldsymbol{i}}\right)=\sum_{j=1}^{k} \operatorname{prob}\left(Y_{i}=j \mid \boldsymbol{X}_{\boldsymbol{i}}\right) \text { for } k=1, \ldots, \mathrm{J}-1 \\
=F\left(\tau_{k}-\boldsymbol{X} \boldsymbol{\beta}\right)=\Lambda\left(\tau_{k}-\boldsymbol{X} \boldsymbol{\beta}\right)
\end{gathered}
$$

Using equations (10) and (7), the odds of an outcome being less than or equal to $k$ versus being greater than $k$ have the simple equation

\footnotetext{
${ }^{11}$ Henceforth ordered log odds estimates will be referred to as log odds, with the "ordered" being implicitly understood.

${ }^{12}$ Note that, for $\mathrm{J}$ possible outcome categories, there are J-1 binary regressions being estimated simultaneously, to obtain estimates of the J-1 thresholds and a common slope parameter $\beta$. See Winship and Mare (1984) or Long (1997).
} 


$$
\Omega_{k}(x)=\exp \left(\tau_{k}-\boldsymbol{X} \boldsymbol{\beta}\right)
$$

The effect of a change in one of the covariates - in $x_{m}$ for example - can be written as

$$
\frac{\Omega_{k}\left(\boldsymbol{X}, x_{m}+1\right)}{\Omega_{k}\left(\boldsymbol{X}, x_{m}\right)}=\exp \left[\left(x_{m}-\left(x_{m}+1\right)\right) \beta\right]=\exp (-\beta)
$$

Note that equation (11) above implies that the odds ratio is the same for all values of $k$, a re-statement of the parallel regression assumption. We will return to this assumption as we discuss the empirical results.

\subsection{Empirical Results}

\subsubsection{Summary Statistics}

As a first step in examining the statistical relationship between outcome and explanatory variables, Table 1.6 shows the summary statistics of skills and family background (SES and family status). The difference in average PPVT score between girls and boys is not statistically significant, with the t-test returning a $p$-value $=0.2383$. For non-cognitive skills, the picture is quite different; the difference between the averages for boys and girls are statistically different from zero, for both teacher-assessed and PMK-assessed scores, with $\mathrm{p}<0.0001$ in both cases.

Moreover, for both boys and girls, the difference between teacher- and PMK-assessed non-cognitive skill scores is also statistically significant. This is indicated in Table 1.6 by comparing PMK and teacher assessed scores within each column (i.e. by gender). Teachers report an average score for boys of 9.15, substantially lower than the average reported for boys by PMKs. The difference between these two reports is statistically significant at the $5 \%$ level $(\mathrm{p}==0.0256)$. Teachers report an average score of 11.0 for girls, substantially higher than the average reported for girls by PMKs. This difference is also statistically significant $(\mathrm{p}=0.0007)$

Figures $1.1 \mathrm{a}$ and $1.1 \mathrm{~b}$ reveal substantive differences in non-cognitive abilities at the distributional level. Recall that the scale score is derived by summing the responses to seven questions pertaining to attention and hyperactivity, and then subtracting the score from 21. The maximum score of 14 indicates that the respondent (PMK or teacher) felt the child never let their attention wander, always stayed focused, never fidgeted while in 
class, and so on. The minimum score of 0 (zero) indicates that the respondent felt that the child never paid attention, was never able to maintain focus, was always fidgeting, and so on. Both distributions (PMK- and teacher-assessed) indicate a clustering for girls around the maximum score of 14. For teacher-assessed scores, this clustering is extreme, with $41 \%$ of girls assigned a score of 14 . For PMK-assessed scores, there is still a clustering of girls at 14 , although less extreme with only $19 \%$ being assigned this value. The distributions for boys' scores are much flatter for both respondent types.

While the distributions differ in shape, two messages are clear. First, young boys have a much harder time sitting still and concentrating in class than girls do. This captures the "slower social development and more serious behavioral problems" that Goldin et al. (2006) highlighted as the key to explaining the overtaking of boys by girls in postsecondary participation. Second, environment matters in the assessment of these skills. Notably, teachers and parents are assessing the same child, but in different environments. Boys appear to lag further behind girls in attention-related skills when assessed in the school environment rather than in the home environment. This is consistent with claims, made for example by Tyre (2008), that changes in the school environment - such as diminished recess time and increased focus on early literacy - have made it more difficult for boys to succeed in school.

\subsubsection{Ordered Logit Estimation Results}

The relationship between skills and class ranking is examined further using the ordered logit estimation techniques discussed above. Table 7 shows the results for a series of ordered logit regressions. Specification (1) contains only background variables. Specification (2) adds cognitive skills (PPVT scores). Specification (3) adds the PMKassessed non-cognitive skills score, and specification (4) substitutes the teacher-assessed non-cognitive skills score for the PMK score. Both the PMK- and teacher-assessed noncognitive skills measures have been standardized, with a mean of 0 (zero) and a standard deviation of 1 .

The coefficients presented in the table are not marginal effects, as would be the case using linear regression techniques. Rather, each coefficient $\beta_{\mathrm{m}}$ represents the change in the (ordered) $\log$ odds that $\mathrm{Y}$ is less than or equal to outcome $k$ versus greater than $k$, associated with a small change in $X_{m}$ given $\mathbf{X}_{-m}$ fixed. Recall from equation (12) that

$$
\frac{\Omega_{k}\left(\boldsymbol{x}, x_{m}+1\right)}{\Omega_{k}\left(\boldsymbol{x}, x_{m}\right)}=\exp \left[\left(x_{m}-\left(x_{m}+1\right)\right) \beta\right]=\exp (-\beta)
$$

or, 


$$
-\beta=\ln \left(\frac{\Omega_{k}\left(\boldsymbol{x}, x_{m}+1\right)}{\Omega_{k}\left(\boldsymbol{x}, x_{m}\right)}\right)
$$

Column (1) establishes a benchmark case, as only gender, SES and family status are included. Recall that SES includes background variables such as family income and parental education. The coefficient on gender using this specification is -0.61 , or taking its negative, 0.612 . Thus, the log odds of a student being in a grade category less than or equal to $k$ increases by 0.612 for a change in the gender dummy variable from girl to boy. This is true for any $k=1,2,3,4{ }^{13}$ The coefficient on SES is of the opposite sign. Taking the negative, we see that an increase of one standard deviation in SES leads to a decrease in the log odds of a student being in a grade category less than or equal to $\mathrm{k}$ of 0.806 . Being from a single-parent family, vis-à-vis an intact family also leads to an increase in the log odds of being in a grade category less than or equal to $k$.

Column (2) introduced cognitive skills, measured by the PPVT score. For the regression analysis and subsequent post-estimation analyses, the PPVT has been standardized. Notably, the coefficient on gender is virtually unchanged with the addition of cognitive skills to the regression. This is as expected, since the difference in cognitive abilities between boys and girls is very small, and statistically insignificant.

The sign on the coefficient for cognitive skills (PPVT) is positive. Taking its negative, we see that the log odds of a student being in a grade category less than or equal to $k$ decreases by 0.39 with a one standard deviation increase in PPVT score. The introduction of cognitive skills to the estimation leads to only a small change in the coefficient on SES. Thus, the advantage conferred on children from families with more income and better-educated parents (i.e., higher SES) is not transmitted through higher levels of cognitive skills, at least not in this instance. Adding the PPVT score to the regression does not lead to any substantial change in coefficient on being from a single family either.

Column (3) shows the results of adding non-cognitive skills to the estimation equation using the PMK-assigned values for these skills. The coefficient on non-cognitive skills is significant and of the expected sign. Taking the negative of the coefficient, $(-\beta=-0.412)$ we see that a one standard deviation increase in non-cognitive skills, as assessed by the PMK, leads to a decrease of 0.412 in the $\log$ odds of a student being in a grade category of $k$ or less versus above $k$, all else held constant. At the same time, the coefficient on gender, while still significant at all conventional levels, has decreased to -0.482 . To some extent, then, the impact of gender on performance has been accounted for by the addition

\footnotetext{
${ }^{13}$ Although there are five outcome categories, there are only four comparison being made: 1 vs $2,3,4$ or 5 ; 1 or 2 vs 3,4 , or $5 ; 1,2$, or 3 vs 4 or 5 ; and $1,2,3$, or 4 vs 5 .
} 
of PMK-assessed non-cognitive skills. However, even after accounting for the lower levels of non-cognitive abilities of boys (as assessed by their PMKs), gender still plays a significant role in determining outcome, with boys being more likely to be assigned to a lower performance category than girls.

We also see that the coefficient on cognitive abilities remains largely unchanged by the addition of non-cognitive skills, suggesting that cognitive and non-cognitive abilities exercise their influence on school outcomes through different channels. Finally, the coefficient on single-parent family has decreased, and is only significant at the $5 \%$ level now. This would suggest that some of the disadvantages associated with being from a single family are manifest in lower non-cognitive skills, consistent with the findings of Bertrand and Pan (2013).

Column (4) shows the results of the estimation with the substitution of teacher-assessed rather than PMK-assessed non-cognitive skills. A one standard deviation increase in non-cognitive skills leads to a decrease of 0.967 in the log odds of a student being in a grade category of $k$ or less versus above $k$, all else held constant. This is a substantially larger coefficient than the one found using the PMK-assessed scores for non-cognitive skills.

Notably, when we use the teacher's assessment of non-cognitive skills in the estimation equation, the coefficient on gender now hovers at the bounds of significance at the 10 percent level. Thus, once the gap in non-cognitive abilities is accounted for, examining the $\log$ odds leads to the conclusion that there is only a small role for gender in explaining the gap in performance (class-rank) outcomes.

Also of note here is that the coefficient on cognitive abilities has not changed dramatically, reinforcing the insights gained from column (3): cognitive and noncognitive skills influence class rank outcomes independently. In addition, the coefficient on SES has decreased (slightly) with the inclusion of teacher-assessed non-cognitive skills, suggesting that some of the benefits conferred through higher SES are transmitted through higher non-cognitive abilities (but, interestingly, not cognitive abilities). Finally, the coefficient on single-parent family has declined further to -0.371 , significant at only the $10 \%$ level, again suggesting that the disadvantages conferred on children from singleparent families work to some extent (although not entirely) through a decrease in noncognitive skills. 


\subsubsection{Endogeneity}

One question that arises in considering these results is whether or not the non-cognitive skills measure is truly exogenous. Endogeneity (simultaneity) problems are often confronted when trying to use non-cognitive skills to explain school outcomes. In this specific context, endogeneity would be a problem if non-cognitive skills, as I have narrowly defined them, were to be influenced by academic outcomes. This is certainly of concern if the child has had many years of schooling, during which time behaviour may be influenced by past academic assessment. For example, children who are repeatedly unsuccessful in school may develop a poor attitude and associated behaviours in response to their lack of success. Thus, performance influences behaviour, and behaviour influences performance.

This sort of dynamic simultaneity is difficult to deal with. Cornwell, Mustard and Van Parys (2013) use an IV approach in their paper to overcome this problem. Groves (2005), on the other hand, uses childhood measures of non-cognitive skills (personality traits) to predict later life wage outcomes, arguing that since the measures were taken long before the outcome they are intended to explain, they can be considered exogenous regressors. In the context of this paper, I argue that my construct of non-cognitive skills is largely free of endogeneity problems. The children in this study are at the very beginning of primary school so there has been little time for past performance to influence behaviour. ${ }^{14}$

Endogeneity can also arise through measurement error. The subjective nature of survey questions inevitably introduces noise into the measurement of the underlying concept of interest, specifically non-cognitive skills. Uncorrected, measurement error in the explanatory variables leads to bias in the estimated coefficients. In linear models this leads to attenuation bias, that is, the bias is toward zero. In non-linear models, such as the ones used in this paper, the direction of the bias is likely to be more complicated.

Endogeneity can also arise through omitted variable bias. As Stock (2010) points out in his discussion on credible identification, the important question is: what control variables do you need so that once you condition on those controls, it is "as if" the variable of interest is randomly assigned? If there are other unmeasured facets of skills, which are correlated with both gender and the outcome variable (class rank), then there will be bias in the estimated coefficient on gender. One of the objectives in introducing the concept

\footnotetext{
${ }^{14}$ It may be argued that children internalize feedback about themselves and their skills very quickly. If this is the case, then there may still be a simultaneity problem as discussed in the text, and the coefficient on non-cognitive skills will likely be biased. However, it is the coefficient on gender (and the associated marginal effect) that is of interest here. As long as gender can be taken as exogenous, the conclusions of this analysis are not invalidated by the endogeneity issues associated with non-cognitive skills.
} 
of non-cognitive skills is to account for previously unidentified individual heterogeneity, so that we move closer to the "as if" world where gender is randomly assigned.

The direction of bias arising from this unobserved heterogeneity is uncertain. If the boys on average lag in unmeasured characteristics that are important in determining school performance, then the coefficient on gender will pick up this effect, biasing the coefficient on gender upward. If the skill could be measured in some way, the coefficient on gender would decrease. Conversely, if the unmeasured skill happened to be one in which boys excelled, then the coefficient on gender would be biased downward. If the skill could be measured, we would find that the coefficient on gender would rise once the skill was accounted for in our analysis.

\subsubsection{Marginal Effects}

The results shown in Table 1.7 are presented in terms of log odds. These are useful when looking at how the estimated coefficients change as new covariates are added, or as substitutions are made, because there is only one set of results per estimation to consider. Thus we can map out channels of influence (as was the case, for example, when the coefficient on gender changed when non-cognitive skills were added) and identify factors which work independently of one another, as was seen with cognitive and non-cognitive skills.

An alternative and more intuitive way of conveying this information is in the calculation of marginal effects. With ordinary least squares regression estimation, the estimated coefficients are the marginal effects. However, with the maximum likelihood estimation that underlies the ordered logit regression, this is not the case, and marginal effects must be calculated post-estimation. Of particular note is that, for these non-linear models, the marginal effects take the form of predicted probabilities of assignment to each category. Thus, for a small change in one of the covariates, we are given the change in likelihood of being in each of the five performance categories

In particular, we are interested in calculating the probability of being assigned to each of the five different categories for boys versus girls. Tables $8 \mathrm{a}-\mathrm{c}$ show the average predicted probabilities of assignment for each gender, and then the difference - the average marginal effect - for specifications (2), (3) and (4) of Table 7. Average marginal effect of gender is calculated for each $j=1, \ldots, 5$ as

$A M E_{j}=\sum_{i=1}^{N}\left[\operatorname{prob}\left(Y_{i}=j \mid \boldsymbol{X}_{i}\right.\right.$, gender $=$ boy $\left.)\right] / N-\sum_{i=1}^{N}\left[\operatorname{prob}\left(Y_{i}=j \mid \boldsymbol{X}_{i}\right.\right.$, gender $\left.\left.=\operatorname{girl}\right)\right] / N$

Figure 1.2 shows the average marginal effect of gender for specifications (2), (3) and (4). These are shown in Tables 8a-c, highlighted on the bottom line of each table. The dotted 
bars represent the benchmark case specification (2), with no non-cognitive skills included. It is clear that as we add non-cognitive skills to the equation, whether PMK- or teacher-assessed (cross-hatched and striped bars, respectively), the difference between boys and girls in assignment probabilities to the different categories is reduced (shorter bars). Thus, there is some evidence to support the hypothesis that the gender gap in performance is driven, to some extent, by a gap in non-cognitive skills.

Notably, however, there remains a statistically significant difference between genders in the probability of being assigned to some of the categories, even after all skills have been accounted for. The probability of a girl being assigned to the highest performance category is higher than that of a boy, averaged over individuals. When non-cognitive skills are not taken into account (the dotted bars), this difference is 9.2 percentage points. When non-cognitive skills are explicitly considered, the difference shrinks noticeably. When it is the PMK-assessed measure that is used, this difference shrinks to 7.5 percentage points. When the teacher-assessed measure is used, the difference shrinks further to 3.6 percentage points. In sum, girls are more likely, on average, to be assigned to the highest performance category, controlling for both cognitive and non-cognitive abilities, no matter whose assessment of non-cognitive abilities we use.

This story is reversed for the second lowest class ranking ("below middle, but not at the bottom"). When non-cognitive skills are not included in the estimation, boys are almost 6 percentage points more likely to be assigned to this category than girls. Using PMKassessed skills in the estimation equation, this difference falls to 4.8 percentage points, falling further to 2.2 percentage points when teacher-assessed skills are substituted for PMK-assessed skills. Thus, even controlling for their lower level of non-cognitive skills, boys are, on average, more likely to be placed in the second lowest class rank category.

\subsubsection{Marginal Effects Along the Skills Distributions}

It is important to remember that the predicted assignment probabilities discussed above are calculated as average marginal effects. Rather than looking at the marginal effect of gender across the whole distribution of non-cognitive skills, we might want to know what the marginal effect of gender is at different points along the skills distribution. This involves the examination of the marginal effects at representative values (MER). Using this empirical technique, we can examine the marginal effect of gender across the noncognitive skills distribution.

In order to do so, the non-cognitive skills measure needs to be categorized, so that we can examine the marginal effects over different ranges of skills. This is done by defining non-cognitive skills as "high", "medium" and "low", as illustrated in Table 9a. The distribution of non-cognitive skills levels by gender is shown in Table 9b. 
There are no surprises here. Consistent with Figures 1.1a and $1.1 \mathrm{~b}$, we see that boys are over-represented in the low skills level, and under-represented in the high skills level, for both teacher- and PMK-assessed skills. Again, we see that teachers assign girls to the high skills level at a much higher rate than do PMKs. $64 \%$ of the high skill level group are girls when non-cognitive skills are assessed by the teacher, while only $55 \%$ of the high skill level group are girls when these skills are assessed by the PMK.

The ordered logit regressions are re-run using the new categorical variable for noncognitive skills, for both the teacher-assessed and PMK-assessed specifications. The coefficients from these regressions are shown in Appendix Table A-1. The results are consistent with those discussed above using the continuous variables (PMK- and teacherassessed) for non-cognitive skills. The coefficients are then used to calculate the marginal effect of gender across the distribution of non-cognitive skills.

Table 1.10a shows the predicted probabilities of assignment to each category at the low end of the non-cognitive skills distribution as assessed by the PMK. ${ }^{15}$ Clearly, these children are most likely to be placed in the "average" category, with no statistical difference between boys and girls. These children are also quite likely to be placed in the "below average" category, with $24 \%$ of boys being assigned this rank. Notably, only $18 \%$ of girls are placed in this category, although they have the same low level of noncognitive skills as boys (and all else is held constant). This represents a predicted gender gap of $6 \%$ in the second lowest ("below average") performance category.

In the same table, we see that these low skills children (ie attention-related skills) are not very likely to be placed in the higher rank categories. However, 19\% of girls are predicted to be assigned to the "above average" category, accompanied by only $15 \%$ of boys, a predicted gender gap of 4 percentage points favouring girls. The marginal effects of gender at low non-cognitive skills, for all performance categories, are shown in the bottom line of the table.

Table 10b shows the marginal effect of gender in the case where non-cognitive skill levels are derived from the teacher assessment of attention-related skills. From this table, we see that most students whose non-cognitive skills are assessed as low by the teacher are predicted to end up in the "average" and "below average" rank categories. However, boys are almost 4 percentage points more likely to be ranked as "below average" than girls, and 3 percentage points more likely to be ranked in the lowest "bottom of class" category than girls with the same assessed levels of non-cognitive skills. This is mirrored in the higher likelihood of girls being assigned to the "average", "above average" or even "top of class" categories.

\footnotetext{
${ }^{15}$ All other variables are held constant at given values (as opposed to using average values).
} 
We can also look at the predicted likelihoods of class ranking at the other end of the distribution of non-cognitive skills. Table 11a shows the marginal effect of gender when non-cognitive skills are assessed as "high" by the PMK. The distribution of outcomes has shifted to the right; as our intuition would suggest, children with high non-cognitive skills are more likely to be assigned a higher class rank than those with low non-cognitive skills. These high skilled boys (as assessed by the PMK) are most likely to be placed in the "average" category while similar girls are most likely to be placed in the "top of class" rank. Specifically, boys are 5 percentage points more likely than the similarly assessed girl to be assigned to the "average" category. This is reversed for the highest ranking, where girls are almost 10 percentage points more like to appear than similarly assessed boys.

Table $11 \mathrm{~b}$ shows the marginal effects of gender at "high" non-cognitive skills as assessed by the teacher. Again, the class rank distribution lies to the right of the distribution we saw for children assessed with low non-cognitive skills. Boys are again most likely to be ranked as "average" (admittedly by a small margin) while girls are most likely to be ranked as "top of class", although we are considering students who are all at the top of the non-cognitive skills distribution. Specifically, girls are 6 percentage points more likely to be placed in the "top of class" category than boys, while boys are more likely to be ranked in the "average" category by 4 percentage points.

Table 12a and 12b show the marginal effect of gender at each of the three levels of noncognitive skills. Table 12a uses the (categorical) PMK-assessed non-cognitive skills measure, while Table $12 \mathrm{~b}$ uses the teacher-assessed measure. These tables bring together the bottom lines of Tables 10 and 11, discussed above, and now include the MER results for medium non-cognitive skills as well. Each table has a corresponding graph which illustrates these changes in the marginal effect of gender as non-cognitive skills levels are changed.

Figure 1.3a accompanies Table 12a and uses PMK-assessed skill levels. Note that bars that extend above the horizontal axis indicate that the probability of a boy being assigned to that category is great than that for an identically categorized girl. Bars that extend below the horizontal axis then indicate that the probabilities are reversed, with girls being more likely to be assigned to that category than comparable boys. We see that the likelihood of a boy being assigned to the highest performance rank, "top of class", is smaller than for the comparable girl, for all levels of non-cognitive skill. The marginal effects of gender are reversed for below average class rankings. Boys are more likely to 
be assigned to the "average" category or below than girls, across all levels of noncognitive skills. ${ }^{16}$

Figure $1.3 \mathrm{~b}$ accompanies Table $1.12 \mathrm{~b}$, and uses teacher-assessed non-cognitive skills levels. Again, boys are more likely to be placed in the below average performance categories, regardless of their level of non-cognitive skills, while girls are more likely to be placed in the highest performance category.

\subsection{Conclusions}

This paper set out to shed light on the genesis of the gender gap that is pervasive throughout the education system, and to explore the possible reasons for this gap. For at least the cohort of children examined here, the gender gap in academic performance begins in the first years of primary school. Boys in grades 1 and 2 are more likely than girls to be ranked as below average or at the bottom of the class. Conversely, girls are more likely than boys to be assessed as a "top" student.

There is a large literature which attributes the gender gap in educational outcomes to differences in non-cognitive skills between girls and boys. The evidence presented in this paper supports this hypothesis to some extent. Boys do display a significant gap in noncognitive skills, as I have narrowly defined them, and the performance gap declines when I control for these skills. The empirical analysis suggests that non-cognitive skills play at least as an important a role as cognitive abilities is determining performance outcomes, and that cognitive and non-cognitive skills work along independent channels to influence outcomes.

Why do boys lag girls in non-cognitive skills? Some point to biological differences, for example Frenette and Zeman (2008). Others point to curriculum and institutional changes such as reduced recess time and increased focus on early literacy (Tyre, 2008). The results of this research give support to both hypotheses. Teachers and parents (PMKs) were asked to report on attention-related skills for the same child, but in different environments. The significant difference between the parental- and teacher-assessment of these non-cognitive skills - with teachers reporting a much larger gender gap in noncognitive skills than parents - suggests that the school environment exacerbates deficits in attention-related skills for boys. However, even in the home environment, the attentionrelated skills of boys lag those of girls, suggesting a root cause outside of the school environment.

\footnotetext{
${ }^{16}$ The exception is for low non-cognitive skills, where the likelihood of being assigned to the "average" category is the same for boys and girls.
} 
Irrespective of the reason for the gap in skills, its existence is of concern. Non-cognitive skills play an important role in determining school performance, and explain a large part of the gender gap in early school outcome that we observe in this study population. The concern is that these early gaps can lead to long-term differences in academic outcomes. There is a large literature (e.g., Elder and Lubotsky, 2009; Sprietsma, 2010) that documents the lasting effects of age - children who are born earlier in the school calendar year appear to be at a disadvantage in the early years, and this disadvantage leads to long run gaps in educational outcomes. Could boys' deficit in non-cognitive skills, which leads to disadvantages in early school outcomes, lead to a "gender effect" that is similar to the age effect?

Even controlling for these differences in non-cognitive skills, however, gender is still a significant determinant of class ranking. When we look deeper, we see that there appears to be systematic gender bias. Focused and cooperative girls are far more likely to be assigned to higher ranking categories than the equivalent boy. Conversely, boys with difficulty sitting still and concentrating are more likely to be assigned to the lower rank categories than the equivalent girl. The strongest evidence of this bias appears in the "top of the class" category.

The origin of this gender bias is unclear. There is some evidence in the literature (Lavy, 2008) that teachers themselves bring bias to the grading of their students, to the benefit of girls. Others (Dee, 2006) have suggested that the gender of the teacher matters, not because of gender bias on the part of teachers, but because boys tend to do better when taught by men, and girls tend to excel when taught by women. The vast majority of primary school teachers are women, creating an environment that favours girls. Still others (Lai, 2010) suggest that the test-orientated nature of the education system, especially in the early years, works to the disadvantage of boys.

It is possible that some important explanatory variables have been omitted which are also correlated with gender. However, if this is not the reason for the importance of gender in determining school outcomes in this paper, then the significance of gender provides cause for concern. Further research in to the root causes of this gender bias are in order. Does this gender-bias persist throughout the education system? Does this compound the "gender effect," leading to early and persistent disenfranchisement of boys?

In sum, boys in this study appear to face at least three serious hurdles. First, their attention-related non-cognitive skills lag those of girls, even in the home environment. Second, this gap is exacerbated by the school environment. These gaps translate into inferior performance outcomes in the classroom, with possible long term implications. Finally, even controlling for these deficits in non-cognitive skill, boys are still at a disadvantage in the classroom, facing a higher likelihood of being assigned to the lower grade categories than the equivalent girl. Together, these suggest that the genesis of the 
gender gap in many later educational outcomes may lie in the numerous early disadvantages faced by boys.

The policy implications that flow from these observations fall into two groups. The first set of policy suggestions target remediation of the gap in non-cognitive skills. Boys clearly lag girls in these important skills. Policies that work to increase awareness of the importance of non-cognitive skills in determining school performance are required. In addition, policies that address the environmental factors which exacerbate the gender gap in these skills are needed. Such policies would require educators to re-assess the learning environment as it currently exists. This would include an examination of: the impacts of earlier literacy and numeracy requirements in primary school; the consequences of decreased access to recess and physical education classes; and the role that the disproportionate number of female primary school teachers has had on the "feminization" of early education, and its influence on skills development.

The second group of policies falls under the heading of "unconscious bias". While the gap in non-cognitive skills played an important role in explaining class rankings in the paper, there remained a significant role for gender, even after controlling for these skills. This would suggest that there is also a need for educators to be made more aware of unconscious bias in the classroom. 


\section{Bibliography}

Bertrand, Marianne and Jessica Pan. 2013. "The Trouble with Boys: Social Influences and the Gender Gap in Disruptive Behavior." American Economic Journal: Applied Economics, 5(1): 32-64.

Bishop, John. 2005. "Drinking from the Fountain of Knowledge: Student Incentive to Study and Learn - Externalities, Information Problems and Peer Pressure." In Handbook of the Economics of Education Vol. 2, Handbooks in Economics, ed. Eric Hanushek and Finis Welch, 910-940. Amsterdam: New Holland.

Borghans, Lex, Angela Lee Duckworth, James J. Heckman, and Bas ter Weel. 2008. "The Economics and Psychology of Personality Traits." Journal of Human Resources, 43(4): 972-1059.

Buchmann, Claudia and Thomas A. DiPrete. 2006. "The Growing Female Advantage in College Completion: The Role of Family Background and Academic Achievement." American Sociological Review, 71(4): 515-541.

Cameron, Colin A. and Pravin K. Trivedi. 2010. Microeconometrics Using Stata, Revised Edition. Texas: Stata Press.

Cameron, Stephen V., and James J. Heckman. 1993. "The Nonequivalence of High School Equivalents." Journal of Labor Economics, 11(1): 1-47.

Cameron, Stephen V., and James J. Heckman. 2001. "The Dynamics of Educational Attainment for Black, Hispanic and White Males," Journal of Political Economy, 109(3): 455-499.

Carneiro, Pedro, Claire Crawford and Alissa Goodman. 2007. "The Impact of Early Cognitive and Non-Cognitive Skills on Later Outcomes." CEE Discussion Papers 0092.

Cho, Donghun. 2007. "The Role of High School Performance in Explaining Women's Rising College Enrollment." Economics of Education Review, 26(4):450-462.

Claessens, Amy, Greg J. Duncan and Mimi Engel. 2009. "Kindergarten Skills and FifthGrade Achievement: Evidence from the ECLS-K." Economics of Education Review, 28(4): 415-427.

Cornwell, Christopher M., David B. Mustard, and Jessica Van Parys. 2013. "NonCognitive Skills and the Gender Disparities in Test Scores and Teacher Assessments: Evidence from Primary School." Journal of Human Resources, 48(1): 236-264. 
Cunha, Flavio, James J. Heckman, Lance Lochner, and Dimitriy V. Masterov. 2006. "Interpreting the Evidence on Life Cycle Skill Formation." In Handbook of the Economics of Education Vol. 1, Handbooks in Economics, eds. Eric Hanushek and Finis Welch, 698-805. Amsterdam: New Holland.

Cunha, Flavio and James J. Heckman. 2007. "The Technology of Skill Formation." American Economic Review, 97(2): 31-47.

Dee, Thomas S. 2006. "Teachers and the Gender Gaps in Student Achievement."Journal of Human Resources, 42(3): 528-554.

Domino, George and Marla L. Domino. 2006. Psychological Testing: An Introduction. Cambridge: Cambridge University Press.

Drewes, Torben. 2010. "Gender Differences in High School Grades: Causes and Possible Impacts on the University Gender Gap." In Pursuing Higher Education in Canada: Economic, Social and Policy Dimension, eds. Ross Finnie, Marc Frenette, Richard E. Mueller and Arthur Sweetman, 43-64. Montreal and Kingston: Queen's Policy Study Series, McGill-Queen's University Press

Duncan, Greg J., Chantelle J. Dowsett, Amy Claessens, Katherine Magnuson, Aletha C. Huston, Pamela Klebanov, Linda S. Pagani, Leon Feinstein, Mimi Engel, Jeanne BrooksGunn, Holly Sexton, Kathryn Duckworth, and Crista Japel. 2007. "School Readiness and Later Achievement." Developmental Psychology, 43(6): 1428-1446.

Elder, Todd E. and Darren H Lubotsky. 2009. "Kindergarten Entrance Age and Children's Achievement: Impacts of State Policies, Family Background and Peers." Journal of Human Resources, 44(3): 641-683.

Fortin, Nicole M., Philip Oreopoulos, and Shelley Phipps (2015), "Leaving Boys Behind: Gender Disparities in High Academic Achievement." Journal of Human Resources, 50(3): 549-579.

Frenette, Marc and Klarka Zeman. 2008. "Understanding the Gender Gap in University Attendance: Evidence Based on Academic Performance, Study Habits and Parental Influences." In Who Goes? Who Stays? What Matters? Accessing and Persisting in Post-Secondary Education in Canada, ed. Ross Finnie, Richard E. Mueller, Arthur Sweetman, and Alex Usher, 135-154. Montreal and Kingston: Queen's Policy Study Series, McGill-Queen's University Press

Goldin, Claudia, Lawrence F. Katz, and Ilyana Kuziemko. 2006. "The Homecoming of American College Women: The Reversal of the College Gender Gap." Journal of Economic Perspectives, 20(4): 133-156. 
Golsteyn, Bart and Trudie Schils. 2014. "Gender Gaps in Primary School Achievement: A Decomposition into Endowment and Returns to IQ and Non-Cognitive Factors." IZA DP No. 8201

Groves, Melissa O. 2005. "How Important is Your Personality? Labor Market Returns to Personality for Women in the US and UK." Journal of Economic Psychology, 26(6): 827-841.

Heckman, James J. and Dimitriy V. Masterov. 2007. “The Productivity Argument for Investing in Young Children." Applied Economic Perspectives and Policy, 29(3): 446493.

Heckman, James J., Jora Stixrud, and Sergio Urzua. 2006. "The Effects of Cognitive and Noncognitive Abilities on Labor Market Outcomes and Social Behavior." Journal of Labor Economics, 24(3): 411-482.

Heckman, James J. and Yona Rubinstein. 2001. "The Importance of Noncognitive Skills: Lessons from the GED Testing Program." American Economic Review, 91(2) Papers and Proceedings of the Hundred Thirteenth Annual Meeting of the American Economic Association: 145-149.

Hernstein, Richard J., and Charles Murray. 1994. The Bell Curve: Intelligence and Class Structure in American Life. New York: Free Press.

Husain, Muna, and Daniel L. Millimet. 2009. "The Mythical Boy Crisis." Economics of Education Review 28(1): 38-48.

Jacob, Brian A. 2002. "Where the Boys Aren't: Non-Cognitive Skills, Returns to School and the Gender Gap in Higher Education." Economics of Education Review 21(6): 589598.

Lai, Fang. 2010. "Are Boys Left Behind? The Evolution of the Gender Achievement Gap in Beijing's Middle Schools." Economics of Education Review, 29(3): 383-399.

Lavy, Victor. 2008. "Do Gender Stereotypes Reduce Girls' or Boys' Human Capital Outcomes? Evidence from a Natural Experiment." Journal of Public Economics, 92(1011): 2083-2105.

Lefebvre, Pierre, and Philip Merrigan. 2010. "Gender Gap in Dropping Out of High School: Evidence from the Canadian NLSCY," Cahier de Recherche du CIRPEE 10-44.

Lefebvre Pierre, and Philip Merrigan. 2010b. "The Impact of Family Background and Cognitive and Non-Cognitive Ability in Childhood on Post-Secondary Education." In Pursuing Higher Education in Canada: Economic, Social and Policy Dimension, eds. 
Ross Finnie, Marc Frenette, Richard E. Mueller and Arthur Sweetman, 219-242. Montreal and Kingston: Queen's Policy Study Series, McGill-Queen's University Press.

Long, J. Scott. 1997. Regression Models for Categorical and Limited Dependent Variables (Advanced Quantitative Techniques in the Social Sciences v.7). Thousand Oaks: SAGE Publications

Murnane, Richard J., John B. Willett, and Frank Levy. 1995. "The Growing Importance of Cognitive Skills in Wage Determination," Review of Economics and Statistics, 77(2): 251-266.

Sax, Leonard. 2009. Boys Adrift: The Five Factors Driving the Growing Epidemic of Unmotivated Boys and Underachieving Young Men. New York: Basic Books.

Spearman, Charles E. 1904. "General Intelligence, Objectively Determined and Measured." American Journal of Psychology, 15(2): 201-293.

Sprietsma, Maresa. 2010. "The Effect of Relative Age in the First Grade of Primary School on Long-term Scholastic Results: International Comparative Evidence Using PISA 2003." Education Economics, 18(1): 1-32.

Stock, James H. 2010. "The Other Transformation in Econometric Practice: Robust Tools for Inference.” Journal of Economic Perspectives, 24(2): 83-94.

Strauss, Esther, Elizabeth M.S. Sherman, and Otfried Spreen. 2006. A Compendium of Neuropsychological Tests: Administration, Norms and Commentary, $3^{\text {rd }}$ Edition. Oxford: Oxford University Press.

Turcotte, Martin. 2011. "Women and Education." In Women in Canada: A Gender-Based Statistical Report. Statistics Canada 89-503-X.

Tyre, Peg. 2008. The Trouble With Boys: A Surprising Report Card on Our Sons, Their Problems at School, and What Parents and Educators Must Do," Place: Three River Press.

Whitmore, Richard. 2011. Why Boys Fail: Saving Our Sons From an Educational System That's Leaving Them Behind. Amacom.

Winship, Christopher and Robert D. Mare. 1984. "Regression Models with Ordinal Variables." American Sociological Review, 49(4): 512-525.

Worswick, Christopher. 2003. "School Program Choice and Streaming: Evidence from French Immersion Programs," CERForum Papers. 


\section{Tables and Figures}

Table 1.1 Distributions of Teacher-Assessed Performance by Gender, Cycle 2

\begin{tabular}{lccc}
\hline Rank & Boys & Girls & Difference \\
\hline Y=1 ("Bottom") & 9.69 & 4.66 & 5.03 \\
Y=2 ("Below Average") & 17.63 & 13.2 & 4.43 \\
Y=3 ("Average") & 36.56 & 34.71 & 1.85 \\
Y=4 ("Above Average") & 20.55 & 19.83 & 0.72 \\
Y=5 ("Top") & 15.58 & 27.6 & -12.02 \\
\hline
\end{tabular}

Table 1.2. Variables and their Origins

\begin{tabular}{lccc}
\hline Variable & Cycle 1 & Cycle 2 & Source \\
\hline $\begin{array}{l}\text { Dependent Variable: } \\
\text { School performance (dependent) }\end{array}$ & & \\
Independent Variables: & $\checkmark$ & Teacher \\
\hline Cognitive skills (PPVT) & & $\checkmark$ & Teacher, PMK \\
Non-cognitive skills & $\checkmark$ & & PMK \\
Family background (SES) & $\checkmark$ & PMK \\
Gender & $\checkmark$ & PMK \\
\hline
\end{tabular}

Table 1.3. Average Student Characteristics over Cycles 1 and 2.

\begin{tabular}{|c|c|c|c|c|c|c|}
\hline Sample & Obs. & PPVT & SES & $\begin{array}{l}\text { Gender } \\
\text { (Male) }\end{array}$ & $\begin{array}{l}\text { Family Status } \\
\quad \text { (Intact) }\end{array}$ & Age \\
\hline A: Cycle 1 & 3728 & $\begin{array}{c}99.49 \\
(15.54)\end{array}$ & $\begin{array}{l}-0.06 \\
(0.78)\end{array}$ & $\begin{array}{c}0.51 \\
(0.50)\end{array}$ & $\begin{array}{c}0.75 \\
(0.43)\end{array}$ & $\begin{array}{c}4.50 \\
(0.50)\end{array}$ \\
\hline $\begin{array}{l}\text { B: Cycle } 2 \\
\text { (PMK attrition) }\end{array}$ & 2426 & $\begin{array}{l}99.73 \\
(15.46)\end{array}$ & $\begin{array}{l}-0.09 \\
(0.75)\end{array}$ & $\begin{array}{c}0.51 \\
(0.50)\end{array}$ & $\begin{array}{l}0.73 * \\
(0.44)\end{array}$ & $\begin{array}{c}4.52 \\
(0.50)\end{array}$ \\
\hline $\begin{array}{l}\text { C: Cycle } 2 \\
\text { (PMK + Teacher attrition) }\end{array}$ & 1938 & $\begin{array}{c}99.86 \\
(15.15)\end{array}$ & $\begin{array}{l}-0.07 \\
(0.74)\end{array}$ & $\begin{array}{c}0.51 \\
(0.50)\end{array}$ & $\begin{array}{c}0.73 \\
(0.45)\end{array}$ & $\begin{array}{l}4.53 * * \\
(0.50)\end{array}$ \\
\hline
\end{tabular}

Standard deviations are shown in brackets below the mean values. Differences in mean values were calculated using an unpaired t-test. Statistically significant differences, vis a vis the Cycle 1 sample, are indicated by $*, * *$,and $* * *$ at the $10 \%, 5 \%$, and $1 \%$ levels respectively. 
Table 1.4. Average Characteristics - Survey Leavers vs. Continuing Respondents

\begin{tabular}{lcccccc}
\hline & Observations & PPVT & SES & $\begin{array}{c}\text { Gender } \\
\text { (Male) }\end{array}$ & $\begin{array}{c}\text { Family Status } \\
\text { (Intact) }\end{array}$ & Age \\
\hline \multirow{2}{*}{ Continuers } & \multirow{2}{*}{2426} & 99.73 & -0.09 & 0.51 & 0.73 & 4.52 \\
& & $(15.46)$ & $(0.75)$ & $(0.50)$ & $(0.44)$ & $(0.50)$ \\
Leavers & \multirow{2}{*}{1302} & $98.43^{* *}$ & $-0.03^{* *}$ & 0.53 & 0.75 & $4.49^{*}$ \\
& & $(15.87)$ & $(0.84)$ & $(0.50)$ & $(0.43)$ & $(0.50)$ \\
\hline
\end{tabular}

Standard deviations are shown in brackets below the mean values. Differences in mean values were calculated using an unpaired t-test. Statistically significant differences in the leaver sample, vis a vis the continuers,

Table 1.5. Average Characteristics of the $\mathrm{C} 2$ Populations by Teacher Responses

\begin{tabular}{lcccccc}
\hline & Obs. & PPVT & SES & $\begin{array}{c}\text { Gender } \\
\text { (Male) }\end{array}$ & $\begin{array}{c}\text { Family Status } \\
\text { (Intact) }\end{array}$ & Age \\
\hline PMK + Teacher - & \multirow{2}{*}{1765} & 99.86 & -0.07 & 0.51 & 0.72 & 4.57 \\
Compete & & $(15.15)$ & $(0.74)$ & $(0.50)$ & $(0.45)$ & $(0.50)$ \\
PMK + Teacher - & \multirow{2}{*}{173} & $102.64^{* *}$ & $-0.17^{*}$ & 0.52 & $0.81^{* *}$ & $4.07^{* * *}$ \\
No Class Rank & & $(17.4)$ & $(0.84)$ & $(0.50)$ & $(0.40)$ & $(0.25)$ \\
PMK Records Only - & \multirow{2}{*}{488} & $98.25^{* *}$ & -0.11 & 0.53 & $0.76^{*}$ & $4.50^{* * *}$ \\
No Teacher Response & & $(15.78)$ & $(0.76)$ & $(0.50)$ & $(0.43)$ & $(0.50)$ \\
\hline
\end{tabular}

Standard deviations are shown in brackets below the mean values.

Table 1.6. Summary Statistics by Gender (Cycle 2 population)

\begin{tabular}{lccc}
\hline & Boys (873) & Girls (892) & Difference (p-value) \\
\hline Cognitive Skills & 99.45 & 100.3 & $\mathrm{p}=0.2383$ \\
Teacher-Reported & $(15.41)$ & $(14.86)$ & \\
Non-Cognitive Skills & 9.15 & 11.0 & $\mathrm{p}<0.0001$ \\
PMK-Reported Non- & $(3.96)$ & $(3.62)$ & \\
Cognitive Skills & $9.54^{*}$ & $10.46^{* * *}$ & $\mathrm{p}<0.0001$ \\
SES & $(3.39)$ & $(3.07)$ & \\
& -0.06 & -0.08 & $\mathrm{p}=0.5704$ \\
Family Status (Intact) & $(0.73)$ & $(0.75)$ & $\mathrm{p}=0.0198$ \\
\hline
\end{tabular}

PMK-reported non-cognitive skills scores are compared to the teacher reported scores. Differences in the scores are calculated by gender, and confidence levels are indicated in the table by " $* "=10 \%, " * * "=5 \%$ and "***" $=1 \%$. 
Table 1.7. Ordered Logit Regression Results.

\begin{tabular}{|c|c|c|c|c|}
\hline & $\begin{array}{l}\text { Background Only, } \\
\text { No Skills } \\
\text { (1) }\end{array}$ & $\begin{array}{l}\text { Add Cognitive } \\
\text { Skills } \\
\text { (2) }\end{array}$ & $\begin{array}{c}\text { Add PMK- } \\
\text { Reported Non- } \\
\text { cognitive Skills } \\
\text { (3) }\end{array}$ & $\begin{array}{c}\text { Sub. Teacher- } \\
\text { Reported Non- } \\
\text { cognitive Skills } \\
\text { (4) }\end{array}$ \\
\hline \multirow[t]{2}{*}{ Male } & $-0.612 * * *$ & $-0.607 * * *$ & $-0.482 * * *$ & $-0.241^{*}$ \\
\hline & $(0.145)$ & $(0.147)$ & (0.147) & $(0.151)$ \\
\hline \multirow[t]{2}{*}{ SES } & $0.806 * * *$ & $0.730 * * *$ & $0.677 * * *$ & $0.611 * * *$ \\
\hline & $(0.107)$ & (0.109) & $(0.115)$ & $(0.116)$ \\
\hline \multicolumn{5}{|l|}{ Family Status } \\
\hline Intact Family & reference & & & \\
\hline \multirow[t]{2}{*}{ Census Family } & -0.320 & -0.346 & -0.267 & 0.065 \\
\hline & (0.319) & (0.309) & (0.304) & $(0.330)$ \\
\hline \multirow[t]{2}{*}{ Single Family } & $-0.581 * * *$ & $-0.623 * * *$ & $-0.497 * *$ & $-0.371 *$ \\
\hline & $(0.222)$ & $(0.245)$ & $(0.218)$ & $(0.214)$ \\
\hline \multirow[t]{2}{*}{$\mathrm{PPVT}^{\mathrm{a}}$} & - & $0.390 * * *$ & $0.403 * * *$ & $0.377^{* * *}$ \\
\hline & & $(0.079)$ & $(0.083)$ & $(0.083)$ \\
\hline \multirow[t]{2}{*}{ Non-cognitive Skills ${ }^{b}$} & - & - & $0.412 * * *$ & $0.967 * * *$ \\
\hline & & & $(0.086)$ & $(0.088)$ \\
\hline Observations & 1513 & 1513 & 1513 & 1513 \\
\hline
\end{tabular}

a: the PPVT score has been standardized to have mean $=0$ and standard deviation $=1$

$\mathrm{b}$ : the non-cognitive skills measure has been standardized to have mean $=0$ and standard deviation $=1$.

( ): Standard deviations are reported in brackets below the coefficients.

$*, * *, * * *$ Indicate statistical significance at the $10 \%, 5 \%$ and $1 \%$ levels, respectively.

Table 1.8a. AME of Gender, Cognitive Skills Only

\begin{tabular}{lccccc}
\hline & $\mathbf{Y = 1}$ & $\mathbf{Y}=\mathbf{2}$ & $\mathbf{Y = 3}$ & $\mathbf{Y = 4}$ & $\mathbf{Y = 5}$ \\
\hline $\operatorname{Pr}\left(\boldsymbol{Y}_{\boldsymbol{i}}=\boldsymbol{j} \mid \boldsymbol{X}_{\boldsymbol{i}}, \boldsymbol{g}\right.$ ender $\left.=\boldsymbol{b}\right)$ & 0.085 & 0.191 & 0.359 & 0.187 & 0.178 \\
& $(0.112)$ & $(0.018)$ & $(0.020)$ & $(0.016)$ & $(0.016)$ \\
$\operatorname{Pr}\left(\boldsymbol{Y}_{\boldsymbol{i}}=\boldsymbol{j} \mid \boldsymbol{X}_{\boldsymbol{i}}, \boldsymbol{g e n d e r}=\boldsymbol{g}\right)$ & 0.05 & 0.132 & 0.325 & 0.222 & 0.27 \\
Difference $\left(\mathrm{AME}_{\mathrm{j}}\right)$ & $(0.008)$ & $(0.015)$ & $(0.02)$ & $(0.018)$ & $(0.022)$ \\
\hline
\end{tabular}

Standard deviations are shown in brackets below the probabilities. This table corresponds to Specification

(2) in Table 1.7. $* * *, * *, *$ indicate that the difference is significant at the $1 \%, 5 \%$ and $10 \%$ levels respectively. In the first column of the table, "b" stands for "boys" and "g" stands for "girls". 
Table 1.8b. AME of Gender: PMK-Assessed Non-Cognitive Skills.

\begin{tabular}{lccccc}
\hline & $\mathbf{Y}=\mathbf{1}$ & $\mathbf{Y}=\mathbf{2}$ & $\mathbf{Y}=\mathbf{3}$ & $\mathbf{Y = 4}$ & $\mathbf{Y}=\mathbf{5}$ \\
\hline $\operatorname{Pr}\left(\boldsymbol{Y}_{\boldsymbol{i}}=\boldsymbol{j} \mid \boldsymbol{X}_{\boldsymbol{i}}, \boldsymbol{g e n d e r}=\boldsymbol{b}\right)$ & 0.082 & 0.186 & 0.358 & 0.19 & 0.185 \\
& $(0.011)$ & $(0.017)$ & $(0.02)$ & $(0.016)$ & $(0.016)$ \\
$\operatorname{Pr}\left(\boldsymbol{Y}_{\boldsymbol{i}}=\boldsymbol{j} \mid \boldsymbol{X}_{\boldsymbol{i}}, \boldsymbol{g e n d e r}=\boldsymbol{g}\right)$ & 0.053 & 0.138 & 0.33 & 0.218 & 0.26 \\
Difference (AME) & $(0.008)$ & $(0.015)$ & $(0.019)$ & $(0.018)$ & $(0.022)$ \\
\hline
\end{tabular}

Standard deviations are shown in brackets below the probabilities. This table corresponds to Specification

(3) in Table $1.7 . * * *, * *, *$ indicate that the difference is significant at the $1 \%, 5 \%$ and $10 \%$ levels.

Table 1.8c. AME of Gender: Teacher-Assessed Non-Cognitive Skills.

\begin{tabular}{lccccc}
\hline & $\mathbf{Y}=\mathbf{1}$ & $\mathbf{Y}=\mathbf{2}$ & $\mathbf{Y = 3}$ & $\mathbf{Y = 4}$ & $\mathbf{Y}=\mathbf{5}$ \\
\hline $\operatorname{Pr}\left(\boldsymbol{Y}_{\boldsymbol{i}}=\boldsymbol{j} \mid \boldsymbol{X}_{\boldsymbol{i}}, \boldsymbol{g e n d e r}=\boldsymbol{b}\right)$ & 0.069 & 0.177 & 0.350 & 0.193 & 0.21 \\
& $(0.01)$ & $(0.016)$ & $(0.02)$ & $(0.016)$ & $(0.017)$ \\
$\operatorname{Pr}\left(\boldsymbol{Y}_{\boldsymbol{i}}=\boldsymbol{j} \mid \boldsymbol{X}_{\boldsymbol{i}}, \boldsymbol{g e n d e r}=\boldsymbol{g}\right)$ & 0.056 & 0.155 & 0.338 & 0.205 & 0.246 \\
Difference (AME) & $(0.009)$ & $(0.163)$ & $(0.019)$ & $(0.016)$ & $(0.021)$ \\
\hline
\end{tabular}

Standard deviations are shown in brackets below the probabilities. This table corresponds to Specification

(4) in Table 1.7. ${ }^{* * *}, * * *$ indicate that the difference is significant at the $1 \%, 5 \%$ and $10 \%$ levels

respectively.

Table 1.9a. Defining Non-Cognitive Skills Levels

\begin{tabular}{ll}
\hline Non-Cognitive Skill Level: & Standardized Non-Cognitive Skills Score \\
\hline Low & $<-0.5$ \\
Medium & $<=-0.5$ and $<0.5$ \\
High & $>=0.5$ \\
\hline
\end{tabular}

Table 1.9b. Distribution of Non-Cognitive Skills Levels

\begin{tabular}{lcccccc}
\hline & \multicolumn{3}{c}{ Teacher-Assessed } & \multicolumn{3}{c}{ PMK-Assessed } \\
\hline & Low & Medium & High & Low & Medium & High \\
Boys & $(\mathbf{3 2 . 4 \% )}$ & $\mathbf{( 2 7 . 7 \% )}$ & $\mathbf{( 3 9 . 9 \% )}$ & $\mathbf{( 2 8 . 8 \% )}$ & $\mathbf{( 2 8 . 8 \% )}$ & $\mathbf{( 4 2 . 4 )}$ \\
Girls & 63.8 & 56.8 & 36.2 & 61.1 & 51.1 & 45.1 \\
\hline
\end{tabular}


Table 1.10a. MER of Gender: LOW Non-Cognitive Skills Levels, PMK

\begin{tabular}{lccccc}
\hline & $\mathbf{Y = 1}$ & $\mathbf{Y}=\mathbf{2}$ & $\mathbf{Y = 3}$ & $\mathbf{Y}=\mathbf{4}$ & $\mathbf{Y = 5}$ \\
\hline \multirow{2}{*}{$\operatorname{Pr}\left(\boldsymbol{Y}_{\boldsymbol{i}}=\boldsymbol{j} \mid \boldsymbol{X}_{\boldsymbol{i}}, \boldsymbol{g e n d e r}=\boldsymbol{b}\right)$} & 0.117 & 0.239 & 0.376 & 0.153 & 0.113 \\
& $(0.017)$ & $(0.024)$ & $(0.021)$ & $(0.017)$ & $(0.017)$ \\
$\operatorname{Pr}\left(\boldsymbol{Y}_{\boldsymbol{i}}=\boldsymbol{j} \mid \boldsymbol{X}_{\boldsymbol{i}}, \boldsymbol{g e n d e r}=\boldsymbol{g}\right)$ & 0.076 & 0.184 & 0.374 & 0.194 & 0.172 \\
& $(0.013)$ & $(0.023)$ & $(0.021)$ & $(0.019)$ & $(0.025)$ \\
Difference (MER) & $0.042^{* * *}$ & $0.055^{* * *}$ & 0.002 & $-0.041^{* * *}$ & $-0.058^{* * *}$ \\
& $(0.012)$ & $(0.016)$ & $(0.008)$ & $(0.012)$ & $(0.018)$ \\
\hline
\end{tabular}

Standard Deviations are shown in brackets beneath the probabilities.

$* * *, * *, *$ indicate that the difference is significant at the $1 \%, 5 \%$ and $10 \%$ levels respectively.

$\mathrm{b}$ and $\mathrm{g}$ stand for boys and girls, respectively.

Table 1.10b. MER of Gender: LOW Non-Cognitive Skills Levels: Teacher.

\begin{tabular}{lccccc}
\hline & $\mathbf{Y}=\mathbf{1}$ & $\mathbf{Y}=\mathbf{2}$ & $\mathbf{Y = 3}$ & $\mathbf{Y}=\mathbf{4}$ & $\mathbf{Y}=\mathbf{5}$ \\
\hline \multirow{2}{*}{$\operatorname{Pr}\left(\boldsymbol{Y}_{\boldsymbol{i}}=\boldsymbol{j} \mid \boldsymbol{X}_{\boldsymbol{i}}, \boldsymbol{g e n d e r}=\boldsymbol{b}\right)$} & 0.133 & 0.302 & 0.392 & 0.109 & 0.064 \\
& $(0.020)$ & $(0.028)$ & $(0.025)$ & $(0.013)$ & $(0.011)$ \\
$\operatorname{Pr}\left(\boldsymbol{Y}_{\boldsymbol{i}}=\boldsymbol{j} \mid \boldsymbol{X}_{\boldsymbol{i}}, \boldsymbol{g e n d e r}=\boldsymbol{g}\right)$ & 0.104 & 0.266 & 0.414 & 0.133 & 0.084 \\
\multirow{2}{*}{ Difference (MER) } & $(0.017)$ & $(0.028)$ & $(0.023)$ & $(0.016)$ & $(0.016)$ \\
& $0.030^{* *}$ & $0.036^{* *}$ & $-0.021^{* *}$ & $-0.024^{* *}$ & $-0.02^{*}$ \\
& $(0.015)$ & $(0.018)$ & $(0.011)$ & $(0.012)$ & $(0.011)$ \\
\hline
\end{tabular}

Standard Deviations are shown in brackets beneath the probabilities.

$* * *, * *, *$ indicate that the difference is significant at the $1 \%, 5 \%$ and $10 \%$ levels respectively

Table 1.11a. MER of Gender: HIGH Non-Cognitive Skills Levels: PMK.

\begin{tabular}{lccccc}
\hline & $\mathbf{Y}=\mathbf{1}$ & $\mathbf{Y}=\mathbf{2}$ & $\mathbf{Y}=\mathbf{3}$ & $\mathbf{Y}=\mathbf{4}$ & $\mathbf{Y}=\mathbf{5}$ \\
\hline $\operatorname{Pr}\left(\boldsymbol{Y}_{\boldsymbol{i}}=\boldsymbol{j} \mid \boldsymbol{X}_{\boldsymbol{i}}, \boldsymbol{g e n d e r}=\boldsymbol{b}\right)$ & 0.050 & 0.137 & 0.345 & 0.225 & 0.244 \\
& $(0.009)$ & $(0.016)$ & $(0.021)$ & $(0.019)$ & $(0.024)$ \\
$\operatorname{Pr}\left(\boldsymbol{Y}_{\boldsymbol{i}}=\boldsymbol{j} \mid \boldsymbol{X}_{\boldsymbol{i}}, \boldsymbol{g e n d e r}=\boldsymbol{g}\right)$ & 0.030 & 0.094 & 0.294 & 0.243 & 0.339 \\
& $(0.006)$ & $(0.013)$ & $(0.021)$ & $(0.020)$ & $(0.028)$ \\
Difference (MER) & $0.020^{* * *}$ & $0.042^{* * *}$ & $0.051^{* * *}$ & $-0.017 * * *$ & $-0.095^{* * *}$ \\
& $(0.006)$ & $(0.012)$ & $(0.015)$ & $(0.007)$ & $(0.026)$ \\
\hline
\end{tabular}

Standard Deviations are shown in brackets beneath the probabilities.

$* * *, * *, *$ indicate that the difference is significant at the $1 \%, 5 \%$ and $10 \%$ levels respectively 
Table 1.11b. MER of Gender: HIGH Non-Cognitive Skills Levels: Teacher.

\begin{tabular}{lccccc}
\hline & $\mathbf{Y}=\mathbf{1}$ & $\mathbf{Y}=\mathbf{2}$ & $\mathbf{Y = 3}$ & $\mathbf{Y}=\mathbf{4}$ & $\mathbf{Y}=\mathbf{5}$ \\
\hline $\operatorname{Pr}\left(\boldsymbol{Y}_{\boldsymbol{i}}=\boldsymbol{j} \mid \boldsymbol{X}_{\boldsymbol{i}}, \boldsymbol{g e n d e r}=\boldsymbol{b}\right)$ & 0.022 & 0.087 & 0.326 & 0.254 & 0.311 \\
& $(0.005)$ & $(0.015)$ & $(0.024)$ & $(0.022)$ & $(0.029)$ \\
$\operatorname{Pr}\left(\boldsymbol{Y}_{\boldsymbol{i}}=\boldsymbol{j} \mid \boldsymbol{X}_{\boldsymbol{i}}, \boldsymbol{g e n d e r}=\boldsymbol{g}\right)$ & 0.016 & 0.068 & 0.285 & 0.257 & 0.373 \\
& $(0.003)$ & $(0.011)$ & $(0.023)$ & $(0.022)$ & $(0.029)$ \\
Difference (MER) & $0.006^{*}$ & $0.020^{*}$ & $0.04 * *$ & -0.003 & $-0.062^{* *}$ \\
& $(0.003)$ & $(0.010)$ & $(0.020)$ & $(0.004)$ & $(0.030)$ \\
\hline
\end{tabular}

Standard Deviations are shown in brackets beneath the probabilities.

$* * *, * *, *$ indicate that the difference is significant at the $1 \%, 5 \%$ and $10 \%$ levels respectively

Table 1.12a. Summary of MER of Gender (Boy-Girl): PMK

\begin{tabular}{lccccc}
\hline & $\mathbf{Y}=\mathbf{1}$ & $\mathbf{Y}=\mathbf{2}$ & $\mathbf{Y}=\mathbf{3}$ & $\mathbf{Y}=\mathbf{4}$ & $\mathbf{Y}=\mathbf{5}$ \\
\hline Level = "Low" & $0.042^{* * *}$ & $0.055^{* * *}$ & -0.002 & $-0.041^{* * *}$ & $-0.058^{* * *}$ \\
& $(0.012)$ & $(0.016)$ & $(0.008)$ & $(0.012)$ & $(0.018)$ \\
Level = "Medium" & $0.031^{* * *}$ & $0.052^{* * *}$ & $0.025^{* * *}$ & $-0.035^{* * *}$ & $-0.073^{* * *}$ \\
& $(0.010)$ & $(0.015)$ & $(0.010)$ & $(0.011)$ & $(0.020)$ \\
Level = "High" & $0.020^{* * *}$ & $0.042^{* * *}$ & $0.051^{* * *}$ & $-0.017 * *$ & $-0.095^{* * *}$ \\
& $(0.006)$ & $(0.012)$ & $(0.015)$ & $(0.007)$ & $(0.026)$ \\
\hline
\end{tabular}

Standard Deviations are shown in brackets beneath the probabilities.

$* * *, * *, *$ indicate that the difference is significant at the $1 \%, 5 \%$ and $10 \%$ levels respectively

Table 1.12b. Summary of MER of Gender (Boy-Girl): Teacher

\begin{tabular}{cccccc}
\hline & $\mathbf{Y = 1}$ & $\mathbf{Y}=\mathbf{2}$ & $\mathbf{Y}=\mathbf{3}$ & $\mathbf{Y = 4}$ & $\mathbf{Y}=\mathbf{5}$ \\
\hline Level = "Low" & $0.030^{* *}$ & $0.036^{* *}$ & $-0.021^{* *}$ & $-0.024^{* *}$ & $-0.02^{*}$ \\
& $(0.015)$ & $(0.018)$ & $(0.011)$ & $(0.012)$ & $(0.011)$ \\
Level = "Medium" & $0.011^{*}$ & $0.030^{* *}$ & $0.027^{*}$ & $-0.020^{* *}$ & $-0.047^{*}$ \\
& $(0.006)$ & $(0.015)$ & $(0.014)$ & $(0.010)$ & $(0.024)$ \\
Level = "High" & $0.006^{*}$ & $0.020^{*}$ & $0.04^{* *}$ & -0.003 & $-0.062^{* *}$ \\
& $(0.003)$ & $(0.010)$ & $(0.020)$ & $(0.004)$ & $(0.030)$ \\
\hline
\end{tabular}

Standard Deviations are shown in brackets beneath the probabilities.

$* * *, * *, *$ indicate that the difference is significant at the $1 \%, 5 \%$ and $10 \%$ levels respectively 
Figure 1.1a. PMK-Assessed Non-cognitive Skills by Gender

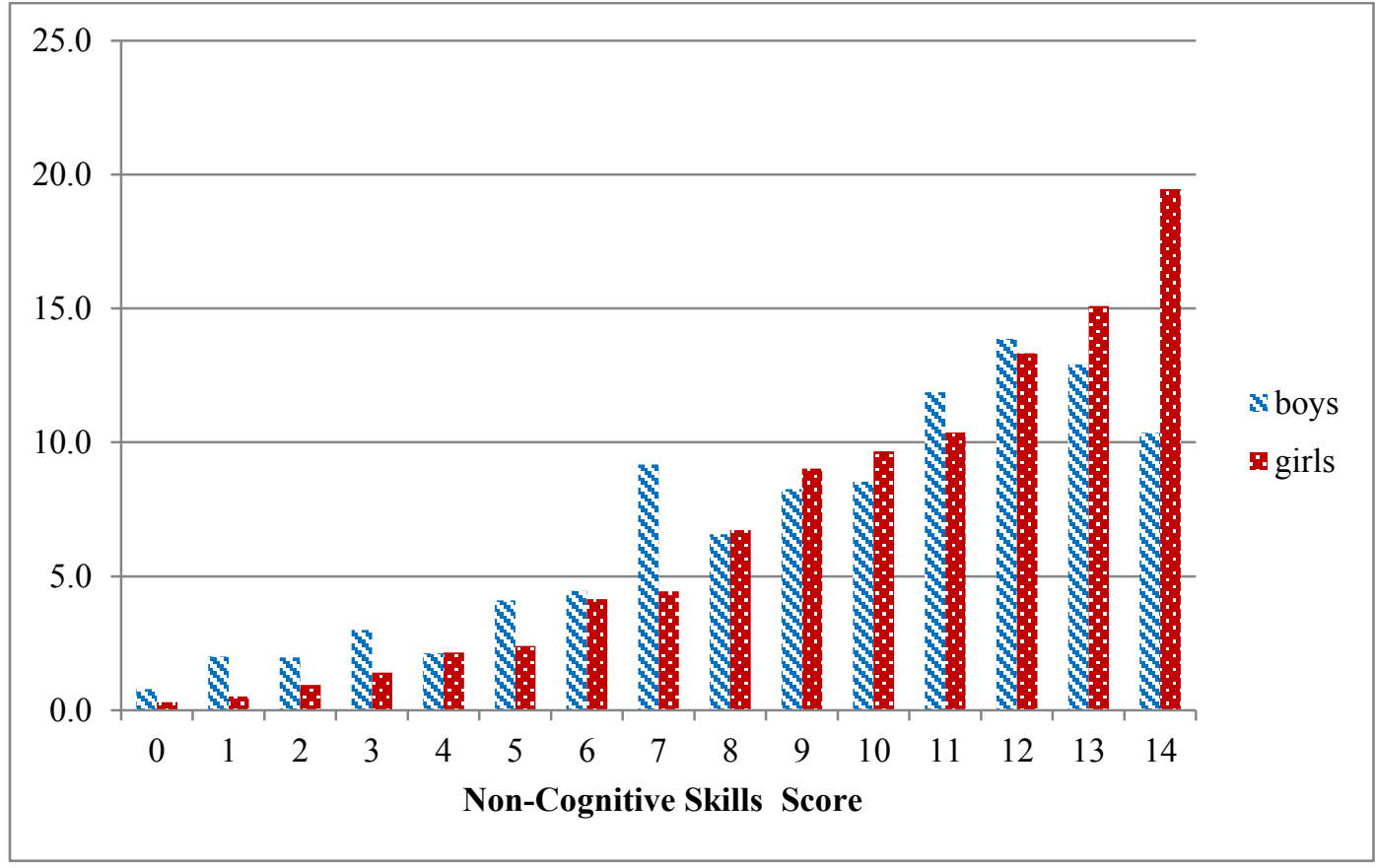

Figure 1.1b. Teacher-Assessed Non-cognitive Skills by Gender

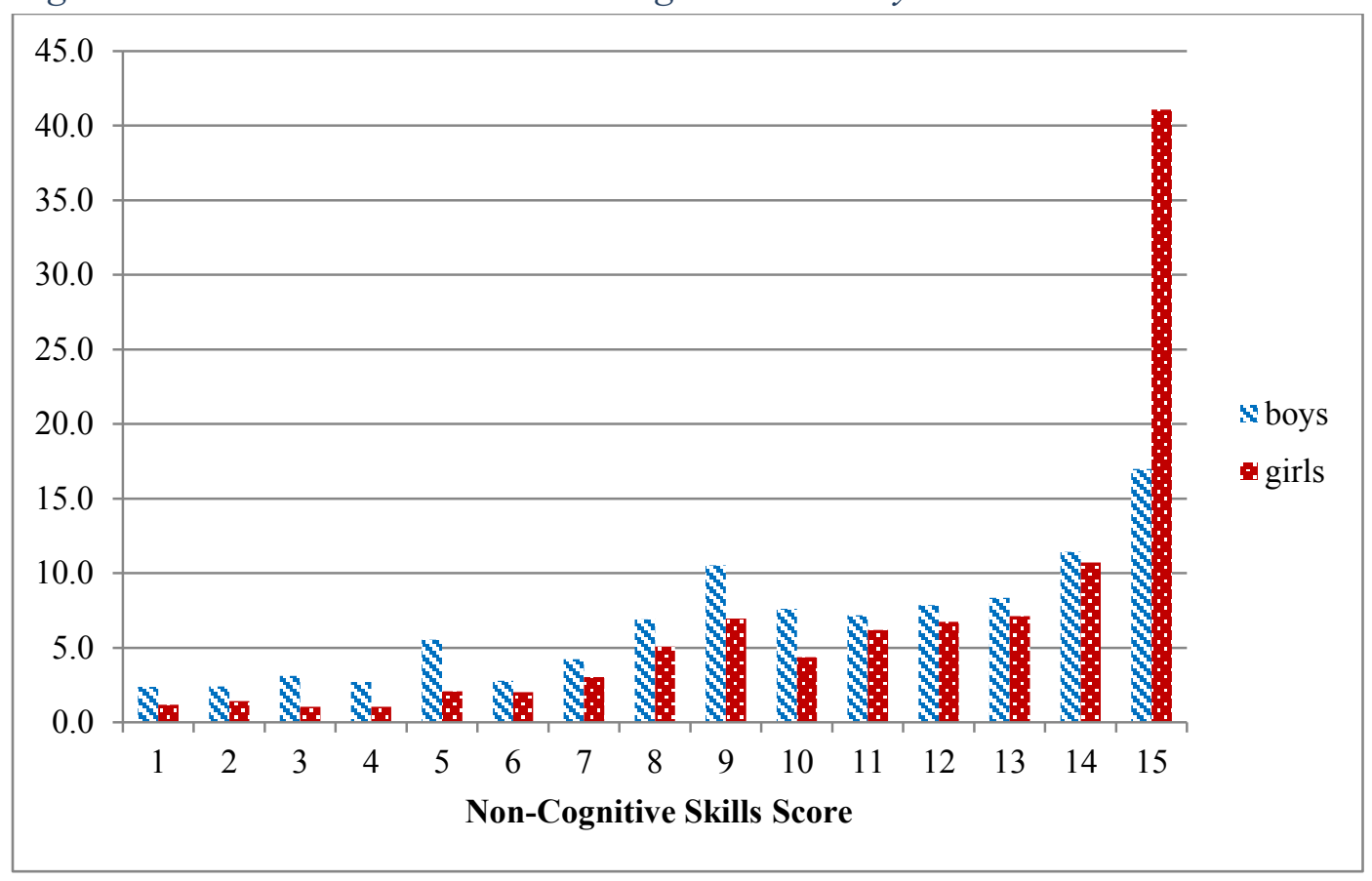


Figure 1.2: AME of Gender Models (2), (3) and (4)

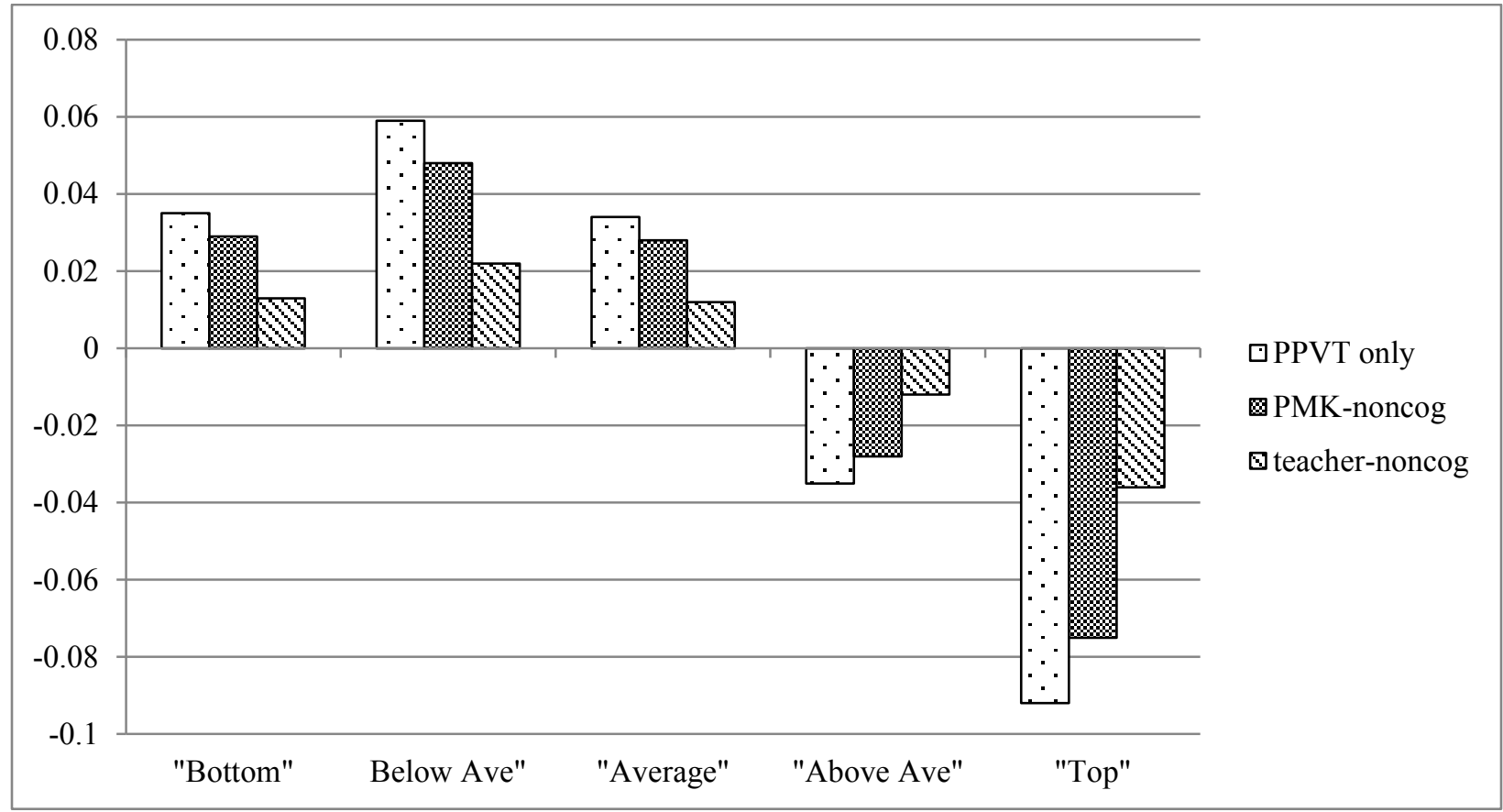

Shown for Prob(Boys) - prob(Girls)

Figure 1.3a: MER-PMK-Assessed Skills



Shown for Prob(Boys) - prob(Girls) 
Figure 1.3b: MER - Teacher-Assessed Skills

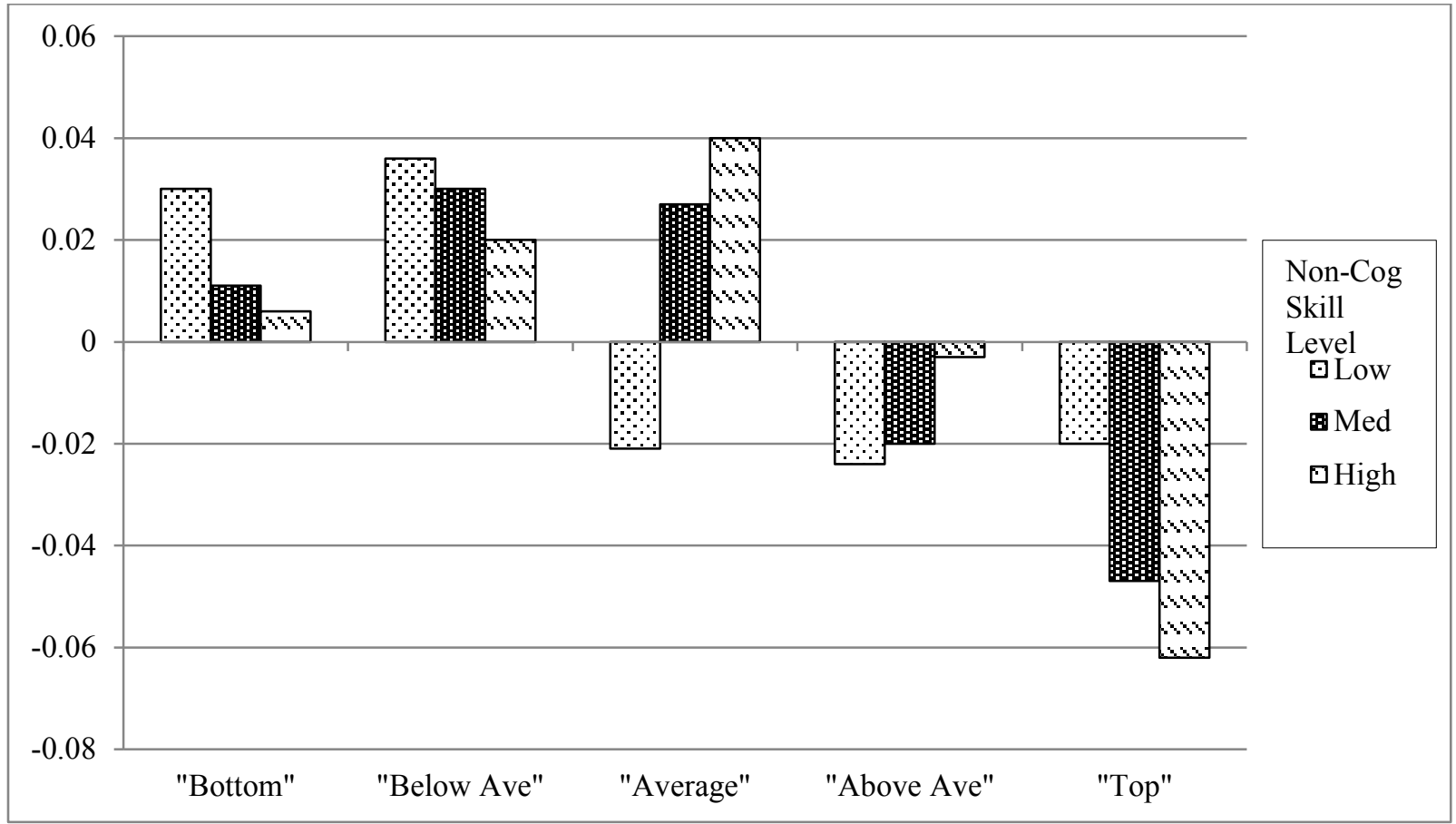

Shown for Prob(Boys) - prob(Girls) 


\section{Appendices:}

Appendix 1.A: Coefficients from Regressions Using Non-Cognitive Skills Levels

Table A-1.

\begin{tabular}{lcc}
\hline & $\begin{array}{c}\text { PMK-Assessed } \\
\text { Non-cognitive } \\
\text { Skills }\end{array}$ & $\begin{array}{c}\text { Teacher-Assessed } \\
\text { Non-cognitive } \\
\text { Skills }\end{array}$ \\
\hline Gender & $-0.501^{* * *}$ & -0.303 \\
SES & 0.142 & $(0.151)$ \\
Intact Family & $0.670^{* * *}$ & $0.644^{* * *}$ \\
Census Family & $(0.107)$ & $(0.118)$ \\
Single Family & reference & \\
& -0.237 & 0.103 \\
Cognitive skills (PPVT) & $(0.281)$ & $(0.354)$ \\
Low Non-Cognitive Skills Level & $-0.560^{* *}$ & $-0.450^{* *}$ \\
Medium Non-Cognitive Skills Level & $(0.221)$ & $(0.209)$ \\
Hi Non-Cognitive Skills Level & $0.028^{* * *}$ & $0.025^{* * *}$ \\
& $(0.006)$ & $(0.006)$ \\
Observations & reference & $1.281^{* * *}$ \\
& $0.406^{* *}$ & $(0.204)$ \\
& $(0.188)$ & $(0.19 *)$ \\
& $0.975^{* * *}$ & 1513 \\
\hline
\end{tabular}




\section{Chapter: Gender and Skills in the Production of High School Grades}

\subsection{Introduction}

One objective of education policy is to provide Canadians, from all walks of life and all backgrounds, with equal access to high quality education. This is particularly the case with respect to policies designed to equalize access to post-secondary education. Higher levels of education are associated with a range of superior outcomes, such as higher wages and lower rates of unemployment. Thus education, "beyond all other devices of human origin, is the great equalizer of the conditions of men, the balance-wheel of the social machinery." (Mann,1848). Concerns about equality of access to higher education are focused on a number of dimensions, including income (Mueller, 2008), race (Frenette, 2010; Cameron and Heckman, 2001), and gender (Goldin, Katz and Kuziemko, 2006). This research focuses on the latter.

Figure 2.1 illustrates college graduation rates for men and women in the US, by birth cohort, providing us with a long historical perspective. For birth cohorts before 1960, which roughly corresponds with individuals who graduated from US colleges prior to 1985, women were under-represented in the university going population. Beginning with the 1960s birth cohort, however, there began a steady shift in the gender composition of US colleges. For the more than three decades since this crossover, there has been a clear and persistent reversal in college graduation rates. Figure 2.2 illustrates recent trends in participation, by gender, at Canadian universities. For the last 15 years, the ratio of men to women at Canadian universities has remained stable at about 2 men for every 3 women. While the participation rate varies by field of study, as indicated in Figure 2.3, women currently represent more than $50 \%$ of the student population in all fields except math, computer and information sciences, and architecture, engineering and related technologies.

The gender gap in participation in higher education is not unique to Canada. With few exceptions (Turkey, Korea and Switzerland) all member countries of the Organization for Economic Cooperation and Development (OECD) have experienced a qualitatively similar phenomenon in university participation (OECD, 2005; OECD, 2017b). It is a phenomenon characterized by its uniqueness in modern history, its persistence, and its presence throughout the developed world. 
What are the implications of this significant reversal in university participation rates? Clearly, there is the potential for impact on wages and employment; increasingly the highest paying jobs depend on a university degree. Marriage and other social contracts are also education dependent. Further, as Frenette and Zeman (2008) note, the increasing fraction of women in professional roles may have implications for skilled labour shortages, for example in the field of medicine where women doctors, on average, work fewer hours than men. Moreover, from a strictly philosophical point of view, this gender gap in participation rates suggests that boys may need to be considered as a disadvantaged group.

This paper sheds light on the gender gap in university participation by focusing on the determinants of academic achievement in the final year of high school, where a significant gender gap also exists. High school grades are the primary mechanism for the allocation of university admissions. As suggested by Cho (2007), understanding the gender differences in the production of senior high school grades may contribute significantly to understanding the gender gap in university participation.

Researchers have examined numerous reasons for this divergence in participation rates. Fortin, Oreopoulos and Phipps (2015) in their study of high performing American high school students, highlight the importance of the gender gap in post-secondary expectations. Their research builds on the work of Christofides, Hoy, Li, and Stengos (2008), who focus on the evolution of aspirations for university education as a key factor in explaining the gender gap in participation rates in Canada. Another strand of research, for example work by Christofides, Hoy, and Yang (2010), focuses on the gender gap in the university earnings premium as a key factor in explaining the participation gender gap. ${ }^{17}$ Still others have focused on changes in societal norms, such as labour force participation and contraception (Goldin, Katz, and Kuziemko, 2006), and changes in family structure (Buchmann and DiPrete, 2006; Bertrand and Pan, 2013; Almas et al., 2016). A final strand of research, and the one that is the primary focus of this paper, examines the importance of gender-based differences in skills, particularly non-cognitive skills, in explaining the gap in university participation between men and women.

In this paper I estimate a production function for academic performance in the final year of high school. The focus of the paper is on non-cognitive skills as a source of previously unobserved heterogeneity. However, the estimation also includes cognitive skills, student aspirations and a set of family background and socio-demographic variables. The important question that this work asks is, once these factors are accounted for, is there any significant role for gender in the determination of high school grades? If so, this may suggest the presence of a gender bias in the assignment of grades in high school.

\footnotetext{
${ }^{17}$ The gender gap in the university earnings premium is disputed by some researchers. See for example Hubbard (2001) and Cho (2007).
} 
It is widely accepted that boys and girls generally differ in terms of their skills sets. ${ }^{18}$ However, while there are widely accepted definitions of and tests for cognitive skills, there is no universal definition or measurement for non-cognitive skills. ${ }^{19}$ This is in part because of the broad scope of non-cognitive skills. As Duckworth and Yeager (2015) note, "Once the term cognitive is appropriated to refer to intellective abilities and subjectmatter achievement...the term noncognitive comes to the fore by default to describe everything else" (p.238). In addition, defining a concept of non-cognitive skills is often limited by the data available to the researcher.

This data dependence, along with the complexity of non-cognitive skills, has led to a diverse set of measures. Cobb-Clarke and Tan (2011), for example, use the term "noncognitive skills" to refer to measures of personality traits such as agreeability and openness. Heckman, Stixrud and Urzua (2006) borrow the concepts of self-esteem and locus of control from the psychology literature as their measures of non-cognitive skills. Carneiro, Crawford and Goodman (2007) construct their measure of non-cognitive skills to capture social mal-adjustment in children, including anxiety for acceptance, hostility and withdrawal. Lefebvre and Merrigan (2010) use the term "non-cognitive skills" to refer to skills such as focused attention and self-control. The OECD (2015) proposes measures of non-cognitive skills for its Programme for International Student Assessment (PISA) using survey constructs of attitudes, engagement and collaborative problem solving.

The first objective of this research is to set out an explicit definition for non-cognitive skills, and to directly measure and document the gender gap in these skills, if indeed one exists. In this analysis, the term "non-cognitive skills" is used to refer to several measures which cover many of the facets of non-intellective abilities. These include measures of psychological capital (self-esteem, mastery, and locus of control), learning skills, engagement, and perceptions, all of which are constructed from the uniquely rich data found in the Youth in Transition Survey (YITS). These measures are constructed from data collected at age 15, around the time that students are in grade 10. Notably, this analysis finds that boys do lag in many, but not all, of these facets of non-cognitive abilities.

The second objective of this research is to determine the extent to which these skills gaps explain the gender gap in overall academic achievement in the final year of high school. The emphasis here is not on estimating the returns to skills, which are likely plagued by problems of endogeneity, but rather on examining the marginal effect of gender, once we

\footnotetext{
${ }^{18}$ For example, boys tend to outperform girls in math tests, but lag girls in literacy assessments (OECD, 2001).

${ }^{19}$ Cognitive skills are routinely measured by tests such as the Armed Forces Qualifying Test (AFQT), or other battery tests. The correlation between different cognitive abilities is high. This correlation is captured in the concept of the g-factor. See Jensen (2002).
} 
have controlled for as much individual heterogeneity as possible, a distinction that is examined more thoroughly in Humphries and Kosse (2016). The novel aspects of this research derive from both the identification of many dimensions of non-cognitive skills, and the direct measures of these skills, which are included as inputs into the grade production function.

In addition, this study explicitly takes into account student aspirations for higher education. Often there is the argument that boys do not perform well in high school because they are not planning to go on to university, as in Fortin et al. (2015). Lower skills are then a function of low levels of investment in the acquisition of those skills by students who see no need for them in their future. The YITS asks participants direct questions about their hopes for educational attainment. By controlling for aspirations for post-secondary education, it is possible to achieve two goals: First, an examination of the residual effect of gender, once aspirations (as well as non-cognitive skills) are taken into account; and second, an examination of the direct impact of aspirations on educational outcomes, net of their influence on the accumulation of skills.

This research finds that, even controlling for the lower level of certain skills possessed by boys, as well as their lower educational aspirations, gender still plays an important role in determining the overall grade in the final year of high school. It is possible that this is because skills and other characteristics are used differently by boys and girls in the production of high school grades. By examining the production functions for girls and boys separately, it becomes apparent that the difference in grade outcomes can be attributed to the difference in the likelihood of academic advancement associated with increases in skills, particularly cognitive skills. Boys with higher cognitive abilities do not appear to reap the benefits of these higher skills to the same extent as girls.

The balance of this paper is structured as follows. Section 2 provides a review of the literature that pertains to the role of non-cognitive skills in the determination of academic achievement. The data discussion is provided in Section 3, and includes a discussion of the restrictions to and attrition within the sample, as well as an extensive description of the study design. The methodology is described in Section 4. Section 5 presents the empirical results. These include descriptive statistics, and the results from numerous regressions and robustness checks. The analysis includes regressions with variables of interest interacted with gender, as well as a decomposition analysis. The robustness checks include a discussion of the inclusion of field of study. Concluding remarks are presented in Section 6. 


\subsection{Literature Review}

This research contributes to a growing literature which examines the importance of gender-based differences in skills, particularly non-cognitive skills, in explaining differences in academic outcomes. One of the most cited papers in this literature is Goldin, Katz, and Kuziemko (2006), who provide a long historical perspective on postsecondary participation. They examined the reversal in college participation by gender in the US that has occurred over the last 50 years. Although the primary focus of their research was on the broader societal changes that have occurred during that time, both in the US and throughout the developed world, they found that these factors could not explain the diverging rates of participation by men and women in university. Rather, they referred to the work of Jacob (2002), pointing to his conclusion that differences in non-cognitive skills were the key to explaining why women have overtaken, rather than simply caught up with men in terms of university participation.

In his research, Jacob highlighted the importance of non-cognitive skills in explaining the gender gap in post-secondary participation. He defined these skills as things like "the inability to pay attention in class, to work with others, or to organize and keep track of homework or class material." Using the National Educational Longitudinal Study (NELS)), Jacob included measures of non-cognitive skills as of grade 8 in his analysis to explain later post-secondary participation, and found that the gender gap all but disappeared when these skills were accounted for.

However, the constructs used to measure these non-cognitive skills did not measure attention skills, sociability or organizational skills. Instead, they were based on information about grade retention, disciplinary incidents, hours spent on homework and middle school grades. As discussed in Bennet (2017), this amounts to imputing skills from outcomes rather than directly measuring attention, organizational and social skills. This imputation method can be misleading, with factors such as gender bias in grading being mistaken for differences in non-cognitive skills. Despite the shortcomings of this imputation method, it has been adopted by other researchers such as Frenette and Zeman (2008), who replicate Jacob (2002) for Canada using the Youth in Transition Survey.

Lai (2010) used direct measures of non-cognitive skills in his examination of the gender achievement gap in Beijing's middle schools. He constructed this measure using questions related to students' self-reported attitudes toward studying, and found that, as measured in this way, "girls seem to possess superior non-cognitive skills; more readily complied with the centralized curriculum, teaching plan, and test-oriented atmosphere; and thus fit more easily into the current education system than boys did." Notably however, Lai found that although gender-based differences in factors such as noncognitive skills contribute to explaining the gender gap in middle school outcomes, there 
is a statistically significant role for gender that remains even after all other mediators are included in the analysis.

Fortin et al. (2015) consider non-cognitive skills in their examination of gender at the high end of the GPA distribution during high school. Their primary conclusion is that differences in educational expectations - and therefore motivations - are the primary driver of the gender gap in high-end performance. However, they point out that, possibly as a result of these differences in educational expectations, boys display significantly more behavioural problems. Inspired by the findings in Fortin et al. (2015), educational expectations are explicitly considered in the research presented in this paper. In this way, the study controls for possible gender-based differences in aspirations, which are likely important in the production of grades, and also disentangles to some extent the relationship between aspirations, non-cognitive skills, and academic achievements.

Drewes (2010) also considers high school grades. He examined whether some or all of the gender gap in university participation would disappear if boys tried as hard as girls. Using the YITS data, the author uses three variables to capture effort: time spent on homework; skipping class; and the student's report about how often they do as little work as possible. ${ }^{20}$ These variables, along with PISA reading scores and student background variables, are used to model the production of final year of high school grade. His research shows that about half of the gender gap can be explained by differences in effort.

The analysis presented in this paper has some relationship to Drewes (2010), in that it focuses in part on the grade in the final year of high school. Beyond this similarity, the research undertaken here departs from Drewes (2010) in a number of significant ways. First, this research focuses on a set of non-cognitive skills, rather than effort. The YITS is very rich in survey questions pertaining to psychological capital, learning skills, engagement and perceptions; this research seeks to mine the rich vein of information contained in the survey about non-cognitive skills. In addition, Drewes chose to deal with the categorical outcome variable by using the midpoint of each category in an ordinary least squares regression. The empirical approach taken in this research exploits the ordinal information in the categories without using the midpoint approach. Instead, as discussed in more detail below, ordered logit and generalized ordered logit approaches are used.

Lefebvre and Merrigan (2010) focus on non-cognitive skills in their study of the determinants of post-secondary participation. They find that two measures of non-

\footnotetext{
${ }^{20}$ It is not clear that hours of homework are positively related to non-cognitive skills. There is some evidence to indicate that there is an inverse relationship, over some ranges, between hours of homework and academic outcomes, as students who struggle are often those who must put in the long hours of homework. There is the possibility that these long hours are a reflection of poor study or attention skills. See Cooper (1989).
} 
cognitive skills - one constructed from a hyperactivity and inattention score and the other from a measure of aggression, both measured during primary school - are significant determinants of university participation. By taking a construct from the early years of school, they are able to circumvent to a large extent any issues of dynamic simultaneity.

The research presented in this paper contributes to the literature in a number of ways. First, it takes advantage of the unique set of questions contained in the YITS to consider a wide range of non-cognitive skills. In addition, these skills are directly measured from the survey data, rather than being imputed. Finally, educational aspirations are explicitly included in the analysis, to control for the possibility that low grades are simply a reflection of the expectation that academic achievement will not play a role in determining future outcomes. This study also includes a number of socio-demographic and family background variables to be discussed in detail below. In particular, it includes family structure as an explanatory variable, which researchers such as Bertrand and Pan (2013) have found to play an important role in the determination of school performance.

\subsection{Data}

\subsubsection{Youth in Transition Survey}

In 2000, approximately 30,000 15-year-old students from 1200 randomly selected Canadian schools participated in a reading assessment administered jointly by the OECD's Programme for International Student Assessment (PISA), the provincial Ministries of Education, and the Government of Canada. ${ }^{21}$ These students were also invited to participate in a longitudinal study, the Youth in Transition Survey (YITS). This survey collected information every second year, from the baseline year of 2000 until the final cycle in 2010. The objective of this survey was to document the aspirations, expectations and characteristics of Canadian youth as they made the transition from high school to post-secondary education and/or to the labour force, from ages 15 to 25 .

The baseline survey in 2000 consisted of three components: a student questionnaire which asked about the student's experiences with school, their perceptions of self, and their hopes for the future; a parent questionnaire which collected information about family income, demographics, and parental hopes for their children; and a school survey, which includes the PISA reading score as well as a questionnaire filled out by the school

\footnotetext{
${ }^{21}$ The schools were randomly selected from across Canada, and 15 year old students from within each school were invited to participate in the joint YITS/PISA survey. While the random nature of the selection of schools should ensure that error terms between schools are uncorrelated, there exists the possibility that error terms are correlated within schools. For this reason, all empirical analysis undertaken in this paper uses cluster-robust standard errors.
} 
principal. Subsequent cycles did not re-survey either the parents or the school. However, the students themselves were re-surveyed, and were asked in each cycle about their investments in education, their employment and wage outcomes and eventually about their own marital and family situations.

These data - the YITS linked to the PISA assessment - provide micro-level longitudinal information about Canadian youth which is rich in measures of skills, aspirations, and educational outcomes, making this data uniquely suited to the research undertaken here. The following sections describe the restrictions imposed on the initial sample, and the study design of this paper, including a description of the variables which have been either taken directly from the survey, or have been constructed from the survey data.

\subsubsection{Restrictions}

Initially, almost 30,000 respondents from across all ten Canadian provinces were asked to participate. Because of the unique CEGEP system that exists in Quebec, students who reported Quebec as their province of residence in Cycle 1 were dropped from the analysis, resulting in the deletion of 4,450 observations. The rationale behind the exclusion of Quebec from the sample is discussed in more detail in Appendix A. In addition, student records which did not include a parent survey (3171 observations) were dropped from the sample. A full discussion of this process is also provided in Appendix A. This leaves an initial sample of 22,066 respondents in Cycle 1 .

This paper uses information from Cycles 1, 2 and 3, collected when students were 15, 17 and 19 years of age, respectively. The Cycle 2 sample consists of students who had complete Cycle 1 records (student plus parent) and who also participated in the Cycle 2 survey. The Cycle 3 sample consists of those who had complete Cycle 1 records, participated in the Cycle 2 survey, and also participated in the Cycle 3 survey. In this way, there are no "holes" in respondents' longitudinal records. Over the course of these first three cycles, more than $20 \%$ of the original respondent population left the survey, as indicated in Table 2-1. Thus, the final restricted population consists of 17,584 observations, representative of 231,940 15-year olds from nine Canadian provinces.

Table 2-1. Attrition from Cycles 1 to 3

\begin{tabular}{|l|l|}
\hline Cycle (Year) & Respondent Population (weighted) \\
\hline $\mathbf{1 ~ ( 2 0 0 0 )}$ & $22,066(267,943)$ \\
\hline $\mathbf{2}(\mathbf{2 0 0 2})$ & $20,639(231,687)$ \\
\hline $\mathbf{3}(\mathbf{2 0 0 4})$ & $17,584(231,940)$ \\
\hline
\end{tabular}

Source: Youth in Transition Survey, author's calculations. 


\subsubsection{Study Design}

\section{A. Dependant Variable: Grade in the Final Year of High School.}

The first outcome variable of interest is final high school grade. Students were asked in Cycle 3 , at age 19 , to report on their grade category (in the $60 \mathrm{~s}$, in the $70 \mathrm{~s}$, and so on) in their last year of high school. For the vast majority of students at age 19, this corresponds to the final year of high school. Table 2-2 shows the distribution of final grade by gender. There are some remarkable differences in outcomes between genders. Boys, for example, are over-represented by almost 9 percentage points in the "in the 60 s" category, while the fraction of girls "in the $80 \mathrm{~s}$ " exceed that of boys by a margin of almost 13 percentage points. Overall, girls are more likely to receive a grade in the $80 \mathrm{~s}$ or above, while boys are more likely to receive a grade in the 70s or below.

Table 2-2. Grade in final year of high school as of 2004 (Age 19) by gender

\begin{tabular}{|l|c|c|c|c|c|c|}
\hline & $\begin{array}{c}\text { Less than } \\
\mathbf{6 0}\end{array}$ & $\begin{array}{c}\text { in the } \\
\mathbf{6 0 s}\end{array}$ & $\begin{array}{c}\text { in the } \\
\mathbf{7 0 s}\end{array}$ & $\begin{array}{c}\text { in the } \\
\mathbf{8 0 s}\end{array}$ & $\begin{array}{c}\text { in the } \\
\mathbf{9 0 s}\end{array}$ & $\begin{array}{c}\text { Total } \\
\mathbf{( 1 4 , 6 8 8 )}\end{array}$ \\
\hline Girls (50.62) & 1.93 & 11.21 & 34.54 & 40.33 & 11.9 & 100 \\
\hline Boys (49.38) & 3.94 & 20 & 40.91 & 27.72 & 7.43 & 100 \\
\hline Difference & -2.01 & -8.79 & -6.37 & 12.61 & 4.47 & \\
\hline
\end{tabular}

Source: Youth in Transition Survey. Author's calculations.

This study attempts to shed light on this gender gap in high school grades by examining the contributions of skills, aspirations, and background variables such as family income, family structure, and parental education, all available in the unique data found in the YITS/PISA survey. A summary of the study design, including the origins of the variables used in the analysis is provided in Table 2.3.

\section{B. Independent Variables}

Cognitive Skills - In the baseline year (2000) of the YITS, all participating students wrote the PISA reading test. Reading was the main domain in that year, so all participants have a reading score in the data file. ${ }^{22}$ Math was among the minor domains in 2000, so only a fraction (4/9ths) of the YITS participants were given the opportunity to write the math test. In this study, the score for the PISA reading test (as opposed to the math test) is used as a proxy for cognitive ability. Reading scores were chosen as the cognitive skills measure for two reasons. First, since only $4 / 9$ ths of the population participated in the math component of the PISA tests, the sample size would have be significantly reduced if the math score had been used. Second, it can be argued that reading is a universal skill,

\footnotetext{
${ }^{22}$ The data files contain both a Warm Likelihood Estimates (WLE) reading score and a set of plausible values for each individual. The plausible values are useful for comparing averages across groups (e.g. countries), but are not appropriate for microdata analysis. See OECD (2002), p.107. For this research, the WLE value for reading was used as the cognitive skills measure.
} 
and on that basis is the preferred measure of cognitive skills. ${ }^{23}$ However, as an added robustness check, results using the smaller sample that participated in both math and reading tests are presented in Appendix C.

Moreover, the broad range of skills being tested, beyond the mere reproduction of curriculum content, suggests that the reading score is a suitable stand-in for cognitive abilities. PISA tests are meant to measure more than curriculum attainment; their intent is to assess whether students can extrapolate from what they have learned and apply their knowledge in new situations. "PISA is based on a dynamic model of lifelong learning in which new knowledge and skills necessary for successful adaptation to a changing world are continuously acquired throughout life. It aims at measuring how well students are likely to perform beyond the school curriculum and therefore conceives content much more broadly than other international studies." (PISA, 2002). It should also be noted that students were at age 15 when they wrote the PISA tests in Cycle 1. Given the rank stability of cognitive abilities after about age 10 (see Mackintosh, 2011: 169), it seems reasonable to use this score as a proxy for cognitive ability to explain outcomes that take place some years after the original PISA test. ${ }^{24}$

Non-Cognitive Skills - As outlined in the literature review, the gender gap in educational outcomes is thought by some, for example Jacob (2002), to be the result of lower noncognitive skills on the part of boys. Recall, however, that Jacob (2002) and others, such as Frenette and Zeman (2008), constructed their measure of non-cognitive skills by using, in part, the gap between test scores and grade outcome. As argued previously, this may not be the ideal way to measure non-cognitive skills.

This research takes advantage of the unique set of questions contained in the YITS relating to personality, learning skills, and other facets of non-cognitive skills - to construct direct measures of these skills. Cycle 1, administered when the students were 15 years old, was particularly rich in these questions. This was the only cycle when students were asked to respond to questions about self-esteem, fatalism and academic self-efficacy. These questions pertained to students' views about their own self-worth, their feelings of control over outcomes in their lives and their ability to master academic challenges. $^{25}$ These concepts have been used for decades by researchers in the field of psychology, and the constructs have been validated over numerous studies. Thus, for the

\footnotetext{
${ }^{23}$ It should be noted that there is a very strong correlation between reading and math marks $(0.6567)$.

${ }^{24}$ Researchers have found that, while an individual's measured intelligence increases over time, the individual's position within the distribution of measured intelligence is quite stable after about age 10 . Those who are at the top of the distribution at age 10 tend to remain there, while those at the bottom of the distribution are likely to also appear at the bottom when tested years later.

${ }^{25}$ The higher the score for fatalism, the more the individual believes that outside forces ("fate") influence outcomes in their lives. A low score then suggests that the individual believes their own actions, rather than exogenous forces, determine life outcomes. The inverse of fatalism is referred to as Locus of Control.
} 
purposes of this paper, the construction of measures for these traits was straightforward. See Appendix B for the list of questions used to construct each measure.

In addition, the YITS asked students to answer questions about their experiences with school including perceptions, behaviours and feelings of engagement, both social and academic. In both Cycle 1 and Cycle 2, this list of questions was extensive. I use the responses from the Cycle 2 interview, administered when students were 17 years old, to construct a variety of non-cognitive skills measures. Factor analysis was employed to identify, from the patterns of correlations between these questions, three different underlying latent factors: Learning skills; disengagement; and perceptions of teachers. The learning skills measure includes questions pertaining to the student's perseverance and conscientiousness. The disengagement measure includes questions about whether or not the student finds school boring, or a waste of time. The concept of perceptions of teachers was related to questions about teacher effort and fairness. A full list of the questions used to construct each of these measures is provided in Appendix B.

The sub-set of non-cognitive skills that is considered in this paper then includes the psychological traits of self-esteem, fatalism and mastery, along with measures of learning skills, disengagement and perceptions of teachers. Thus, this paper is novel in that it utilizes a set of directly measured non-cognitive skills, covering many facets of this multi-dimensional skill.

It should be noted that the skills being used to explain final year grade are measured in the years prior to the final grade of high school. In the case of the survey specific skills, such as learning skills, this gap is minimal. Learning skills, disengagement and perceptions are measure at age 17, while students usually graduate from high school at age 18 (with students born late in the year being only 17 at high school graduation). The gap between graduation and measurement of psychological capital (self-esteem, selfefficacy, and fatalism) is larger, with psychological capital being measured at age 15 . Arguably, this gap is sufficiently small that these measures are still useful in explaining senior year high school outcomes.

Aspirations - Fortin et al. (2015) point to gender-based differences in aspirations as the key driving force behind the gender gap in post-secondary (university) participation in the US. Inspired by this work, I have included educational aspirations as an input into the grade production function. The YITS contains responses in each cycle to questions about aspirations for post-secondary education. For the purposes of this study, aspirations at age 17 (cycle 2) were used. At this age, students are close to or in the final year of high school, and most have not yet begun post-secondary education. Thus, to the extent that aspirations are driving academic outcomes, this is the most relevant year in which to measure aspirations. Aspirations at age 15, observed in the previous cycle (cycle 1) are still evolving, as shown in Christofides et al. (2008), while at age 19, many students are 
already pursing post-secondary education, so that reported aspirations may be reflecting education decisions already taken.

Specifically, the YITS asks students at age 17 "What is the highest level of education you would like to get?"26 For the purposes of this study, the responses are recoded into three levels of education aspirations: less than a university degree (includes less than high school, high school only, some college, and college diploma); Bachelor's degree only (which includes Bachelor of Science, Bachelor of Business Administration, Bachelor of Music, and other equivalent first degrees); and more than a Bachelor's degree (MA, PhD, professional degrees). In the weighted sample, $30.6 \%$ of 17 year olds report aspirations of less than a university degree, while $30.7 \%$ report wanting a Bachelor's degree only, and another $38.7 \%$ aspire toward more than a Bachelor's degree.

It is likely that the educational aspirations variable is endogenous. Concerns about this endogeneity arise because of the likelihood of a dynamic, simultaneous relationship between aspirations and academic outcomes. However, the primary focus of this analysis is on the relationship between academic outcomes and gender. While the coefficient on aspirations will be suspect due to this endogeneity problem, the coefficient on gender (which I argue is truly exogenous) will not be plagued by this doubt. The same argument can be used in discussing the endogeneity of other variables, such as self-esteem. This distinction is discussed in Stock (2010).

\section{Control Variables.}

Family Status. This variable is reported on the parent survey, which was administered in the first Cycle of the survey, when students were 15 years old. There were originally 23 categories describing family status. For the purposes of this analysis, these categories have been collapsed into two - either from an intact family (at the time of the baseline survey in 2000) or not. Of the respondents who remained in Cycle 3, 74\% reported at the time of the baseline survey that they lived in an intact family. ${ }^{27}$

Immigrant Status. Three different measures of immigrant status were considered:

A. Is the student's parent-respondent a Canadian citizen by birth? $\mathrm{No}=\mathrm{immigrant}$

$B$. Is the student a Canadian citizen by birth? No=immigrant

\footnotetext{
${ }^{26}$ As opposed to the level of education you think you will get, which is meant to elicit perceived barriers to education.

${ }^{27}$ It should be noted that this variable is not measured contemporaneously with senior high school grade. It may be the case that family status has changed from Cycle 1, when the information from parents was gathered, to Cycle 3, when senior high school grade is observed (for most students). The marginal effect of family status variable on senior high school grade must then be interpreted as the ME of family status as of age 15 (the student's age in Cycle 1).
} 
C. Did the student's parent-respondent arrive in Canada as an immigrant during the period 1975-1999? Yes=immigrant

The (weighted) fraction of the student population who, in Cycle 1, were Canadian citizens by birth (definition B) was $91 \%$, with $9 \%$ defined as immigrants. Using measure C, $14 \%$ of Cycle 3 respondents are identified as being an immigrant. Measure A provides the largest sample of "immigrants" at $22 \%$. Immigrant status is included as a dummy variable in this study, taking on a value of 1 if the student is identified as an immigrant, and zero otherwise. In the results presented in this study, individuals are identified as being an immigrant using measure $\mathrm{B}$, as indicated in italics above. However, the way in which immigrant status is defined (A, B or C) made no substantial difference to the magnitude of the estimated coefficient on the immigrant dummy or its statistical significance.

Family Income. Parents were asked to report their total household income in the parent survey of 2000, which includes the before-tax income of both the respondent and the respondent's spouse, if applicable. Before-tax income is calculated using numerous income sources, including wages before deductions, self-employment income, government transfers such as Canada Child Tax Benefit and Social Assistance, spousal and child support payments, and other sources of income such as dividend and interest income. The log of family income is used in all analysis. ${ }^{28}$

To the extent that family income influences socioeconomic outcomes through the accumulation of higher skills, the fact that income is measured four years prior to the outcome of interest is not of concern. If, on the other hand, family income is important in determining senior high school grade through its contemporaneous effect on grades, then the four year lag is of concern. Since family income is only collected once, during the parent questionnaire in the baseline survey, this analysis cannot shed light on the contemporaneous influences. However, the lifecycle influences of income - through skills acquisitions over many facets - can be accounted for using this measure. This lifecycle concept of family income is discussed in Cunha et al. (2006) and Cameron and Heckman (2001).

Parental Education. It is sometimes argued that students from well-educated families do better than those from less-well-educated families. While it is not expected that parental

\footnotetext{
${ }^{28}$ There were 64 respondents to the parent survey who reported zero income. It is not possible to take the $\log$ of zero (it is undefined). Further, it is hard to believe that, according to the definition of income given in the YITS, there are families with no financial resources. One possible solution is to impute income for these individuals. However, because there is dispute about the optimal imputation method, and the number of respondents who report zero income represents is very small (less than $1 \%$ of sample), these individuals are dropped from the sample.
} 
education will vary by gender, it may be the case that parental education will influence outcomes differently by gender. Not all student records included information about both parents. If only one parent's educational attainment is reported, this will be the education level that is used in the construction of the dummy variable. If more than one parental education level is reported, the higher of the two is taken. Parental education dummy variables are created for less-than-high school, high school only, a college diploma, or at least one university degree.

Parental Expectations. Parent respondents are asked: "What is the highest level of education you hope your child will get?" For the purposes of this study, a dummy variable was created which takes on the value of 1 if parents report hoping that their child will receive at least one university degree, and zero otherwise.

Province of Residence. A dummy variable is created for each province, with Ontario as the reference province. Recall that, as outlined in Appendix A, Quebec is not included in this research.

\subsubsection{Attrition Revisited}

Because the attrition that takes place between Cycles 1 and 3 is substantial in size, it is important to establish whether or not it is random in nature. Non-random attrition would mean that, over time, the unweighted remaining respondents become increasingly unrepresentative of the initial target population. This can be remediated to some extent by the use of weighting, which is the purpose of the longitudinal weights provided in the data files by Statistics Canada. ${ }^{29}$ In order to establish the nature of the attrition, the average characteristics of each weighted sample must be considered, particularly over characteristics that are important in this study.

Table 2-4 shows the average characteristics of the original sample (weighted), labeled "Cycle 1". This weighted initial sample was constructed to be representative of the Canadian population of 15 year olds in 2000 . The weighted cycle 1 population is made up of equal number of men and women, with $71 \%$ of the (weighted) sample coming from an intact family, $10 \%$ being immigrants, $65 \%$ with parents who hope their children will go on to university, and an average family income is $\$ 71,364$.

In each cycle, the weights are adjusted according to the characteristics of the remaining population, with the objective being to maintain the representativeness of each cycle to

\footnotetext{
${ }^{29}$ These weights also served to correct for the oversampling of the smaller provinces in this survey. For example Ontario contributes only 3 times as many respondents as PEI to the survey sample, clearly not in line with their populations. Without weights, regions that are oversamples (like PEI) will contribute disproportionately to the analysis. If characteristics of respondents differ by province, this will lead to biased results. The weights provided by Statistics Canada in effect undo this oversampling.
} 
the initial target population. The weighting appears to have been largely successful. The proportion of males is statistically unchanged from Cycle 1 to Cycle 3, as is the proportion of immigrants, and the fraction of parents who hope their children receive a university education. The large p-values from the two-tailed t-tests indicate that the difference in average family income between cycles 1 and 3 is statistically insignificant, as are the differences in fatalism, self-efficacy and disengagement. However, the average characteristics of the sample over some dimensions differ from Cycle 1 to Cycle 3. For example, the weighted sample in Cycle 3 has on average higher skills - reading skills, learning skills, self-esteem and perceptions. They are more likely to come from an intact family, and have parents who have a higher level of education. Perhaps as a result, the remaining Cycle 3 population has a higher average grade at age 15 than the full Cycle 1 population. However, these differences are small enough to justify moving forward with the analysis.

Table A-3 in Appendix A provides a full description of the average characteristics of survey leavers and survey participants from cycle to cycle. Clearly, the attrition is nonrandom. However, the adjustments made to the longitudinal weights in each cycle appear to successfully compensate for this, leaving the weighted samples in each cycle largely representative of the initial target population

\subsection{Methodology}

The dependent variable in this analysis, the overall grade in the final year of high school, is categorical. Grades are self-reported as being in distinct ranges, e.g. "in the 60s" or "in the 90s". These five grade outcomes are explained by the variables discussed above. The independent variables, represented by the vector $\mathbf{X}_{\mathbf{i}}$, include skills (both cognitive and non-cognitive), aspirations, family background and gender. We can think of this as a grade production function, where inputs of skills and effort (accounted for by the inclusion of aspirations) are transformed into grades. Once these skills and background variables are accounted for, does gender play a significant role in the determination of final high school grade?

There are a number of empirical techniques that could be applied to estimating this production function. The easiest is to assign a numerical grade to each student equal to the midpoint of their grade category, and then estimate using ordinary least squares (OLS). However, this is an unsatisfactory approach, as we will be left with variation in our explanatory variables that are not associated with variation in grade outcomes. In this regard, Greene and Hensher (2009) caution: 
There is a temptation to treat this model using linear regression analysis, substituting, e.g., the midpoints of the brackets for intermediate values...The temptation should be resisted, since (1) the likelihood for the data and the structural parameters is well defined, and (2) least squares in this setting will be inconsistent. The OLS estimator will suffer from truncation bias. The overall result is that, because there is variation in $\mathrm{x}$ that is not associated with variation in $y$, the OLS slopes will tend to be biased toward zero. (p. 106)

Another alternative is to use interval regression, which is a generalization of censored regression. An advantage of interval regression is that one can interpret the estimated coefficients in the same way one interprets the coefficients from OLS regressions. The downside, however, is that both the marginal effects and the estimated parameters reflect linear effects of the independent variables on the dependent variable.

The other alternative is maximum likelihood estimation (MLE), which underlies ordered logit and ordered probit estimation. MLE avoids the pitfalls associated with linearization using category midpoints, as discussed above. The analysis in this paper uses ordered logit estimation techniques.

The ordered logit model can be motivated in two ways. One way is to think of the observed categories, $\mathrm{Y}_{\mathrm{i}}=(1, . .5)$, as being related to an unobserved latent variable, $\mathrm{y}_{\mathrm{i}}{ }^{*}$, such that

$$
\mathrm{Y}_{\mathrm{i}}=j \text { if } \mathrm{T}_{\mathrm{j}-1}<=\mathrm{y}_{\mathrm{i}}^{*}<\mathrm{T}_{\mathrm{j}} \text {, }
$$

where the T's are thresholds or cut-points which are unknown. Specifically, in this paper $\mathrm{y}_{\mathrm{i}} *$ is student i's actual grade (performance) in the class, while $j$ is one of five categories of class rank as reported by the student.

At first glance it may seem that the thresholds are already known. For example, if a student reports a grade in the $70 \mathrm{~s}$, then the actual grade must fall between 70 and 79 . However, this need not be the case. A student who receives some grades in the 70s (e.g. for English and History) and other in the 80s (e.g. Math and Science) may see themselves as an $80 \mathrm{~s}$ student, and report an overall grade in the $80 \mathrm{~s}$, even if their average overall grade is in fact a high 70. Conversely, a person with a combination of 80s and 70s may report their overall grade to be in the 70s, when in fact the overall average is in the $80 \mathrm{~s}$. Thus, the thresholds are not clearly delineated. In sum, it is the self-reported nature of the outcome variable that leads to uncertainty about the thresholds. 
Using the continuous outcome variable, $\mathrm{y}_{\mathrm{i}}{ }^{*}$, the model is then written as

$$
y_{i}^{*}=\boldsymbol{X}_{i}^{\prime} \beta+u_{i}
$$

While the underlying latent variable can be expressed as a linear function of the explanatory variables, the relationship between the categorical variable and the covariates is potentially non-linear, and is therefore estimated using maximum likelihood algorithms. The coefficients are estimated using the following relationships:

$$
\begin{aligned}
\operatorname{Prob}\left(\mathrm{Y}_{\mathrm{i}}=j \mid \mathbf{x}_{\mathrm{i}}\right) & =\operatorname{Prob}\left(\mathrm{T}_{\mathrm{j}-1}<=\mathrm{y}_{\mathrm{i}}{ }^{*}<\mathrm{T}_{\mathrm{j}}\right) \\
& =\operatorname{Prob}\left(\mathrm{T}_{\mathrm{j}-1}<=\mathbf{X}_{\mathrm{i}}^{\prime} \beta+\mu_{\mathrm{i}}<\mathrm{T}_{\mathrm{j}}\right) \\
& =\operatorname{Prob}\left(\mathrm{T}_{\mathrm{j}-1}-\mathbf{X}_{\mathrm{i}}^{\prime} \beta<=\mu_{\mathrm{i}}<\mathrm{T}_{\mathrm{j}}-\mathbf{X}_{\mathrm{i}}{ }^{\prime} \beta\right) .
\end{aligned}
$$

Ordered logit estimation assumes that the error term has a logistic distribution, so that equation (3) can be rewritten as,

$$
\operatorname{Prob}\left(\mathrm{Y}_{\mathrm{i}}=j \mid \mathbf{X}_{\mathrm{i}}\right)=\Lambda\left(\mathrm{T}_{\mathrm{j}-1}-\mathbf{X}_{\mathrm{i}}^{\prime} \beta\right)-\Lambda\left(\mathrm{T}_{\mathrm{j}}-\mathbf{X}_{\mathrm{i}}{ }^{\prime} \beta\right),
$$

where $\Lambda$ is the cumulative density function for the logistic distribution, expressed as

$$
\Lambda(*)=\frac{1}{1+e^{-(*)}}
$$

The likelihood function for individual $i$ is then

$$
L^{i}=\prod_{j=0}^{J} \operatorname{Prob}\left(Y_{i}=j \mid \boldsymbol{X}_{i}\right)^{I\left(Y_{i}=j\right)}
$$

The coefficients returned from the solution to this problem are in the form of ordered logodds. It should be noted that only one set of coefficients (one for each covariate) is returned from the estimation algorithm. ${ }^{30}$ This is a result of the underlying assumption that the relationship between each pair of outcome groups is the same. Ordered logistics regression assumes that the coefficients that describe the relationship between the lowest versus all higher categories of the response variable are the same as those that describe the relationship between the next lowest categories and all higher categories, etc. This is called the parallel regression assumption.

\footnotetext{
${ }^{30}$ Note that, for $\mathrm{J}$ possible outcome categories, there are J-1 binary regressions being estimated simultaneously, to obtain estimates of the J-1 thresholds and a common slope parameter $\beta$. See Winship and Mare (1984) or Long (1997).
} 
Alternatively, the ordered logit can be interpreted without reference to a latent variable, but instead derived in terms of odd ratios for cumulative probabilities. The odds that $\mathrm{Y}$ is less than or equal to outcome $k$ versus greater than $k$ (for $k=1$ to J-1) given $\mathbf{X}$, can be written as,

$$
\Omega_{k}(\boldsymbol{X})=\frac{\operatorname{Prob}(Y \leq k \mid \boldsymbol{X})}{1-\operatorname{Prob}(Y \leq k \mid \boldsymbol{X})}=\frac{\operatorname{Prob}(Y \leq k \mid \boldsymbol{X})}{\operatorname{Prob}(Y>k \mid \boldsymbol{X})}
$$

where

$$
\begin{gathered}
\operatorname{Prob}(Y \leq k \mid \boldsymbol{X})=\sum_{j=1}^{k} \operatorname{Prob}(Y=j \mid \boldsymbol{X}) \text { for } \mathrm{k}=1, \ldots, \mathrm{J}-1 \\
=F\left(\tau_{k}-\boldsymbol{X} \boldsymbol{\beta}\right)=\Lambda\left(\tau_{k}-\boldsymbol{X} \boldsymbol{\beta}\right)
\end{gathered}
$$

Using equations (7) and (8), the odds of an outcome being less than or equal to $k$ versus being greater than $k$ have the simple equation

$$
\Omega_{k}(\boldsymbol{X})=\exp \left(\tau_{k}-\boldsymbol{X} \boldsymbol{\beta}\right)
$$

The effect of a change in one of the covariates - in $X_{m}$ for example - can be written as

$$
\frac{\Omega_{k}\left(\boldsymbol{X}, X_{m}+1\right)}{\Omega_{k}\left(\boldsymbol{X}, X_{m}\right)}=\exp \left[\left(X_{m}-\left(X_{m}+1\right)\right) \beta\right]=\exp (-\beta)
$$

Note that equation (9) above implies that the odds ratio is the same for all values of k, a re-statement of the parallel regression assumption. We will return to this assumption as we discuss the empirical results.

Thus, given five possible outcome categories, there are four binary regressions which generate one set of coefficients (one for each explanatory variable) plus four cut-points. While the parallel regressions assumption may appear excessively restrictive, the ordered logit provides a reasonable starting point for the estimation. As a robustness check, the analysis includes results using generalized ordered logit estimation, which allows for the relaxation of the parallel lines assumption. 


\subsection{Empirical Results}

\subsubsection{Summary Statistics}

Table 2.5 illustrates the mean and standard deviation, by gender, of the inputs into the production of high school grades. In reading scores, perceptions of teachers, and learning behaviours, girls have, on average, higher (standardized) scores. Further, their average score on the standardized disengagement scale is lower than boys, indicating a higher level of school engagement by girls than boys. Possibly as a result of these higher skills, parents of girls appear to have higher educational aspirations for them than do parents of boys. Notably, however, boys report on average having higher self-esteem and (academic) self-efficacy than girls, as well as having more control over outcomes in their lives. $^{31}$ There is also a statistically significant difference between the mean family incomes of boys and girls, as well as the indicator for family status. However, these are not substantively significant differences. The difference in log income, for example, translates to a raw difference of \$2014.

Table 2.6 provides information about the distribution of aspirations by gender of the student. There is a gender gap favouring girls of 5 percentage points in the "aspiring toward a Bachelor's degree" category, and just over 7 percent points in the "aspiring toward more than a Bachelor's degree" category - in sum, more than a 12 percent gap between girls and boys who aspire toward at least one university degree.

These findings are consistent with the existing literature. The fact that girls outperform boys on literacy tests is widely and consistently documented (e.g., CMEC, 2013). The differences in the non-cognitive skills scores, particularly learning skills, is consistent with the hypothesis of Goldin et al. (2006) and the findings of Jacob (2002), although his constructs of non-cognitive skills are less detailed, and depend to some extent on imputation. The gender-based differences in aspirations documented in Table 2.6 are in line with the findings in Fortin et al. (2015) and Christofides et al. (2008). It seems possible then that the gender gap in high school grades is being driven by gender-based gaps in skills and aspirations.

Although boys appear to lag girls in many skills, there are still boys who appear in the high end of the distributions of both cognitive and non-cognitive skills. Similarly, while

\footnotetext{
${ }^{31}$ Fatalism is measured as the degree to which one believes "fate" or outside forces control the outcomes in their lives. Girls have a higher average fatalism score, suggesting that they believe that they exert less personal control over life outcomes than do boys. Thus, boys are said to feel, on average, that they have more control over outcomes in their lives. Researcher have found that those with higher feelings of control over their lives tend to have higher educational attainment and higher wages [see for example Coleman and DeLeire (2000) and Groves (2005)].
} 
fewer boys aspire to at least one university degree than girls, there are still some boys who have high education aspirations. What do the grade distributions look like for high performing boys relative to high performing girls, or for boys who have high education aspirations vis a vis comparable girls? Tables $2.7 \mathrm{a}, 2.7 \mathrm{~b}$, and $2.7 \mathrm{c}$ examine the grade distribution of students with high reading skills, high learning skills, and high aspirations, respectively, by gender.

Table 2.7a shows the grade distribution of students who achieved in the top $10 \%$ of reading scores. These are students who achieved a score of more than 645 on the PISA reading test. The last column of Table $2 .+$

2.7a shows the composition of this group of students with the top reading scores. Consistent with the summary statistics discussed above, the majority of this group (61\%) are girls. There is a substantial disparity by gender in the distribution of outcomes for this group of high performers; $31 \%$ of girls in this group report having a grade in the $90 \mathrm{~s}$, compared to only $25 \%$ of boys. This pattern is also seen in the 80 s, with $52 \%$ of girls with very high reading scores in the 80 s, compared to only $45 \%$ of similarly high scoring boys. This is mirrored in the lower end of the grade distribution. Notably, boys who achieved in the top $10 \%$ of the PISA reading test are 12 percentage points more likely to be assigned to the 70s than girls who also achieved at the top end of the reading test distribution.

Table $2.7 \mathrm{~b}$ shows the grade distribution of students with very high (self-reported) learning skills. While the differences in outcomes in this group are less dramatic than differences noted between students with high reading skills, the distribution again favours girls. The gap in favour of girls is 5 percentage points in the 80s category, and almost 1 percentage point in the $90 \mathrm{~s}$.

Finally, the distribution of grades for students with high educational aspirations is shown in Table 2.7c. These students have reported aspirations of more than a BA. Again, the population of these high aspiration students is made up largely of girls, with boys representing $45 \%$ of the group. However, there is a significant difference in distributions of grades within this high aspirations group, again favouring girls. $47 \%$ of girls in this group receive a grade in the 80 s, compared with $41 \%$ of boys, leading to a difference of almost 6 percentage points favouring girls. In the 90 s grade category, this difference, again favouring girls, is almost 4 percentage points.

While these are only two-way tabulations, they nonetheless shed light on correlations that are of concern. Why is it that the distribution of grades appears to favour girls, even when we are considering populations of high achieving students, or students with high 
educational aspirations? The balance of this research seeks to answer these questions using a variety of regression analyses.

\subsubsection{Regression Analysis - Ordered Logit}

The analysis proceeds by using ordered logit estimation to estimate equation (6), derived above,

$$
L^{i}=\prod_{j=0}^{J} \operatorname{prob}\left(Y_{i}=j \mid x_{i}\right)^{I\left(Y_{i}=j\right)}
$$

where $x_{i}$ contains the variables of interest (gender, skills, aspirations) and a list of other covariates, and $Y_{i}$ is the categorical outcome variable (grade in final year of high school). In particular, the analysis proceeds by adding blocks of variables to the grade production function sequentially. Thus, in each step we estimate the parameters of $L^{i}$ where $x_{i}$ contains progressively more covariates. The focus of attention is on the coefficient on gender, and how this changes (or not) as covariates are added to the model.

In Table 2.8, the results from a series of six ordered logit estimations are presented. This table presents the results of the regressions in the form of ordered $\log$ odds ${ }^{32}$. While the log odds concept is not intuitively appealing, this method of presenting results has the benefit of being parsimonious. It is possible to present the results in the more intuitive form of marginal effects. However, in a model with five possible outcome categories, each model would have associated with it a series of five sets of marginal effects. ${ }^{33}$ That would mean comparing five sets of probabilities across six models. This would make it difficult to make comparisons between models, which can yield rich insights into the relationship between explanatory factors and their effects on the outcome variable. For this reason, the results in Table 2.8 are presented in the form of (ordered) log odds.

In column (A) gender, as well as covariates not expected to be correlated with gender, are the only regressors. These include immigrant status (immigrant or not), log of family income, family status (intact or not), parental education and province (coefficients not shown but available on request). The coefficient on gender under this specification is 0.726. Thus, being male decreases the log odds of being in a higher category of (final year) high school performance by 0.726 vis-a-vis girls, controlling for the other included background variables. There was already evidence to suggest that the sign on this coefficient would be negative from the simple tabulations of gender and outcomes. Now,

\footnotetext{
${ }^{32}$ For the remainder of the discussion, ordered log odds results will be referred to simply as log odds, with the remainder being implicitly understood.

${ }^{33}$ Marginal effects here take the form of changes in probabilities of assignment to each grade category, so that for each model (A-D) there are five sets of marginal effects.
} 
however, this first regression specification has provided a benchmark measure for gender (being male) that can be used as a reference point once other covariates are added.

In column (B), aspirations for the students' education - held by both parents and by students themselves - are added to the list of covariates. Notably, there is still a statistically significant and substantial coefficient on gender; even controlling for the lower educational aspirations of boys, they are still less likely than girls to be in a higher category of academic performance in the last year of high school. ${ }^{34}$ The coefficient on aspirations, particularly the student's own aspirations, is statistically significant, and of the expected sign - higher aspirations are associated with higher performance.

Column (C) adds measured reading skill, which is a partial proxy for cognitive abilities. Once this skill is included, the absolute value of the coefficient on gender is reduced. While boys are still less likely to be in a higher performance category than girls, part of the effect is absorbed by reading skills. This is consistent with the summary statistics discussed above, which indicated that boys have lower scores on reading tests. However, even though the coefficient on gender is reduced, it is still statistically significant and substantial. It is also noteworthy to point out that the coefficient on aspirations has also declined with the addition of reading scores (see column (C)). This suggests that those with higher educational aspirations (BA and More than a BA, relative to those who aspire to an education level less than university) have higher reading skills; once reading skills are taken into account, the importance of aspirations is partially diminished.

In Columns (D) and (E), non-cognitive skills are added. In Column (D), all noncognitive skills are added except for learning skills. This includes perceptions of teachers, disengagement, self-esteem, fatalism and self-efficacy. The coefficient on gender has increased (in absolute value). This is due to the fact that boys have higher reported self-esteem and self-efficacy scores, which are both associated with higher performance outcomes. However, once learning skills are added in Column (E), the coefficient on gender declines (in absolute value) to its lowest level yet. Thus, while the higher levels of self-esteem and self-efficacy enjoyed by boys do contribute to higher grades for them, these effects are swamped by the influence of learning skills. Once the lower levels of learning skills of boys are taken into account, gender plays a smaller (but still significant) role in grade determination. Notably, the coefficient on learning skills approaches in magnitude that of the reading score; thus, a one standard deviation increase

\footnotetext{
${ }^{34}$ The statistical significance in large samples may not be a sufficient indication of importance, as p-values quickly go to zero as sample size increases. It is possible to have very small but statistically significant coefficients, which are irrelevant because of their magnitude for policy design. In this paper, a "substantial" coefficient is one that is large enough to be of policy relevance. See Lin, Lucas and Shmueli (2013).
} 
in learning skills has an effect on grade which is on par with the effect of a one standard deviation increase in reading score on grade.

Column (E) represents the full model, which is the one that will be used for all further analysis. This includes gender, background variables such as income and parental education, aspirations, and skills (reading and the suite of non-cognitive skills). However, as an experiment, the results of one final regression specification are presented in column (F). This regression includes the categorical grade obtained at age 15 in Cycle 1 (usually grade 10) in the list of covariates. When performance at age 15 is taken into account, the impact of skills - both reading and learning - decreases, although both are still substantial and statistically significant. Moreover, the direct role of aspirations is also diminished. Aspiring toward a BA is no longer significant at any conventional level, and aspiring to more than a BA, although still statistically significant at the $1 \%$ level, has a much lower coefficient. Part of the influence of skills and aspirations on final high school grade is captured in prior academic performance.

\subsubsection{Marginal Effects of Gender and Other Covariates in the Full Model}

As discussed above, the log odds concept is not intuitive, but has the advantage that it allows us to make comparisons across models more easily. In the last section, for example, it was possible to compare regressions with and without aspirations or skills in order to disentangle their effects on high school performance. However, it is hard to explain log odds in concrete terms. For example, using the full model (Column (E)), the coefficient on male is -0.352 . This means that, when all other factors are taken into account, being male decreases the (ordered) log odds of being in a higher grade category by 0.352 vis-a-vis girls. Is that a lot or a little? This is where the concept of marginal effect is useful. Log odds can be transformed into average marginal effects postestimation. These are shown in Table 2.9 for each covariate. ${ }^{35}$

Note that these take the form of changes in probability of assignment to each outcome category, where categories are indexed by the counter $j=1, \ldots, 5$. For example, a one standard deviation increase in reading scores results in a decrease in the likelihood of being "in the $60 \mathrm{~s}$ " by 6.7 percentage points, and an increase in the likelihood of being "in the 80 s' of 8.5 percentage points.

Of particular interest are the marginal effects of gender. Boys are 2.9 and 1.9 percentage points more likely to be "in the $60 \mathrm{~s}$ " or "in the 70 s", respectively, than girls; conversely,

\footnotetext{
${ }^{35}$ These are average marginal effects (AME). For non-linear models, average behaviour of individuals differs from behaviour of the average individual which is measured by Marginal Effects at Means (MEM). See Cameron Trivedi, (2010).
} 
boys are 3.7 percentage points less likely to be "in the $80 \mathrm{~s}$ " than girls, and 2.2 percentage points less likely to be "in the $90 \mathrm{~s}$ ". These differences in predicted probabilities of grade assignment are calculated after having controlled for factors such as reading and learning skills, as well as aspirations.

\subsubsection{Robustmess Check - Generalized Ordered Logit.}

An important assumption underlying the ordered logit methodology is the parallel lines assumption. That is, it is assumed that there is only one coefficient calculated for each covariate. The relationship of predictors to the odds of a response being in the next higher order category is the same regardless of which categories are being compared. Generalized ordered logit models relax this assumption, by estimating a separate set of regression coefficients for each comparison. There are then a set of 4 coefficients for each covariate. ${ }^{36}$

Once the coefficients are calculated using the generalized ordered logit model, they can be used in the post-estimation calculation of the marginal effects for each covariate. These marginal effects, derived from the generalized ordered logit estimation, are shown in Table 2.10, alongside the marginal effects calculated using the ordered logit model (from Table 2.9). The message from this robustness exercise is clearly that the parallel regressions assumption is not problematic. Of particular note for this paper are the comparisons of the marginal effects of gender. In all cases, the signs are the same across methodologies, while the magnitudes are in the same ballpark. For example boys are estimated to be 5.6 percentage points less likely than girls to be assigned an overall grade in the $80 \mathrm{~s}$ using the generalized ordered logit model, compared to 3.7 percentage point less likely using the (not-generalized) ordered logit model.

This reasonably close correspondence of results holds over most covariates and grade categories. Generally, marginal effects that are both statistically significant and substantial using the ordered logit methodology are also significant and of the same sign and ballpark magnitude using the generalized ordered logit. See for example the marginal effects of a change in reading score, learning skills, self-efficacy, parental education (university), or student aspirations (more than BA)). ${ }^{37}$

\footnotetext{
${ }^{36}$ For example, one set of coefficients would be generated from the binary comparison between the lowest category $(<60 \%)$ and all higher categories. Another set of coefficients is generated for the binary comparison of the lowest two categories ( $<60 \%$ and in the $60 \mathrm{~s})$ versus the others, and so on. Thus, for five possible outcomes, there are four binary comparisons which generate four sets of coefficients. These coefficients need not differ from the ordered logit coefficients, which is the case if the parallel regression assumption is appropriate.

${ }^{37}$ There are a few marginal effects which appear to be influenced by choice of methodology. For instance, the magnitude of the marginal effect of being an immigrant differs substantially across methodologies in the "in the 70s" grade category, and exhibits a sign reversal in the "in the 60 s" category. This may be a
} 
It appears then the parallel regressions assumption is not causing any systematic biases. This is good news for two reasons. First, using the ordered logit methodology facilitates decomposition analysis. It is not currently possible to conduct decomposition exercises when the underlying regressions use generalized ordered logit techniques, while it is possible to do so using ordered logit. Decomposition analysis, to be presented shortly, allows for the examination of the contribution of differing endowments to the observed gap in outcomes. Second, and more generally, it is good to know that the results of this study are largely robust to changes in empirical technique. Going forward, ordered logit is the estimation technique that will be used for all empirical analysis.

\subsubsection{Interactions with Gender}

The results to this point do not include any interactions by gender. By running pooled regressions with only a dummy variable for gender, the implicit assumption is made that the coefficients on all covariates are the same for boys and girls. All of the difference between groups is captured in the gender dummy variable, which to this point has been large and statistically significant. To examine whether or not the coefficients in fact vary by gender, one of two approaches can be taken; the regressions can be run separately by gender, or interaction terms between gender and covariates of interest can be added to the pooled model.

In fact, running separate regressions by gender amounts to fully interacting gender with each covariate. However, estimating separate models for each group can result in loss of statistical power, i.e., one is less likely to reject the null when it is false. ${ }^{38}$ This section then allows for interactions between gender and a number of covariates, within the context of the pooled regression model. Specifically, gender is interacted with reading scores, learning skills, self-efficacy, and student aspirations, all variables which appeared as statistically significant in the regressions discussed above. There are also substantial differences in the endowments of these variables across gender. The question naturally arises whether or not there are gender-based differences in the returns to these variables in the grade production function.

Table 2.11 shows the results of the interacted regression. For ease of reference, the results from the pooled non-interacted regression (the "Full Model" of column E) are reiterated in the first column. The second column shows the results from the interacted regression - that is, the coefficients for all the covariates included in the "Full Model", as

reflection of the small sample of immigrants. Generalized ordered logit is not robust in the presence of small cell counts, which may the case here. This is another reason for moving forward with the (nongeneralized) ordered logit estimation.

38 See Williams (2015). 
well as the coefficients on the interacted terms, which indicate how the effects of the covariates differ across groups. For example, the coefficient on [Male*Reading score] is -0.135 , and is statistically significant at the $5 \%$ level. Thus, for a given increase in reading scores, the log odds of being in a higher grade category are lower for boys than for girls. The reverse is true for aspirations; the coefficient on [Male*BA] and [Male*More than BA] are both positive and statistically significant at the $10 \%$ and $5 \%$ levels respectively. The coefficient on the interaction between gender and learning skills is not statistically significant, as is also the case for the interaction between gender and self-efficacy.

Table $2.11 \mathrm{~b}$ shows the marginal effects of reading scores and student aspirations - the only interactions for which the coefficients were statistically significant - for the interacted regressions. For a one standard deviation increase in reading score, girls are 6.1 percentage points more likely to be assigned a grade in the $90 \mathrm{~s}$; for the same increase in reading scores, boys are only 4.2 percentage points more likely to end up in this grade category. A one standard deviation increase in reading score leads to a decrease in the likelihood of being assigned to the 70 s grade category be 5.8 percentage points for girls, but only 3.4 percentage point for boys. Notably, changes in student aspirations work in the opposite direction to changes in reading scores. Compared to students with aspirations for less than a BA, boys who aspire to more than BA are 9.2 percentage points more likely to end up in the $80 \mathrm{~s}$, while girls with the same aspirations are only 5.3 percentage points more likely to be assigned a grade in the $80 \mathrm{~s}$.

Table 2-11b - Selected Marginal Effects with Interactions Included.

\begin{tabular}{|c|c|c|c|c|c|c|c|c|c|c|}
\hline & \multicolumn{2}{|l|}{$<60 \%$} & \multicolumn{2}{|c|}{ in the 60s } & \multicolumn{2}{|c|}{ in the $70 \mathrm{~s}$} & \multicolumn{2}{|c|}{ in the $80 \mathrm{~s}$} & \multicolumn{2}{|c|}{ in the $90 \mathrm{~s}$} \\
\hline & girls & boys & girls & boys & girls & boys & girls & boys & girls & boys \\
\hline $\begin{array}{l}\text { Reading score } \\
\text { Aspirations: }\end{array}$ & -0.023 & -0.026 & -0.071 & -0.064 & -0.058 & -0.034 & 0.091 & 0.082 & 0.061 & 0.042 \\
\hline Less than BA & reference & & & & & & & & & \\
\hline BA & -0.004 & -0.014 & -0.011 & -0.036 & -0.008 & -0.013 & 0.016 & 0.047 & 0.008 & 0.016 \\
\hline More than BA & -0.012 & -0.024 & -0.038 & -0.069 & -0.034 & -0.037 & 0.053 & 0.092 & 0.032 & 0.038 \\
\hline
\end{tabular}

\subsubsection{Decompositions}

There are clearly differences between girls and boys in both their endowments of factors important in the production of grades and the coefficients associated with the transformation of these factors into grade outcomes. Is it the differences in endowment of the factors or differences in their returns that drive the gender gap in high school performance? In order to answer this question, the observed differences in grade outcomes are decomposed into their constituent components - that which is attributed to 
differences in endowments across boys and girls, and that which is "unexplained", and therefore attributed to factors such as discrimination or bias in grade assignment.

Decompositions use the coefficients generated from regression run separately by gender. The results of these regressions are not shown, but are available on request. However, the marginal effects associated with the regressions - one for boys and one for girls - are shown in Table 2-12. Before discussing the results of the decompositions, it is worthwhile to briefly examine the marginal effects calculated using the gender-specific regressions, to see how they correspond to the results of the interacted pooled regression. Table 2-12 indicates that the marginal effect of reading scores for girls differs from that of boys. A one standard deviation increase in reading score leads to an increase in the likelihood of being in the 90 s by 6.8 percentage points for girls, but only 3.8 percentage points for boys, suggesting that girls enjoy an advantage in grade assignment from an increase in this measure of cognitive skills. This corresponds closely to the marginal effects derived using the interacted pooled model.

There is also a close correspondence between the marginal effects of increases in student aspiration shown in Table 5-8 and results obtained in the interacted pooled regressions (Table 5-7b). The gender-specific regressions indicate that, vis-à-vis students with aspirations to less than a BA, boys with aspirations to more than a BA are 7.6 percentage points more likely to be in the $80 \mathrm{~s}$; for the same change in aspirations, girls are only 5.1 percentage points more likely to be in the 80 s.

Notably, the marginal effects of learning skills and self-efficacy in the regressions which are run separately by gender indicate differences between boys and girls that do not appear in the interacted pooled regressions discussed above. In the decompositions to follow, the analysis is based on the regressions run separately by gender, and these differences will potentially be of importance. It is therefore worth noting the genderbased differences in the marginal effects of learning skills and self-efficacy. For example, the Table 2-12 indicates that a one standard deviation increase in learning skills leads to an increase in the probability of boys (girls) being assigned to the $90 \mathrm{~s}$ of $3.6(5.0)$ percentage points. Notably, this is reversed for the 80s; a one standard deviation increase in learning skills leads to an increase in the likelihood of being assigned to the $80 \mathrm{~s}$ of 7.4 percentage points for boys, and 6.7 percentage points for girls. ${ }^{39}$

To decompose the observed differences in grade outcomes into their constituent parts endowments and "unexplained" - the difference in outcomes are written as

\footnotetext{
${ }^{39}$ This bonus for "good behaviour" by boys has been noted in the literature see Cornwell Mustard and Van Parys, 2013
} 


$$
\bar{Y}_{g}-\bar{Y}_{b}=\left\{E_{\beta_{g}}\left(Y_{i, g} \mid \boldsymbol{X}_{i, g}\right)-E_{\beta_{b}}\left(Y_{i, b} \mid \boldsymbol{X}_{i, b}\right)\right\} .
$$

By subtracting and then adding the term $E_{\beta_{g}}\left(Y_{i, b} \mid \boldsymbol{X}_{i, b}\right)$, equation (10) can be rewritten as

$$
\bar{Y}_{g}-\bar{Y}_{b}=\left\{E_{\beta_{g}}\left(Y_{i, g} \mid \boldsymbol{X}_{i, g}\right)-E_{\beta_{g}}\left(Y_{i, b} \mid \boldsymbol{X}_{i, b}\right)+E_{\beta_{g}}\left(Y_{i, b} \mid \boldsymbol{X}_{i, b}\right)-E_{\beta_{b}}\left(Y_{i, b} \mid \boldsymbol{X}_{i, b}\right)\right\} .
$$

The first term is the difference in average outcome due to differences in endowments (covariates), evaluated using $\beta_{\mathrm{g}}\left(E_{\beta_{g}}\left(Y_{i, b} \mid \boldsymbol{X}_{i, b}\right)\right.$ has been added and then subtracted). The second term is simply the difference in mean outcome that is attributed to differences in the coefficients, which is evaluated using the endowments of boys as the reference. This was the approach taken by Oaxaca (1973).

Alternatively the term $E_{\beta_{b}}\left(Y_{i, g} \mid \boldsymbol{X}_{i, g}\right)$ could be added and then subtracted, so that the equation that describes the difference in mean outcomes becomes

$$
\bar{Y}_{g}-\bar{Y}_{b}=\left\{E_{\beta_{g}}\left(Y_{i, g} \mid \boldsymbol{X}_{i, g}\right)-E_{\beta_{b}}\left(Y_{i, g} \mid \boldsymbol{X}_{i, g}\right)+E_{\beta_{b}}\left(Y_{i, g} \mid \boldsymbol{X}_{i, g}\right)-E_{\beta_{b}}\left(Y_{i, b} \mid \boldsymbol{X}_{i, b}\right)\right\}
$$

or,

$$
\bar{Y}_{g}-\bar{Y}_{b}=\left\{E_{\beta_{b}}\left(Y_{i, g} \mid \boldsymbol{X}_{i, g}\right)-E_{\beta_{b}}\left(Y_{i, b} \mid \boldsymbol{X}_{i, b}\right)+E_{\beta_{g}}\left(Y_{i, g} \mid \boldsymbol{X}_{i, g}\right)-E_{\beta_{b}}\left(Y_{i, g} \mid \boldsymbol{X}_{i, g}\right)\right\} .
$$

Again, the first term represents the difference in average outcome that is attributable to the difference in endowments, this time evaluated using the coefficients for boys. The second term represents the difference in outcome attributable to the difference in coefficients, this time evaluated using the girls' endowment as the reference. This was the approach taken by Blinder (1973).

Clearly, these are not the only possible ways of decomposing the difference in mean outcomes. For example, as suggested by Neumark (1988), one could pool the two populations (boys and girls) to find the vector of pooled coefficient, $\beta^{*}$, and then rewrite the difference in means to be

$$
\begin{aligned}
\bar{Y}_{g}-\bar{Y}_{b}=\left\{E_{\beta^{*}}\left(Y_{i, g} \mid \boldsymbol{X}_{i, g}\right)-E_{\beta^{*}}\left(Y_{i, b} \mid \boldsymbol{X}_{i, b}\right)\right\}+\left\{E_{\beta_{g}}\left(Y_{i, g} \mid \boldsymbol{X}_{i, g}\right)-\right. \\
\left.E_{\beta^{*}}\left(Y_{i, g} \mid \boldsymbol{X}_{i, g}\right)\right\}+\left\{E_{\beta^{*}}\left(Y_{i, b} \mid \boldsymbol{X}_{i, b}\right)-E_{\beta_{b}}\left(Y_{i, b} \mid \boldsymbol{X}_{i, b}\right)\right\},
\end{aligned}
$$

where the first term is the contribution of the differences in attributes, evaluated using the pooled coefficient, and the next two terms are, respectively, the contributions of the 
differences in coefficients from the advantaged and the disadvantaged groups, relative to the pooled coefficients $\beta^{*}$. $^{40}$

Estimates for these three decompositions are shown in Table 2.13. These results are from non-linear decompositions; in particular, the underlying regressions are ordered logit. Consider the results from the Oaxaca decomposition first. Recall that the Oaxaca decomposition, shown in equation (11), considers the outcome from a redistribution of boys' endowments to girls, evaluated using girls' grade production function. This answers the question "what if girls were just like boys in their skills, aspirations, and other covariates?" The results indicate that, of the observed difference of -0.71 (which is the log odds of boys being in a higher grade category vis-a-vis girls, with no other covariates included), -0.23 can be accounted for by (all) characteristics. Giving girls the same endowments as boys causes the gender gap to decrease by $33 \%$. The remaining two thirds is "unexplained", and can be attributed to both differences in grade production technologies and/or differences in intercepts.

The results are substantially reversed using the Blinder approach, which is of the form presented in equation (12). Here, boys are given the same endowments of skills, aspirations and other background variables as girls, and the expected outcomes are evaluated using boys' grade production technology. Notably, this exercise leads to an increase in the gap in outcomes; when boys have the same endowments as girls, there is an additional gap of 0.20 . This suggests that boys have some characteristics which confer an advantage, at least when evaluated using the grade production technology for boys.

This can be explained by looking at the gender specific regressions in Table 2.12. Not only do boys have higher stocks of self-efficacy (one of the measured facets of noncognitive skills), they are also slightly better at transforming this skill into grades at the upper end of the distribution than are girls. In addition, boys in this sample are more likely to come from an intact family, and from parents with a university education. It is beyond the scope of this research to comment on why this difference might exist between populations. What can be said is that family status and parental education (university) are statistically significant determinants of grade outcomes. Thus, when boys are given the same endowments as girls, they are receiving lower stocks of the skills they are good at transforming into grades (self-efficacy), as well as lower stocks of other variables that contribute positively to grade outcomes, specifically an intact family and at least one university educated parent.

Of course boys are also receiving higher endowments of reading and learning skills, as well as higher aspirations in the Blinder decomposition. However, boys are not very good at transforming these into grades, so the higher endowments in these areas are not

\footnotetext{
${ }^{40} \beta^{*}$ can be written more generally as $\beta^{*}=\Omega \beta_{\mathrm{g}}+(1-\Omega) \beta_{\mathrm{b}}$. Using this more general from, the Oaxaca decomposition sets $\Omega=1$, and the Blinder decomposition sets $\Omega=0$.
} 
sufficient to outweigh the effects discussed in the previous paragraph. The net result is that, when girls' endowments are transformed into grades using the boys' production function, the gap in predicted grade outcomes increases by 0.2 . This represents an increase of $28 \%$ in the gender gap, which leaves $128 \%$ of the difference as "unexplained", attributed to either differences in grade production technologies (slopes) and/or differences in intercepts.

The final decomposition, following Neumark (1988), uses a pooled regression to generate the vector of coefficients $\beta^{*}$, as shown in equation (13). Evaluated using $\beta^{*}$, about one third of the total mean difference in outcomes is accounted for by differences in characteristics between boys and girls. The difference between girls' coefficients and the pooled coefficients accounts for $60 \%$ of the total difference, with the remaining $6 \%$ attributed to the difference between boys' coefficients and the pooled coefficients.

\subsubsection{Adding Field of Study}

One possible reason for the large unexplained component of the gender gap may be that girls and boys take different subjects in high school. If boys were more likely to take the harder math and science courses than girls, then the lower overall grades of boys could be attributed to course composition. This idea was addressed by Cho (2007), who considered the evolution of high school grades and course selection over three decades in his examination of the gender gap in US college participation. ${ }^{41}$ Cho found that during the period 1970-72, boys took significantly more math and science courses than girls. The 1982 data indicates that this trend was still in place, although the gap in science had narrowed substantially. Notably, by the 1990s the gaps in both math and science had all but disappeared. These findings are reiterated in Fortin et al. (2015) and Goldin et al. (2006).

Such evidence notwithstanding, this section examines the importance of course composition on grade. The YITS does not provide sufficient information on the individual courses that students took during their final year of high school to control for course composition directly. However, the survey provides information about the field of study associated with participation in post-secondary education. This field of study information is in the form of Classification of Instruction Programme (CIP) codes. These are provided in the YITS at the primary groupings level, where the many possible fields of study (CIP) are aggregated to 13 groupings, shown in Table 2.14, with examples. Controlling for field of study in the first year of post-secondary serves to control to some

\footnotetext{
${ }^{41}$ The data comes from the National Longitudinal Study of the High School Class of 1972 (NLS72), High School and Beyond (1982 follow-up), and the National Educational Longitudinal Study (1992 and 1994 cycles).
} 
extent for the courses students took in the final year of high school, which may help to explain some of the observed gender gap in overall high school outcomes.

It is well documented that boys and girls tend to go on to different fields of study after high school. Table 2.15 shows the first field of study (CIP) by gender for YITS students who have taken at least some post-secondary education by age 19 (Cycle 3). Clearly boys are far more likely to attend Architecture and Engineering programmes after high school than girls are. Boys are also more likely to attend Math and Computer and Information Sciences programmes, while girls tend to go on to Social and Behavioral Sciences, Law, and Health-related studies. There are varying entry requirements associated with these different degree programs. For example, students who go on to Engineering have all taken English, two maths and at least two sciences - specifically Physics and Chemistry - as well as a sixth course. ${ }^{42}$ A degree program such as life sciences (an example of health-related studies) will require only English and math plus four others eligible courses, which may include history, music or other courses which are arguably easier than physics and chemistry. ${ }^{43}$ These differences in course difficulty may be driving some of the differences in overall grade outcomes in the final year of high school.

Table 2.16 shows the regression results when field of study (CIP) is included as a control variable. In column $\mathrm{A}$, the full model that has been discussed at length above is rerun using only observations which include field of study information - essentially, any student who has gone on to at least some post-secondary education after high school by the end of Cycle 3. This is obviously a restricted, smaller sample, as all students who have not yet graduated high school, or have graduated but not gone on to PSE, are excluded. The coefficient on gender in this restricted sample is -0.247 , indicating that, as with the full Cycle 3 sample, boys have a lower log odds of being in a higher grade category than girls, all else held constant. Column (B) shows the results for the regression which includes field of study. Notable, once fields of study is added as a control, the coefficient on gender increases (in absolute value) to -0.297.

These results can be recalculated in terms of average marginal effects, which have a more intuitive interpretation. Table 2-17 shows the average marginal effect of gender, first without field of study (CIP) included in the regression, and then with CIP included as a

\footnotetext{
${ }^{42}$ These are the requirements at University of Toronto. See http://discover.engineering.utoronto.ca/admission-requirements/canadian-high-schools/. Most Canadian universities have almost identical requirement, with variation between universities coming from variation in the grade cutoff for admission.

${ }^{43}$ For Life Sciences at University of Toronto. See http://www.artsci.utoronto.ca/futurestudents/admissions/high-school-students/ontario. Again, within a field of study, universities do not differ in course requirements as much as in grade requirements for those courses.
} 
control variable. When CIP is added to the analysis, the marginal effect of gender changes; boys are now less likely to be assigned a grade in the $80 \mathrm{~s}$ or $90 \mathrm{~s}$, while girls are more likely to receive these grades. The net effect (highlighted in gray) is that boys are 5 percentage points less likely than girls to receive a "university bound" grade in the 80 s or 90 s, a change of almost one percentage point from the "No CIP" benchmark.

Thus, to the extent that controlling for field of study adequately controls for course composition, this exercise indicates that the gender gap in final high school grade is not caused by boys taking harder courses in high school than girls. In fact, the inclusion of field study leads to a larger role for gender in explaining the observed gap in performance. It is possible that girls taking the "harder" courses are treated advantageously in terms of grade assignment.

\subsection{Conclusions}

This study has examined the influence of gender-based differences in skills, both cognitive and non-cognitive, and aspirations on the gender gap in academic performance in the final year of high school. As high school grades are used as the primary selection criteria for university admission, explaining the gender gap in high school grades may go a long way toward explaining the gap in university participation.

Boys clearly lag girls in a number of important dimensions. The reading skills of boys lag those of girls significantly. In addition, boys lag girls over many important facets of non-cognitive skills. Perhaps as a consequence, fewer boys aspire to a university education than girls. However, the examination of students with high education aspirations reveals that, within this group of highly motivated youth, girls are much more likely to receive university-bound grades (80s and 90s) than similarly motivated boys. This is also true of youth with high literacy scores, where girls are again much more likely to receive grades in the 80 s and 90 s than equivalent boys.

Simple tabulations are not sufficient, as it could easily be argued that highly motivated boys may lack the skills necessary to translate their aspirations into the grades necessary for university admission, or that boys with high reading skills lack the non-cognitive skills to translate cognitive skills into high overall grades. However the regression analysis presented here, which controls for many skills, supports the findings of the tabulations. That is, being male confers a significant disadvantage in terms of academic outcomes in high school. 
By estimating the grade production functions separately by gender, differences in specific coefficients are explicitly examined. There appear to be key differences in the way that skills are transformed into grades. A one standard deviation increase in reading skills reaps a higher reward for girls than for boys, with girls being placed in the highest two performance categories at a significantly higher rate than boys for the same increase in reading skills. The marginal effect of learning skills also differs between boys and girls; for a one standard deviation increase in learning skills, boys are more likely to be in the 80 s, while girls are more likely to end up in the 90 s.

Using a variety of decomposition techniques, this study delves more deeply into the causes of the gap in outcomes between boys and girls. Using three decomposition techniques - specifically as developed by Oaxaca, Blinder and Neumark - this analysis reveals that while difference in attributes may contribute to the gap in high school outcomes, the majority of the gender gap in high school performance is unexplained. This unexplained portion may be due to either differences in slopes or intercepts of the grade production function. Both possibilities raise questions about the origin of these differences, with one possibility being that there is discrimination in the assignment of grades.

There are then two important questions that present themselves for further researcher. First, why do boys have lower levels of non-cognitive skills, at least over some important dimensions? This question has been the subject of recent research by Bertrand and Pan (2013), who point to the importance of family structure and support in the formation of non-cognitive skills. This topic merits further investigation.

The research presented in this paper begs a second question. Clearly, the differences in skills and aspirations between boys and girls do not fully explain the gap in performance outcomes in high school; there is a large unexplained component suggested by all decomposition exercises. What underlies this substantial unexplained gap? One point that should be considered is omitted variable bias. It may be that an important skill - that is, correlated with gender and important in the determination of grade - has been omitted. However, there are two arguments that must be considered on this point. First, science and math skills are not included (through lack of adequate data) in this study. It is widely reported that boys, on average, lead girls in math scores, and, at least in Canada, perform at least on par in the sciences (OECD, 2017). Were these measures, which in general favour boys, to be included in the analysis, the gender gap in final grades would be harder to explain. This assertion is substantiated in Appendix C, which shows selected results when math scores are included the measure of cognitive skills. In addition, even when high school performance at age 15 is included in the list of covariates (Column $\mathrm{F}$ of figure 5-4), gender still plays a statistically significant role in the determination of 
academic performance. One might expect that skills not explicitly included in the analysis would be taken into account by including performance at age 15 .

While it is impossible to account for all unobserved heterogeneity, this paper does include many factors which are routinely suggested as the cause of the gender gap in education. Despite this attempt to measure as many factors as possible, there is still the significant role played by gender. If the significant role for gender is not an artifact of omitted variable bias, then there are only a few possibilities to explain the significance of gender in this analysis. Some researchers including Lavy (2008) and Cornwell, Mustard and Van Parys (2013), point to systematic biases in grading by teachers which favour girls over boys. Lai (2010) notes that boys may not perform as well as girls do in the highly test-oriented education system, suggesting an institutional-level problem. Dee (2006) points to the lack of male educators, from whom boys appear to be better able to learn, as a potential cause for the differences in outcomes by gender. These possibilities also merit further research.

It is not possible to identify the root cause(s) using the YITS data. However, the fact remains that boys have lower levels of skills in many critical areas. Moreover, even bright, motivated boys appear to face gender-based barriers, unrelated to skills, in making their way into the university-bound grade categories in the last year of high school. As a result, boys are significantly underrepresented in these grade categories in the final year of high school and, consequently, in the university population in Canada. 


\section{Bibliography}

Almas, Ingvild, Alexander W. Cappelen, Kjell G. Salvanes, Erik O. Sorensen, and Bertil Tungodden. 2016. "What Explains the Gender Gap in College Track Dropout? Experimental and Administrative Evidence." AEA Papers and Proceedings, 106(5): 296302.

Bennet, Susan. 2017. "Gender and Skills in the Determinants of Primary School Performance." Unpublished dissertation chapter.

Bertrand, Marianne and Jessica Pan. 2013. "The Trouble with Boys: Social Influences and the Gender Gap in Disruptive Behavior." American Economic Journal: Applied Economics, 5(1): 32-64.

Blinder, Alan. 1973. "Wage Discrimination: Reduced Form and Structural Estimates." Journal of Human Resources, 8(4):436-455.

Buchmann, Claudia and Thomas A. DiPrete. 2006. "The Growing Female Advantage in College Completion: The Role of Family Background and Academic Achievement." American Sociological Review, 71(4): 515-541.

Cameron, Colin A. and Pravin K. Trivedi. 2010. Microeconometrics Using Stata, Revised Edition. Texas: Stata Press.

Cameron, Stephen V., and James J. Heckman. 2001. "The Dynamics of Educational Attainment for Black, Hispanic and White Males," Journal of Political Economy, 109(3): 455-499.

Carneiro, Pedro, Claire Crawford and Alissa Goodman. 2007. "The Impact of Early Cognitive and Non-Cognitive Skills on Later Outcomes.” CEE Discussion Papers 0092.

Cho, Donghun. 2007. “The Role of High School Performance in Explaining Women's Rising College Enrollment." Economics of Education Review, 26(4):450-462.

Christofides, Louis N., Michael Hoy, and Ling Yang. 2010. "Participation in Canadian Universities: The Gender Imbalance (1997-2005)." Economics of Education Review, 29(3): 400-410.

Christofides, Louis N., Michael Hoy, Zhi (Jane) Li, and Thanasis Stengos. 2008. "The Evolution of Aspirations for University Attendance." In Who Goes? Who Stays? What Matters? Accessing and Persisting in Post-Secondary Education in Canada, ed. Ross Finnie, Richard E. Mueller, Arthur Sweetman, and Alex Usher, 109-134. Montreal and Kingston: Queen's Policy Study Series, McGill-Queen's University Press. 
Cobb-Clarke, Deborah A., and Michelle Tan. 2011. "Non-cognitive Skills, Occupational Attainment and Relative Wages," Labour Economics, 18(1): 1-13.

Coleman, Margo, and Thomas DeLeire. 2003. "An Economic Model of Locus of Control and the Human Capital Investment Decision." Journal of Human Resources, 38(3): 701721.

Cooper, Harris. 1989. "Synthesis of research on homework." Educational Leadership, 47(3), 85-91).

Cornwell, Christopher M., David B. Mustard, and Jessica Van Parys. 2013. "NonCognitive Skills and the Gender Disparities in Test Scores and Teacher Assessments: Evidence from Primary School.” Journal of Human Resources, 48(1): 236-264.

Council of Ministers of Education Canada (CMEC). 2013. "PISA 2009: Explaining the Gender Gap in Reading Through Reading Engagement and Approaches to Learning." CMEC Research Report, retrieved from http://www.piaac.ca/9/Publications/?searchCat=29

Cunha, Flavio, James J. Heckman, Lance Lochner, and Dimitriy V. Masterov. 2006. "Interpreting the Evidence on Life Cycle Skill Formation." In Handbook of the Economics of Education Vol. 1, Handbooks in Economics, eds. Eric Hanushek and Finis Welch, 698-805. Amsterdam: New Holland.

Dee, Thomas S. 2006. "Teachers and the Gender Gaps in Student Achievement." Journal of Human Resources 42(3): 528-554.

Drewes, Torben. 2010. "Gender Differences in High School Grades: Causes and Possible Impacts on the University Gender Gap." In Pursuing Higher Education in Canada: Economic, Social and Policy Dimension, eds. Ross Finnie, Marc Frenette, Richard E. Mueller and Arthur Sweetman, 43-64. Montreal and Kingston: Queen's Policy Study Series, McGill-Queen's University Press

Duckworth, Angela Lee and Martin E.P. Seligman. 2005. "Self-Discipline Outdoes IQ in Predicting Academic Performance of Adolescents." Psychological Science, 16(12): 939944.

Duckworth, Angela L. and David Scott Yeager. 2015. "Measurement Matters: Assessing Personal Qualities Other Than Cognitive Ability for Educational Purposes. " Educational Researcher, 44(4):237-251.

Elder, Todd E., John H. Goddeeris, and Steven J. Haider. 2010. "Unexplained Gaps and Oaxaca-Blinder decompositions." Labour Economics, 17: 284-290. 
Fortin, Nicole M., Philip Oreopoulos, and Shelley Phipps. 2015. "Leaving Boys Behind: Gender Disparities in High Academic Achievement." Journal of Human Resources, 50(3): 549-579.

Frenette, Mark and Klarka Zeman. 2008. "Understanding the Gender Gap in University Attendance: Evidence Based on Academic Performance, Study Habits and Parental Influences." In Who Goes? Who Stays? What Matters? Accessing and Persisting in Post-Secondary Education in Canada, ed. Ross Finnie, Richard E. Mueller, Arthur Sweetman, and Alex Usher, 135-154. Montreal and Kingston: Queen's Policy Study Series, McGill-Queen's University Press.

Frenette, Mark. 2010. "What Explains the Educational Attainment Gap between Aboriginal and Non-Aboriginal Youth?" In Pursuing Higher Education in Canada: Economic, Social and Policy Dimension, eds. Ross Finnie, Marc Frenette, Richard E. Mueller and Arthur Sweetman, 175-190. Montreal and Kingston: Queen's Policy Study Series, McGill-Queen's University Press.

Goldin, Claudia, Lawrence F. Katz, and Ilyana Kuziemko. 2006. "The Homecoming of American College Women: The Reversal of the College Gender Gap." Journal of Economic Perspectives, 20(4): 133-56.

Greene, William H., and David A. Hensher. 2010. Modelling Ordered Choices: A Primer. Cambridge: Cambridge University Press.

Groves, Melissa O. 2005. "How Important is Your Personality? Labor Market Returns to Personality for Women in the US and UK." Journal of Economic Psychology, 26(6): 827-841.

Heckman, James J., Jora Stixrud, and Sergio Urzua. 2006. "The Effects of Cognitive and Non-Cognitive Abilities on Labor Market Outcomes and Social Behavior." Journal of Labor Economics, 24(3): 411-482.

Hubbard, William H.J. 2001. "The Phantom Gender Difference in the College Wage Premium," Journal of Human Resources, Vol 46(3): 568-586.

Humphries, Eric, and Fabian Kosse. 2016. "On the Interpretation of Non-Cognitive Skills: What Is Being Measured and Why It Matters." IZA Discussion Paper No. 10397.

Jacob, Brian A. 2002. "Where the Boys Aren't: Non-Cognitive Skills, Returns to School and the Gender Gap in Higher Education." Economics of Education Review 21(6): 58998. 
Jensen, A.R. (2002). "Psychometric g: Definition and substantiation". In General factor of intelligence: How general is it? eds. R.J. Sternberg and E.L. Grigorenko, 39-54.

Mahwah, NJ: Erlbaum .

Lai, Fang. 2010. "Are Boys Left Behind? The Evolution of the Gender Achievement Gap in Beijing's Middle Schools.” Economics of Education Review, 29(3): 383-399.

Lavy, Victor. 2008. "Do Gender Stereotypes Reduce Girls' or Boys' Human Capital Outcomes? Evidence from a Natural Experiment." Journal of Public Economics, 92(1011): 2083-2105.

Lefebvre Pierre, and Philip Merrigan. 2010. "The Impact of Family Background and Cognitive and Non-Cognitive Ability in Childhood on Post-Secondary Education." In Pursuing Higher Education in Canada: Economic, Social and Policy Dimension, eds. Ross Finnie, Marc Frenette, Richard E. Mueller and Arthur Sweetman, 219-242. Montreal and Kingston: Queen's Policy Study Series, McGill-Queen's University Press.

Lin, Mingfeng, Henry C. Lucas Jr., and Galit Shmueli. 2013. "Too Big to Fail: Large Samples and the p-Value Problem.” Information Systems Research, 24(4): 906-917.

Long, J. Scott. 1997. Regression Models for Categorical and Limited Dependent Variables (Advanced Quantitative Techniques in the Social Sciences v.7). Thousand Oaks: SAGE Publications.

Mackintosh, Nicholas J. 2011. IQ and Human Intelligence (2 ${ }^{\text {nd }}$ Edition). Oxford: Oxford University Press.

Mann, Horace. 1868. "Twelfth annual report to the Massachusetts State Board of Education, 1848" in Life and Works of Horace Mann, ed. Mrs Mary Mann, Vol. 3: 669

Mueller, Richard E. 2008. "Access and Persistence of Students in Canadian PostSecondary Education: What We Know, What We Don't Know, and Why It Matters." In Who Goes? Who Stays? What Matters? Accessing and Persisting in Post-Secondary Education in Canada, ed. Ross Finnie, Richard E. Mueller, Arthur Sweetman, and Alex Usher, 33-62. Montreal and Kingston: Queen's Policy Study Series, McGill-Queen's University Press.

Neumark, David. 1988. "Employers' Discriminatory Behavior and the Estimation of Wage Discrimination.” Journal of Human Resources, 23(3): 279-295.

Oaxaca, Ronald L. 1973. "Male-Female Wage Differentials in Urban Labor Markets." International Economic Review, 14(3): 693-709.

OECD. 2001. Knowledge and Skills for Life. First Results from the OECD Programme for International Student Assessment (PISA) 2000: OECD, Paris 
OECD. 2002. PISA 2002 Technical Report. Eds Ray Adams and Margaret Wu: OECD, Paris

OECD, 2005. The Reversal of Gender Inequalities in Higher Education: An On-going Trend, retrieved from https://www.oecd.org/edu/ceri/41939699.pdf

OECD. 2015. PISA 2015 Draft Framework, retrieved from https://www.oecd.org/pisa/pisaproducts/PISA-2015-draft-questionnaire-framework.pdf

OECD. 2017. PISA 2015 Key Findings for Canada, retrieved from http://www.oecd.org/ canada/pisa-2015-canada.htm

OECD. 2017b. Education at a Glace, 2017, retrieved from http://www.oecd.org ledu/education-at-a-glance-19991487.htm

Stock, James H. 2010. "The Other Transformation in Econometric Practice: Robust Tools for Inference.” Journal of Economic Perspectives, 24(2): 83-94

Williams, R. 2015. "Interaction effects and group comparisons" at https://www3.nd.edu / rwilliam/stats2/151.pdf

Winship, Christopher and Robert D. Mare. 1984. "Regression Models with Ordinal Variables." American Sociological Review, 49(4): 512-525. 


\section{Tables and Figures}

Table 2.3. Summary and Origin of Variables Used in Analysis

\begin{tabular}{|l|c|c|c|c|c|}
\hline & \multicolumn{3}{|c|}{$\begin{array}{c}\text { Cycle 1 } \\
\text { (Age 15) }\end{array}$} & $\begin{array}{c}\text { Cycle 2 } \\
\text { (Age 17) }\end{array}$ & $\begin{array}{c}\text { Cycle 3 } \\
\text { (Age 19) }\end{array}$ \\
\hline Variable: & Parent & Student & PISA & Student & Student \\
\hline Overall grade, last year of high school & & & & & $\bullet$ \\
\hline Reading score & & & $\bullet$ & & \\
\hline Non-cognitive skills: & & & & & \\
\hline \multicolumn{1}{|c|}{ Learning skills } & & & & $\bullet$ & \\
\hline Disengagement & & & & $\bullet$ & \\
\hline Perceptions of teachers & & & & $\bullet$ & \\
\hline Fatalism & & $\bullet$ & & & \\
\hline Self-esteem & & $\bullet$ & & & \\
\hline Self-efficacy (mastery) & & $\bullet$ & & & \\
\hline Family income & $\bullet$ & & & & \\
\hline Family status & $\bullet$ & & & & \\
\hline Parental education & $\bullet$ & & & & \\
\hline Province & $\bullet$ & & & & \\
\hline Gender & & $\bullet$ & & & \\
\hline Immigrant & $\bullet$ & & & & \\
\hline Parental hope for child's education & $\bullet$ & & & & \\
\hline Student's education aspirations & & & & $\bullet$ & \\
\hline
\end{tabular}


Table 2.4. Average Population Characteristics, $\mathrm{C} 1$ and $\mathrm{C} 3$

\begin{tabular}{llllll}
\hline & $\begin{array}{l}\text { Cycle 1 } \\
(\mathbf{2 2 , 0 6 6 )}\end{array}$ & $\begin{array}{l}\text { Cycle 3 } \\
(\mathbf{1 7 , 5 8 4})\end{array}$ & $\begin{array}{l}\text { Mean (Cycle 1) } \\
\text { Mean (C3) }\end{array}$ \\
\hline & Mean & $\begin{array}{l}\text { Std. } \\
\text { Dev. }\end{array}$ & Mean & $\begin{array}{l}\text { Std. } \\
\text { Dev. }\end{array}$ & p-value \\
Male & 0.50 & 0.50 & 0.50 & 0.50 & $\mathrm{p}=1.000$ \\
Reading score & 532 & 96 & 534 & 95 & $\mathrm{p}=0.0375$ \\
Learning Skills & 1.85 & 0.76 & 1.87 & 0.76 & $\mathrm{p}=0.0092$ \\
Disengagement & 1.74 & 0.74 & 1.73 & 0.74 & $\mathrm{p}=0.1813$ \\
Perceptions & 2.56 & 0.65 & 2.58 & 0.63 & $\mathrm{p}=0.002$ \\
Self-esteem & 30.65 & 5.06 & 30.75 & 4.99 & $\mathrm{p}=0.0492$ \\
Fatalism & 14.51 & 3.23 & 14.46 & 3.19 & $\mathrm{p}=0.1236$ \\
Self-efficacy & 13.66 & 3.35 & 13.71 & 3.33 & $\mathrm{p}=0.1388$ \\
Family income & 71,364 & 69,797 & 71,866 & 66,390 & $\mathrm{p}=0.4672$ \\
Family status (intact) & 0.71 & 0.45 & 0.73 & 0.45 & $\mathrm{p}<0.0001$ \\
Immigrant & 0.10 & 0.30 & 0.10 & 0.30 & $\mathrm{p}=1.000$ \\
Parental Education & 2.88 & 0.90 & 2.90 & 0.89 & $\mathrm{p}=0.0272$ \\
Parental hopes - univ & 0.65 & 0.48 & 0.65 & 0.48 & $\mathrm{p}=1.000$
\end{tabular}

All variables presented here are as measured at age 15. Source: YITS, author's calculations. 
Table 2.5. Summary Statistics of Explanatory Variables by Gender.

\begin{tabular}{|c|c|c|c|c|c|}
\hline & \multicolumn{2}{|c|}{ Girls $(8,834)$} & \multicolumn{2}{|c|}{ Boys $(8,750)$} & \multirow{2}{*}{$\begin{array}{l}\text { Significance } \\
\text { Null: Girls = } \\
\text { Boys }\end{array}$} \\
\hline & Mean & Std. Dev. & Mean & Std. Dev. & \\
\hline Reading Score $^{b, c}$ & 0.25 & 0.93 & -0.08 & 1.02 & \\
\hline Disengagement $^{\mathrm{a}, \mathrm{c}}$ & -0.06 & 0.97 & 0.16 & 1.03 & $\mathrm{p}<0.001$ \\
\hline $\begin{array}{l}\text { Perceptions - } \\
\text { Teachers }^{\text {a,c }}\end{array}$ & -0.03 & 1.04 & -0.13 & 1.00 & $\mathrm{p}<0.001$ \\
\hline Self-Esteem ${ }^{\text {b,c }}$ & -0.04 & 0.98 & 0.08 & 1.00 & $\mathrm{p}<0.001$ \\
\hline Fatalism $^{b, c}$ & 0.07 & 0.98 & 0.00 & 1.01 & $\mathrm{p}<0.001$ \\
\hline Self-Efficacy $^{\text {b,c }}$ & -0.10 & 0.99 & 0.12 & 1.03 & $\mathrm{p}<0.001$ \\
\hline Learning Skills ${ }^{\text {a,c }}$ & 0.20 & 0.92 & -0.22 & 1.03 & $\mathrm{p}<0.001$ \\
\hline Immigrant $^{b}$ & 0.10 & 0.30 & 0.09 & 0.29 & $\mathrm{p}=0.2$ \\
\hline Family Income $(\log )^{b}$ & 11.00 & 0.61 & 11.04 & 0.63 & $\mathrm{p}<0.001$ \\
\hline Family Status (Intact) & 0.73 & 0.44 & 0.75 & 0.43 & $\mathrm{p}=0.014$ \\
\hline Parental Education $^{\text {b }}$ & 2.90 & 0.89 & 2.92 & 0.89 & $\mathrm{p}=0.12$ \\
\hline Parents' Hope for Univ ${ }^{b}$ & 0.71 & 0.45 & 0.61 & 0.49 & $\mathrm{p}<0.001$ \\
\hline
\end{tabular}

a - measured at age 17; b - measured at age 15; c - standardized score

Table 2.6. Aspirations (measured at age 17) by Gender.

\begin{tabular}{llll}
\hline Aspirations & Girls & Boys & Difference (Boys - Girls) \\
\hline Less than BA & 24.5 & 36.7 & 12.2 \\
BA & 33.2 & 28.2 & $-\mathbf{5 . 0}$ \\
More than BA & 42.3 & 35.1 & -7.2 \\
\hline
\end{tabular}

Source: Youth In Transition Survey. Author's calculations. 
Table 2.7a. Distribution of Overall Grade for High Performers in Reading.

\begin{tabular}{lllllll}
\hline \multicolumn{7}{c}{ Grade in Final Year of HS } \\
\hline & $<\mathbf{6 0 s}$ & $\mathbf{6 0 s}$ & $\mathbf{7 0 s}$ & $\mathbf{8 0 s}$ & $\mathbf{9 0 s}$ & Total \\
Female & 0.1 & 2.6 & 14.0 & 52.0 & 31.3 & $60.7 \%$ \\
Male & 0.2 & 4.0 & 26.0 & 44.9 & 24.9 & $39.3 \%$ \\
Difference (Male-Female) & 0.1 & 1.4 & 12.0 & -7.1 & -6.4 & \\
\hline
\end{tabular}

Source: Youth In Transition Survey. Author's calculations.

Table 2.7b. Distribution of Overall Grade for Student with High Learning Skills.

\begin{tabular}{lllllll}
\hline \multicolumn{7}{c}{ Final Grade } \\
\hline & $<\mathbf{6 0 s}$ & $\mathbf{6 0 s}$ & $\mathbf{7 0 s}$ & $\mathbf{8 0 s}$ & $\mathbf{9 0 s}$ & Total \\
Female & 0.6 & 5.4 & 27.9 & 47.5 & 18.6 & $63.9 \%$ \\
Male & 1.1 & 9.0 & 29.9 & 42.4 & 17.7 & $36.1 \%$ \\
Difference (Male-Female) & 0.5 & 3.6 & 1.9 & -5.1 & -0.9 & \\
\hline
\end{tabular}

Source: Youth In Transition Survey. Author's calculations.

Table 2.7c. Distribution of Overall Grades for Students with High Aspirations (>BA)

\begin{tabular}{lllllll}
\hline \multicolumn{7}{l}{ Final Grade } \\
& $<\mathbf{6 0 s}$ & $\mathbf{6 0 s}$ & $\mathbf{7 0 s}$ & $\mathbf{8 0 s}$ & $\mathbf{9 0 s}$ & Total \\
Female & 1.3 & 5.2 & 30.3 & 46.6 & 16.6 & $55.0 \%$ \\
Male & 2.2 & 10.4 & 33.5 & 40.9 & 13.0 & $45.0 \%$ \\
Difference (Male-Female) & 0.9 & 5.2 & 3.2 & -5.7 & -3.6 & \\
\hline
\end{tabular}

Source: Youth In Transition Survey. Author's calculations. 
Table 2.8. Ordered Logit Coefficients for Models (A) - (F).

\begin{tabular}{|c|c|c|c|c|c|c|}
\hline Variable & $\begin{array}{l}\text { Background } \\
\text { (A) }\end{array}$ & $\begin{array}{l}\text { Add } \\
\text { Student } \\
\text { Aspirations } \\
\text { (B) } \\
\end{array}$ & $\begin{array}{l}\text { Add } \\
\text { Reading } \\
\text { Score } \\
\text { (C) } \\
\end{array}$ & $\begin{array}{l}\text { Add } \\
\text { Noncog } \\
\text { no LS } \\
\text { (D) } \\
\end{array}$ & $\begin{array}{l}\text { Add } \\
\text { Noncog } \\
\text { with LS } \\
\text { (E) } \\
\end{array}$ & $\begin{array}{l}\text { Add } \\
\text { Overall } \\
\text { Grade } 15 \\
\text { (F) } \\
\end{array}$ \\
\hline \multirow[t]{2}{*}{ Male } & $-0.726 * * *$ & $-0.585 * * *$ & $-0.440 * * *$ & $-0.545 * * *$ & $-0.355 * * *$ & $-0.186 * * *$ \\
\hline & $(0.050)$ & $(0.048)$ & 0.048 & 0.050 & 0.052 & 0.053 \\
\hline \multirow[t]{2}{*}{ Immigrant } & $0.270 * * *$ & -0.037 & $0.241^{* *}$ & $0.183 *$ & $0.185^{*}$ & 0.153 \\
\hline & $(0.105)$ & $(0.108)$ & $(0.104)$ & $(0.103)$ & $(0.103)$ & $(0.114)$ \\
\hline \multirow[t]{2}{*}{ Family income (log) } & $0.082 *$ & -0.024 & $-0.093 *$ & $-0.103 * *$ & $-0.118 * *$ & $-0.086^{*}$ \\
\hline & $(0.051)$ & $(0.053)$ & $(0.051)$ & $(0.052)$ & $(0.050)$ & $(0.052)$ \\
\hline \multirow[t]{2}{*}{ Intact } & $0.412 * * *$ & $0.406^{* * *}$ & $0.399 * * *$ & $0.351 * * *$ & $0.312 * * *$ & $0.180 * * *$ \\
\hline & $(0.059)$ & $(0.061)$ & $(0.062)$ & $(0.061)$ & $(0.062)$ & $(0.064)$ \\
\hline \multicolumn{7}{|l|}{$\underline{\text { Parental Education }}$} \\
\hline$\overline{\text { Less than High School }}$ & $\begin{array}{l}-0.628 * * * \\
(0.101)\end{array}$ & $\begin{array}{l}-0.392 * * * \\
(0.106)\end{array}$ & $\begin{array}{l}-0.151 \\
(0.113)\end{array}$ & $\begin{array}{l}-0.228 * * \\
(0.113)\end{array}$ & $\begin{array}{l}-0.159 \\
(0.115)\end{array}$ & $\begin{array}{l}-0.133 \\
(0.121)\end{array}$ \\
\hline High School only & $\begin{array}{l}-0.158^{* * * *} \\
(0.057)\end{array}$ & $\begin{array}{l}-0.099 * \\
(0.059)\end{array}$ & $\begin{array}{l}-0.044 \\
(0.059)\end{array}$ & $\begin{array}{l}-0.078 \\
(0.061)\end{array}$ & $\begin{array}{l}-0.048 \\
(0.063)\end{array}$ & $\begin{array}{l}-0.048 \\
(0.068)\end{array}$ \\
\hline College & reference & & & & & \\
\hline University & $\begin{array}{l}0.854 * * * \\
(0.058)\end{array}$ & $\begin{array}{l}0.553 * * * \\
(0.060)\end{array}$ & $\begin{array}{l}0.436 * * * \\
(0.061)\end{array}$ & $\begin{array}{l}0.447 * * * \\
(0.062)\end{array}$ & $\begin{array}{l}0.461 * * * \\
(0.062)\end{array}$ & $\begin{array}{l}0.341 * * * \\
(0.067)\end{array}$ \\
\hline Parental hopes - univ & & $\begin{array}{l}0.570 * * * \\
(0.060)\end{array}$ & $\begin{array}{l}0.274 * * * \\
(0.065)\end{array}$ & $\begin{array}{l}0.200 * * * \\
(0.064)\end{array}$ & $\begin{array}{l}0.169 * * * \\
(0.063)\end{array}$ & $\begin{array}{l}0.044 \\
(0.064)\end{array}$ \\
\hline \multicolumn{7}{|l|}{ Student Ed. Aspirations: } \\
\hline \multicolumn{7}{|l|}{ Less than a BA } \\
\hline BA & & $\begin{array}{l}0.752 * * * \\
(0.061)\end{array}$ & $\begin{array}{l}0.475 * * * \\
(0.064)\end{array}$ & $\begin{array}{l}0.329 * * * \\
(0.063)\end{array}$ & $\begin{array}{l}0.259 * * * \\
(0.063)\end{array}$ & $\begin{array}{l}0.167 * * * \\
(0.065)\end{array}$ \\
\hline More than a BA & & $\begin{array}{l}1.387 * * * \\
(0.065)\end{array}$ & $\begin{array}{l}1.002 * * * \\
(0.068)\end{array}$ & $\begin{array}{l}0.737 * * * \\
(0.069)\end{array}$ & $\begin{array}{l}0.635^{* * *} \\
(0.068)\end{array}$ & $\begin{array}{l}0.473 * * * \\
(0.071)\end{array}$ \\
\hline Reading score & & & $\begin{array}{l}0.880 * * * \\
(0.033)\end{array}$ & $\begin{array}{l}0.811 * * * \\
(0.036)\end{array}$ & $\begin{array}{l}0.832 * * * \\
(0.036)\end{array}$ & $\begin{array}{l}0.589 * * * \\
(0.040)\end{array}$ \\
\hline Disengagement & & & & $\begin{array}{l}-0.285^{* * * *} \\
(0.036)\end{array}$ & $\begin{array}{l}-0.043 \\
(0.035)\end{array}$ & $\begin{array}{l}-0.059 \\
(0.037)\end{array}$ \\
\hline Perceptions of teachers & & & & $\begin{array}{l}0.036 \\
(0.033)\end{array}$ & $\begin{array}{l}-0.016 \\
(0.033)\end{array}$ & $\begin{array}{l}-0.019 \\
(0.033)\end{array}$ \\
\hline Self-esteem & & & & $\begin{array}{l}0.058^{*} \\
(0.035)\end{array}$ & $\begin{array}{l}0.030 \\
(0.036)\end{array}$ & $\begin{array}{l}0.017 \\
(0.038)\end{array}$ \\
\hline Fatalism & & & & $\begin{array}{l}0.099 * * * \\
(0.034)\end{array}$ & $\begin{array}{l}0.108 * * * \\
(0.036)\end{array}$ & $\begin{array}{l}0.093 * * \\
(0.037)\end{array}$ \\
\hline Self-efficacy & & & & $\begin{array}{l}0.401 * * * \\
(0.030)\end{array}$ & $\begin{array}{l}0.320 * * * \\
(0.032)\end{array}$ & $\begin{array}{l}0.048 \\
(0.036)\end{array}$ \\
\hline Learning skills & & & & & $\begin{array}{l}0.708 * * * \\
(0.038)\end{array}$ & $\begin{array}{l}0.542 * * * \\
(0.039)\end{array}$ \\
\hline \multicolumn{7}{|l|}{ Overall grade at age 15} \\
\hline$<60 \%$ & & & & & & $\begin{array}{l}-1.075^{* * *} \\
(0.132)\end{array}$ \\
\hline in the $60 \mathrm{~s}$ & & & & & & $\begin{array}{l}-0.643 * * * \\
(0.085)\end{array}$ \\
\hline in the $70 \mathrm{~s}$ & reference & & & & & \\
\hline in the $80 \mathrm{~s}$ & & & & & & $\begin{array}{l}1.214 * * * \\
(0.072)\end{array}$ \\
\hline in the $90 \mathrm{~s}$ & & & & & & $\begin{array}{l}2.918 * * * \\
(0.121)\end{array}$ \\
\hline Observations & 13,441 & 13,441 & 13,441 & 13,441 & 13,441 & 13,441 \\
\hline Pseudo r2 & 0.051 & 0.094 & 0.145 & 0.170 & 0.199 & 0.254 \\
\hline
\end{tabular}

Standard errors are reported in parenthesis beneath coefficients. $*, * *, * * *$ represent significance at the $10 \%, 5 \%$ and $1 \%$

Source: Youth In Transition Survey. Author's calculations. 1 - Includes less than HS completion, HS graduation only, and college diplomas. 2 - Includes BSc, BBA and other undergraduate degrees. Province of residence was included as a control variable. Results are available upon request. 
Table 2.9. Average Marginal Effect Using Ordered Logit, for Model (E)

\begin{tabular}{|c|c|c|c|c|c|c|c|c|c|c|}
\hline & $<60 \%$ & & in the 60s & & in the 70s & & in the 80s & & in the 90s & \\
\hline & Probability & Std. Err. & Probability & Std. Err. & Probability & Std. Err. & Probability & Std. Err. & Probability & Std. Err. \\
\hline Male & $0.011 * * *$ & 0.002 & $0.029 * * *$ & 0.004 & $0.019 * * *$ & 0.003 & $-0.037 * * *$ & 0.006 & $-0.022 * * *$ & 0.003 \\
\hline Reading Score & $-0.026^{* * *}$ & 0.002 & $-0.067 * * *$ & 0.003 & $-0.044 * * *$ & 0.002 & $0.085^{* * *}$ & 0.004 & $0.052 * * *$ & 0.003 \\
\hline \multicolumn{11}{|l|}{ Non-cognitive skills: } \\
\hline Learning Skills & $-0.022 * * *$ & 0.002 & $-0.056 * * *$ & 0.003 & $-0.037 * * *$ & 0.002 & $0.072 * * *$ & 0.004 & $0.044 * * *$ & 0.003 \\
\hline Disengagement & 0.001 & 0.001 & 0.003 & 0.003 & 0.002 & 0.002 & -0.003 & 0.004 & -0.002 & 0.002 \\
\hline Perceptions & 0.000 & 0.001 & 0.001 & 0.003 & 0.000 & 0.002 & -0.001 & 0.003 & -0.001 & 0.002 \\
\hline Self esteem & -0.001 & 0.001 & -0.002 & 0.003 & -0.002 & 0.002 & 0.003 & 0.004 & 0.002 & 0.002 \\
\hline Fatalism & $-0.003 * * *$ & 0.001 & $-0.009 * * *$ & 0.003 & $-0.006 * * *$ & 0.002 & $0.011 * * *$ & 0.004 & $0.007 * * *$ & 0.002 \\
\hline Self-efficacy & $-0.010 * * *$ & 0.001 & $-0.027 * * *$ & 0.003 & $-0.018 * * *$ & 0.002 & $0.034 * * *$ & 0.003 & $0.021 * * *$ & 0.002 \\
\hline Immigrant & $-0.005^{*}$ & 0.003 & $-0.014^{*}$ & 0.008 & $-0.010^{*}$ & 0.006 & $0.018 *$ & 0.010 & $0.012 *$ & 0.007 \\
\hline Family income (log) & $0.004 * * *$ & 0.002 & $0.010 * * *$ & 0.004 & $0.007 * * *$ & 0.003 & $-0.013 * * *$ & 0.005 & $-0.008 * * *$ & 0.003 \\
\hline Family status (intact) & $-0.010 * * *$ & 0.002 & $-0.025 * * *$ & 0.005 & $-0.015 * * *$ & 0.003 & $0.032 * * *$ & 0.006 & $0.018 * * *$ & 0.003 \\
\hline \multicolumn{11}{|l|}{ Parental Education: } \\
\hline Less than HS & $0.009 * *$ & 0.004 & $0.021 * *$ & 0.010 & $0.011 * * *$ & 0.004 & $-0.028 * *$ & 0.013 & $-0.012 * *$ & 0.005 \\
\hline HS only & 0.001 & 0.002 & 0.003 & 0.005 & 0.002 & 0.003 & -0.004 & 0.007 & -0.002 & 0.003 \\
\hline College & reference & & reference & & reference & & reference & & reference & \\
\hline University & $-0.013 * * *$ & 0.002 & $-0.037 * * *$ & 0.005 & $-0.030 * * *$ & 0.004 & $0.050 * * *$ & 0.007 & $0.031 * * *$ & 0.004 \\
\hline $\begin{array}{l}\text { Parental hopes } \\
\text { (university) } \\
\text { Student aspirations: }\end{array}$ & $-0.005 * * *$ & 0.002 & $-0.013 * * *$ & 0.005 & $-0.008 * * *$ & 0.003 & $0.016^{* * *}$ & 0.007 & $0.009 * * *$ & 0.004 \\
\hline Less than a BA & reference & & reference & & reference & & reference & & reference & \\
\hline $\mathbf{B A}$ & $-0.009 * * *$ & 0.002 & $-0.024 * * *$ & 0.006 & $-0.013 * * *$ & 0.003 & $0.031 * * *$ & 0.007 & $0.014 * * *$ & 0.003 \\
\hline More than a BA & $-0.018 * * *$ & 0.002 & $-0.053 * * *$ & 0.006 & $-0.037 * * *$ & 0.004 & $0.072 * * *$ & 0.008 & $0.037 * * *$ & 0.004 \\
\hline
\end{tabular}

Obs $=14,214 . *{ }^{* *}, * * *$ represent significance at the $10 \%, 5 \%$ and $1 \%$ levels respectively. Source: Youth In Transition Survey. Author's calculations. 
Table 2.10. AME, Ordered Logit vs Generalized Ordered Logit for Model (E)

\begin{tabular}{|c|c|c|c|c|c|c|c|c|c|c|}
\hline & \multicolumn{2}{|c|}{ Less than $60 \%$} & \multicolumn{2}{|l|}{ in the 60s } & \multicolumn{2}{|l|}{ in the 70s } & \multicolumn{2}{|l|}{ in the 80s } & \multicolumn{2}{|l|}{ in the 90s } \\
\hline & $\begin{array}{l}\text { Ordered } \\
\text { Logit }\end{array}$ & $\begin{array}{l}\text { Generalized } \\
\text { Ordered } \\
\text { Logit } \\
\end{array}$ & $\begin{array}{l}\text { Ordered } \\
\text { Logit }\end{array}$ & $\begin{array}{l}\text { Generalized } \\
\text { Ordered } \\
\text { Logit } \\
\end{array}$ & $\begin{array}{l}\text { Ordered } \\
\text { Logit }\end{array}$ & $\begin{array}{l}\text { Generalized } \\
\text { Ordered } \\
\text { Logit } \\
\end{array}$ & $\begin{array}{l}\text { Ordered } \\
\text { Logit }\end{array}$ & $\begin{array}{l}\text { Generalized } \\
\text { Ordered } \\
\text { Logit } \\
\end{array}$ & $\begin{array}{l}\text { Ordered } \\
\text { Logit }\end{array}$ & $\begin{array}{l}\text { Generalized } \\
\text { Ordered } \\
\text { Logit } \\
\end{array}$ \\
\hline Male & $0.011 * * *$ & 0.005 & $0.029 * * *$ & $0.041 * * *$ & $0.019 * * *$ & $0.025^{*}$ & $-0.037 * * *$ & $-0.056 * * *$ & $-0.022 * * *$ & $-0.015 * *$ \\
\hline Reading score & $-0.026^{* * *}$ & $-0.018 * * *$ & $-0.067 * * *$ & $-0.055^{* * *}$ & $-0.044 * * *$ & $-0.075 * * *$ & $0.085^{* * *}$ & $0.083 * * *$ & $0.052 * * *$ & $0.066 * * *$ \\
\hline \multicolumn{11}{|l|}{ Non-cognitive skills: } \\
\hline Learning Skills & $-0.022 * * *$ & $-0.017 * * *$ & $-0.056 * * *$ & $-0.059 * * *$ & $-0.037 * * *$ & $-0.038 * * *$ & $0.072 * * *$ & $0.064 * * *$ & $0.044 * * *$ & $0.050 * * *$ \\
\hline Disengagement & 0.001 & $0.008 * * *$ & 0.003 & -0.004 & 0.002 & -0.004 & -0.003 & 0.004 & -0.002 & -0.004 \\
\hline Perception of teachers & 0.000 & 0.004 & 0.001 & 0.001 & 0.000 & -0.002 & -0.001 & -0.004 & -0.001 & 0.001 \\
\hline Self-esteem & -0.001 & 0.000 & -0.002 & 0.000 & -0.002 & -0.009 & 0.003 & 0.007 & 0.002 & 0.003 \\
\hline Fatalism & $-0.003 * * *$ & 0.001 & $-0.009 * * *$ & -0.009 & $-0.006^{* * *}$ & $-0.017 * *$ & $0.011 * * *$ & $0.013^{*}$ & $0.007 * * *$ & $0.012 * *$ \\
\hline Self-efficacy & $-0.010 * * *$ & -0.002 & $-0.027 * * *$ & $-0.026^{* * *}$ & $-0.018 * * *$ & $-0.033 * * *$ & $0.034 * * *$ & $0.030 * * *$ & $0.021 * * *$ & $0.031 * * *$ \\
\hline Immigrant & $-0.005^{*}$ & -0.013 & $-0.014^{*}$ & 0.023 & $-0.010 *$ & $-0.072 * *$ & $0.018^{*}$ & $0.055^{*}$ & $0.012 *$ & 0.007 \\
\hline Family Income (log) & $0.004 * * *$ & 0.001 & $0.010 * * *$ & 0.013 & $0.007 * * *$ & 0.006 & $-0.013 * * *$ & -0.006 & $-0.008 * * *$ & $-0.013 * *$ \\
\hline Family Status (Intact) & $-0.010 * * *$ & -0.007 & $-0.025 * * *$ & $-0.022 * *$ & $-0.015 * * *$ & -0.024 & $0.032 * * *$ & $0.038 * *$ & $0.018 * * *$ & $0.015^{*}$ \\
\hline \multicolumn{11}{|l|}{ Parental Education: } \\
\hline Less than high school & $0.009 * *$ & 0.003 & $0.021 * *$ & 0.025 & $0.011 * * *$ & 0.023 & $-0.028 * *$ & -0.022 & $-0.012 * *$ & -0.030 \\
\hline High school only & 0.001 & -0.008 & 0.003 & 0.010 & 0.002 & 0.004 & -0.004 & -0.005 & -0.002 & -0.002 \\
\hline College & reference & & reference & & reference & & reference & & reference & \\
\hline University & $-0.013 * * *$ & -0.004 & $-0.037 * * *$ & $-0.036^{* * *}$ & $-0.030 * * *$ & $-0.040 * *$ & $0.050 * * *$ & $0.044 * * *$ & $0.031 * * *$ & $0.037 * * *$ \\
\hline Parental hopes (university) & $-0.005 * * *$ & $-0.013 * *$ & $-0.013 * * *$ & $-0.017 * *$ & $-0.008 * * *$ & 0.006 & $0.016^{* * *}$ & $0.037 * * *$ & $0.009 * * *$ & -0.013 \\
\hline \multicolumn{11}{|l|}{ Student aspirations: } \\
\hline Less than BA & reference & & reference & & reference & & reference & & reference & \\
\hline BA & $-0.009^{* * *}$ & -0.007 & $-0.024 * * *$ & $-0.031 * * *$ & $-0.013^{* * *}$ & 0.004 & $0.031^{* * *}$ & 0.029 & $0.014 * * *$ & 0.005 \\
\hline More than BA & $-0.018 * * *$ & -0.004 & $-0.053 * * *$ & $-0.056^{* * *}$ & $-0.037 * * *$ & $-0.029 *$ & $0.072 * * *$ & $0.044 * *$ & $0.037 * * *$ & $0.044 * * *$ \\
\hline
\end{tabular}


Table 2.11: Model (E) with Interactions

\begin{tabular}{|c|c|c|}
\hline & No Interactions & With Interactions \\
\hline \multirow[t]{2}{*}{ Male } & $-0.352 * * *$ & $-0.520 * * *$ \\
\hline & $(0.051)$ & $(0.101)$ \\
\hline \multirow[t]{2}{*}{ Reading score } & $0.826^{* * *}$ & $0.896^{* * *}$ \\
\hline & $(0.035)$ & $(0.045)$ \\
\hline \multirow[t]{2}{*}{ Learning skills } & $0.697 * * *$ & $0.655^{*} * *$ \\
\hline & $(0.037)$ & $(0.050)$ \\
\hline \multirow[t]{2}{*}{ Disengagement } & -0.033 & -0.033 \\
\hline & $(0.035)$ & $(0.035)$ \\
\hline \multirow[t]{2}{*}{ Perceptions } & -0.009 & -0.007 \\
\hline & $(0.032)$ & $(0.032)$ \\
\hline \multirow[t]{2}{*}{ Self-esteem } & 0.030 & 0.033 \\
\hline & $(0.035)$ & $(0.035)$ \\
\hline \multirow[t]{2}{*}{ Fatalism } & $0.107 * * *$ & $0.107 * * *$ \\
\hline & $(0.035)$ & $(0.035)$ \\
\hline \multirow{2}{*}{ Self-efficacy } & $0.332 * * *$ & $0.330 * * *$ \\
\hline & $(0.030)$ & $(0.042)$ \\
\hline \multirow[t]{2}{*}{ Immigrant } & $0.179 *$ & $0.177 *$ \\
\hline & $(0.102)$ & $(0.101)$ \\
\hline \multirow[t]{2}{*}{ Family Income } & $-0.129 * * *$ & $-0.129 * * *$ \\
\hline & $(0.047)$ & $(0.047)$ \\
\hline \multirow[t]{2}{*}{ Intact } & $0.300 * * *$ & $0.300 * * *$ \\
\hline & $(0.058)$ & $(0.058)$ \\
\hline \multicolumn{3}{|l|}{ Parental Education: } \\
\hline \multirow[t]{2}{*}{ Less than high school } & $-0.243 * *$ & $-0.242 * *$ \\
\hline & $(0.110)$ & $(0.110)$ \\
\hline \multirow[t]{2}{*}{ High school only } & -0.036 & -0.036 \\
\hline & $(0.061)$ & $(0.061)$ \\
\hline College & reference & \\
\hline \multirow{2}{*}{ University } & $0.470 * * *$ & $0.467 * * *$ \\
\hline & $(0.059)$ & $(0.059)$ \\
\hline \multirow[t]{2}{*}{ Parental hopes (university) } & $0.155^{* * *}$ & $0.153 * * *$ \\
\hline & $(0.061)$ & $(0.061)$ \\
\hline \multicolumn{3}{|l|}{ Student Aspirations: } \\
\hline Less than BA & reference & \\
\hline \multirow{2}{*}{$\begin{array}{l}\text { Less than BA } \\
\text { BA }\end{array}$} & $0.266^{* * *}$ & 0.135 \\
\hline & $(0.062)$ & $(0.101)$ \\
\hline \multirow[t]{2}{*}{ More than BA } & $0.628 * * *$ & $0.478 * * *$ \\
\hline & $(0.067)$ & $(0.105)$ \\
\hline \multirow[t]{2}{*}{ Male * reading } & & $-0.135^{* *}$ \\
\hline & & $(0.057)$ \\
\hline \multirow[t]{2}{*}{ Male * learning skills } & & 0.077 \\
\hline & & $(0.068)$ \\
\hline \multirow[t]{2}{*}{ Male * Self-efficacy } & & 0.008 \\
\hline & & $(0.059)$ \\
\hline \multirow{2}{*}{ Male * BA } & & $0.246^{*}$ \\
\hline & & $(0.129)$ \\
\hline Male * More than BA & & $0.284 * *$ \\
\hline & & $(0.141)$ \\
\hline
\end{tabular}


Table 2.12. Average Marginal Effects, by Gender (Ordered Logit)

\begin{tabular}{|c|c|c|c|c|c|c|c|c|c|c|}
\hline & \multicolumn{2}{|c|}{$<\mathbf{6 0}$} & \multicolumn{2}{|c|}{ in $60 \mathrm{~s}$} & \multicolumn{2}{|c|}{ in $70 s$} & \multicolumn{2}{|c|}{ in $80 \mathrm{~s}$} & \multicolumn{2}{|c|}{ in $90 \mathrm{~s}$} \\
\hline & girls & boys & girls & boys & girls & boys & girls & boys & girls & boys \\
\hline $\begin{array}{l}\text { Reading score } \\
\text { Non-cognitive skills: } \\
\end{array}$ & $-0.020 * * *$ & $-0.031 * * *$ & $-0.064 * * *$ & $-0.069 * * *$ & $-0.076 * * *$ & $-0.016^{* * *}$ & $0.092 * * *$ & $0.078 * * *$ & $0.068 * * *$ & $0.038 * * *$ \\
\hline Learning Skills & $-0.015^{* * *}$ & $-0.030 * * *$ & $-0.047 * * *$ & $-0.066 * * *$ & $-0.056 * * *$ & $-0.015 * * *$ & $0.067 * * *$ & $0.074 * * *$ & $0.050 * * *$ & $0.036 * * *$ \\
\hline Disengagement & -0.001 & $0.003 *$ & -0.003 & $0.008^{*}$ & -0.003 & $0.002 *$ & 0.004 & $-0.009 *$ & 0.003 & $-0.004 *$ \\
\hline Perceptions & 0.000 & 0.001 & -0.001 & 0.001 & -0.001 & 0.000 & 0.001 & -0.002 & 0.001 & -0.001 \\
\hline Self-esteem & -0.002 & 0.000 & -0.005 & 0.001 & -0.006 & 0.000 & 0.007 & -0.001 & 0.005 & 0.000 \\
\hline Fatalism & $-0.002 *$ & $-0.005 * *$ & $-0.006^{*}$ & $-0.011 * *$ & $-0.007 *$ & $-0.003 * *$ & $0.009 *$ & $0.012 * *$ & $0.007^{*}$ & $0.006 * *$ \\
\hline Self-efficacy & $-0.007 * * *$ & $-0.014 * * *$ & $-0.022 * * *$ & $-0.032 * * *$ & $-0.026^{* * *}$ & $-0.007 * * *$ & $0.032 * * *$ & $0.036^{* * *}$ & $0.023 * * *$ & $0.018 * * *$ \\
\hline Immigrant & -0.005 & -0.005 & $-0.015^{*}$ & -0.011 & $-0.018^{*}$ & -0.003 & $0.022^{*}$ & 0.012 & $0.016^{*}$ & 0.006 \\
\hline Family Income (log) & 0.000 & $0.010 * * *$ & 0.001 & $0.022 * * *$ & 0.001 & $0.005^{* * *}$ & -0.001 & $-0.025 * * *$ & -0.001 & $-0.012 * * *$ \\
\hline Family Status (Intact) & $-0.008 * * *$ & $-0.009 * *$ & $-0.026 * * *$ & $-0.020 * *$ & $-0.031 * * *$ & $-0.005 * *$ & $0.037 * * *$ & $0.022 * *$ & $0.028 * * *$ & $0.011^{* *}$ \\
\hline \multicolumn{11}{|l|}{ Parental Education: } \\
\hline $\begin{array}{l}\text { Less than high } \\
\text { school }\end{array}$ & 0.005 & 0.010 & 0.017 & 0.023 & 0.020 & 0.005 & -0.024 & -0.026 & -0.018 & -0.013 \\
\hline High school only & 0.001 & 0.000 & 0.003 & 0.001 & 0.004 & 0.000 & -0.005 & -0.001 & -0.003 & -0.001 \\
\hline College & reference & & reference & & reference & & reference & & reference & \\
\hline University & $-0.011 * * *$ & $-0.019 * * *$ & $-0.034 * * *$ & $-0.042 * * *$ & $-0.041 * * *$ & $-0.010 * * *$ & $0.049 * * *$ & $0.047 * * *$ & $0.036^{* * *}$ & $0.023 * * *$ \\
\hline Parental Hopes (univ.) & -0.001 & $-0.011 * * *$ & -0.003 & $-0.024 * * *$ & -0.003 & $-0.006^{* * *}$ & 0.004 & $0.027 * * *$ & 0.003 & $0.013 * * *$ \\
\hline \multicolumn{11}{|l|}{ Student Aspirations: } \\
\hline Less than $\mathbf{B A}^{1}$ & reference & & reference & & reference & & reference & & reference & \\
\hline BA only ${ }^{2}$ & -0.003 & $-0.015 * * *$ & -0.010 & $-0.034 * * *$ & -0.012 & $-0.008 * * *$ & 0.014 & $0.038 * * *$ & 0.011 & $0.019 * * *$ \\
\hline More than BA & $-0.011 * * *$ & $-0.030 * * *$ & $-0.035 * * *$ & $-0.067 * * *$ & $-0.042 * * *$ & $-0.016^{* * *}$ & $0.051 * * *$ & $0.076^{* * *}$ & $0.037 * * *$ & $0.037 * * *$ \\
\hline
\end{tabular}

$*, * *, * * *$ represent significance at the $10 \%, 5 \%$, and $1 \%$ levels respectively

Boys $=6,888$ observations. Girls $=7,326$ observations. 
Table 2.13. Decomposition Results Using Oaxaca, Blinder and Neumark approaches

\begin{tabular}{|l|l|l|}
\hline & Coefficient & Percentage \\
\hline Oaxaca & & \\
\hline Characteristics & -0.23 & $33 \%$ \\
\hline Blinder & -0.48 & $67 \%$ \\
\hline Characteristics & & \\
\hline Coefficients & 0.20 & $-28 \%$ \\
\hline Neumark & -0.91 & $128 \%$ \\
\hline Characteristics & & \\
\hline Coefficients (advantaged) & -0.24 & $34 \%$ \\
\hline Coefficients (disadvantaged) & -0.43 & $60 \%$ \\
\hline Raw & -0.043 & $6 \%$ \\
\hline Som & -0.71 & $100 \%$ \\
\hline
\end{tabular}

Source: Youth in Transition Survey. Author's calculations using nonlinear composition algorithms. 
Table 2.14. CIP Primary Groupings with Their Constituent Series and Subseries

\begin{tabular}{|c|c|}
\hline 001 Personal improvement and leisure & $\begin{array}{l}\text { 32. Basic skills (not for credit) } \\
\text { 33. Citizenship activities (not for credit) } \\
\text { 34. Health-related knowledge and skills (not for credit) } \\
\text { 35. Interpersonal and social skills (not for credit) } \\
\text { 36. Leisure and recreational activities (not for credit) } \\
\text { 37. Personal awareness and self-improvement (not for credit) }\end{array}$ \\
\hline 010 Education & 13. Education \\
\hline $\begin{array}{l}020 \text { Visual and performing arts, and } \\
\text { communications technologies }\end{array}$ & $\begin{array}{l}\text { 10. Communications technologies/technicians and support services } \\
\text { 50. Visual and performing arts }\end{array}$ \\
\hline 030 Humanities & $\begin{array}{l}\text { 16. Aboriginal and foreign languages, literatures and linguistics } \\
\text { 23. English language and literature/letters } \\
\text { 24. Liberal arts and sciences, general studies and humanities } \\
\text { 30.13 Medieval and renaissance studies } \\
\text { 30.21 Holocaust and related studies } \\
\text { 30.22 Classical and ancient studies } \\
\text { 30.29 Maritime studies } \\
\text { 38. Philosophy and religious studies } \\
\text { 39. Theology and religious vocations } \\
\text { 54. History } \\
\text { 55. French language and literature/letters }\end{array}$ \\
\hline $\begin{array}{l}040 \text { Social and behavioural sciences and } \\
\text { law }\end{array}$ & $\begin{array}{l}\text { 05. Area, ethnic, cultural, gender, and group studies } \\
\text { 09. Communication, journalism and related programs } \\
\text { 19. Family and consumer sciences/human sciences } \\
\text { 22. Legal professions and studies } \\
\text { 30.05 Peace studies and conflict resolution } \\
\text { 30.10 Biopsychology } \\
\text { 30.14 Museology/museum studies } \\
\text { 30.15 Science, technology and society } \\
\text { 30.17 Behavioural sciences } \\
\text { 30.20 International/global studies } \\
\text { 30.23 Intercultural/multicultural and diversity studies } \\
\text { 30.25 Cognitive science } \\
\text { 30.26 Cultural studies/critical theory and analysis } \\
\text { 30.28 Dispute resolution } \\
\text { 30.31 Human computer interaction } \\
\text { 42 Psychology } \\
\text { 45. Social Sciences }\end{array}$ \\
\hline
\end{tabular}




\begin{tabular}{|c|c|}
\hline $\begin{array}{l}050 \text { Business, management and public } \\
\text { administration }\end{array}$ & $\begin{array}{l}\text { 30.16 Accounting and computer science } \\
\text { 44. Public administration and social service professions } \\
\text { 52. Business, management, marketing and related support services }\end{array}$ \\
\hline $\begin{array}{l}\text { 060 Physical and life sciences and } \\
\text { technologies }\end{array}$ & $\begin{array}{l}\text { 26. Biological and biomedical sciences } \\
\text { 30.01 Biological and physical sciences } \\
\text { 30.18 Natural sciences } \\
\text { 30.19 Nutrition sciences } \\
\text { 30.27 Human biology } \\
\text { 30.32 Marine sciences } \\
\text { 40. Physical sciences } \\
\text { 41. Science technologies/technicians }\end{array}$ \\
\hline $\begin{array}{l}\text { 070 Mathematics, computer and } \\
\text { information sciences }\end{array}$ & $\begin{array}{l}\text { 11. Computer and information sciences and support services } \\
\text { 25. Library science } \\
\text { 27. Mathematics and statistics } \\
\text { 30.06 Systems science and theory } \\
\text { 30.08 Mathematics and computer science } \\
\text { 30.30 Computational science }\end{array}$ \\
\hline $\begin{array}{l}\text { 080 Architecture, engineering, and related } \\
\text { technologies }\end{array}$ & $\begin{array}{l}\text { 04. Architecture and related services } \\
\text { 14. Engineering } \\
\text { 15. Engineering technologies and engineering-related fields } \\
\text { 30.12 Historic preservation and conservation } \\
\text { 46. Construction trades } \\
\text { 47. Mechanic and repair technologies/technicians } \\
\text { 48. Precision production }\end{array}$ \\
\hline $\begin{array}{l}090 \text { Agriculture, natural resources and } \\
\text { conservation }\end{array}$ & $\begin{array}{l}\text { 01. Agriculture, agriculture operations and related sciences } \\
\text { 03. Natural resources and conservation }\end{array}$ \\
\hline 100 Health and related fields & $\begin{array}{l}\text { 31. Parks, recreation, leisure and fitness studies } \\
\text { 51. Health professions and related programs } \\
\text { 60. Dental, medical and veterinary residency programs }\end{array}$ \\
\hline $\begin{array}{l}\text { 110Personal, protective and } \\
\text { transportation services }\end{array}$ & $\begin{array}{l}\text { 12. Personal and culinary services } \\
\text { 28. Military science, leadership and operational art } \\
\text { 29. Military technologies and applied sciences } \\
\text { 43. Security and protective services } \\
\text { 49. Transportation and materials moving }\end{array}$ \\
\hline 120 Other & $\begin{array}{l}\text { 21. Pre-technology education/pre-industrial arts programs } \\
\text { 30.99 Multidisciplinary/interdisciplinary studies, other } \\
\text { 53. High school/secondary diploma and certificate programs }\end{array}$ \\
\hline
\end{tabular}


Table 2.15. Field of Study by Primary Groupings and Gender.

\begin{tabular}{lll}
\hline Classification of Instructional Programme (CIP) & Girls & Boys \\
\hline Personal Improvement and Leisure & 0.1 & 0.1 \\
Education & 3.4 & 0.4 \\
Visual and Performing Arts, Communication Technologies & 5.8 & 4.5 \\
Humanities & 13.5 & 7.7 \\
Social and Behavioral Sciences and Law & 25.0 & 11.9 \\
Business, Management, and Public Administration & 16.0 & 18.2 \\
Physical and Life Sciences and Technology & 11.6 & 9.7 \\
Mathematics, Computer and Information Sciences & 2.3 & 9.1 \\
Architecture, Engineering and Related Technologies & 2.5 & 22.8 \\
Agriculture, Natural Resources and Conservation & 1.9 & 2.6 \\
Health and Related Fields & 11.8 & 5.8 \\
Personal, Protective and Transportation Services & 4.9 & 5.6 \\
Other & 1.4 & 1.5 \\
\hline
\end{tabular}

Source: YITS, author's calculations. All students who participated in PSE by Cycle 3 
Table 2.16. Ordered Logit Results Controlling for Field of Study

\begin{tabular}{|c|c|c|}
\hline Variable & $\begin{array}{l}\begin{array}{l}\text { No FOS } \\
\text { (A) }\end{array} \\
\end{array}$ & $\begin{array}{l}\begin{array}{l}\text { Add FOS } \\
\text { (B) }\end{array} \\
\end{array}$ \\
\hline Male & $-0.247 * * *$ & $-0.297 * * *$ \\
\hline Immigrant & $0.386^{* * *}$ & $0.303 * *$ \\
\hline Family Income (log) & $-0.129 *$ & $-0.135 * *$ \\
\hline Intact & $0.263 * * *$ & $0.262 * * *$ \\
\hline \multicolumn{3}{|l|}{ Parental Education: } \\
\hline Less than HS & $-0.463 * *$ & $-0.463 * *$ \\
\hline High School Only & -0.078 & -0.069 \\
\hline College & reference & reference \\
\hline University & $0.502 * * *$ & $0.481 * * *$ \\
\hline Parental hopes - univ & $0.205^{* *}$ & $0.170 *$ \\
\hline \multicolumn{3}{|l|}{ Student Education Aspirations: } \\
\hline Less than a BA & reference & reference \\
\hline BA & $0.336^{* * *}$ & $0.354 * * *$ \\
\hline More than a BA & $0.743 * * *$ & $0.712 * * *$ \\
\hline Reading Score & $0.943 * * *$ & $0.917 * * *$ \\
\hline Learning Skills & $0.766^{* * *}$ & $0.762 * * *$ \\
\hline Disengagement & -0.004 & 0.004 \\
\hline Perceptions of Teachers & 0.025 & 0.025 \\
\hline Self Esteem & 0.049 & 0.061 \\
\hline Fatalism & $0.129 * * *$ & $0.126 * * *$ \\
\hline Self-Efficacy & $0.347 * * *$ & $0.319 * * *$ \\
\hline \multicolumn{3}{|l|}{ Field of Study (first): } \\
\hline Personal Improvement and Leisure & & 0.987 \\
\hline Education & & $-0.390 *$ \\
\hline Visual and Performing Arts, Communication & & $0.409 * *$ \\
\hline \multicolumn{3}{|l|}{ (20) } \\
\hline Humanities & & 0.152 \\
\hline Social and Behavioral Sciences, Law & & 0.127 \\
\hline Business, Management, Public Administration & reference & reference \\
\hline Physical and Life Sciences and Technology & & $0.702 * * *$ \\
\hline Mathematics, Computer and Information Sciences & & 0.203 \\
\hline Architecture, Engineering and Related Technologies & & $0.341 * *$ \\
\hline Agriculture, Natural Resources and Conservation & & -0.279 \\
\hline Health and Related Fields & & -0.011 \\
\hline Personal, Protective and Transportation Services & & -0.337 \\
\hline Other & & 0.129 \\
\hline Observations & 7,215 & 7,215 \\
\hline Pseudo R2 & 0.1965 & 0.2030 \\
\hline
\end{tabular}

$*, * *, * * *$ represent significance at the $10 \%, 5 \%$ and $1 \%$ levels respectively. Source: YITS, author's calculations.

Standard Errors are not included to economize on space, but are available on request. 
Table 2.17. Average Marginal Effect of Gender, with/without Field of Study

\begin{tabular}{|c|c|c|}
\hline & Prob (in 60s) & Prob (in 70s) \\
\hline
\end{tabular}

\begin{tabular}{llllll}
\hline No CIP: & & & & & \\
Girls & 0.01 & 0.074 & 0.341 & 0.444 & 0.131 \\
Boys & 0.013 & 0.087 & 0.367 & 0.424 & 0.11 \\
AME (Boys-Girls) & 0.003 & 0.013 & 0.026 & -0.021 & -0.021 \\
\hline CIP Included as Control: & & & & 0.133 \\
\hline Girls & 0.01 & 0.072 & 0.339 & 0.446 & 0.107 \\
Boys & 0.013 & 0.089 & 0.37 & 0.421 & -0.025 \\
AME (Boys-Girls) & 0.003 & 0.016 & 0.031 & -0.025 & \\
\hline
\end{tabular}

All reported probabilities and marginal effects are significant at less than the 1\% level of confidence. Source: Youth in Transition Survey, author's calculations 
Figure 2.1. U.S. College Graduation Rates by Gender: Cohorts born 1876-1975

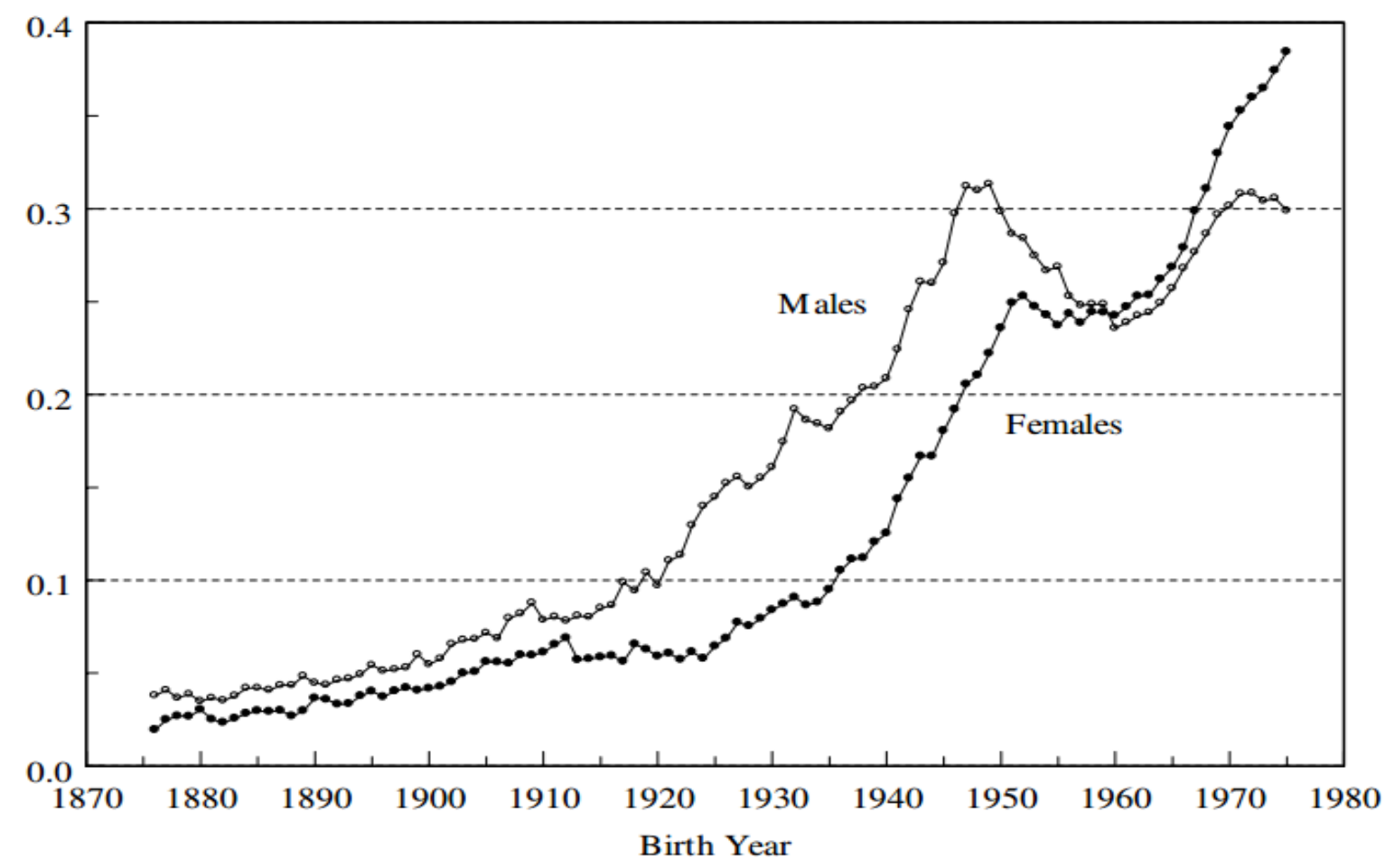

Source: Goldin, Katz and Kuziemko (2006) 
Figure 2-2. Participation by Gender at Canadian Universities

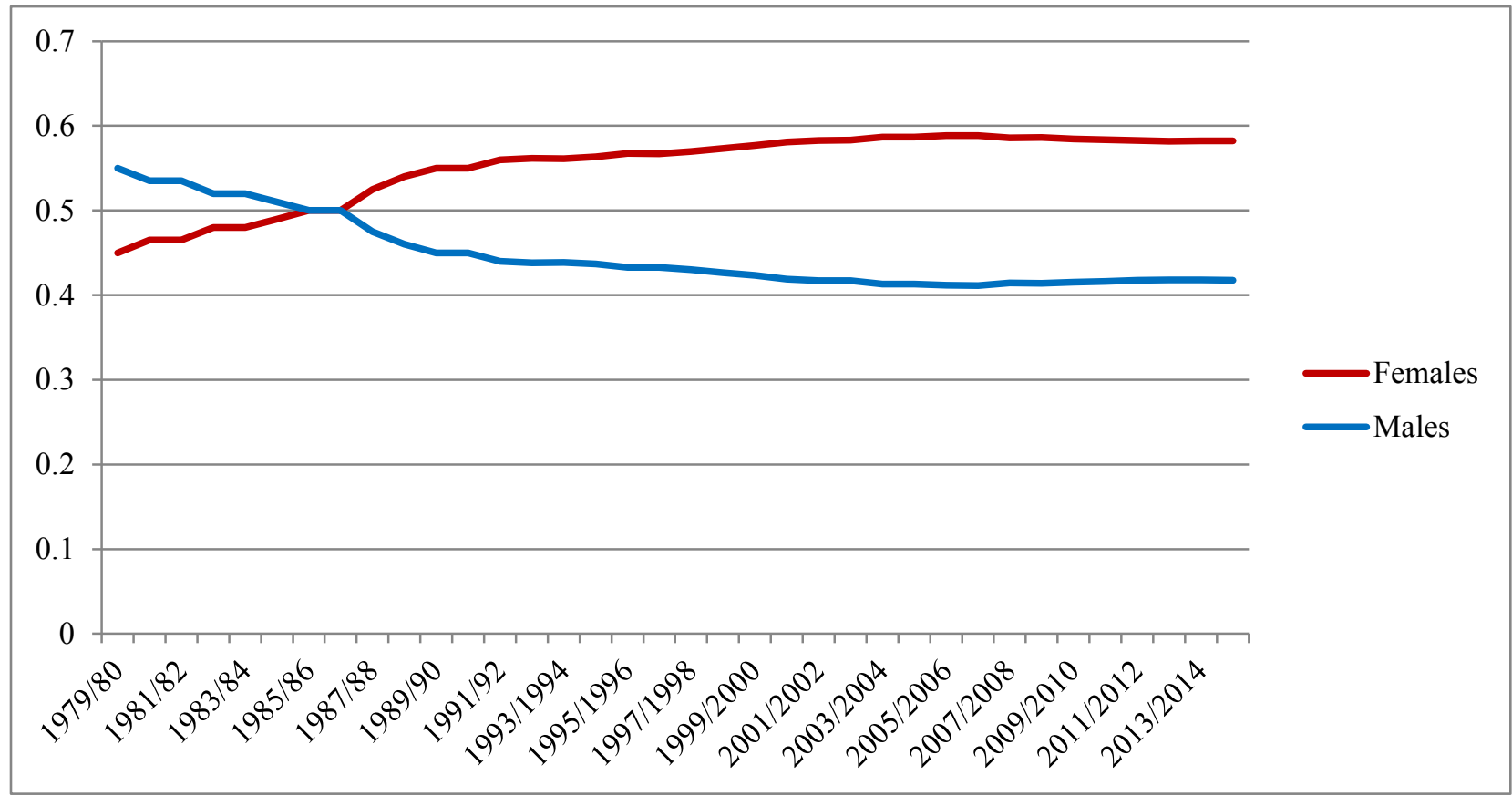

Source: CANSIM Table 477-0019. Shows full-time university participation by Canadian students, all ages. Author's calculation.

Figure 2-3. Field of Study by Gender, Canadian Universities, 2014/15

\section{Field of Study by Gender, 2014/15}

Other instructional programs

Personal, protective and transportation services

Health and related fields

Agriculture, natural resources and conservation Architecture, engineering and related technologies Mathematics, computer and information sciences

Physical and life sciences and technologies Business, management and public administration Social and behavioural sciences and law

Humanities

Visual and perform arts, com. technologies

Education

Personal improvement and leisure

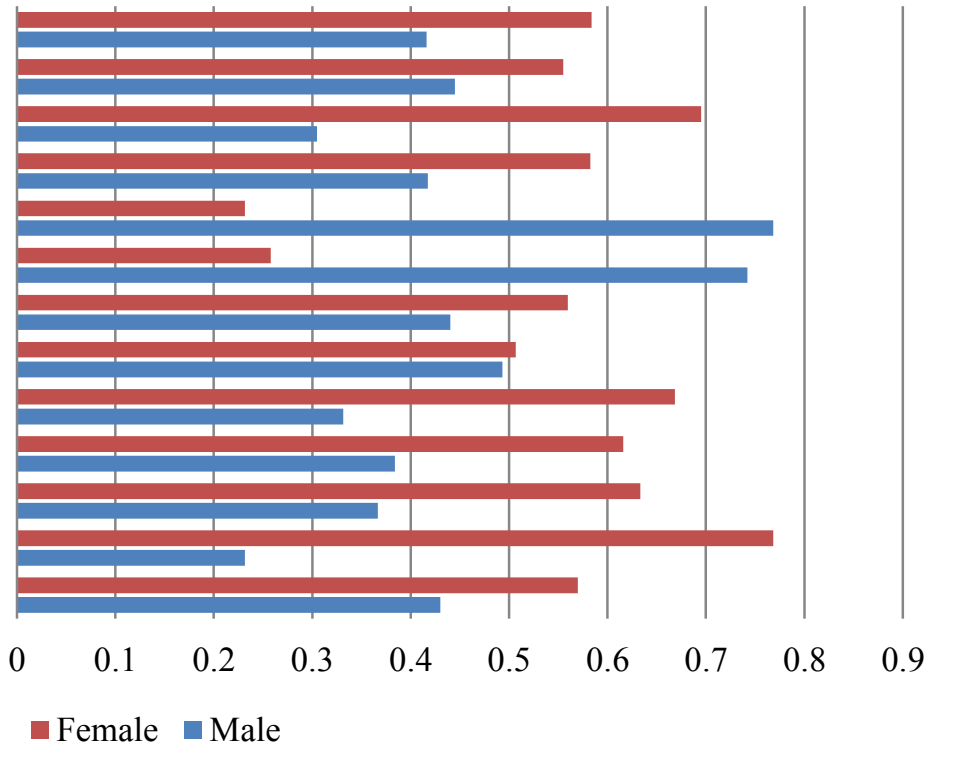

Source: CANSIM Table 477-0019. Shows field of study for full-time students, all ages. Author's calculation. 


\section{Appendices}

\section{Appendix 2.A. Sample Restrictions and Attrition Analysis}

\section{A.1 Dropping Quebec students from the sample}

The Quebec education system is unique in Canada, as its high school system ends in Grade 11. From there, students can choose to go on to the CEGEP (a general and vocational college which is meant to provide a step between secondary school and university) or to leave the education system, having graduated with a high school diploma (at age 17). For the purposes of examining educational attainment, this would lead to spurious differences between populations. For example, a Quebec student might graduate from high school after grade 11, and then go on to CEGEP, but quit before completing the first year. This student would be described as having "some postsecondary education", although their highest completed level of education would be "graduated high school". A student from neighbouring Ontario who also completes only grade 11 does not have a CEGEP option; thus the Ontario student's highest education attained (and completed) is "less than high school". It is this lack of comparability that leads many researchers to exclude Quebec observations from their sample, which is also the approach adopted here. Specifically, students who reported Quebec as the province of residence in Cycle 1 were excluded from the analysis, resulting in the deletion of 4,450 observations.

\section{A.2 Dropping records without completed parent survey}

For the purposes of this study, information from both the parent and student surveys was used. While almost all students who were invited to participate did so, a significant number of parents did not $(3,171)$. Recall that the parent survey was the primary source of information about family income, immigrant status, family structure, and other family background variables. There are other sources of data about family background, specifically the PISA student survey. Here, students were asked questions about immigrant status, parental education and occupation, and family status as well as questions regarding household possessions. In principle, then, family background variables could be constructed from the student PISA survey, where the response rate was very high, rather than from the parent survey which suffered from a lower response rate

However, the trade-off is that the information contained in the student survey is in some cases of lower quality than in the parent survey. For example, household income is not directly available. Instead, a measure of "wealth" is created from questions about: the availability of a dishwasher, a room of one's own, educational software and the internet; and the number of cell phones, TVs, computers, cars and bathrooms in one's house. This measure of wealth is only moderately correlated $(0.36)$ with the family income variable that is directly measured in the parent survey. Further, while this construction of 
wealth has sufficient variation between countries to serve as an explanatory variable, the variation within Canada is small, as many Canadians have access to a dishwasher, the internet, etc. Without sufficient variation, this wealth construct cannot explain much. [also want to make direct comparisons to the research of Finnie, Drewes, and others, who used the YITS income measure]

Another variable of concern from the PISA survey is the parental education variable. It is derived from questions which do not distinguish between college and university, but simply ask whether or not a parent has completed different levels of high school, and whether or not a parent had any tertiary education. The distinction between college- and university-educated parents has been shown to be statistically important in numerous papers, and the loss of information in using the PISA construct makes it difficult to justify.

In some cases, the questions asked are similar across the YITS and PISA surveys, but the responses differ depending on whether it is the student or the parent who is responding. For example, Table A.1a below shows the cross tabulation between the parent's and student's responses to "was the child born in Canada", which is the definition of immigrant used in this paper. Clearly this comparison is only possible for cases where the parent has responded to the survey. $8.3 \%$ of student who report being an immigrant are in conflict with their parent's response.

Table A-1a: Immigrant Status of Student. "Is the student a Canadian citizen by birth?"

\begin{tabular}{llll}
\hline & \multicolumn{2}{l}{ Parent Survey (YITS) } & \\
\hline Student Survey (PISA): & YES & $\begin{array}{l}\text { NO } \\
\text { (student is an immigrant) }\end{array}$ & Total \\
& & $45(0.2)$ & 100.0 \\
YES & $20,506(99.8 \%)$ & 100.0 \\
NO & $102(8.3)$ & $1122(91.7)$ & \\
(student is an immigrant) & & & \\
\hline
\end{tabular}

There is a similar conflict in responses regarding family status, where students are more likely to report coming from an intact family than their parents. This is shown in Table A.1b. The source of this conflict may be in the differences in framing of the question. The PISA questionnaire asked students "who usually lives at home with you?" From these responses, a family status variable was derived so that the students' family structure fell into one of four categories: "single", "nuclear", "mixed" and "other". For the purposes of this research, these four possible responses were further collapsed into two intact (nuclear), or not intact. The YITS questionnaire, on the other hand, asked parents a long and complicated series of questions about family structure. The family structure variable provided by the survey was derived, and included 23 categories. Again, these 
were collapsed into only two categories for the purposes of this paper - intact (living with both biological parents) or not. As Table A.1b indicates, there is some disagreement between parents and students about family status; of the students who reported coming from an intact family, $15 \%$ had parents who reported that the family was not intact.

Table A-1b: Family Status

\begin{tabular}{llll}
\hline & \multicolumn{3}{l}{ Family Status (Parental Report) } \\
\hline Student Survey (PISA) & Intact & Not Intact & Total \\
Intact (Nuclear Family) & 0.85 & 0.15 & 100 \\
Not Intact & 0.03 & 0.97 & 100 \\
\hline
\end{tabular}

For the purposes of this research, the decision was made to use the information from the parent survey, as family income and parental education are key variables of interest. Records without a parent survey were therefore dropped from the analysis, even though they represent almost $13 \%$ of the original sample, and despite the fact that there is sometimes subsequent information about the student. The omission of these parents from the survey introduces selection bias, and should be explicitly considered. Table A.2 shows the average characteristics of these two groups over a number of domains. Since demographic information from the parent survey is not available for non-responders, comparable information is taken from the PISA student survey (as discussed above) for both groups.

Table A-2. Average Characteristics on Parent Non-Responders versus Parent Responders in Cycle 1

\begin{tabular}{|c|c|c|}
\hline & $\begin{array}{l}\text { No parent survey } \\
\text { (student_weightc1) }\end{array}$ & $\begin{array}{l}\text { With parent survey } \\
\text { (student_weightc1) }\end{array}$ \\
\hline Observations & 3,171 & 22,066 \\
\hline \multicolumn{3}{|l|}{ Immigrant (PISA): } \\
\hline Student born in Canada (NO) & 0.21 & 0.09 \\
\hline Mother born in Canada & 0.38 & 0.23 \\
\hline Father born in Canada & 0.40 & 0.25 \\
\hline Intact & 0.63 & 0.73 \\
\hline Reading score (PISA) & 510 & 535 \\
\hline \multicolumn{3}{|l|}{ Home language (PISA): } \\
\hline Language of test & 0.77 & 0.9 \\
\hline Other official language & 0.02 & 0.02 \\
\hline Other & 0.2 & 0.08 \\
\hline Present by Cycle 6 (YITS) & 0.20 & 0.39 \\
\hline
\end{tabular}

Table A.2 indicates that there are significant differences between groups. Parents who did not respond to the parent survey are more likely to be immigrants and to speak a 
language at home that is neither French nor English. They are also less likely to be from a nuclear (intact) family. Further, students from families that did not submit the parent survey in Cycle 1 are less likely to remain in the survey until Cycle 6 . Almost $40 \%$ of students whose parents completed the parent survey continued as participants until Cycle 6 compared to only $20 \%$ of students whose parents did not complete the survey.

\section{A.3 Attrition Analysis}

Table A-3. Comparing average characteristics of survey leavers and survey participants

\begin{tabular}{|c|c|c|c|c|c|}
\hline & \multirow{2}{*}{$\begin{array}{c}\begin{array}{c}\text { Cycle } 1 \\
\text { (C1 weights) }\end{array} \\
\text { Initial sample }\end{array}$} & \multicolumn{2}{|c|}{$\begin{array}{c}\text { Cycle 2 } \\
\text { (C1 weights) }\end{array}$} & \multicolumn{2}{|c|}{$\begin{array}{c}\text { Cycle } 3 \\
\text { (C2 } 2 \text { weights) }\end{array}$} \\
\hline & & Leavers & Particip. & Leavers & Particip. \\
\hline Observations & 22,066 & 1427 & 20,639 & 3,055 & 17,584 \\
\hline Male & $\begin{array}{l}0.5 \\
(0.5)\end{array}$ & $\begin{array}{l}0.5 \\
(0.5)\end{array}$ & $\begin{array}{l}0.5 \\
(0.5)\end{array}$ & $\begin{array}{l}0.51 \\
(0.5)\end{array}$ & $\begin{array}{l}0.49 \\
(0.5)\end{array}$ \\
\hline Family income & $\begin{array}{l}71364 \\
(69797)\end{array}$ & $\begin{array}{l}66206 \\
(98091)\end{array}$ & $\begin{array}{l}71728 \\
(67342)\end{array}$ & $\begin{array}{l}66728 \\
(58325)\end{array}$ & $\begin{array}{l}72727 \\
(68721)\end{array}$ \\
\hline Reading score & $\begin{array}{l}532 \\
(96)\end{array}$ & $\begin{array}{l}497 \\
(101)\end{array}$ & $\begin{array}{l}534 \\
(95)\end{array}$ & $\begin{array}{l}509 \\
(96)\end{array}$ & $\begin{array}{l}539 \\
(93)\end{array}$ \\
\hline Grade age 15 & $\begin{array}{l}3.08 \\
(1.1)\end{array}$ & $\begin{array}{l}2.75 \\
(1.18)\end{array}$ & $\begin{array}{l}3.1 \\
(1.09)\end{array}$ & $\begin{array}{l}2.82 \\
(1.12)\end{array}$ & $\begin{array}{l}3.15 \\
(1.08)\end{array}$ \\
\hline Intact & $\begin{array}{l}0.71 \\
(0.45)\end{array}$ & $\begin{array}{l}0.54 \\
(0.5)\end{array}$ & $\begin{array}{l}0.72 \\
(0.45)\end{array}$ & $\begin{array}{l}0.61 \\
(0.49)\end{array}$ & $\begin{array}{l}0.74 \\
(0.44)\end{array}$ \\
\hline Immigrant & $\begin{array}{l}0.1 \\
(0.3)\end{array}$ & $\begin{array}{l}0.13 \\
(0.34)\end{array}$ & $\begin{array}{l}0.1 \\
(0.3)\end{array}$ & $\begin{array}{l}0.12 \\
(0.32)\end{array}$ & $\begin{array}{l}0.1 \\
(0.3)\end{array}$ \\
\hline Parental ed. & $\begin{array}{l}2.88 \\
(0.9)\end{array}$ & $\begin{array}{l}2.74 \\
(0.96)\end{array}$ & $\begin{array}{l}2.88 \\
(0.9)\end{array}$ & $\begin{array}{l}2.74 \\
(0.94)\end{array}$ & $\begin{array}{l}2.91 \\
(0.89)\end{array}$ \\
\hline Hope university & $\begin{array}{l}0.65 \\
(0.48)\end{array}$ & $\begin{array}{l}0.6 \\
(0.49)\end{array}$ & $\begin{array}{l}0.65 \\
(0.48)\end{array}$ & $\begin{array}{l}0.62 \\
(0.49)\end{array}$ & $\begin{array}{l}0.66 \\
(0.47)\end{array}$ \\
\hline
\end{tabular}




\section{Appendix 2.B: Using Math Scores in Addition to Reading Scores.}

The main testing domain of PISA 2000 was reading. As a result, every YITS participant had the opportunity to write the PISA reading test In addition, a fraction of the students $\left(5 / 9^{\text {th }}\right)$ were also given the opportunity to write the PISA math test. The bulk of this research used the PISA reading score as the proxy for cognitive skills, for reasons elaborated previously. The purpose of this appendix is to examine the relationship between math scores, gender and outcomes for the subsample who participated in the math test. Notably, the relationship between math and reading scores is positive and strong, with a correlation coefficient is 0.6567 . However, a scatterplot of the scores reveals significant outliers. It is then of interest to examine the relationship between skills and outcomes when the cognitive skills score is measured by both reading and math.

Recall that girls outperformed boys in the reading test by a wide margin (refer to Table 51). In the math test, as indicate in Figure B-1, boys outperformed girls on average, although by a smaller margin.

Table B-1. Average score (standardized) on the PISA math test by gender.

\begin{tabular}{llll}
\hline & Mean Score & Std. Dev. & Frequency \\
\hline Girls & -0.037 & 0.98 & 5,040 \\
Boys & 0.047 & 1.06 & 4,747 \\
\hline
\end{tabular}

One objective of this appendix is to identify the top performing students on both the PISA math and reading test. For the purposes of this study, top performers in math are those who achieved a raw score of at least 625 on the PISA math test, while top performers in reading are those with a score of more than 645 on the PISA reading test ${ }^{44}$. Table B-2 shows the frequency of top performance, by gender. While $12.9 \%$ of girls qualify as top performers in reading, only $8.7 \%$ of boys performed well enough on the reading test to end up in this category. The results for the math scores are almost the mirror-image of those for reading; $12.7 \%$ of boys qualify as high performers in math, while only $8.9 \%$ of girls fall into this category. The last column of the table indicates the fractions of the male and female populations that end up in the high performance categories for both reading and math. There is very little gender gap here, with $4.8 \%$ of

\footnotetext{
${ }^{44} 10.7 \%$ of the population who participated in the math test achieved a score of at least 625 in math. $10.1 \%$ of the population who participated in the math test achieved a score of least 645 in reading. Note that the entire analysis of this appendix is based on the subsample who wrote the math test, approximately $5 / 9$ ths of the sample who wrote the reading test.
} 
boys and $4.4 \%$ of girls scoring at the top end of the distribution in both math and reading tests. $^{45}$

Table $B$-2. Frequency of top performance in reading and math, by gender

\begin{tabular}{|l|l|l|l|}
\hline & $\begin{array}{l}\text { High in } \\
\text { Reading }\end{array}$ & $\begin{array}{l}\text { High in } \\
\text { Math }\end{array}$ & High in Reading and Math \\
\hline Boys & 0.087 & 0.127 & 0.048 \\
\hline Girls & 0.129 & 0.089 & 0.044 \\
\hline
\end{tabular}

The second objective of this appendix is to examine the distribution of grade outcomes for this group of high performing students (in both math and reading). Recall that the distribution of grade outcomes amongst students who performed in the top of the reading score distribution differed by gender. Specifically, girls who scored in the top $10 \%$ in the PISA reading test were substantially more likely to report an overall grade in the 80 s or in the 90 s than boys who also scored in the top $10 \%$ in reading (refer to Table $2.7 \mathrm{a}$, reproduced here for reference). In this appendix, the results from Table $2.7 \mathrm{a}$ are reproduced using the top $10 \%$ of performers on both the PISA math and reading tests.

These results are shown in Table B-3.

Table 2.7a. Distribution of overall grades of top performers in reading, by gender

\begin{tabular}{|c|c|c|c|c|c|c|}
\hline & \multicolumn{5}{|c|}{ Grade in Final Year of $\mathrm{HS}$} & \multirow[b]{2}{*}{ Total } \\
\hline & $<60 \mathrm{~s}$ & $60 s$ & $70 s$ & $80 \mathrm{~s}$ & 90s & \\
\hline Female & 0.1 & 2.6 & 14.0 & 52.0 & 31.3 & $60.7 \%$ \\
\hline Male & 0.2 & 4.0 & 26.0 & 44.9 & 24.9 & $39.3 \%$ \\
\hline Difference (Male-Female) & 0.1 & 1.4 & 12.0 & -7.1 & -6.4 & 21.4 \\
\hline
\end{tabular}

Source: Youth In Transition Survey. Author's calculations.

Table B-3. The distribution of overall grades of top performers in both math and reading, by gender

\begin{tabular}{|l|l|l|l|l|l|l|}
\hline & $<\mathbf{6 0 s}$ & $\mathbf{6 0 s}$ & $\mathbf{7 0 s}$ & $\mathbf{8 0 s}$ & $\mathbf{9 0 s}$ & Total \\
\hline Female & $\mathrm{xx}$ & $\mathrm{xx}$ & 7.9 & 45.9 & 45.3 & $49.6 \%$ \\
\hline Male & $\mathrm{xx}$ & $\mathrm{xx}$ & 21.1 & 39.1 & 34.7 & $50.4 \%$ \\
\hline Difference (Male-Female) & $\mathrm{xx}$ & $\mathrm{xx}$ & 13.2 & -6.8 & -10.6 & $0.8 \%$ \\
\hline
\end{tabular}

Source: Youth In Transition Survey. Author's calculations.

$\mathrm{xx}$ - results are suppressed because cell counts fell below the thresholds set by Statistics Canada

These results are qualitatively similar to those presented using reading scores as the measure of cognitive skills. Specifically, boys and girls who score at the top end of the distribution in both math and reading, end up with substantially different overall grade

${ }^{45}$ Alternatively, the results indicate that $49.6 \%$ of high performers in both math and reading are girls and $50.4 \%$ are boys. 
outcomes. Specifically, girls who perform at the top end of the distribution in both math and reading tests are more than 10 percentage points more likely to report a grade in the 90 s than boys who are high performers in both math and reading. This gender gap in overall grade outcomes in evident in the $80 \mathrm{~s}$ as well, with high-performing girls being 6.8 percentage points more likely to be in this grade category than high performing boys.

The final objective of this appendix is to substantiate the claim made earlier in the paper that the gender gap would be harder to explain if math scores were taken into account in the measure of cognitive skills. Intuitively, this is because boys do better than girls in math - adding math scores to the analysis would not explain why boys do not perform as well as girls overall, when their math scores exceed those of girls. The stepwise regression analysis is reproduced in Figure B-4, in this case using both math and reading as measures of cognitive skills. Columns (A'), (B') and (C') reproduce the results from the first three columns of Table 2.8. Column (D') adds math scores to the analysis. When math scores are added to the regression, the coefficient on gender increases (in absolute value) to -0.591 . When both math and reading are used to measure cognitive skill, gender has a larger direct role to play than when only reading is used to measure cognitive skills. $^{46}$ This is because boys lead girls in PISA math scores. In this sense, the gap between girls and boys in terms of overall grade outcomes is harder to explain. In Column (E') all non-cognitive skills are added to the regression model. As noted in Table 5-4, the addition on non-cognitive skills reduces the coefficient on gender, although it is still statistically significant, and substantial in size.

\footnotetext{
${ }^{46}$ Note that the standard error increases with the addition of math scores. This is because of the much smaller subsample of students who wrote the PISA math test.
} 
Table $B-4$. Ordered logit results using math and reading as the measure of cognitive skills.

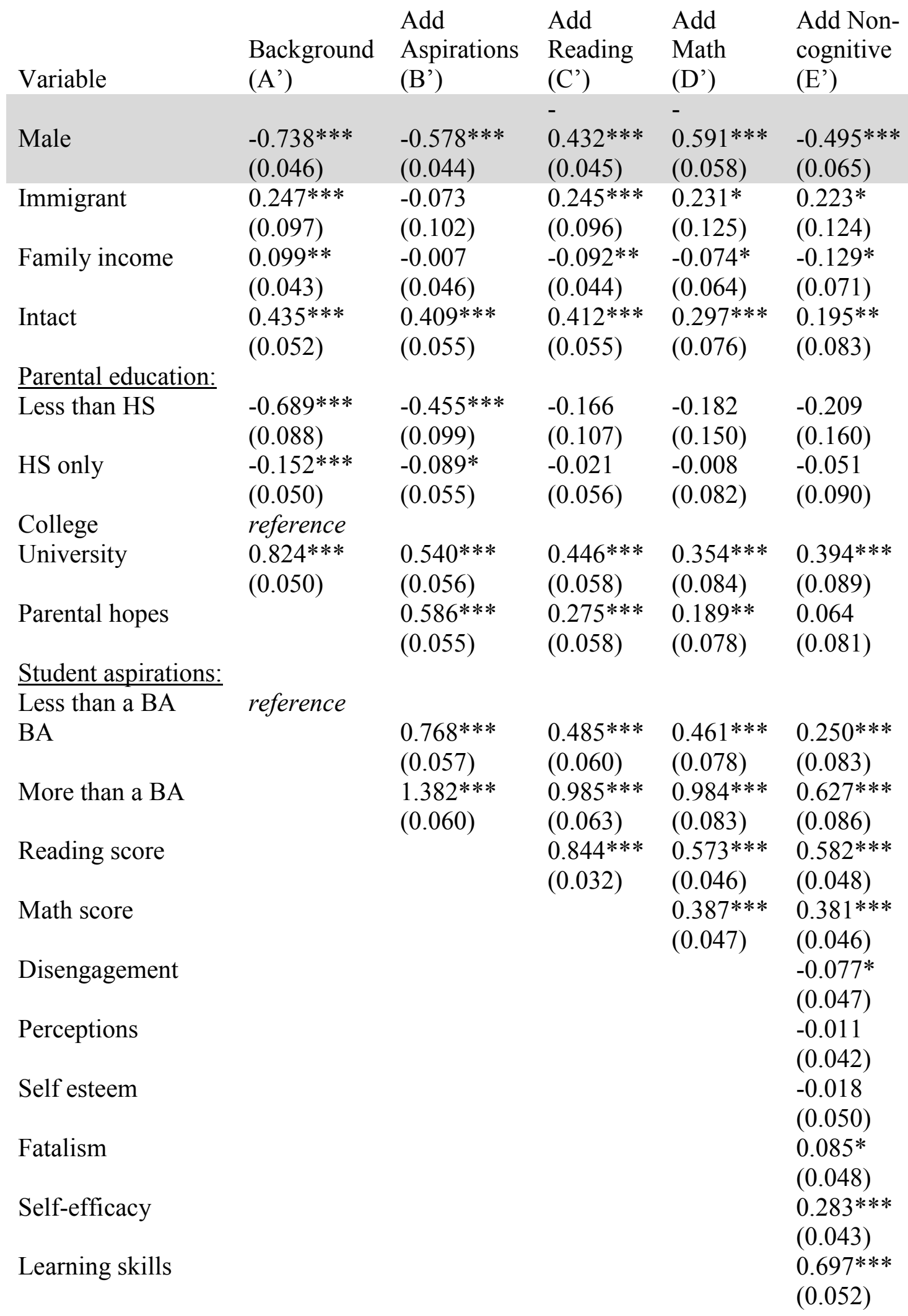




\section{Appendix 2.C: Factor Analysis to Identify Latent Factors:}

Factor analysis is used in this paper to reduce the number of dimensions in the data. The YITS provides information about students' experiences in high school through a long series of questions, from both the YITS survey and the associated PISA student survey. It is not possible to include every question in the regression analysis, so factor analysis is used to analyse patterns of correlation between multiple indicators in order to infer their relationship to an underlying "latent" variable. ${ }^{47}$ This is a way to create an index which is a linear combination of the observed variables.

There are a number of approaches to factor analysis, including principal component analysis, and principal factor analysis. Principal component analysis assumes that the commonality is equal to 1.0. This is often an unrealistic assumption and is particularly so with respect to the data studied here. For this reason, principal factor analysis is used here.

The output from the factor analysis indicates that there are three latent factors. This is determined by a scree test, which plots the eigenvalues associated with the factor analysis, as shown in Figure C-1. The conventional criterion is to keep (select) the factors up until the line becomes flatter, which in this case occurs after the third factor. Thus, I construct three indexes in order to capture as much information as possible from the long list of questions with the minimum number of indicators.

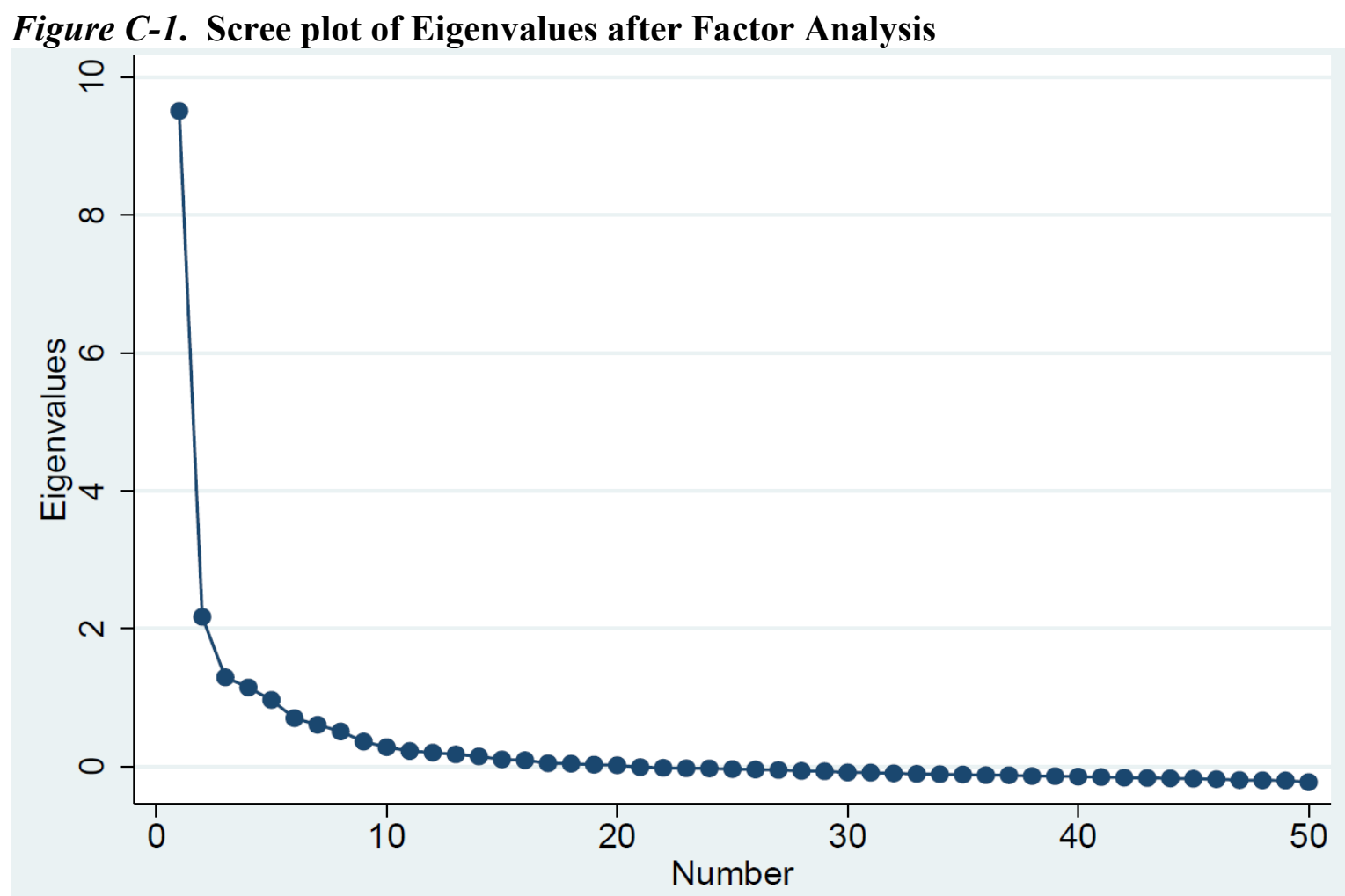

${ }^{47}$ From http://www.albany.edu/faculty/kretheme/PAD705/SupportMat/FactorAnalysisTheory.pdf 
In order to construct the indices, I use the first rotation (varimax) to identify the factors on which each of the questions loads. This output is available on request. Having identified the factor loadings, they are verified using Cronbach's alpha, with a cut-off criterion of 0.7 . This is also available on request. The indexes are then constructed using regression analysis. The factor loadings from the first rotation guide the choice of regressors. Variables with loadings of 0.5 or higher on a given factor are included in the regression analysis for each factor. The index construction, including weighting of each variable, is shown in Figure C-2

Figure C-2. Creating the Indices Using the Results of the Factor Analysis

\begin{tabular}{|c|c|c|}
\hline Variable Name & Question & Weight \\
\hline \multicolumn{3}{|l|}{ Learning Skills: } \\
\hline YSA8A & I paid attention to the teacher & 0.16 \\
\hline ST32Q01 & I completed my assignments & 0.32 \\
\hline YSA8F & $\begin{array}{l}\text { When school work was difficult I stopped trying } \\
\text { (reverse) }\end{array}$ & 0.18 \\
\hline YSA8G & $\begin{array}{l}\text { I did as little work as possible; I just wanted to get } \\
\text { by (reverse) }\end{array}$ & 0.23 \\
\hline YSA8B & I completed my homework on time & 0.27 \\
\hline \multicolumn{3}{|l|}{ Disengagement: } \\
\hline ST31Q08 & My school is a place where I often felt bored & 0.2 \\
\hline ST31Q07 & My school is a place where I did not want to go & 0.22 \\
\hline YSA9L & School was often a waste of time & 0.25 \\
\hline YSA9H & $\begin{array}{l}\text { Most of the time I would have like to be anyplace } \\
\text { else }\end{array}$ & 0.31 \\
\hline YSA8J & $\begin{array}{l}\text { I was interested in what I was learning in class } \\
\text { (reverse) }\end{array}$ & 0.2 \\
\hline \multicolumn{3}{|l|}{ Perceptions of } \\
\hline \multicolumn{3}{|l|}{ Teachers: } \\
\hline YSA8I & I got along well with teachers & 0.23 \\
\hline YSA9N & Most of my teachers did a good job of teaching & 0.22 \\
\hline YSA9G & $\begin{array}{l}\text { Most of my teachers don't really care about me } \\
\text { (reverse) }\end{array}$ & 0.21 \\
\hline ST30Q03 & $\begin{array}{l}\text { Most of my teachers really listened to what I had to } \\
\text { say }\end{array}$ & 0.26 \\
\hline ST30Q05 & Most of my teachers treated me fairly & 0.25 \\
\hline
\end{tabular}

After the creation of the indices, the raw scores were standardized to have a mean of zero and a standard deviation of 1 . This makes all scales comparable, and makes the interpretation of coefficients in the regression analysis for which these were constructed straightforward.

In addition, three measures of psychological capital were used, as described below. These measures are taken directly from the psychology literature, and have been 
validated over numerous studies. All of these scales are constructed by simply summing the responses, and then standardizing to have a mean of zero and a standard deviation of 1.

\section{$\underline{\text { Self-Esteem YSI1 series }}$}

This series is based on the Rosenberg Self-Esteem Scale (Rosenberg, 1965), which is considered a reliable and valid quantitative tool for self-esteem assessment. Individuals are asked to consider the following statements and respond according to $1=$ strongly disagree, $2=$ disagree, $3=$ agree, $4=$ strongly agree.

(YSI1)A I feel I am a person of worth, at least equal with others

B I feel I have a number of good qualities

* $\quad$ C All in all, I tend to feel I am a failure

D I am able to do things as well as most other people

* E I feel that I don't have much to be proud of

F I have a positive attitude toward myself

G On the whole, I am satisfied with myself

* H I wish I could like myself more

* I I certainly feel useless at times

* J At times I feel I am not good at all

Statements with an asterisk are reverse scored. Responses are summed, with a higher total indicating a higher level of self-esteem.

\section{$\underline{\text { Locus of Control YSI2 series }}$}

Locus of control, sometimes referred to as mastery, concerns the extent to which one regards one's life-chances as being under one's own control in contrast to being externally determined (Pearlin and Schooler, 1978:5). The inverse of this concept is fatalism.

These YITS questions, based on Rotter's (1966) original survey, were modified by Pearlin and Schooler, 1978) To obtain a measure of LOC, individuals are asked to consider the following statements, and respond according to $1=$ strongly disagree, $2=$ disagree, $3=$ agree, $4=$ strongly agree. 
(YSI2)A Sometimes I feel I am being pushed around in life

* B What happens to me in future mostly depends on me

C There is really no way I can solve some of the problems I have

D There is little I can do to change many of the important things in my life

E I often feel helpless in dealing with problems of life

F I have little control over the things that happen to me

* G I can do anything I set my mind to

Statements with an asterisk are reverse scored. Responses are totalled, with a higher score corresponding to a more external orientation, or a higher degree of fatalism.

\section{Academic Self-Efficacy YSA8K,L,M,N}

This concept measures the student's confidence in performance of class work, as perceived by the student. Students are asked to consider the following statements, and respond according to $1=$ never, $2=$ rarely, $3=$ sometimes, $4=$ often, $5=$ =always.

(YSA8)K I am certain I can understand the most difficult material presented in texts

L I am confident I can understand the most difficult material presented by the teacher

M I am confident I can do an excellent job on assignments and tests

$\mathrm{N}$ I am certain I can master the skills being taught

The responses are totalled, a higher sum indicating a higher measure of self-efficacy 


\section{Chapter: The Role of Gender in PSE Participation in Canada}

\subsection{Introduction}

The gender gap in post-secondary education participation in Canada is well-documented (e.g., Foley, 2017). This gap has persisted for the last two decades, with women currently making up almost $60 \%$ of the university campus population (e.g., Frenette and Zeman, 2008). As discussed in Bennet (2017), there is a similar gender gap in high school performance, with girls being substantially more likely than boys to be awarded university bound grades - e.g., grades in the 80 s and in the $90 \mathrm{~s}-$ in the final year of high school. Much of this gap in high school grades can be accounted for by the lower skill levels - both reading skills and non-cognitive skills - and lower aspirations of boys, accompanied by the lower educational expectations their parents hold for them. A significant fraction of the gap, however, remains unexplained; being male is associated with a substantial grade penalty in the final year of high school, which is unexplained by skills or aspirations or family characteristics.

The key question that this research addresses is to what extent the gender gap that is observed in participation in post-secondary education (PSE), particularly in university participation, is explained by outcomes in the senior year of high school. Clearly overall senior high school grade is an important, if not the most important, determinant of PSE participation, as high school marks are the primary mechanism by which admissions are allocated, particularly at universities. Once academic performance in the senior year of high school is taken into account, is there any further role for gender in explaining the gap in PSE participation? It is clear that there are skills and aspirations differences between boys and girls. Do these differences play any direct role in the decision to participate in post-secondary education, or do they work only indirectly through the lower grades that boys achieve in the senior year of high school?

The data used in this research come from the Youth in Transition Survey (YITS). The analysis focuses on the subsample of respondents who participated in all six cycles of the survey. This provides a continuous set of data from ages 15 to 25 . Although there is significant attrition throughout the survey, a detailed analysis confirms that the sample that remains by the final cycle is representative of the original target population, when weighted. By using the sample of respondents who participated in all six cycles of the survey, this research is able to consider both the short term determinants of participation 
in post-secondary education (PSE) - that is, for those who move directly to postsecondary studies without any gap years - as well the longer-term determinants.

The data provided in the YITS allows for the inclusion of many explanatory variables that are unique in the study of PSE participation. Detailed questions about engagement, persistence and psychological traits such as self-esteem allow for the construction of a number of measures that cover many facets of non-cognitive skills. In addition, the YITS provides information about family background, such as family income and family structure at age 15, as well as the students' educational aspirations. Finally, through the linkage of the YITS survey to the Programme for International Student Assessment (PISA) reading test, this study is also able to include individual reading scores, which provide a cognitive skills benchmark.

This research has a number of objectives. First, it documents the evolution of postsecondary education participation by gender over time. It identifies a gender gap in university participation, beginning when the students are 19 years old and continuing until the final cycle of data collection at age 25. This analysis then goes on to document gender-based differences in various factors associated with participation in PSE. Gender gaps are identified in academic performance in the senior year of high school, as well as in skills and aspirations. Boys lag girls in reading skills, school engagement, and noncognitive skills related to motivation and perseverance, as well as in aspirations for postsecondary education. Finally, various empirical techniques are used to examine the statistical importance of these factors in determining participation in post-secondary education, both directly from high school and over a longer time horizon, with a specific focus on the importance of skills, aspirations and gender.

The results of this analysis suggest that, controlling for senior grade, gender plays only a small direct role in post-secondary education participation, specifically amongst students with grades in the $70 \mathrm{~s}$. Gender continues to play an indirect role in two ways: first, through its influence on grade in the senior year of high school, which is a primary determinant of university participation; and second, through its influence on skills and aspirations, factors which differ significantly by gender and which are also key determinants of post-secondary education participation. In addition, this study finds that the roles of these factors are not fixed over time; students' aspirations, for example, are more important in determining long-run than short run participation; conversely, cognitive skills play a larger role in explaining participation in short-run than in the longrun.

The balance of this paper is organized as follows. Section 2 provides a review of the literature. The data is discussed in Section 3. This includes a description of the YITS and a discussion of the sample restrictions implemented, which includes an analysis of the survey's attrition. In addition, Section 3 provides a detailed discussion of the study 
design, with descriptions of the dependent and explanatory variables used. Section 4 describes the methodology, followed by the empirical results in Section 5. Section 5 includes the stepwise regression results, as well as robustness checks. The conclusions are presented in Section 6.

\subsection{Literature Review}

This research builds on the work of Bennet (2017), which focused on the importance of aspirations and skills, especially non-cognitive skills, in explaining the gender gap in high school performance. Girls obtain "university bound" grades - in the 80 s and in the $90 \mathrm{~s}-$ at a substantially higher rate than boys, potentially explaining some, if not all, of the gender gap in university participation. Bennet attempted to determine the extent to which the gender gap in high school outcomes can be explained by differences in skills and aspirations, with a specific focus on non-cognitive skills. ${ }^{48}$

Specifically, Bennet documented significant gender gaps in reading skills, over some facets of non-cognitive skills, and in aspirations for post-secondary education. The results of Bennet suggest that these are statistically significant and substantial factors in the determination of overall high school grade. However, while these factors played important roles in the production of high school academic achievement, they did not fully explain the observed gender-gap in high school outcomes, leaving a significant role for gender itself. This is the departure point for the current research. Conditioning on grade in the senior year of high school, this study examines the direct effects of gender, skills (including non-cognitive skills), aspirations, and background variables on the decision to participate in post-secondary education.

Card, Payne and Sechel (2011) also look at the critical transition point between high school and university. They use data from the Ontario University Application Centre (OUAC) combined with school level data on grade 9 math scores, as well as census data on neighbourhood characteristics, to examine how the application behaviour of Ontario high school students differs by gender from 1991-2004. Although they do not use individual-level micro-data, their findings are nonetheless compelling. They find that, while application rates to Ontario universities vary significantly by school, the gender gap in applications is similar across high schools, with girls applying to Ontario universities at a rate, on average, 10 percentage points above that of boys. Of particular

48 Bennet (2017) constructed numerous measures of non-cognitive skills, including measures of psychological capital that routinely appear in the literature, as well as other measures that are specific to the YITS. 
note is their finding that the bulk of the gender difference in OUAC applications comes from lower-end-GPA applicants.

This research is also inspired by the work of Frenette and Zeman (2008). ${ }^{49}$ In their work, which also uses the YITS, participation in university education (by age 19) is the outcome variable of interest, and is explained by a variety of skills measures, family background and peer group measures, all derived from data collected at age 15 . Of particular note is the emphasis their research places on the role of non-cognitive skills in determining university participation. They find that, using standard decomposition techniques, more than half of the gender gap in university participation is explained by differences in observable characteristics, with much of this being attributed to differences in endowments of non-cognitive skills.

As in Frenette and Zeman, this research assigns a significant role to non-cognitive skills. However, this research differs significantly from Frenette and Zeman in the approach taken in the identification and measurement of non-cognitive skills. While Frenette and Zeman used hours spent on homework and whether or not students repeated a grade to capture non-cognitive skills, the research presented in this paper uses a measure of noncognitive skills that is constructed from the wealth of questions included in the YITS which pertain to conscientiousness, perseverance, engagement and other measures of psychological capital.

As discussed in detail in Bennet (2017), the current research is also inspired by a number of other papers: Fortin, Oreopoulos and Phipps (2015), who focused on the evolution of educational aspirations of high school seniors in the US, over three decades beginning in the 1980s; Goldin, Katz and Kuziemko (2006) who examined the cultural changes that have taken place since the 1960s, and their relationship to educational outcomes among US high school students; Cho (2007) who studied high school course composition and non-cognitive skills; and Foley (2017) and Bertrand and Pan (2013), who examined the importance of parental educational expectations and family structure, respectively, in the formation of high school grades.

\footnotetext{
${ }^{49}$ Frenette and Zeman follow the same basic methodology as Jacob (2002) who considered the role of noncognitive skills in the context of US college participation.
} 


\subsection{Data}

\subsubsection{Survey description}

The data used in this research comes from the Youth in Transition Survey (YITS). The YITS is a unique longitudinal data set that provides micro-level information about Canadian youth who were 15 years old in 2000. Students from 1,200 randomly selected schools from across Canada were invited to participate in the baseline survey, which was administered in 2000. Students were re-surveyed every two years thereafter until the final (sixth) cycle in 2010. Thus the survey attempted to follow the initial cohort of 15 year olds until age 25 , and documented the evolution of their educational and labour market participation, as well as their early transitions to adulthood and families of their own.

During the initial baseline survey, students, their parents, and their school principals were asked to complete surveys that provided comprehensive information about family demographics, school resources, and student experiences in high school. At the same time, students also participated in PISA reading and math tests, which were administered by the Organization for Economic Cooperation and Development (OECD). As reading was the main testing domain in PISA 2000, the reading test is of particular interest to this research. ${ }^{50}$ This test was designed to assess many components of literacy, beyond curriculum attainment, and provides a benchmark for cognitive abilities.

Every two years thereafter, only students were re-surveyed. Information was collected in each cycle about their high school experiences and transitions into post-secondary education and/or the labour market. In addition, students were asked detailed questions about their skills, attitudes and performance in high school and beyond. This included questions about learning skills, psychological traits such as self-esteem, and feelings of academic and social engagement. Moreover, their participation in post-secondary education was followed until age 25, and information about field of study, changes of programme or institution, and completion of studies was collected in each cycle.

This survey then provides a rich set of variables to use in the examination of the determinants of participation in PSE. The data provides information about family income, socio-demographic variables and high school performance, along with a wide variety of questions relating to both cognitive and non-cognitive skills.

${ }^{50} 5 / 9^{\text {th }}$ of students were given the opportunity to write a test in Math, another $5 / 9^{\text {th }}$ a test in Science, with a subset (2/9ths) writing both. 


\subsubsection{Restrictions}

Initially, almost 30,000 respondents from the ten Canadian provinces were asked to participate. Because of the unique CÉGEP system that exists in Quebec, students who reported Quebec as their province of residence in Cycle 1 were dropped from the analysis. This resulted in the deletion of 4,450 observations. In addition, student records which did not include a parent survey (3,171 observations) were dropped from the sample. A full discussion of this decision is provided in Appendix A of Chapter 2. This leaves an initial sample of 22,066 respondents in Cycle 1 (2000).

For the purposes of this research, which focuses on individuals' decisions to participate in post-secondary education, the population of interest is the respondent population as of Cycle 6. For these individuals, there is a complete 10 year history of high school and post-secondary education participation (where applicable) spanning the ages 15-25. This final sample numbers 8,570 respondents, much smaller than the initial sample in Cycle 1, as there was steady attrition throughout all cycles of the survey. However, the longitudinal weights provided by Statistics Canada are sufficient to maintain the generalizability of the Cycle 6 sample to the initial target population. Appendix A provides a full discussion of respondent attrition over the life of the survey.

\subsubsection{Study design}

\section{Outcome variable: Participation in post-secondary education}

This research examines participation in post-secondary education as the outcome variable of interest. Students are asked in each cycle to answer questions about the highest level of education they have taken (as distinct from highest education attained). For the purposes of this research, these responses are categorized into four groups:

- No PSE: less than high school graduation, which includes all levels of schooling below a high school diploma;

- No PSE: high school graduation;

- at least some college education; and

- at least some university education.

For the college and university categories, it is not necessary for the student to have completed the program, but simply to have taken some courses toward completion. Note that if a student has taken both college and university courses, it is the highest taken that is documented here, which is assumed to be university. A full discussion of the construction of this variable can be found in the Appendix B. 
In order to explore the determinants of participation in PSE, it is important to establish the time frame of the study, as the picture of participation in post-secondary education may change as students age. Figure 3.1 shows the evolution of participation in postsecondary education from Cycle 3 (when students are 19 years old, the first survey year in which most of the students are old enough to be in university) to Cycle 6, which is the last cycle of the survey (students are 25 years old in this final cycle). In Cycle 3, less than $40 \%$ of these respondents reported having attended university, while $10 \%$ report that they have not yet graduated from high school. By Cycle 6 , only $3 \%$ of respondents reported less than high school graduation as the highest level of education taken, while half attempted at least some university courses. Notably, the rates of both college and university participation are increasing over time. ${ }^{51}$ Recall that the sample being considered here are the students who have responded to all six cycles of the survey, so that whether it is Cycle 3 or Cycle 6 participation that is being considered, it is always using the same sample of respondents.

The evolution of participation in post-secondary education differs significantly by gender, as indicated in Figures 3.2a, b and c. Note that in Figure 3c, the "No PSE: less than high school graduation" and "No PSE: high school graduation" categories have been combined into one group called "No PSE". While participation in post-secondary education is rising over time for both genders, at each cycle girls have a higher university participation rate than boys, a gap which is stable at around 15 percentage points. This gap is mirrored in the higher rates of participation in college and high school or less by boys. For example, by Cycle $657 \%$ of girls report having participated in at least some university, compared to only $42 \%$ of boys. This gap of 15 percentage points is mirrored in a higher participation rate of boys in college of 7 percentage points, and "high school or less" of 8 percentage points.

Participation is clearly fluid over time. Over the six years that pass between Cycles 3 and 6 , there are significant flows between categories. Respondents move from high school to college, from college to university, or directly from high school to university. ${ }^{52}$ It is therefore important to be clear about the point in time to which one is referring in any participation discussion. Moving forward, this research considers two distinct points in time: age 19 participation (Cycle 3), which corresponds more or less to movement

\footnotetext{
${ }^{51}$ While Figure 3-1 indicates a rising rate of college participation over time, this need not be the case. It is possible for college participation to decline, if both high school graduates and college participants shift into university participation at a rate sufficient to offset flows from high school into college. Clearly this is not the case in Figure 3-1, where flows into college are sufficiently large to produce a rising college participation rate over time.

${ }_{52}$ There are likely flows from university to college as well, but these are not picked up in the outcome variable constructed here, since university is considered to be a higher level of education than college. Thus, students who report having taken some university will still report that the highest level of education taken is university, even if they eventually change institutions to (and even graduate from) a college.
} 
directly from high school to post-secondary education with no intervening gap years; and age 25 (Cycle 6), which allows for a longer-term view of participation, with students potentially taking a number of gap years in between high school and post-secondary education, taking extra years to complete high school, or moving between post-secondary education levels.

The relationships between Cycle 3 and Cycle 6 participation are shown by gender in Table 3.1. The relationships indicated here are consistent with the gender differences that were identified in Figures $3.2(\mathrm{a}-\mathrm{c})$. For instance, of girls who reported at least some college as the highest taken in Cycle 3,23.4\% report having taken some university by Cycle 6. By comparison, of boys who report at least some college in cycle 3, only $17 \%$ report having gone on to take at least some university by Cycle 6. Similarly, of those girls (boys) who reported high school graduation as the highest taken in Cycle 3, 23.7\% $(19.5 \%)$ report having taken some university by cycle 6 . Notably, there is also a gender difference observed in the evolution of college participation. Of girls (boys) who report having less than high school graduation as their highest taken in Cycle 3, 32.5\% (24.8\%) report having gone on to at least some college by Cycle 6. This is mirrored in a large gender gap of almost 9 percentage points in those who still have not completed high school by Cycle 6 .

Since participation changes over time, it may be the case that the factors which influence the decision to participate in post-secondary education also change over time. Because different factors may be more or less important depending on the time horizon that is being considered (age 19 or age 25), the structure of this study is such that age 19 and age 25 participation are considered separately. However, the explanatory variables included in these participation equations are the same, and are described in the next section.

The primary focus of this analysis is on the role of gender in determining participation in PSE. The description, to this point, has referred to four categories of highest education taken: Less than high school; high school graduation; at least some college; and at least some university. In general it is not possible to proceed to post-secondary education without first completing high school. In some cases individuals who have left high school without graduating are able later in life to gain admission to college or university as mature students, but this is uncommon. ${ }^{53}$ Therefore, when estimating a model of participation in post-secondary education, it is implicitly conditional on having completed high school. In a sense, there is first the decision of whether or not to finish high school. Having decided to complete high school, the decision is then whether to continue on to university, attend college, or leave the education system with a "terminal" high school

\footnotetext{
${ }^{53}$ Of the $3.6 \%$ of Cycle 6 respondents who do not have a high school diploma, only $3.4 \%$ report having attended university, and $17.9 \%$ having attended college.
} 
diploma. ${ }^{54}$ Thus, the "No PSE: less than high school gradation" category will be excluded from the analysis. The dependent variable then takes only three values. The sub-sample of students who have not completed high school is examined in Appendix C.

\section{Explanatory variables.}

This study uses information taken from all six cycles of the YITS. Table 3.2 summarizes the origins of these variables. Of primary interest as an explanatory variable is the grade the student achieved in the senior year of high school. This is a derived variable that measures the categorical, self-reported grade in the last year of high school. Students were asked in Cycles 1, 2, and 3 to provide their overall grade in their last year of high school. This study takes the last reported value as the grade in the senior year, which in most cases is reported in the Cycle 3 interview, administered at age $19 .^{55}$ The categories that are used in this research are: in the 90s; in the 80s; in the 70; in the 60's; and less than $60 \%{ }^{56}$. In all reported findings, the reference group is "in the $70 \mathrm{~s}$ " so that all results for the effect of grade on participation in PSE are vis-à-vis those who reported a grade in the $70 \mathrm{~s}$.

In Bennet (2017), a production function for grade in the final year of high school was estimated, using skills, aspirations, and socioeconomic and family background measures as explanatory variables. ${ }^{57}$ In the context of the research presented here, grades appear as an explanatory variable, rather than the outcome variable. By including grade in the final year of high school, skills, aspirations, family structure, and other sociodemographic variables are also implicitly included via their influence on grade. One important question that this study addresses is whether or not there is any direct role for these factors, beyond their influence on grade in the final year of high school. Specifically, this study examines the direct effect of skills (both cognitive and non-cognitive), aspirations, family background and socioeconomic factors on participation in post-secondary education.

In order to consider the influence of non-cognitive skills, this study focuses on creating direct measures of multiple facets of non-cognitive skills, following the methodology set out in Bennet (2017). While there is a wide consensus that these skills are important in determining many long run socioeconomic outcomes (Heckman and Rubinstein, 2001), it

\footnotetext{
${ }^{54}$ A "terminal" high school diploma refers to high school graduation that is not followed by any PSE.

${ }^{55}$ In a few cases there is no value reported in Cycle 3, at age 19, so the Cycle 2 value is used.

${ }^{56}$ This final category combines three categories that were reported in the data files. Specifically, it is made up of those who reported a grade of: less than 50\%; from 50-54\% ; and from $55-59 \%$.

${ }^{57}$ The distinction between final and senior year of high school is subtle. The final year may not be the senior year for students who drop out before grade 12 . However, it is generally the case that only students who have completed grade 12 can go on to PSE. Thus, the analysis of PSE participation considers the stduents' overall grade in the senior year of high school.
} 
is not always possible to directly measure these skills. As a result, some researchers have used measures that partially impute these skills rather than measuring them directly, as in Jacob (2002) and Frenette and Zeman (2008). In addition, non-cognitive skills are multi-faceted, so that there are many different skills that can be thought of as noncognitive. Many researchers are constrained by their data to examine only one or two subsets of non-cognitive skills. Groves (2005) for example, used personality traits; Deming (2015) considered extroversion or "social skills"; Heckman, Stixrud and Urzua (2006) consider various measures of psychological capital.

The YITS data used in this study is unusual in that the questions in the survey probe many facets of non-cognitive skills. These include measures of psychological capital such as self-esteem and self-efficacy, as well as measures pertaining to school engagement, learning skills, and perceptions of teachers. Appendix B in Chapter 2 provides a full list of the questions used to construct the various skills measures, and a review of the methodology behind the construction of the skill scales. Bennet (2017) finds that some of these skills, particularly learning skills and self-efficacy, play an important role in determining high school performance. This study seeks to understand the extent to which these skills are important in determining post-secondary education participation, even after taking into account their influence on the production of grades in the final year of high school.

In addition to including measures of non-cognitive skills, this research also controls for cognitive abilities as measured by the PISA reading scores. ${ }^{58}$ The PISA reading scores are thought to measure more than curriculum learning, capturing instead the skills associated with "achieving one's goals, developing one's knowledge and potential, and participating in society." (OECD, 2017) The importance of cognitive skills in determining grade outcomes is documented in Bennet (2017). Here, as with noncognitive skills, the focus is on the extent to which cognitive skills influence participation in PSE net of their influence on high school grades.

It is sometimes argued that, because boys have lower levels of some skills that are important in determining academic performance, they also have lower levels of educational aspirations, as in Fortin et al. (2015). ${ }^{59}$ This study therefore attempts to control for aspirations as well as skills. Students are asked at age 17, prior to beginning

\footnotetext{
${ }^{58} \mathrm{~A}$ fraction of students $\left(5 / 9^{\text {th }}\right)$ also participated in a PISA math test. Because the subset of the sample that participated in the math test is small, math scores are not used in the measure of cognitive skills constructed for this paper. However, Bennet (2017) considers the contribution of math skills to final year of high school outcomes, and finds that boys lead girls in math scores, making the gap in overall achievement harder to explain.

${ }^{59}$ It is also sometimes argued that boys have lower educational aspirations because the university wage premium for boys is smaller than for girls. See for example Christofides, Hoy and Yang (2010). See Hubbard (2001) for a rebuttal of the wage premium argument.
} 
their post-secondary education, what are their aspirations for PSE. ${ }^{60}$ In this study, the numerous possible responses are collapsed into three categories: Less than a university degree, which includes those who report aspiring to less than high school graduation, high school graduation only and a college diploma; an undergraduate degree only; and a graduate university degree, which includes graduate degrees (MA, $\mathrm{PhD}$ ), veterinary studies, law and medicine degrees.

Finally, information from the parental survey provides a rich set of background variables for the analysis. Information about the student's socio-economic status, specifically family income and parental education, is taken from the parent survey, which was completed only in Cycle 1 when the student was age $15 .^{61}$ The parent survey also provides information about family structure and parental hopes for their child's education. ${ }^{62}$ The information about family status is used to construct a dummy variable that takes on the value of 1 if the student comes from an intact family at age 15. Another dummy variable is used to capture information about parental hopes. Specifically, a dummy variable is created that takes on the value of 1 if the parent hopes for a university education (an undergraduate degree or higher), and zero otherwise. Demographic information about the student is also found in the parent survey, specifically regarding the student's country of birth (Canada or other), province of residence, and urban versus rural status. For the purposes of this study, students who reside in Quebec are not included in the analysis. This is because of the unique CÉGEP system that exists in that province, which is discussed in more detail in Appendix A of Chapter 2.

60 Students are also asked this question at age 15, but as aspirations evolve over time, the age 17 aspirations are used in this study. See Christofides, Hoy, Li, and Stengos (2008) for a discussion of the evolution of aspirations.

61 Foley (2017) and Day (2010) present evidence that these are important determinants of post-secondary participation.

62 Bertrand and Pan (2013) find in their research that family structure plays an important role in determining school disciplinary incidents and other behaviours, and that this effect differs by gender. 


\subsection{Methodology}

The dependent variable in this analysis, PSE participation, is categorical. The participation variable, $\mathrm{Y}_{\mathrm{i}}$, takes on one of three values:

$$
Y_{i}=\left\{\begin{array}{l}
1=\text { No PSE } \\
2=\text { At least some college } \\
3=\text { At least some university }
\end{array}\right.
$$

These three participation outcomes are explained by the variables discussed above; overall senior high school grade, skills, aspirations, and a range of socioeconomic and demographic control variables, including gender. These are represented by the vector $\mathbf{X}_{\mathrm{i}}$

Conditional on having completed high school, a model of post-secondary education participation is estimated using an ordered logit model. A multinomial logit model would not be appropriate here, as there is a meaningful order to the levels of education being considered here. While there are some college courses which require as much time as a $\mathrm{BA}$, in general a university degree represents more years of schooling and therefore a higher level of human capital acquisition.

Ordered logit estimation assumes that the error term has a logistic distribution, so that the probability of observing any outcome $\mathrm{Y}_{\mathrm{i}}$ can be rewritten as,

$$
\operatorname{Prob}\left(Y_{i}=j \mid \mathbf{X}_{i}\right)=\Lambda\left(T_{j-1}-\mathbf{X}_{i}^{\prime} \beta\right)-\Lambda\left(T_{j}-\mathbf{X}_{\mathrm{i}}^{\prime} \beta\right) \quad j=1,2,3,
$$

where $\Lambda$ is the cumulative density function for the logistic distribution, expressed as

$$
\Lambda(*)=\frac{1}{1+e^{-(*)}} .
$$

The likelihood function for individual $i$ is then,

$$
L^{i}=\prod_{j=0}^{J} \operatorname{Prob}\left(Y_{i}=j \mid \boldsymbol{X}_{i}\right)^{I\left(Y_{i}=j\right)}
$$


The ordered logit regression analysis returns coefficient values which maximize the likelihood of observing the given data. ${ }^{63}$

Ordered logit models have built into them the implicit assumption that the log odds of moving from one category to another are the same across all categories, sometimes called the parallel regression assumption (therefore returning only one set of coefficients for each regression). This is an assumption that may be particularly inappropriate when considering high school graduation versus college versus university. As a robustness check, this analysis also estimates a generalized ordered logit model, which relaxes the parallel regressions assumption. Instead of generating one coefficient per variable, the generalized ordered logit returns two coefficients, one for high school only versus at least some PSE (university or college) and one for high school or College versus University. These coefficients are used to generate marginal effects which are compared to those derived using the ordered logit coefficients.

\subsection{Empirical results}

\subsubsection{Short-run determinants of PSE participation: Cycle 3 analysis}

In this section, participation in PSE by Cycle 3 is considered. At the time of interview in 2004, participants are 19 years old (or near to their $19^{\text {th }}$ birthday). The interview is retrospective over the previous two years, so any new or continuing participation in PSE that took place between Jan 2002 and Dec 2003 is recorded.

\section{A. Descriptive statistics}

Table 3.3 shows the relationship between self-reported grade in the senior year of high school and highest education taken as of Cycle 3 (age 19) by gender. A number of points are highlighted in this table. First, there is a clear positive relationship between overall grade in the senior year of high school and university participation, for both boys and girls. This is mirrored in the negative relationship between senior year grade and both college participation and no participation in PSE.

Table 3.3 also illustrates the under-representation of boys in the $80 \mathrm{~s}$ and $90 \mathrm{~s}$ grade categories (i.e. the bracketed figures shown beneath gender); while $50 \%$ of girls report a grade of 80 or above, only $32 \%$ of boys report a grade in these categories. The reverse is

\footnotetext{
${ }^{63}$ This empirical discussion draws on the techniques for modelling categorical dependent variables described in Long (1997)
} 
true in the lower part of the distribution. For example, $22 \%$ of boys report a grade in the 60 s, while only $11 \%$ of girls report a grade in that range. The relationship between gender and senior year grade was examined in Chapter 2.

Finally, the table shows rates of participation by gender within grade categories. At the upper end of the grade distribution the rate of participation in PSE by gender is almost identical. For example, of students who report an overall grade in the $80 \mathrm{~s}, 64.7 \%$ of boys and $65.7 \%$ of girls go on to at least some university by Cycle 3. Although there are significantly fewer boys in this grade category, boys and girls within this grade category participate in both university and college at almost the same rate. This is also true in the 90s grade category. However, participation in PSE differs substantially by gender at the lower end of the grade distribution. For example, Table 3.3 indicates that, within the grade category "in the $70 \mathrm{~s}$ ", $33 \%$ of girls go on to participate in university, while only $21.7 \%$ of boys do so by Cycle 3. This is mirrored in a much higher rate of no participation in PSE (i.e., terminal high school diploma) for boys within the 70s grade category. There are also gender-based differences in PSE participation in the "less than 60 " category. Within this category, $77.3 \%$ of boys have taken no postsecondary education (either university or college) by age 19 , while only $56.5 \%$ of girls report having taken no PSE by age 19 .

While grade in the final year of high school plays a critical role in understanding PSE participation, there are clearly other factors at play. The "university bound" grades of $80 \mathrm{~s}$ and 90s, for example, do not necessarily lead to university participation. Further, of those who report a grade in the 70s or below, PSE participation diverges substantially by gender. Other factors, such as skills, aspirations and parental influences, likely play a role in determining PSE participation, and may shed light on the documented differences in PSE participation by gender. ${ }^{64}$ The balance of this study examines the broader determinants of participation in PSE, by gender, conditional on having completed high school.

Table 3.4 summarizes the average characteristics, by gender, of the sample, excluding those who have not completed high school. (The population who has not completed high school by Cycle 3 is described in Appendix C.) As noted by Bennet (2017), Fortin et al. (2015), and Frenette and Zeman (2008), boys and girls differ along many dimension that likely contribute to the decision to pursue post-secondary education or not. Of particular note are the gender gaps in skills. Girls lead boys in reading scores, and learning skills, but lag boys in self-esteem and self-efficacy. Moreover, the parents of girls tend to hold

\footnotetext{
${ }^{64}$ Moreover, as Jacob (2002) suggested, differences in non-cognitive skills may increase the "psychic" cost of attending university for boys. This research considers both the direct and indirect influences of skills, particularly non-cognitive skills, on the decision to proceed to college or university.
} 
higher educational aspirations for them than do the parents of boys, perhaps a reflection of the gender gaps that have been documented in high school grades and in skills. Finally, girls have higher educational aspirations than boys. For example, $42 \%$ of girls in this sample have aspirations for a university graduate degree, compared to only $34 \%$ of boys. $^{65}$

\section{B. Regression analysis}

The primary goal of this analysis is to understand the gender gap that exists between boys and girls in post-secondary education participation, particularly university participation. As noted above, among those who reported taking at least some university by Cycle 3, only $42 \%$ are boys. This section examines the channels through which gender influences PSE participation, both college and university.

Gender can potentially influence PSE outcomes in a number of ways. Clearly, one way is through grade in the final year of high school, which differs significantly by gender and is a critical determinant of post-secondary education participation, particularly university. Gender enters the high school grade production function in a number of places, both directly and indirectly. Gender may also play a role through other inputs into the PSE determination model. For example, skills may work directly on PSE participation, as well as indirectly through their influence on final grade. If skills are an important determinant of PSE participation (above and beyond their influence on grade in the final year of high school), and skills differ by gender, then this is another channel of influence for gender. Finally, there is the potential for gender to have a direct influence on PSE participation. This would be the case if, for example, boys received different guidance or advice from the career counsellors (or guidance counsellors) at school.

This section attempts to disentangle these various channels of influence through stepwise regression analysis. Ordered logit regression analysis is used to examine these questions. Recall that only those who have completed high school are considered in this part of the analysis, as those who are still in high school, or who have dropped out of high school, are not at the decision node for post-secondary education.

\section{Coefficients - Ordered log odds}

Table 3.5 shows the results of a series of ordered logit regressions. In Column (A), the model for post-secondary education participation includes only background variables, such as student gender, family income and parental education. The coefficients returned from this regression establish a benchmark value for each variable, in the absence of any

${ }^{65}$ Note that boys also have, on average, a higher family income and are slightly more likely to come from an intact family. While these differences in populations are noted, this research provides no explanation for them. 
controls for academic performance, aspirations, or skills. These coefficients are not marginal effects, as ordered logit regressions return coefficients which represent ordered log odds. ${ }^{66}$ However, the sign and significance of the coefficients are informative. For example, the coefficient for Male is -0.639 , suggesting that, controlling only for background variables, the effect of gender is negative and statistically significant at all conventional levels. Being male decreases the (ordered) log odds of having taken a higher level of education by 0.639 compared to the reference group who are female. The coefficients on the other background variables are also significant in the absence of controls for skills and aspirations. Being from an intact family, for example, confers a substantial advantage; being from an intact family increases the log odds of having taken a higher level of education by 0.286 .

Column (B) shows the estimated coefficients when grade in the final year of high school is added as an explanatory variable to the regression analysis. The coefficient on gender declines (in absolute value) substantially, from -0.639 to -0.374 . This is expected, as prior analysis showed that boys lag girls in high school academic performance. The coefficients on grades (all calculated with respect to the reference group of "in the 70s") are all statistically significant and substantial. Those with grades in the $80 \mathrm{~s}$ and in the 90 s are more likely to have taken a higher level of education, while those with grades in the 60s or below are less likely to have participated in any form of PSE. This is also expected, as grades are clearly an important determinant of PSE participation.

It should be noted that the coefficients on grades include the effects of skills, aspirations and gender through their correlation with grade. For example, students with high reading scores will often have high grades. Reading skills are also positively correlated with educational outcomes. In the absence of an explicit control variable for reading scores, the coefficients on grades will be picking up some of the direct influence of reading skills on outcomes as well as the indirect effect. Similarly, students with high educational aspirations tend to have higher grades. To the extent that high aspirations are correlated with higher educational outcomes, the coefficients on grades will include not only the effects of grades on PSE participation, but also the effects of aspirations. For this reason, first education aspirations and then skills are added as explanatory variables to the regression analysis.

Column (C) documents the results with the addition of education aspirations, held by both the students themselves and their parents. Notably, the coefficients on aspirations are all substantial and statistically significant. This suggests that aspirations have a direct effect on PSE outcomes, independent of their influence on grades. In addition, the

\footnotetext{
${ }^{66}$ Henceforth ordered log odds results will be referred to simply as log odds, with the "ordered" implicitly understood.
} 
coefficients on grade in the final year of high school have decreased, suggesting that some of the influence of aspirations on outcomes was being captured, in column (B), by grades. Moreover, because aspirations have been explicitly considered, the coefficient on gender has decreased. Fewer boys than girls aspire to either an undergraduate or a graduate university degree. Boys who have lower educational aspirations will be less likely to work hard to achieve university bound grades. This effect is captured in moving from column (A) to (B); now, in moving from column (B) to (C), the direct effects of their lower aspirations are taken into account. Once this is taken into account, there is a smaller (yet still significant) role for gender in determining PSE participation.

Column (D) adds reading scores (cognitive skills) to the analysis. The coefficient for reading skills is statistically significant and of the expected sign - a one standard deviation increase in reading skills increases the log odds of participating in a higher level of education by 0.402 . This is the direct effect of an increase in reading skills, having controlled for grade achieved in the final year of high school. As with the addition of aspirations, the addition of reading scores to the analysis reduces the influence of grades. In the results reported in column (C), some of the coefficient on grade was capturing the direct effect of reading skills on PSE outcomes. The coefficient on gender (Male) is also reduced (in absolute value); being male is now associated with a decrease in the log odds of participating in a higher level of PSE of -0.195 , significant at the $5 \%$ level of confidence. Thus, the coefficient on gender was in part reflecting the lower reading skills of boys.

Column (E) adds the set of non-cognitive skills as covariates to the regression model. The coefficient on learning skills is the only one that is statistically significant. A one standard deviation increase in learning skills leads to an increase in the log odds of having taken a higher level of education of 0.309 , controlling for grade achieved in the final year of high school. Notably, the coefficient on reading skills is entirely unchanged with the addition of non-cognitive skills to the estimation equation.

Of particular importance for this research is the change in the coefficient on gender, which is reduced with the introduction of non-cognitive skills. Since non-cognitive skills (specifically learning skills) are correlated with both gender and the outcome variable, it is to be expected that the coefficient on gender will fall when non-cognitive skills are added to the regression analysis. Notably, when everything is accounted for - the direct effects of skills (both cognitive and non-cognitive), aspirations, grade in the final year of high school, and background variable - there remains a small residual role for gender in the determination of PSE participation. 
This set of regressions then suggests that there are a number of channels through which gender influences PSE participation. First, gender works through grade in the final year of high school, with the academic performance of boys lagging girls. In addition, gender works indirectly through the influences of reading and learning skills, where boys again lag girls. Both of these skills are important predictors of PSE participation. Further, gender works through aspirations; boys are less likely to have educational aspirations that include university, and these aspirations are an important determinant of actual participation. Finally, there is a small direct role for gender itself, with boys being less likely than girls to pursue higher education, net of the effects of lower skills, aspirations and grades.

In this analysis of short run participation in post-secondary education, there are also a number of factors that are of interest because of their lack of importance. For example, family income is insignificant in the models specified in columns (C), (D), and (E). Clearly, the observed (unconditional) relationship between income and university attendance is being driven by factors that are correlated with income. This is an important point to note from a policy perspective, as efforts are often made to increase participation rates of students from low income families through government loan or subsidy programmes. The results here, which are consistent with those of Cameron and Heckman (2001), suggest that these policies will be ineffective. Income is correlated with skills, and these skills are the important determinant of PSE participation. Skills deficits, accumulated over the lifetime, cannot be remediated with loans or bursaries at age $18 .^{67}$

Because of the parallel regression assumption that is implicit in ordered logit estimation, the same set of coefficients describe the (log) likelihood of participation in university versus either college or high school only. For example, having a final high school grade in the 80 s increases the log odds of participating in university (instead of either college or high school only) by 0.868 vis-à-vis students in the reference group (with a final grade in the 70s). By construction of the ordered logit model, this is also true of the comparison between high school only and either college or university; having a final high school grade in the $80 \mathrm{~s}$ increases the log odds of participating in either college or university (instead of high school only) by 0.868 vis-à-vis students in the reference group.

While the downside of this approach is clear (i.e., the parallel regressions assumption may be inappropriate), the benefit is that it allows for only one set of coefficients, which makes the presentation of the coefficients more parsimonious. Because there is only one

\footnotetext{
${ }^{67}$ These finding are conditional on the financing structures that are currently in place. It is not expected that this "unimportance' of family income would persist were current loan and bursary programmes to be removed.
} 
set of coefficients, it is straightforward to make comparisons between models. These comparisons can yield rich insights in some circumstances. In this paper, for example, it is possible to compare regressions with and without aspirations, skills and final grades in order to disentangle direct and indirect effects.

\section{Marginal Effects}

The coefficients table is useful for making comparisons across models. Now that the direct and indirect effects have been noted, the balance of this paper presents results for the full model only (Column (E)), which includes all covariates. Going forward, results will be in the form of marginal effects only, which are calculated using the coefficients returned from the regression analysis.

The average marginal effects associated with the full model are shown in Table 3.6. Average marginal effect takes all individual characteristics as given, and calculates the change in outcome for a change in one covariate. For example, to find the average marginal effect of gender, every observation in the sample is first treated as though they are a girl (gender $=0$ ), and the probability of being in each educational category is calculated for each individual. These are then averaged to find the average probability of assignment to each category treating all individuals in the population as girls. Then everyone is treated as though they are a boy, and the average probability of being in each educational category is recalculated. The (average) marginal effect is the difference between these two averages, and indicates the effect on post-secondary education participation from simply changing gender, with all else held constant at actual values (as opposed to average values, as in marginal effect at means calculations).

The table indicates that the marginal effect of gender is statistically significant, although only at the $10 \%$ confidence level. Boys are 2 percentage points more likely to report high school graduation as the highest taken (by Cycle 3) than girls, and a corresponding 2 percentage points less likely to report having taken at least some university education. This is the direct effect of gender, having controlled for reading scores, non-cognitive skill, aspirations and grades.

Table 3.6 also shows the marginal effects of other covariates. Given a one standard deviation increase in reading score, students in this sample are 5.7 percentage points less likely to report high school graduation as the highest education taken by Cycle 3 . This is mirrored in the university category, where a one standard deviation increase in reading score leads to an increase in the likelihood of at least some university participation by almost 6.6 percentage points. Notably, the marginal effect of reading scores on college participation is very small. 
The marginal effect of a one standard deviation increase in learning skills is on par with those for reading scores; the likelihood of high school graduation decreases by 4.6 percentage points, while the likelihood of at least some university participation increase by 5.3 percentage points. Notably, the influence of changes in reading or learning skills on college participation is small. ${ }^{68}$ These marginal effects - of reading and learning skills - are measured holding grade in the final year of high school constant, and are thus direct effects.

The marginal effect of a change in student aspirations is sizable. Students who aspire to more than an undergraduate degree are 18.8 percentage points less likely to report high school graduation as the highest education taken, and 3 percentage points less likely to report having taken some college, compared to students in the reference group (who aspire to less than a university degree). This is of course mirrored in a higher likelihood (21.7 percentage points) of reporting at least some university education.

\section{Relaxing the parallel regressions assumption}

As discussed above, an important assumption that underlies ordered logit estimation is the parallel regressions assumption. This assumes that the coefficients that describe the odds of being in the lowest category versus all higher categories of the response variable are the same as those that describe the odds between the second lowest category and all higher categories, and so on. For the outcome variable considered in this paper, the parallel regression assumption may be particularly onerous. The assumption would suggest that the odds of being in the high school only category versus either college or university are the same as the odds of being in either the high school only or the college category versus university.

It is possible to relax the proportional odds assumption by using a generalized ordered logit model. This empirical approach relaxes the assumption that the log odds of going to university versus either college or high school-only is the same as the log odds of going either to university or college versus high school-only. Thus, two sets of coefficients, one for high school-only versus college or university, and one for high school-only or college versus university, are returned from the generalized ordered logit regression. Table 3.7a shows the more easily interpretable marginal effects, which again take the form of probabilities of being each of the three possible outcome categories. A glance at the marginal effect of high school grades shown in this table reveals one of the problems with using generalized ordered logit - that small cell counts can lead to model instability, with the regressions returning implausibly large coefficients for independent variables. There are few students who report a final grade of less than $60 \%$, and of these a very

\footnotetext{
${ }^{68}$ Recall that these marginal effects are calculated after having controlled for grade in the senior year of high school, as noted above.
} 
small number go on to college and an even smaller number to university. These small cell counts lead to the very high probabilities seen for grade in the final year of high school (esp. in the final grade $<60 \%$ row). However, it is worthwhile to consider the balance of the results as a robustness check for the ordered logit estimation.

First, the generalized ordered logit was re-estimated using a modified variable for grade in the senior year of high school. Specifically, the lowest categories ("less than $60 \%$ " and "in the 60s") were combined into a single grade category to avoid the instability issue discussed above. The marginal effects calculated using the revised generalized ordered logit estimation and the ordered logit estimation (which maintains the parallel regression assumption) are then presented side by side Table 3.7b. ${ }^{69}$ In many instances the results are similar using the two methodologies. The marginal effect of a one standard deviation increase in reading score, for example, is almost identical, with the ordered logit model estimating an increase of 6.6 percentage points in the likelihood of university participation while the generalized ordered logit predicts an increase of 6.4 percentage points. The marginal effects of learning skills, gender and parental education are also largely unchanged across the two methodologies. The marginal effect of student aspirations, on the other hand, differs significantly over the two methodologies. For instance, for those with aspirations to more than a BA, the likelihood of university participation is predicted to increases by 21.7 percentage points using ordered logit, and by 34.7 percentage points using generalized ordered logit.

This robustness check gives us two useful pieces of information. First, the results from the ordered logit methodology, with its restrictive parallel regressions assumption, are for the most part consistent with the results from the less restrictive (but more unstable) generalized ordered logit. The second piece of information is that the ordered logit model appears to underestimate the marginal effect of aspirations (both parental and student). While the marginal effects have the same sign and significance across methodologies, the generalized ordered logit model predicts a much greater marginal effect. Thus, in moving forward, it should be kept in mind that the marginal effect of aspirations on participation in PSE may be under-estimated using the ordered logit model, and should perhaps be considered an estimate of the lower bound of the effects.

\section{Marginal effects by gender}

The regression results suggest that gender has a small direct role to play in determining participation in PSE, particularly with respect to university. Recall that the marginal effects from the ordered logit regressions run on the whole sample suggests that boys are 2 percentage points more likely than girls to report high school graduation as the highest

\footnotetext{
${ }^{69}$ This re-categorization results in slight changes to the coefficient estimates for other variables. This is the reason for the differences between the generalized ordered logit results presents in Tables 3.7a and 3.7b.
} 
taken (by Cycle 3), and a corresponding 2 percentage points less likely to report having taken at least some university education. ${ }^{70}$ It is important to note that these marginal effects are calculated using the coefficients returned from the ordered logit estimation of the model for the whole sample. Thus, the coefficients did not differ between girls and boys.

It may be the case, however, that the influence of the various factors in the model influence boys and girls in their decisions to participated in post-secondary education in different ways. The effect of factors such as family status and parental expectations may differ by gender. For example, researchers such as Bertrand and Pan (2013) and Buchmann and DiPrete (2006) have found that the effect of family structure is larger for boys; boys from single parent homes tend to have more disciplinary problems, and lower educational attainment than the equivalent girl.

Because the marginal effect across factors may differ by gender, it is useful to estimate the model for boys and girls separately. The results of these regressions are detailed in Table 3.8, which looks at the marginal effect of each variable by gender, presenting them side by side. There are a few results which are particularly notable in the context of this research. First, boys and girls differ substantially in the marginal effect of aspirations. Girls with aspirations of more than a BA are 25.6 percentage points more likely to attend university by Cycle 3 than girls who report aspiring to less than a BA. This marginal effect for boys is only 17.4 percentage points, still a large marginal effect, but substantially lower than that for girls. Thus the previously noted difference in endowments, where boys have lower aspirations for university than girls, is augmented by the marginal effect of aspirations, which suggests that high aspiring girls are much more likely than boys to end up in university.

The marginal effect of academic performance also differs substantially by gender. Girls with a final grade in the 90 s are 19.6 percentage points more likely to attend university than girls with a final grade in the 70s (the reference group) by Cycle 3. For boys, this figure is 34.4 percentage points. One way to look at these results, which is consistent with the earlier tabular results, is that boys with final grades in the 70 s have a low likelihood of attending university, while girls in the 70s have a much higher likelihood. Thus, having a grade in the 80 s or 90 s, vis-à-vis those with a grade in the 70 s, means less for girls than for boys in terms of university participation.

The marginal effect of a one standard deviation increase in reading scores also differs between boys and girls, holding all else constant. For girls, a one standard deviation increase in reading scores leads to an increase of 9.4 percentage points in the likelihood

\footnotetext{
${ }^{70}$ Note that this is the average marginal effect, which is distinct from the marginal effect calculated at means.
} 
of attending university; for boys the marginal effect is only $4.1 \mathrm{pp}$. Notably, the marginal effects of learning skills are similar for boys and girls. Finally, as other researchers (e.g., Bertrand and Pan, 2013) have noted, the effect of family status differs by gender. For girls, intact family status is an insignificant determinant of participation in PSE. For boys, however, being from an intact family leads to an increase of 4.3 percentage points in the likelihood of attending university.

In sum, regression analyses that consider boys and girls separately point to significant differences in the way in which factor endowments translate into post-secondary education participation. Boys have a lower marginal effect of aspirations, compounding the influence of their lower level of aspirations. At the same time, family status appears to have a significant impact on boys, with the likelihood of boys attending university being 4 percentage points higher for those from an intact family than for boys who are not. The influence of reading skills, parental education and parental hopes also differs by gender. These effects are measured while controlling for grade in the final year of high school, so that it is not their influence on high school performance that is being captured, but the direct effect.

\subsubsection{Longer-run determinants of PSE participation - Cycle 6 analysis}

As noted previously, post-secondary education participation is not static; over time there are substantial changes as individuals may leave high school and take gap years before entering post-secondary education, or may move from college to university or vice versa. It may be the case, then that the determinants of longer term participation are different from short term determinants.

\subsubsection{Descriptive statistics}

Table 3.9 shows the distribution of final high school grade by gender and post-secondary education participation as of Cycle 6. By Cycle 6, there is little change in the overall gender gaps in post-secondary education, with a gap of almost 15 percentage points in favour of girls existing at the university level, mirrored in higher rates of terminal high school diplomas (or less) and college participation for boys. Boys and girls in the highest grade categories are about as likely to have participated in at least some university by the end of Cycle 6, although by this age (25) boys in the these categories are slightly more likely to have participated in university. Boys in the 70s are more likely to have attended some college than girls by age 25 , mirrored in the higher likelihood of girls in the 70 s having tried at least some university. At the lowest end of the grade distribution (in the 60 s, or less than 60 ), boys are more likely than girls to have left formal schooling with a terminal high school diploma. 
Table 3.10 shows the average characteristics of the four groups in Cycle 3 and Cycle 6 . Clearly there have been significant flows of individuals over time, from high school as the highest education taken to having participated in at least some college or university. This leads to some large changes in the average characteristics of each group. In Cycle 3, the average standardized reading score of those who reported having taken at least some university ( $38 \%$ of the sample) was 0.71 . By Cycle 6 , almost half of the sample reported university as their highest education taken. The average standardized reading score in this larger group is 0.61 , significantly lower than the average reading score for the smaller Cycle 3 group of university participants. The Cycle 6 group of university participants also has lower average learning skills than the Cycle 3 group who reported having taken some university. This decline in average reading and learning skills is evident across all groups. The final grade in the last year of high school is also lower for students who delay participation in PSE, as evidenced by the lower average final grade for Cycle 6 PSE participants (both levels) than for Cycle 3 participants.

Men make up $44 \%$ of the Cycle 6 population who report having taken some university. This compares to the Cycle 3 figure of $42 \%$. Men are clearly not making up much lost ground in the intervening years between Cycles 3 and 6. Family structure still differs significantly across educational groups. $80 \%$ of students who report attending university by Cycle 6 are from an intact family. Conversely, only $65 \%$ of those who report having high school graduation as the highest education taken are from an intact family.

\subsubsection{Regression analysis}

Regression analysis is again used to determine the marginal effect of each factor on the likelihood of post-secondary education participation. These results are shown in Table 311. There are a number of results which stand out. First, the effects of academic performance (grade in final year of high school) are muted over time. For example, those who score in the 90s are 26.5 percentage points more likely to attend university in C3 than those who receive an overall grade in the 70 s during the final year of high school. By Cycle 6, these high achievers are only 19 percentage points more likely than those with grades in the 70 s to attend university. This is likely because those who report participating in at least some university by Cycle 3 are students who are going directly into university from high school. These university participants will be admitted almost exclusively on the basis of their grades in the final year of high school. Those who report at least some university participation by Cycle 6 (but not in Cycle 3) include students who tried college first, or who took gap years during which time they may have taken night school or other courses to improve their chances of admission to university. These students had lower grades in the final year of high school, and were perhaps unable to move directly from secondary to post-secondary education. 
The direct effects of cognitive skills are reasonably stable over time with a one standard deviation increase in reading scores leading to a 7.4 percentage points increase in the probability of going to university by Cycle 6, compared to 6.6 percentage points for Cycle 3. The same increase in reading score leads to a decrease of 5.7 percentage points in the likelihood of stopping formal education with a high school diploma by Cycle 3 . That likelihood falls slightly to 3.9 percentage points by Cycle 6 . Thus, cognitive skills have a moderate but declining effect on participation in PSE over time. This is true to an even greater extent for non-cognitive skills, whose effects are very muted by Cycle 6 .

On the other hand, the marginal effects of aspirations, which are substantial in Cycle 3, have an even larger influence by Cycle 6. Compared to students who aspire to less than a BA, those who aspire to more than a BA are 21.7 percentage points more likely to take at least some university by Cycle 3; by Cycle 6, these students are 32.4 percentage points more likely to go to university that those who aspire to less than a BA. Parental aspirations do not appear to exert a notably larger (or smaller) influence over time, although in both Cycle 3 and 6 they are a statistically significant predictor of university participation.

Notably, the marginal effect of gender in determining participation in university by Cycle 6 is still 2 percentage points, only slightly smaller than in Cycle 3, but no longer statistically significant at any conventional level. Thus, in the long run, the gender gap appears to be driven by differences in skills and aspirations (both directly and indirectly through grade). Boys have lower educational aspirations and lower levels of skills than girls; once we control for these, gender has only a small role to play which diminishes over time.

\subsubsection{Discussion of Results: The Residual Effect of Gender.}

Throughout this analysis, the unconditional gender gap in PSE participation, particularly university participation, has been whittled away by adding explanatory variables that are correlated with gender. Once all covariates are considered - skills (both cognitive and non-cognitive), aspirations and, critically, senior high school grade - the role of gender is substantially reduced. There remains, however, a residual role for gender that deserves consideration. Specifically, the marginal effect of gender predicts a lower participation rate in university for boys, mirrored by a higher rate of "no PSE" (that is, a terminal high school diploma).

One possible explanation for the continued significance of gender in determining university participation is that there remain unmeasured determinants of participation which are also correlated with gender. Of these possible unmeasured determinants, differences in preference over field of study (and subsequent field of employment) have received considerable attention in the literature (Hango, 2013; Card and Payne, 2017). 
While field of study is not included in the model of PSE participation that is estimated in this paper, this section provides some insights into the possible role of field of study on the gender gap in PSE participation. A more detailed analysis is left for future research.

Table 3.12 illustrates the field of study choices for boys and girls who have participated in at least some university education by the Cycle 3 interview. Field of study here is measured by the 13 primary groupings of the Classification of Instructional Programme (CIP). The results are shown by overall grade category in the senior year of high school. $^{71}$ The table documents a substantial difference in choice of field of study in university between boys and girls. For example, of boys who report an overall senior high school grade in the $90 \mathrm{~s}, 33.5 \%$ go on to study in the field of architecture and engineering. Of girls who report an overall senior high school grade in the 90s, only $3.5 \%$ go on to study in the areas of architecture and engineering. This trend is reversed for students who choose to study in humanities, where $21 \%$ of girls with an overall senior high school grade in the $90 \mathrm{~s}$ choose this field of study, compared to only $8.2 \%$ of boys.

Of particular interest are the fields of study choices made by students with grades in the $70 \mathrm{~s}$ in the senior year of high school. Recall that the university participation rates for boys and girls differed substantially within this grade category (see Table 3.3). Table 3.12 indicates that, within this grade category, boys are still more likely than girls to be studying in architecture and engineering, although the gender gap is narrower than for students with a grade in the $80 \mathrm{~s}$ or in the 90 s (due entirely to the reduced participation rate of boys, not the increased participation rate of girls). Boys in this grade category are also more likely to study math or computer science that girls. Notably however, boys with a senior high school grade in the 70 s are more likely than girls to study in the humanities. Girls in all grade categories are much more likely than boys to study education.

Given this marked difference in field of study choices across all grade categories, it seems likely that at least some of the residual effect of gender, conditional on all other measured factors, is attributable to differences in preferences. It is possible then that boys with marginal grades in the senior year of high school (i.e. in the 70s) are willing to forego the higher income associated with a university education in a field that is not of particular interest to them, and instead move into the labour force with a terminal high school diploma. This is analogous to the observation that girls are willing to forego the

\footnotetext{
${ }^{71}$ Because very few students with grades in the 60 s or below participate in university by Cycle 3 , there were many cells with low counts. These cannot be released because of Statistics Canada reporting guidelines. The table then shown field of study participation for only students who reported an overall grade of at least 70 in the senior year of high school.
} 
higher incomes associated with engineering and computer science fields in order to pursue studies in preferred fields (such as humanities) associated with lower incomes. ${ }^{72}$.

However, it is unlikely this is the full story. While the humanities and social sciences do not appear to be the preferred fields of study for boys, they nonetheless appear willing to participate in these fields of study when their high school grades are not sufficient to access fields of study such as engineering. Another possible explanation for the significant residual for gender may be that boys coming directly from high school, particularly those with grades from the lower end of the distribution, are not encouraged at the same rate as equivalent girls to apply to university. Guidance counsellors may feel that girls require more encouragement (Whitmore, 2011). The possibility of such unconscious bias, in the context of grade assignment, is documented in Lavy (2008).

\subsection{Conclusions}

Boys lag girls in the rate at which they attend PSE. There is a particularly large difference in university participation, where an unconditional gap of about 15 percentage points in favour of girls opens up directly after high school. Although the rate of university participation increases for both boys and girls over time, this gender gap remains constant, at least up to age 25 . This difference is mirrored in both the college and high school categories, with boys being more likely than girls to participate in college or simply leave formal education with (or without) a high school diploma.

It is well documented that higher education is associated with many benefits: higher earnings (Angrist and Krueger, 1991); greater employment stability (e.g., Cairo and Cajner, 2017); increased fringe benefits such as pensions and medical insurance, as well as increased job satisfaction (Oreopoulous and Salvanes, 2011); and better health outcomes (Brunello et. al., 2016). The gender gap in university participation is thus of considerable concern to policy makers. The findings of this research suggest a number of areas where policy can play a role in remediating this gender gap.

Foremost is the remediation of the gender gap in overall senior high school grade. Boys lag girls substantially in the production of grades at the upper end of the distribution - in the $80 \mathrm{~s}$ and $90 \mathrm{~s}$. The analysis presented in this paper suggests that senior high school grade is among the most important factors influencing PSE participation, particularly

\footnotetext{
${ }^{72}$ This difference in preferences over field of study also explains the fact the, while over male participation rates in university lag those of females, the male participation rate in certain fields of study, such as architecture an engineering, is higher than that for females
} 
university participation. A large part of the explanation for the gender gap in university participation then rests on the gap in senior high school grades. The results from Chapter 2 suggest that gender based differences in reading and learning skill, as well as educational aspirations, play an important role in determining senior high school grade.

In addition, addressing the gender gap within grade categories is also required. Within grade categories at the top end of the high school grade distribution, the university participation rate is similar for boys and girls, at both ages 19 and 25. However, there is an important divergence in PSE participation, by gender, at the middle and lower ends of the high school grade distribution. In the middle of the grade distribution, girls are more likely to go on to university than boys; at the lower end of the grade distribution, girls are more likely to obtain either some university or some college education than boys.

The regression analysis highlighted aspirations as one of the most important factors, conditional on senior high school grade, in determining participation in PSE, particularly university participation. To some extent then, gender gaps within grade categories are a function of gender gaps in educational aspiration. Moreover, while the marginal effect of aspirations is larger for girls, it is nonetheless a critical determinant of PSE participation for boys. One important question that this research begs is why there exists such a large gap in educational expectations between boys and girls. Fortin et al. (2015) suggest a link between non-cognitive skills and aspirations which is deserving of further consideration. In general, there is a need for a deeper understanding of the formation of aspirations.

The gender gaps in reading and learning skills were also highlighted as important determinants of the participation gender gap within grade categories. Addressing these skills gap - both in reading and learning skills - would work to decrease the gap in university participation through two channels; both indirectly by increasing senior high school grades of boys, and directly through the positive influences these skills have on PSE participation within senior high school grade categories.

Finally, the evidence suggests that gender itself also plays a direct role in determining university participation. Notably, the marginal effect of gender on university participation is mirrored almost identically on the decision not to pursue PSE. The marginal effect of gender is insignificant on college participation. Preliminary analysis regarding preferences over field of study indicates that the statistically significant role for gender may be an artifact of unmeasured differences in these preferences. The residual role for gender may also be a result of an unconscious bias on the part of teachers or guidance counsellors in schools. Educators should be made aware of the potential for these biases to exist, and of their implications. 


\section{Bibliography}

Angrist, J.D. and A.B. Krueger. 1991. "Does Compulsory School Attendance Affect Schooling and Earnings?" The Quarterly Journal of Economics, 106(4): 979-1014.

Bennet, Susan. 2017. "Gender and Skills in the Production of High School Grades". Unpublished Disseration Chapter.

Bertrand, Marianne and Jessica Pan. 2013. "The Trouble with Boys: Social Influences and the Gender Gap in Disruptive Behavior." American Economic Journal: Applied Economics, 5(1): 32-64.

Brunello, Giorgio, Margherita Fort, Nicole Schneeweis And Rudolf Winter-Ebmer. 2016. "The Causal Effect of Education on Health: What Is The Role of Health Behaviors?" Health Economics 25: 314-336.

Buchmann, Claudia and Thomas A. DiPrete. 2006. "The Growing Female Advantage in College Completion: The Role of Family Background and Academic Achievement." American Sociological Review, 71(4): 515-541.

Cairo, Isabel, and Tomaz Cajner. 2017. "Human Capital and Unemployment Dynamics: Why more educated Workers Enjoy Greater Employment Stability." The Economic Journal. doi: 10.1111/ecoj.12441.

Cameron, Stephen V., and James J. Heckman. 2001. "The Dynamics of Educational Attainment for Black, Hispanic and White Males." Journal of Political Economy, 109(3): 455-499.

Cameron, Stephen V., and James J. Heckman. 1993. "The Nonequivalence of High School Equivalents." Journal of Labor Economics, 11(1): 1-47.

Card, David, and A. Abigail Payne. 2017. "High School Choices and the Gender Gap in STEM.” NBER Working Paper No. 23769

Card, David, A. Abigail Payne, and Christina Sechel. 2011. Understanding the Gender Gap in University Participation: An Exploration of the Application Behaviour of Ontario High School Students. Toronto: Higher Education Quality Council of Ontario.

Cho, Donghun. 2007. "The Role of High School Performance in Explaining Women's Rising College Enrollment." Economics of Education Review, 26(4):450-462.

Christofides, Louis N., Michael Hoy, and Ling Yang. 2010. "Participation in Canadian Universities: The Gender Imbalance (1997-2005)." Economics of Education Review, 29(3): 400-410. 
Christofides, Louis N., Michael Hoy, Zhi (Jane) Li, and Thanasis Stengos. 2008. "The Evolution of Aspirations for University Attendance." In Who Goes? Who Stays? What Matters? Accessing and Persisting in Post-Secondary Education in Canada, ed. Ross Finnie, Richard E. Mueller, Arthur Sweetman, and Alex Usher, 109-134. Montreal and Kingston: Queen's Policy Study Series, McGill-Queen's University Press.

Day, Kathleen. 2010. "Teachers, Books, or Mortar? High School Resources and Educational Outcomes in Canada." In Pursuing Higher Education in Canada: Economic, Social and Policy Dimension, eds. Ross Finnie, Marc Frenette, Richard E. Mueller and Arthur Sweetman, 43-64. Montreal and Kingston: Queen's Policy Study Series, McGill-Queen's University Press.

Deming, David J. 2015. "The Growing Importance of Social Skills in the Labor Market.” NBER Working Paper No. 21473.

Duckworth, Angela L., and Martin E.P. Seligman. 2005. "Self-Discipline Outdoes IQ in Predicting Academic Performance of Adolescents." Psychological Science, 16(12): 939944.

Foley, Kelly. 2017. "The Gender Gap in University Participation: What Roles do Skills and Parents Play?” CLEF Working Paper Series, WP \#8.

Fortin, Nicole M., Philip Oreopoulos, and Shelley Phipps (2015), "Leaving Boys Behind: Gender Disparities in High Academic Achievement." Journal of Human Resources, 50(3): 549-579.

Frenette, Marc, and Klarka Zeman. 2008. "Understanding the Gender Gap in University Attendance: Evidence Based on Academic Performance, Study Habits and Parental Influences." In Who Goes? Who Stays? What Matters? Accessing and Persisting in Post-Secondary Education in Canada, ed. Ross Finnie, Richard E. Mueller, Arthur Sweetman, and Alex Usher, 135-154. Montreal and Kingston: Queen's Policy Study Series, McGill-Queen's University Press.

Goldin, Claudia, Lawrence F. Katz, and Ilyana Kuziemko. 2006. "The Homecoming of American College Women: The Reversal of the College Gender Gap." Journal of Economic Perspectives, 20(4): 133-156.

Groves, Melissa O. 2005. "How Important is Your Personality? Labor Market Returns to Personality for Women in the US and UK." Journal of Economic Psychology, 26(6): 827-841. 
Hango, Darcy. 2013. "Gender Differences in Science, Technology, Engineering, Mathematics and Computer Science (STEM) Programs at University." Statistics Canada, Catalogue no. 75-006-X.

Heckman, James J. and Yona Rubinstein. 2001. "The Importance of Noncognitive Skills: Lessons from the GED Testing Program." American Economic Review, 91(2) Papers and Proceedings of the Hundred Thirteenth Annual Meeting of the American Economic Association: 145-149.

Heckman, James J., Jora Stixrud, and Sergio Urzua. 2006. "The Effects of Cognitive and Non-Cognitive Abilities on Labor Market Outcomes and Social Behavior." Journal of Labor Economics, 24(3): 411-482.

Hubbard, William H.J. 2001. "The Phantom Gender Difference in the College Wage Premium," Journal of Human Resources, 46(3): 568-586.

Jacob, Brian A. 2002. "Where the Boys Aren't: Non-Cognitive Skills, Returns to School and the Gender Gap in Higher Education." Economics of Education Review 21(6): 589598.

Lavy, Victor. 2008. "Do Gender Stereotypes Reduce Girls' or Boys' Human Capital Outcomes? Evidence from a Natural Experiment." Journal of Public Economics, 92(1011): 2083-2105.

Long, J. Scott. 1997. Regression Models for Categorical and Limited Dependent Variables (Advanced Quantitative Techniques in the Social Sciences v.7). Thousand Oaks: SAGE Publications.

Milligan, Kevin, Enrico Moretti and Philip Oreopoulos. 2004. "Does Education Improve Citizenship? Evidence from the US and the UK." Journal of Public Economics, 88(910):1667-1695.

OECD. 2002. PISA 2002 Technical Report. Eds Ray Adams and Margaret Wu: Organization for Economic Co-operation and Development, Paris

OECD. 2015. PISA 2015 Draft Framework, retrieved from https://www.oecd.org/pisa/pisaproducts/PISA-2015-draft-questionnaire-framework.pdf

OECD. 2017. Reading Performance (PISA) (indicator). doi: 10.1787/79913c69-en. (Accessed 02 Nov 2017).

Oreopoulos, Philip, and Kjell G. Salvanes. 2011. "Priceless: The Nonpecuniary Benefits of Schooling." Journal of Economic Perspectives, 25(1): 159-184. 
Whitmore, Richard. 2011. Why Boys Fail: Saving Our Sons From an Educational System That's Leaving Them Behind. Amacom.

Winship, Christopher and Robert D. Mare. 1984. "Regression Models with Ordinal Variables." American Sociological Review, 49(4): 512-525. 
Tables and Figures

Table 3.1. Tabulation of Highest Education Taken, by Cycle 3 and Cycle 6

Highest taken by Cycle 6

\begin{tabular}{|c|c|c|c|c|c|c|c|c|}
\hline \multirow[b]{2}{*}{ Highest Taken by Cycle 3: } & \multicolumn{2}{|c|}{ Some university } & \multicolumn{2}{|c|}{ Some college } & \multicolumn{2}{|c|}{ High school grad } & \multicolumn{2}{|c|}{ Less than HS } \\
\hline & girls & boys & girls & boys & girls & boys & girls & boys \\
\hline Some university & 100.0 & 100.0 & 0.0 & 0.0 & 0.0 & 0.0 & 0.0 & 0.0 \\
\hline Some college & 23.4 & 16.6 & 76.7 & 83.4 & 0.0 & 0.0 & 0.0 & 0.0 \\
\hline High school grad & 23.7 & 19.5 & 42.6 & 41.6 & 33.7 & 38.9 & 0.0 & 0.0 \\
\hline Less than HS & 11.1 & 7.5 & 32.5 & 24.8 & 27.4 & 29.7 & 29.0 & 38.0 \\
\hline Total & 57.5 & 41.9 & 30.2 & 37.7 & 10.0 & 16.0 & 2.2 & 4.4 \\
\hline
\end{tabular}

Source: Youth in Transition Survey, author's calculations. 
Table 3.2. Summary and Origin of Variables Used in Empirical Analyses

\begin{tabular}{|c|c|c|c|}
\hline Variable name & Origin & Variable Type & Values \\
\hline \multicolumn{4}{|l|}{ Dependent variable: } \\
\hline Highest level of education taken & Cycle 3, Cycle 6 & Categorical & $(\text { Less HS })^{* *}$, HS only, college, university \\
\hline \multicolumn{4}{|l|}{ Explanatory variables: } \\
\hline Overall grade (senior year HS) & Cycle $3 *$ & Categorical & $<60,60 \mathrm{~s}, 70 \mathrm{~s}, 80 \mathrm{~s}, 90 \mathrm{~s}$ \\
\hline Reading score & Cycle 1, PISA & Continuous & Mean $=0$, Std Dev $=1$ \\
\hline Disengagement & Cycle 2, Student & Continuous & Mean $=0$, Std Dev $=1$ \\
\hline Learning Skills & Cycle 2, Student & Continuous & Mean $=0$, Std Dev $=1$ \\
\hline Perceptions & Cycle 2, Student & Continuous & Mean $=0$, Std Dev $=1$ \\
\hline Fatalism & Cycle 1, Student & Continuous & Mean $=0$, Std Dev $=1$ \\
\hline Self-esteem & Cycle 1, Student & Continuous & Mean $=0$, Std Dev $=1$ \\
\hline Mastery & Cycle 1, Student & Continuous & Mean $=0$, Std Dev $=1$ \\
\hline Family income (log) & Cycle 1, Parent & Continuous & $\min =0, \max =14.9$ \\
\hline Family status & Cycle 1, Parent & Dummy & Intact $=1$ \\
\hline Parental education & Cycle 1, Parent & Categorical & Less HS, HS only, College, Univ \\
\hline Province & Cycle 1, Parent & Dummies & One per province \\
\hline Urban & Cycle 1, Parent & Dummy & Urban $=1$ \\
\hline Gender & Cycle 1, Student & Dummy & Male $=1$ \\
\hline Immigration status & Cycle 1, Parent & Dummy & Immigrant $=1$ \\
\hline Parental hope for ed. & Cycle 1, Parent & Dummy & Hope for university. $=1$ \\
\hline Student's aspirations & Cycle 2, Student & Categorical & Less than univ, Undergrad, Grad degree \\
\hline
\end{tabular}


Table 3.3. Highest Education Taken (C3) by Grade, Boys vs Girls

\begin{tabular}{|c|c|c|c|c|c|c|c|c|c|c|c|c|}
\hline & \multicolumn{2}{|c|}{$<60$} & \multicolumn{2}{|c|}{ in 60s } & \multicolumn{2}{|c|}{ in 70s } & \multicolumn{2}{|c|}{ in 80s } & \multicolumn{2}{|c|}{ in 90s } & \multicolumn{2}{|c|}{ Total } \\
\hline & $\begin{array}{l}\text { Girls } \\
(\mathbf{3 . 0})\end{array}$ & $\begin{array}{l}\text { Boys } \\
\text { (5.1) }\end{array}$ & $\begin{array}{l}\text { Girls } \\
(11.3)\end{array}$ & $\begin{array}{l}\text { Boys } \\
\text { (21.5) }\end{array}$ & $\begin{array}{c}\text { Girls } \\
(\mathbf{3 6 . 6})\end{array}$ & $\begin{array}{c}\text { Boys } \\
(41.3)\end{array}$ & $\begin{array}{c}\text { Girls } \\
(\mathbf{3 9 . 3})\end{array}$ & $\begin{array}{l}\text { Boys } \\
(26.0)\end{array}$ & $\begin{array}{c}\text { Girls } \\
(9.7)\end{array}$ & $\begin{array}{l}\text { Boys } \\
(6.1)\end{array}$ & Girls & Boys \\
\hline No PSE & 56.5 & 77.3 & 52.6 & 56.5 & 33.6 & 44.1 & 14.6 & 15.4 & 10.0 & 10.4 & 25.7 & 36.8 \\
\hline College & 43.5 & 22.7 & 37.5 & 37.6 & 33.4 & 34.2 & 19.7 & 19.9 & 7.4 & 7.4 & 25.7 & 28.6 \\
\hline University & 0.0 & 0.0 & 9.93 & 5.9 & 33.0 & 21.7 & 65.7 & 64.7 & 82.6 & 82.2 & 48.6 & 34.6 \\
\hline
\end{tabular}


Table 3.4. Average Characteristics by Gender

\begin{tabular}{|c|c|c|c|c|c|}
\hline \multirow[b]{2}{*}{ Variable: } & \multicolumn{2}{|c|}{ Girls $(3,868)$} & \multicolumn{2}{|c|}{ Boys $(3,571)$} & \multirow{2}{*}{$\begin{array}{l}\text { Girls - Boys } \\
\text { p-value }\end{array}$} \\
\hline & Mean & Std. Dev. & Mean & Std. Dev. & \\
\hline Urban & 0.787 & 0.408 & 0.799 & 0.409 & 0.8275 \\
\hline Immigrant & 0.100 & 0.302 & 0.085 & 0.276 & $<0.0001$ \\
\hline Family income & 11.03 & 0.612 & 11.08 & 0.620 & 0.0009 \\
\hline Family status (intact) & 0.738 & 0.449 & 0.772 & 0.439 & 0.0451 \\
\hline \multicolumn{6}{|l|}{ Parental education: } \\
\hline Less than HS & 0.047 & 0.224 & 0.036 & 0.209 & 0.1508 \\
\hline HS only & 0.263 & 0.442 & 0.272 & 0.451 & 0.0728 \\
\hline College (reference) & 0.378 & & 0.360 & & \\
\hline University & 0.312 & 0.458 & 0.332 & 0.462 & 0.4390 \\
\hline \multicolumn{6}{|l|}{ Student aspirations: } \\
\hline Less than university (ref.) & 0.230 & & 0.346 & & \\
\hline Undergrad degree & 0.336 & 0.471 & 0.281 & 0.445 & $<0.0001$ \\
\hline Graduate degree & 0.434 & 0.493 & 0.373 & 0.475 & $<0.0001$ \\
\hline Parental hopes (univ.) & 0.719 & 0.456 & 0.629 & 0.491 & $<0.0001$ \\
\hline Reading score & 0.349 & 0.946 & -0.030 & 1.052 & $<0.0001$ \\
\hline Disengagement & -0.169 & 0.968 & 0.041 & 1.046 & $<0.0001$ \\
\hline Learning skills & 0.304 & 0.893 & -0.098 & 1.053 & $<0.0001$ \\
\hline Perceptions & 0.085 & 1.017 & -0.000 & 0.976 & $<0.0001$ \\
\hline Self esteem & -0.000 & 0.976 & 0.116 & 0.987 & $<0.0001$ \\
\hline Fatalism & 0.029 & 0.976 & -0.050 & 0.996 & $<0.0001$ \\
\hline Self-efficacy & -0.037 & 0.976 & 0.218 & 0.995 & $<0.0001$ \\
\hline
\end{tabular}

Source: Youth in Transition Survey, author's calculations. Calculated for those who have completed high school by Cycle 3 interview. 
Table 3.5. Coefficients from Ordered Logit Regressions, Cycle 3.

\begin{tabular}{|c|c|c|c|c|c|}
\hline & $\begin{array}{l}\text { Background } \\
\text { (A) }\end{array}$ & $\begin{array}{l}\text { Add senior } \\
\text { HS grade } \\
\text { (B) }\end{array}$ & $\begin{array}{l}\text { Add } \\
\text { aspirations } \\
\text { (C) }\end{array}$ & $\begin{array}{l}\text { Add } \\
\text { reading } \\
\text { (D) }\end{array}$ & $\begin{array}{l}\text { Add } \\
\text { non-cog } \\
\text { (E) }\end{array}$ \\
\hline \multirow[t]{2}{*}{ Male } & $-0.639 * * *$ & $-0.374 * * *$ & $-0.235 * * *$ & $-0.195 * *$ & $-0.145^{*}$ \\
\hline & $(0.074)$ & $(0.078)$ & $(0.083)$ & $(0.083)$ & $(0.091)$ \\
\hline \multirow{2}{*}{ Urban } & $0.395 * * *$ & $0.397 * * *$ & $0.161 *$ & 0.138 & $0.183 * *$ \\
\hline & $(0.081)$ & $(0.092)$ & $(0.086)$ & $(0.088)$ & $(0.090)$ \\
\hline \multirow[t]{2}{*}{ Immigrant } & $0.526^{* * *}$ & $0.447 * *$ & 0.104 & $0.298 *$ & 0.198 \\
\hline & $(0.203)$ & $(0.200)$ & $(0.177)$ & $(0.186)$ & $(0.194)$ \\
\hline \multirow[t]{2}{*}{ Family income } & $0.177 * *$ & $0.193 * * *$ & 0.084 & 0.056 & 0.027 \\
\hline & $(0.080)$ & $(0.078)$ & $(0.076)$ & $(0.074)$ & $(0.077)$ \\
\hline \multirow[t]{2}{*}{ Intact family } & $0.286^{* * *}$ & 0.136 & $0.219 * *$ & $0.261 * * *$ & $0.262 * * *$ \\
\hline & $(0.090)$ & $(0.096)$ & $(0.101)$ & $(0.101)$ & $(0.104)$ \\
\hline \multicolumn{6}{|l|}{ Parental education: } \\
\hline \multirow[t]{2}{*}{ Less HS } & $-0.924 * * *$ & $-0.658 * * *$ & $-0.505 * *$ & $-0.404 *$ & $-0.415^{*}$ \\
\hline & 0.199 & 0.214 & 0.213 & 0.220 & 0.229 \\
\hline \multirow[t]{2}{*}{ HS only } & $-0.242 * * *$ & $-0.212^{* *}$ & $-0.227 * *$ & $-0.179 *$ & -0.144 \\
\hline & $(0.086)$ & $(0.093)$ & $(0.097)$ & $(0.098)$ & $(0.101)$ \\
\hline College & reference & & & & \\
\hline \multirow{2}{*}{ University } & $0.862 * * *$ & $0.637 * * *$ & $0.445 * * *$ & $0.450 * * *$ & $0.472 * * *$ \\
\hline & $(0.101)$ & $(0.108)$ & $(0.110)$ & $(0.111)$ & $(0.114)$ \\
\hline \multicolumn{6}{|l|}{ Grade in senior HS: } \\
\hline \multirow[t]{2}{*}{$<60$} & & $-1.423 * * *$ & $-1.154 * * *$ & $-1.129 * * *$ & $-0.833 * *$ \\
\hline & & $(0.266)$ & $(0.299)$ & $(0.306)$ & $(0.357)$ \\
\hline \multirow[t]{2}{*}{ in $60 \mathrm{~s}$} & & $-0.677 * * *$ & $-0.405^{* * *}$ & $-0.359 * * *$ & -0.194 \\
\hline & & $(0.106)$ & $(0.119)$ & $(0.118)$ & $(0.132)$ \\
\hline in $70 \mathrm{~s}$ & reference & & & & \\
\hline \multirow[t]{2}{*}{ in $80 \mathrm{~s}$} & & $1.395 * * *$ & $1.175 * * *$ & $0.987 * * *$ & $0.868 * * *$ \\
\hline & & $(0.094)$ & $(0.099)$ & $(0.099)$ & $(0.103)$ \\
\hline \multirow[t]{2}{*}{ in 90s } & & $2.275 * * *$ & $1.934 * * *$ & $1.568 * * *$ & $1.434 * * *$ \\
\hline & & $(0.203)$ & $(0.182)$ & $(0.185)$ & $(0.182)$ \\
\hline \multicolumn{6}{|l|}{ Student aspirations: } \\
\hline \multirow{3}{*}{$\begin{array}{l}\text { Less than univ. } \\
\text { Undergrad degree }\end{array}$} & reference & & & & \\
\hline & & & $0.814 * * *$ & $0.732 * * *$ & $0.656^{* * *}$ \\
\hline & & & $(0.098)$ & $(0.103)$ & $(0.102)$ \\
\hline \multirow[t]{2}{*}{ Graduate degree (univ) } & & & $1.468 * * *$ & $1.344 * * *$ & $1.251 * * *$ \\
\hline & & & $(0.109)$ & $(0.110)$ & $(0.113)$ \\
\hline \multirow[t]{2}{*}{ Hope university (parents) } & & & $0.720 * * *$ & $0.572 * * *$ & $0.530 * * *$ \\
\hline & & & $(0.087)$ & $(0.092)$ & $(0.097)$ \\
\hline \multirow[t]{2}{*}{ Reading score } & & & & $0.402 * * *$ & $0.402 * * *$ \\
\hline & & & & $(0.058)$ & $(0.060)$ \\
\hline \multirow[t]{2}{*}{ Disengagement } & & & & & -0.016 \\
\hline & & & & & $(0.061)$ \\
\hline Learning skills & & & & & $0.309 * * *$ \\
\hline & & & & & $(0.060)$ \\
\hline Perceptions & & & & & -0.024 \\
\hline & & & & & $(0.054)$ \\
\hline Self-esteem & & & & & -0.044 \\
\hline & & & & & $(0.063)$ \\
\hline Fatalism & & & & & -0.094 \\
\hline & & & & & $(0.062)$ \\
\hline Self-efficacy & & & & & 0.043 \\
\hline & & & & & $(0.046)$ \\
\hline Observations & 7,634 & 7,619 & 7,072 & 7,067 & 6,604 \\
\hline Pseudo R2 & 0.0694 & 0.1595 & 0.2167 & 0.2279 & 0.2288 \\
\hline
\end{tabular}


Table 3.6. AME using Ordered Logit (Model E)

\begin{tabular}{|c|c|c|c|c|c|c|}
\hline & \multicolumn{2}{|c|}{ High School Graduate } & \multicolumn{2}{|c|}{ College } & \multicolumn{2}{|c|}{ University } \\
\hline & Probability & Std. Err. & Probability & Std. Err. & Probability & Std. Err. \\
\hline Male & $0.020^{*}$ & 0.013 & 0.003 & 0.002 & $-0.023^{*}$ & 0.014 \\
\hline Urban & $-0.028 * *$ & 0.013 & $-0.004 * *$ & 0.002 & $0.032 * *$ & 0.014 \\
\hline Immigrant & -0.021 & 0.026 & -0.004 & 0.005 & 0.024 & 0.031 \\
\hline Family income (log) & -0.002 & 0.010 & 0.000 & 0.002 & 0.002 & 0.012 \\
\hline Intact family & $-0.035 * *$ & 0.015 & $-0.005 * * *$ & 0.002 & $0.040 * *$ & 0.016 \\
\hline \multicolumn{7}{|l|}{ Parental education: } \\
\hline Less than HS & $0.061 *$ & 0.035 & $0.005 * * *$ & 0.002 & $-0.066^{*}$ & 0.036 \\
\hline HS grad & 0.022 & 0.015 & 0.003 & 0.002 & -0.025 & 0.017 \\
\hline College & reference & & & & & \\
\hline University & $-0.064 * * *$ & 0.016 & $-0.015 * * *$ & 0.004 & $0.079 * * *$ & 0.019 \\
\hline \multicolumn{7}{|c|}{ Grade in senior year high school: } \\
\hline$<60 s$ & $0.124 *$ & 0.066 & -0.006 & 0.011 & $-0.118 * *$ & 0.055 \\
\hline in $60 \mathrm{~s}$ & 0.035 & 0.023 & $0.002 *$ & 0.001 & -0.037 & 0.023 \\
\hline in $70 \mathrm{~s}$ & reference & & & & & \\
\hline in $80 \mathrm{~s}$ & $-0.130 * * *$ & 0.014 & $-0.038 * * *$ & 0.006 & $0.167 * * *$ & 0.020 \\
\hline in 90s & $-0.187 * * *$ & 0.021 & $-0.078 * * *$ & 0.017 & $0.265 * * *$ & 0.036 \\
\hline Less than university & reference & & & & & \\
\hline Undergrad degree & $-0.108 * * *$ & 0.017 & $-0.005 * *$ & 0.002 & $0.113 * * *$ & 0.017 \\
\hline Graduate degree & $-0.188 * * *$ & 0.017 & $-0.030 * * *$ & 0.006 & $0.217 * * *$ & 0.020 \\
\hline Hope university (parents) & $-0.078 * * *$ & 0.015 & $-0.010 * * *$ & 0.002 & $0.087 * * *$ & 0.017 \\
\hline Reading score & $-0.057 * * *$ & 0.008 & $-0.009 * * *$ & 0.002 & $0.066 * * *$ & 0.010 \\
\hline Disengagement & 0.003 & 0.008 & 0.000 & 0.001 & -0.003 & 0.010 \\
\hline Learning skills & $-0.046^{* * *}$ & 0.008 & $-0.007 * * *$ & 0.001 & $0.053 * * *$ & 0.009 \\
\hline Perceptions & 0.005 & 0.008 & 0.001 & 0.001 & -0.006 & 0.009 \\
\hline Self-esteem & 0.005 & 0.009 & 0.001 & 0.001 & -0.006 & 0.010 \\
\hline Fatalism & $0.014^{*}$ & 0.009 & $0.002 *$ & 0.001 & -0.016 & 0.010 \\
\hline Self-efficacy & -0.005 & 0.007 & -0.001 & 0.001 & 0.005 & 0.008 \\
\hline
\end{tabular}

Source: Youth in Transition Survey, author's calculations. *, **, *** represent significance at the $10 \%, 5 \%$ and $1 \%$ levels respectively. 
Table 3.7a. AME from the Generalized Ordered Logit Estimation (Model E)

\begin{tabular}{|c|c|c|c|c|c|c|}
\hline & \multicolumn{2}{|c|}{ High School Graduate } & \multicolumn{2}{|c|}{ College } & \multicolumn{2}{|c|}{ University } \\
\hline & Probability & Std. Err. & Probability & Std. Err. & Probability & Std. Err. \\
\hline Male & 0.025 & 0.017 & 0.000 & 0.014 & $-0.024^{*}$ & 0.013 \\
\hline Urban & $-0.039 * *$ & 0.017 & 0.012 & 0.014 & $0.027 * *$ & 0.013 \\
\hline Immigrant & -0.006 & 0.038 & -0.034 & 0.029 & 0.040 & 0.027 \\
\hline Family income & -0.010 & 0.016 & 0.018 & 0.013 & -0.009 & 0.010 \\
\hline Intact family & $-0.037 *$ & 0.020 & 0.001 & 0.017 & $0.036 * *$ & 0.015 \\
\hline \multicolumn{7}{|l|}{ Parental education: } \\
\hline Less HS & 0.065 & 0.043 & -0.006 & 0.036 & -0.059 & 0.036 \\
\hline HS only & 0.022 & 0.020 & 0.000 & 0.018 & -0.022 & 0.015 \\
\hline College & reference & & & & & \\
\hline University & $-0.046^{* *}$ & 0.022 & -0.023 & 0.016 & $0.069 * * *$ & 0.015 \\
\hline \multicolumn{7}{|l|}{ Grade in senior year high } \\
\hline \multicolumn{7}{|l|}{ school: } \\
\hline$<60$ & 0.076 & 0.063 & $0.521 * * *$ & 0.163 & $-0.597 * * *$ & 0.150 \\
\hline in $60 \mathrm{~s}$ & 0.019 & 0.025 & $0.086^{* * *}$ & 0.029 & $-0.105 * * *$ & 0.025 \\
\hline in $70 \mathrm{~s}$ & reference & & & & & \\
\hline in $80 \mathrm{~s}$ & $-0.122 * * *$ & 0.021 & 0.007 & 0.017 & $0.115 * * *$ & 0.013 \\
\hline in $90 \mathrm{~s}$ & $-0.179 * * *$ & 0.041 & 0.008 & 0.029 & $0.171 * * *$ & 0.025 \\
\hline \multicolumn{7}{|l|}{ Aspirations: } \\
\hline Less than university & reference & & & & & \\
\hline Undergrad degree & $-0.044 * *$ & 0.021 & $-0.225 * * *$ & 0.025 & $0.270 * * *$ & 0.021 \\
\hline Graduate degree & $-0.096^{* * *}$ & 0.021 & $-0.250 * * *$ & 0.023 & $0.346 * * *$ & 0.021 \\
\hline Hope university (parents) & $-0.046^{* *}$ & 0.019 & $-0.080 * * *$ & 0.018 & $0.126^{* * *}$ & 0.015 \\
\hline Reading score & $-0.058 * * *$ & 0.011 & -0.005 & 0.008 & $0.063 * * *$ & 0.009 \\
\hline Disengagement & 0.001 & 0.011 & 0.004 & 0.009 & -0.005 & 0.009 \\
\hline Learning skills & $-0.060 * * *$ & 0.011 & $0.020 * * *$ & 0.008 & $0.040 * * *$ & 0.008 \\
\hline Perceptions & 0.007 & 0.010 & -0.004 & 0.008 & -0.003 & 0.008 \\
\hline Self-esteem & 0.006 & 0.012 & -0.004 & 0.010 & -0.002 & 0.009 \\
\hline Fatalism & 0.018 & 0.012 & -0.004 & 0.010 & -0.014 & 0.009 \\
\hline Self-efficacy & -0.005 & 0.009 & 0.002 & 0.008 & 0.003 & 0.007 \\
\hline
\end{tabular}

Source: Youth in Transition Survey, author's calculations. ${ }^{*}, * *, * *$ represent significance at the $10 \%, 5 \%$ and $1 \%$ levels respectively. 
Table 3.7b. AMEs from Ordered Logit vs. Generalized Ordered Logit Estimations

\begin{tabular}{|c|c|c|c|c|c|c|}
\hline & \multicolumn{2}{|c|}{ High School Graduate } & \multicolumn{2}{|c|}{ College } & \multicolumn{2}{|c|}{ University } \\
\hline & GOLOGIT & OLOGIT & GOLOGIT & OLOGIT & GOLOGIT & OLOGIT \\
\hline Male & $0.024 *$ & $0.020 *$ & -0.001 & 0.003 & $-0.023 *$ & $-0.023 *$ \\
\hline Urban & $-0.040^{*}$ & $-0.028 * *$ & 0.012 & $-0.004 * *$ & $0.028 * *$ & $0.032 * *$ \\
\hline Immigrant & -0.004 & -0.021 & -0.033 & -0.004 & 0.037 & 0.024 \\
\hline Family income (log) & -0.011 & -0.002 & 0.018 & 0.000 & -0.007 & 0.002 \\
\hline Intact family & $-0.036^{*}$ & $-0.035 * *$ & 0.000 & $-0.005 * * *$ & $0.036 * *$ & $0.040 * *$ \\
\hline \multicolumn{7}{|l|}{ Parental education: } \\
\hline Less than HS & 0.063 & $0.061 *$ & -0.008 & $0.005 * * *$ & -0.055 & $-0.066^{*}$ \\
\hline HS grad & 0.021 & 0.022 & 0.001 & 0.003 & -0.022 & -0.025 \\
\hline College & reference & & & & & \\
\hline University & $-0.045 * *$ & $-0.064 * * *$ & -0.022 & $-0.015 * * *$ & $0.067 * * *$ & $0.079 * * *$ \\
\hline \multicolumn{7}{|c|}{ Grade in senior year high school: } \\
\hline$<60 \mathrm{~s} \dagger$ & 0.026 & $0.124 *$ & $0.101 * * *$ & -0.006 & $-0.127 * * *$ & $-0.118 * *$ \\
\hline in $60 \mathrm{~s} \uparrow$ & & 0.035 & & $0.002 *$ & & -0.037 \\
\hline in $70 \mathrm{~s}$ & reference & & & & & \\
\hline in 80s & $-0.122 * * *$ & $-0.130 * * *$ & 0.006 & $-0.038 * * *$ & $0.116^{* * *}$ & $0.167 * * *$ \\
\hline in $90 \mathrm{~s}$ & $-0.179 * * *$ & $-0.187 * * *$ & 0.007 & $-0.078 * * *$ & $0.172 * * *$ & $0.265 * * *$ \\
\hline \multicolumn{7}{|l|}{ Aspirations: } \\
\hline Less than university & reference & & & & & \\
\hline Undergrad degree & $-0.044 * *$ & $-0.108 * * *$ & $-0.225 * * *$ & $-0.005^{* *}$ & $0.269 * * *$ & $0.113 * * *$ \\
\hline Graduate degree & $-0.097 * * *$ & $-0.188 * * *$ & $-0.251 * * *$ & $-0.030 * * *$ & $0.347 * * *$ & $0.217 * * *$ \\
\hline Hope University (parents) & $-0.046^{* *}$ & $-0.078 * * *$ & $-0.081 * * *$ & $-0.010 * * *$ & $0.127 * * *$ & $0.087 * * *$ \\
\hline Reading score & $-0.058 * * *$ & $-0.057 * * *$ & -0.006 & $-0.009 * * *$ & $0.064 * * *$ & $0.066 * * *$ \\
\hline Disengagement & 0.001 & 0.003 & 0.004 & 0.000 & -0.005 & -0.003 \\
\hline Learning skills & $-0.061 * * *$ & $-0.046 * * *$ & $0.021 * * *$ & $-0.007 * * *$ & $0.040 * * *$ & $0.053 * * *$ \\
\hline Perceptions & 0.008 & 0.005 & -0.004 & 0.001 & -0.004 & -0.006 \\
\hline Self-esteem & 0.006 & 0.005 & -0.003 & 0.001 & -0.003 & -0.006 \\
\hline Fatalism & 0.018 & $0.014 *$ & -0.004 & $0.002 *$ & -0.014 & $-0.016^{*}$ \\
\hline Self-efficacy & -0.006 & -0.005 & 0.002 & -0.001 & 0.003 & 0.005 \\
\hline
\end{tabular}

Source: Youth in Transition Survey, author's calculations.

$\dagger$ Grade categories of "in 60 s" and " $<60 \%$ " were combined for the generalized ordered logit regressions because of low cell counts which make the algorithm unstable.

$*, * *, * * *$ represent significance at the $10 \%, 5 \%$ and $1 \%$ levels respectively. 
Table 3.8. Marginal Effects by Gender (Model E)

\begin{tabular}{|c|c|c|c|c|c|c|}
\hline & \multicolumn{2}{|c|}{ Prob. high school graduate } & \multicolumn{2}{|c|}{ Prob. some college } & \multicolumn{2}{|c|}{ Prob. some university } \\
\hline & girls & boys & girls & boys & girls & boys \\
\hline Urban & -0.007 & $-0.043 * *$ & -0.002 & 0.001 & 0.009 & $0.042 * *$ \\
\hline Immigrant & -0.039 & -0.004 & -0.014 & 0.000 & 0.053 & 0.004 \\
\hline Family income (log) & $-0.028 *$ & 0.019 & $-0.009 *$ & 0.000 & $0.037 *$ & -0.019 \\
\hline Intact family & -0.021 & $-0.044 *$ & -0.006 & 0.001 & 0.027 & $0.043 *$ \\
\hline \multicolumn{7}{|l|}{ Parental education: } \\
\hline Less than high school & 0.029 & 0.085 & 0.008 & -0.007 & -0.036 & $-0.078 *$ \\
\hline High school only & 0.012 & 0.035 & 0.003 & -0.002 & -0.015 & -0.034 \\
\hline College & reference & & & & & \\
\hline University & $-0.069 * * *$ & $-0.058 * * *$ & $-0.028 * * *$ & -0.003 & $0.097 * * *$ & $0.061 * *$ \\
\hline \multicolumn{7}{|c|}{ Grade in senior year high school: } \\
\hline$<60 \%$ & 0.102 & $0.156^{*}$ & $0.014 * * *$ & -0.039 & -0.116 & $-0.118 * *$ \\
\hline in the $60 \mathrm{~s}$ & 0.036 & 0.037 & 0.008 & -0.005 & -0.044 & -0.032 \\
\hline in the $70 \mathrm{~s}$ & reference & & & & & \\
\hline in the $80 \mathrm{~s}$ & $-0.078 * * *$ & $-0.193 * * *$ & $-0.031 * * *$ & $-0.041 * * *$ & $0.109 * * *$ & $0.234 * * *$ \\
\hline in the $90 \mathrm{~s}$ & $-0.131 * * *$ & $-0.253 * * *$ & -0.065 & $-0.091 * * *$ & $0.196 * * *$ & $0.344 * * *$ \\
\hline \multicolumn{7}{|l|}{ Aspirations: } \\
\hline Less than university & reference & & & & & \\
\hline Undergrad degree & $-0.125 * * *$ & $-0.091 * * *$ & $-0.021 * * *$ & $0.008 * *$ & $0.146^{* * *}$ & $0.083 * * *$ \\
\hline Graduate degree & $-0.198 * * *$ & $-0.172 * * *$ & $-0.058 * * *$ & -0.002 & $0.256 * * *$ & $0.174 * * *$ \\
\hline Hope university (parents). & $-0.088 * * *$ & $-0.063 * * *$ & $-0.024 * * *$ & 0.001 & $0.112 * * *$ & $0.061 * * *$ \\
\hline Reading score & $-0.071 * * *$ & $-0.041 * * *$ & $-0.022 * * *$ & 0.000 & $0.094 * * *$ & $0.041 * * *$ \\
\hline Disengagement & -0.003 & 0.005 & -0.001 & 0.000 & 0.004 & -0.005 \\
\hline Learning skills & $-0.043 * * *$ & $-0.049 * * *$ & $-0.014 * * *$ & 0.000 & $0.057 * * *$ & $0.049 * * *$ \\
\hline Perceptions-teachers & -0.002 & 0.013 & -0.001 & 0.000 & 0.002 & -0.013 \\
\hline Self-esteem & -0.009 & 0.018 & -0.003 & 0.000 & 0.012 & -0.018 \\
\hline Fatalism & 0.000 & $0.030 * *$ & 0.000 & 0.000 & 0.000 & $-0.030 * *$ \\
\hline Self-efficacy & 0.003 & -0.015 & 0.001 & 0.000 & -0.004 & 0.015 \\
\hline
\end{tabular}

Source: Youth in Transition Survey, author's calculations. *, **, *** represent significance at the $10 \%, 5 \%$ and $1 \%$ levels respectively. 
Table 3.9. Highest Education Taken (C6) by Grade and Gender.

\begin{tabular}{|c|c|c|c|c|c|c|c|c|c|c|c|c|}
\hline & \multicolumn{2}{|c|}{$<60$} & \multicolumn{2}{|c|}{ in 60s } & \multicolumn{2}{|c|}{ in $70 \mathrm{~s}$} & \multicolumn{2}{|c|}{ in $80 \mathrm{~s}$} & \multicolumn{2}{|c|}{ in $90 \mathrm{~s}$} & \multicolumn{2}{|c|}{ Total } \\
\hline & $\begin{array}{c}\text { Girls } \\
(3.0) \\
\end{array}$ & $\begin{array}{l}\text { Boys } \\
(5.1) \\
\end{array}$ & $\begin{array}{c}\text { Girls } \\
(11.3)\end{array}$ & $\begin{array}{c}\text { Boys } \\
(21.5) \\
\end{array}$ & $\begin{array}{r}\text { Girls } \\
\mathbf{( 3 6 . 6 )} \\
\end{array}$ & $\begin{array}{c}\text { Boys } \\
(41.3)\end{array}$ & $\begin{array}{c}\text { Girls } \\
(39.3)\end{array}$ & $\begin{array}{c}\text { Boys } \\
(26.0) \\
\end{array}$ & $\begin{array}{c}\text { Girls } \\
(9.7) \\
\end{array}$ & $\begin{array}{c}\text { Boys } \\
(6.1)\end{array}$ & Girls & Boys \\
\hline No PSE & 24.7 & 31.6 & 23.8 & 28.3 & 12.9 & 18.5 & 4.5 & 6.3 & 2.2 & 1.9 & 10.0 & 16.7 \\
\hline College & 66.1 & 61.6 & 54.8 & 56.4 & 40.0 & 47.4 & 20.7 & 17.4 & 10.8 & 10.0 & 31.7 & 39.4 \\
\hline Univer. & 9.2 & 6.8 & 21.4 & 15.3 & 47.1 & 34.2 & 74.9 & 76.3 & 87.0 & 88.1 & 58.3 & 43.9 \\
\hline
\end{tabular}

Source: Youth in Transition Survey, author's calculations. 
Table 3.10. Average Characteristics by Highest Education Taken, C3 and C6.

\begin{tabular}{|c|c|c|c|c|c|c|c|c|}
\hline & \multicolumn{2}{|c|}{ University } & \multicolumn{2}{|c|}{ College } & \multicolumn{2}{|c|}{ HS grad } & \multicolumn{2}{|c|}{ Less HS } \\
\hline & $\begin{array}{c}\text { Cycle } 3 \\
(37.9 \%)\end{array}$ & $\begin{array}{c}\text { Cycle 6 } \\
(49.5 \%)\end{array}$ & $\begin{array}{l}\text { Cycle } 3 \\
(24.5 \%)\end{array}$ & $\begin{array}{c}\text { Cycle } 6 \\
(34.1 \%)\end{array}$ & $\begin{array}{l}\text { Cycle } 3 \\
(28.0 \%)\end{array}$ & $\begin{array}{c}\text { Cycle 6 } \\
(13.1 \%)\end{array}$ & $\begin{array}{l}\text { Cycle } 3 \\
(9.6 \%)\end{array}$ & $\begin{array}{l}\text { Cycle 6 } \\
(3.3 \%)\end{array}$ \\
\hline \multirow[t]{2}{*}{ Reading score } & 0.71 & 0.61 & -0.06 & -0.24 & -0.24 & -0.51 & -0.60 & -0.73 \\
\hline & $(0.84)$ & $(0.85)$ & $(0.89)$ & $(0.91)$ & $(0.95)$ & $(1.00)$ & $(0.96)$ & $(0.88)$ \\
\hline \multirow[t]{2}{*}{ Learning Skills } & 0.44 & 0.31 & 0.00 & -0.14 & -0.26 & -0.51 & -0.94 & -1.02 \\
\hline & $(0.74)$ & $(0.84)$ & $(0.94)$ & $(1.01)$ & $(1.00)$ & (1.06) & (1.17) & $(1.23)$ \\
\hline \multirow[t]{2}{*}{ Self-efficacy } & 0.42 & 0.36 & -0.07 & -0.20 & -0.18 & -0.33 & -0.47 & -0.70 \\
\hline & $(0.91)$ & $(0.92)$ & $(0.97)$ & (0.99) & $(0.98)$ & $(0.98)$ & $(1.06)$ & $(1.05)$ \\
\hline \multirow[t]{2}{*}{ Fatalism } & -0.20 & -0.15 & 0.05 & 0.12 & 0.16 & 0.24 & 0.20 & 0.23 \\
\hline & $(0.96)$ & $(0.97)$ & $(0.96)$ & (0.99) & $(0.97)$ & $(0.96)$ & $(0.98)$ & $(0.86)$ \\
\hline \multirow[t]{2}{*}{ Self-esteem } & 0.27 & 0.22 & 0.00 & -0.05 & -0.09 & -0.17 & -0.19 & -0.36 \\
\hline & $(0.97)$ & $(0.98)$ & $(0.98)$ & $(0.97)$ & $(0.96)$ & $(0.95)$ & $(0.99)$ & $(1.02)$ \\
\hline \multirow[t]{2}{*}{ Disengagement } & -0.28 & -0.21 & 0.06 & 0.15 & 0.12 & 0.30 & 0.76 & 0.77 \\
\hline & $(0.87)$ & $(0.93)$ & (1.03) & $(1.02)$ & $(0.97)$ & $(1.00)$ & $(1.21)$ & $(1.41)$ \\
\hline \multirow[t]{2}{*}{ Perceptions } & 0.21 & 0.16 & -0.04 & -0.12 & -0.10 & -0.22 & -0.59 & -0.67 \\
\hline & $(0.90)$ & $(0.94)$ & (0.99) & $(1.01)$ & $(0.93)$ & $(0.93)$ & $(1.22)$ & $(1.22)$ \\
\hline \multirow[t]{2}{*}{ Urban } & 0.84 & 0.85 & 0.78 & 0.75 & 0.74 & 0.70 & 0.77 & 0.77 \\
\hline & $(0.36)$ & $(0.36)$ & $(0.41)$ & $(0.43)$ & $(0.44)$ & $(0.46)$ & $(0.42)$ & $(0.42)$ \\
\hline \multirow[t]{2}{*}{ Male } & 0.42 & 0.44 & 0.54 & 0.57 & 0.59 & 0.63 & 0.62 & 0.68 \\
\hline & $(0.49)$ & $(0.50)$ & $(0.50)$ & $(0.50)$ & $(0.49)$ & $(0.48)$ & $(0.49)$ & $(0.47)$ \\
\hline \multirow[t]{2}{*}{ Family income (log) } & 11.15 & 11.13 & 11.03 & 10.99 & 10.97 & 10.88 & 10.78 & 10.68 \\
\hline & $(0.63)$ & $(0.63)$ & $(0.54)$ & $(0.55)$ & $(0.62)$ & $(0.60)$ & $(0.60)$ & $(0.55)$ \\
\hline \multirow[t]{2}{*}{ Intact family } & 0.81 & 0.80 & 0.75 & 0.71 & 0.71 & 0.65 & 0.50 & 0.47 \\
\hline & $(0.39)$ & $(0.40)$ & $(0.44)$ & $(0.45)$ & $(0.45)$ & $(0.48)$ & $(0.50)$ & $(0.50)$ \\
\hline \multirow[t]{2}{*}{ Hope university (par.) } & 0.89 & 0.86 & 0.55 & 0.48 & 0.50 & 0.38 & 0.41 & 0.39 \\
\hline & $(0.31)$ & $(0.35)$ & $(0.50)$ & $(0.50)$ & $(0.50)$ & $(0.48)$ & $(0.49)$ & $(0.49)$ \\
\hline \multirow[t]{2}{*}{ Parental education } & 3.26 & 3.22 & 2.82 & 2.75 & 2.74 & 2.47 & 2.53 & 2.50 \\
\hline & $(0.81)$ & $(0.81)$ & $(0.83)$ & $(0.83)$ & $(0.86)$ & $(0.82)$ & $(0.86)$ & $(0.95)$ \\
\hline \multirow[t]{2}{*}{ Immigrant } & 0.12 & 0.12 & 0.07 & 0.07 & 0.07 & 0.02 & 0.08 & 0.05 \\
\hline & $(0.33)$ & $(0.33)$ & $(0.25)$ & $(0.26)$ & $(0.25)$ & $(0.12)$ & $(0.26)$ & $(0.21)$ \\
\hline \multirow[t]{2}{*}{ Senior HS grade } & 3.86 & 3.70 & 3.05 & 2.86 & 2.87 & 2.69 & 2.29 & 2.10 \\
\hline & $(0.71)$ & $(0.79)$ & $(0.81)$ & $(0.86)$ & $(0.85)$ & $(0.83)$ & $(0.90)$ & $(0.90)$ \\
\hline
\end{tabular}

Source: Youth in Transition Survey, author's calculations. 
Table 3.11. AMEs, Short-Term (C3) vs. Longer-Term (C6).

\begin{tabular}{|c|c|c|c|c|c|c|}
\hline & \multicolumn{2}{|c|}{ High school graduate } & \multicolumn{2}{|c|}{ College } & \multicolumn{2}{|c|}{ University } \\
\hline & Cycle 3 & Cycle 6 & Cycle 3 & Cycle 6 & Cycle 3 & Cycle 6 \\
\hline Male & $0.020^{*}$ & 0.010 & 0.003 & 0.009 & $-0.023 *$ & -0.020 \\
\hline Urban & $-0.028 * *$ & $-0.013^{*}$ & $-0.004 * *$ & $-0.011^{*}$ & $0.032 * *$ & $0.024 *$ \\
\hline Immigrant & -0.021 & $-0.038 * * *$ & -0.004 & $-0.042 * *$ & 0.024 & $0.080 * * *$ \\
\hline Family income (log) & -0.002 & -0.008 & 0.000 & -0.007 & 0.002 & 0.016 \\
\hline Intact family & $-0.035 * *$ & $-0.024 * * *$ & $-0.005 * * *$ & $-0.021 * * *$ & $0.040 * *$ & $0.045 * * *$ \\
\hline \multicolumn{7}{|l|}{ Parental education: } \\
\hline Less than HS & $0.061 *$ & $0.070 * * *$ & $0.005 * * *$ & $0.054 * * *$ & $-0.066^{* *}$ & $-0.124 * * *$ \\
\hline HS grad & 0.022 & $0.029 * * *$ & 0.003 & $0.027 * * *$ & -0.025 & $-0.057 * * *$ \\
\hline College & reference & & & & & \\
\hline University & $-0.064 * * *$ & $-0.034 * * *$ & $-0.015^{* * *}$ & $-0.045^{* * *}$ & $0.079 * * *$ & $0.079 * * *$ \\
\hline \multicolumn{7}{|c|}{ Grade in senior year high school: } \\
\hline$<60 \mathrm{~s}$ & $0.124^{*}$ & $0.039 *$ & -0.006 & $0.033^{*}$ & $-0.118 * *$ & $-0.071^{*}$ \\
\hline in $60 \mathrm{~s}$ & 0.035 & $0.019 *$ & $0.002 *$ & $0.018 *$ & -0.037 & $-0.037 *$ \\
\hline in $70 \mathrm{~s}$ & reference & & & & & \\
\hline in $80 \mathrm{~s}$ & $-0.130 * * *$ & $-0.054 * * *$ & $-0.038 * * *$ & $-0.077 * * *$ & $0.167 * * *$ & $0.131 * * *$ \\
\hline in 90s & $-0.187 * * *$ & $-0.072 * * *$ & $-0.078 * * *$ & $-0.117 * * *$ & $0.265 * * *$ & $0.190 * * *$ \\
\hline \multicolumn{7}{|l|}{ Aspirations: } \\
\hline Less than university & reference & & & & & \\
\hline Undergrad degree & $-0.108 * * *$ & $-0.103 * * *$ & $-0.005 * *$ & $-0.103 * * *$ & $0.113 * * *$ & $0.205 * * *$ \\
\hline Graduate degree & $-0.188 * * *$ & $-0.135 * * *$ & $-0.030 * * *$ & $-0.189 * * *$ & $0.217 * * *$ & $0.324 * * *$ \\
\hline Hope university (parents) & $-0.078 * * *$ & $-0.051 * * *$ & $-0.010 * * *$ & $-0.051 * * *$ & $0.087 * * *$ & $0.102 * * *$ \\
\hline Reading score & $-0.057 * * *$ & $-0.039 * * *$ & $-0.009 * * *$ & $-0.035^{* * *}$ & $0.066^{* * *}$ & $0.074 * * *$ \\
\hline Disengagement & 0.003 & 0.005 & 0.000 & 0.004 & -0.003 & -0.009 \\
\hline Learning skills & $-0.046 * * *$ & $-0.014 * * *$ & $-0.007 * * *$ & $-0.012 * * *$ & $0.053 * * *$ & $0.026 * * *$ \\
\hline Perceptions & 0.005 & 0.001 & 0.001 & 0.001 & -0.006 & -0.001 \\
\hline Self-esteem & 0.005 & 0.003 & 0.001 & 0.003 & -0.006 & -0.005 \\
\hline Fatalism & $0.014^{*}$ & 0.006 & 0.002 & 0.005 & $-0.016^{*}$ & -0.011 \\
\hline Self-efficacy & -0.005 & -0.004 & -0.001 & -0.003 & 0.005 & 0.007 \\
\hline
\end{tabular}

Source: Youth in Transition Survey, author's calculations. * , **, *** represent significance at the 10\%, 5\% and 1\% levels respectively. 
Table 3.12. CIP by Gender and Senior Year Grade, University Participants (C3).

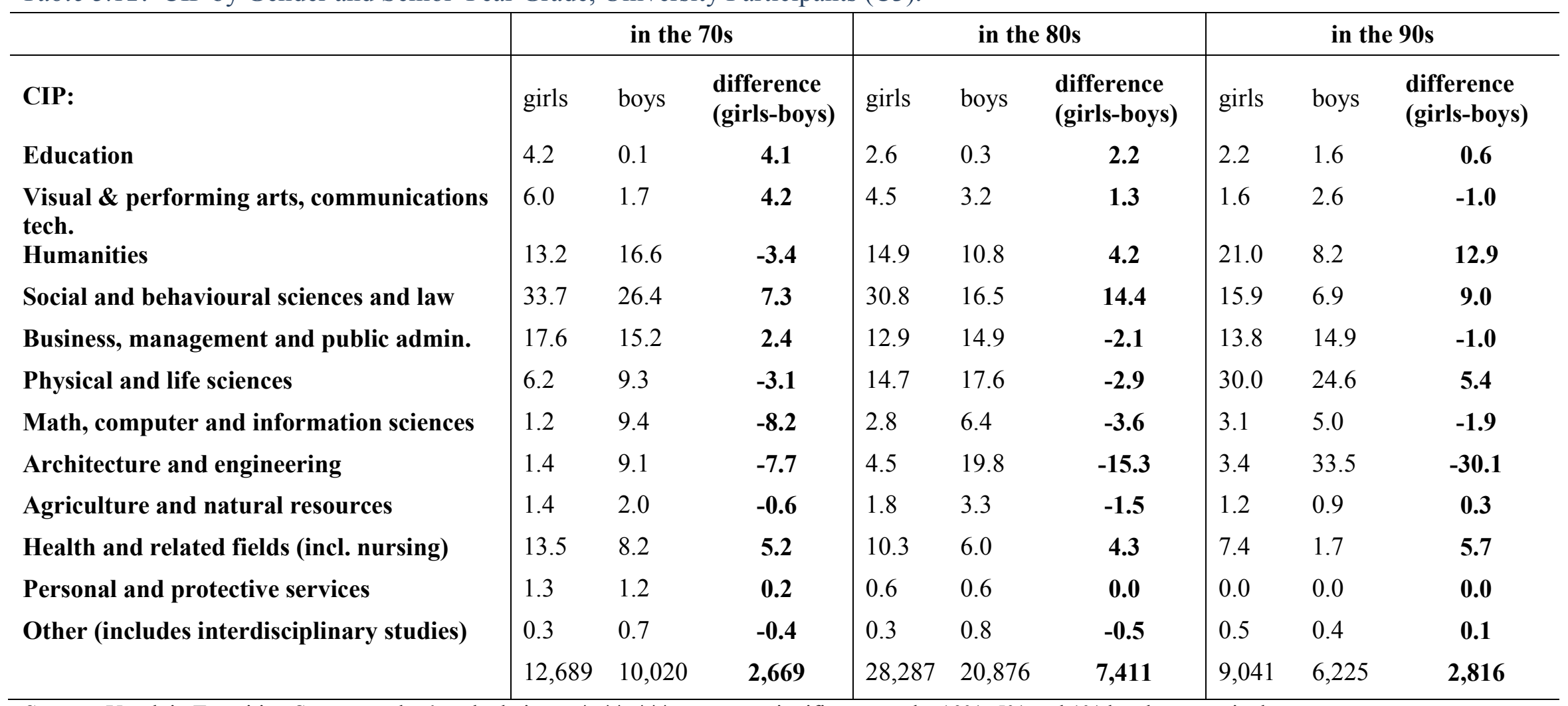

Source: Youth in Transition Survey, author's calculations. ${ }^{*}, * *, * * *$ represent significance at the $10 \%, 5 \%$ and $1 \%$ levels respectivel 
Figure 3-1. Rates of Participation in PSE from Cycle 3 to Cycle 6

\section{Chart Title}

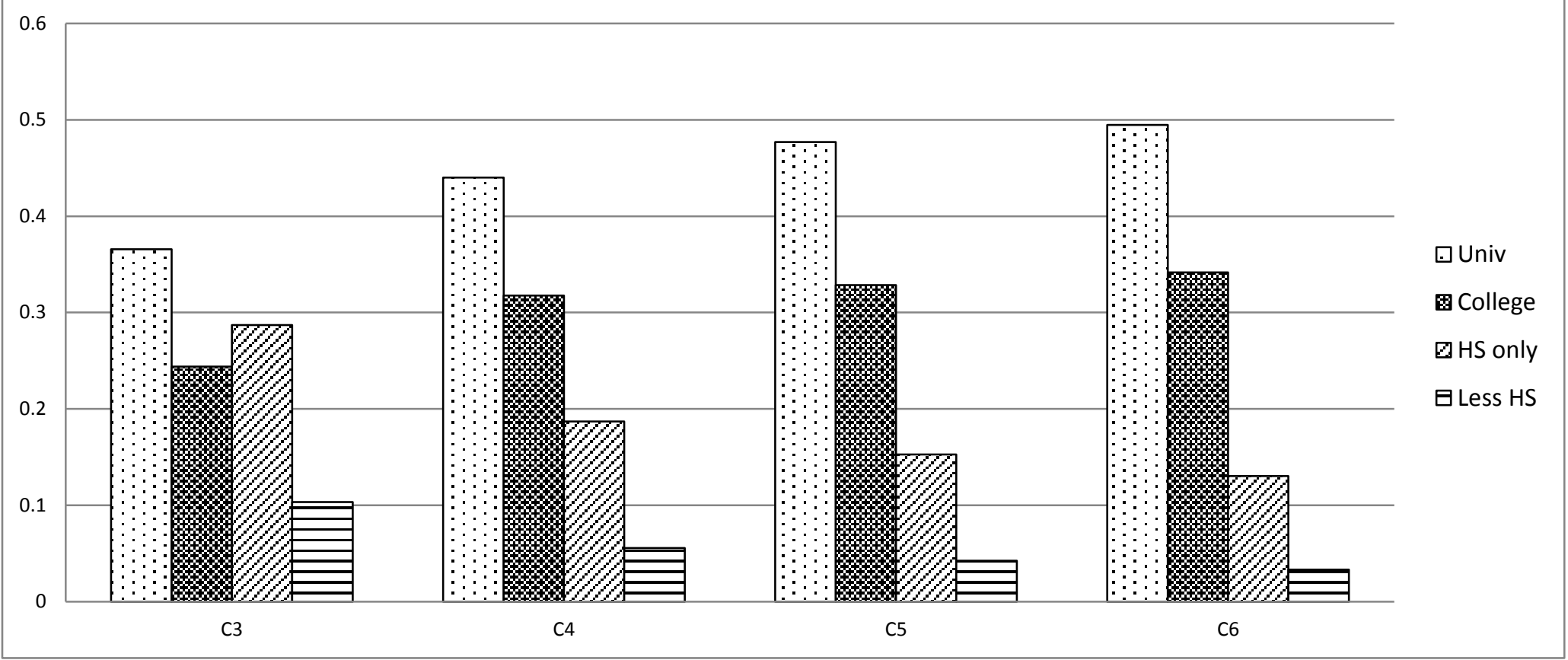

Source: Youth in Transition Survey, author's calculations. 
Figure 3-2. PSE Participation Rates by Gender, Cycles 3 to 6

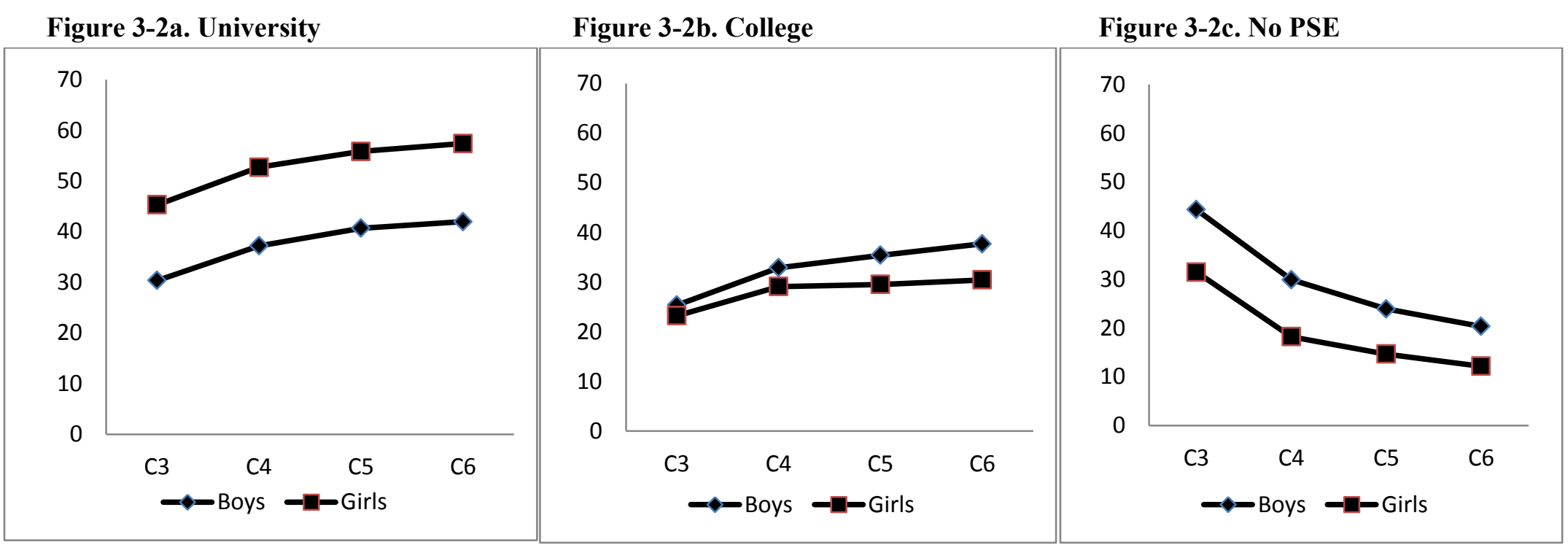

Source: Youth in Transition Survey, author's calculations. 


\section{Appendices:}

\section{Appendix 3.A: Attrition}

After dropping individuals from Quebec (as reported in Cycle1) and records without a parent survey, the Cycle 1 sample consists of 22,066 observations. The average characteristics of this sample are shown in the first data column of Table A-3, labeled "Cycle 1". All summary statistics are weighted using the weights provided by Statistics Canada; this initial sample was then representative of the Canadian population of 15 year olds in $2000 .^{73}$ The weighted cycle 1 population is made up of are equal number of men and women, with $71 \%$ of the weighted sample coming from an intact family, $10 \%$ being immigrants, $65 \%$ with parents who hope their children will go on to university, and an average family income is $\$ 71,364$.

Table A-3. Selected Average Characteristics of Weighted Populations, C1-C6

\begin{tabular}{lcccccc}
\hline & $\begin{array}{c}\text { Cycle 1 } \\
(\mathbf{2 2 , 0 6 6 )}\end{array}$ & $\begin{array}{c}\text { Cycle 2 } \\
\mathbf{( 2 0 , 6 3 9 )}\end{array}$ & $\begin{array}{c}\text { Cycle 3 } \\
(\mathbf{1 7 , 5 8 4 )}\end{array}$ & $\begin{array}{c}\text { Cycle 4 } \\
(\mathbf{1 4 , 6 5 7 )}\end{array}$ & $\begin{array}{c}\text { Cycle 5 } \\
(\mathbf{1 1 , 4 0 1 )})\end{array}$ & $\begin{array}{c}\text { Cycle 6 } \\
(\mathbf{8 , 5 7 0 )}\end{array}$ \\
\hline Male & 0.50 & 0.50 & 0.50 & 0.50 & 0.50 & 0.52 \\
& $(0.50)$ & $(0.50)$ & $(0.50)$ & $(0.50)$ & $(0.50)$ & $(0.50)$ \\
Family income & 71,364 & 71,804 & 71,866 & 72,338 & 72,489 & 73,512 \\
& $(69,797)$ & $(67,259)$ & $(66,390)$ & $(66,971)$ & $(67,430)$ & $(69,936)$ \\
Reading score & 532 & 534 & 534 & 535 & 534 & 535 \\
& $(96)$ & $(94)$ & $(95)$ & $(95)$ & $(96)$ & $(97)$ \\
Grade age 15 & 3.08 & 3.10 & 3.11 & 3.12 & 3.11 & 3.11 \\
& $(1.10)$ & $(1.10)$ & $(1.09)$ & $(1.09)$ & $(1.10)$ & $(1.10)$ \\
Intact family & 0.71 & 0.72 & 0.73 & 0.73 & 0.73 & 0.74 \\
& $(0.45)$ & $(0.45)$ & $(0.45)$ & $(0.44)$ & $(0.44)$ & $(0.44)$ \\
Immigrant & 0.10 & 0.10 & 0.10 & 0.09 & 0.09 & 0.09 \\
& $(0.30)$ & $(0.30)$ & $(0.30)$ & $(0.29)$ & $(0.29)$ & $(0.28)$ \\
Parental education & 2.88 & 2.89 & 2.90 & 2.91 & 2.92 & 2.94 \\
& $(0.90)$ & $(0.90)$ & $(0.89)$ & $(0.89)$ & $(0.88)$ & $(0.87)$ \\
Parental hopes-univ. & 0.65 & 0.65 & 0.65 & 0.65 & 0.65 & 0.65 \\
& $(0.48)$ & $(0.48)$ & $(0.48)$ & $(0.48)$ & $(0.48)$ & $(0.48)$ \\
\hline
\end{tabular}

Source: Youth in Transition Survey, author's calculations. Standard deviations are shown in parenthesis.

This research makes use of all six cycles of the YITS. As with all longitudinal surveys, attrition is an issue, and is especially important here; by Cycle 6, which marked the final cycle of the survey, only 8,570 respondents remained, representing less than 40 percent of the origin sample. In the intervening cycles, attrition was steady and significant, as indicated in Figure A-1. With such substantial attrition from cycle to cycle, the

\footnotetext{
${ }^{73}$ Statistics Canada provides numerous weights for Cycle 1. After the non-respondent parents are dropped from the Cycle 1 sample, the appropriate weights for Cycle 1 are the "parent weights" rather than the "student weights". The student weights represent the entire responding student population, while the parent weights are adjusted to take into account the characteristics of non-responding parents.
} 
generalizability of the results is in question. To determine the extent to which results found using these diminishing samples can be generalized to the original target population, this section analyses the nature of the attrition from cycle to cycle. ${ }^{74}$

Figure A-1. Attrition, Cycles 1-6 (excluding Quebec)



Source: Youth in Transition Survey, author`s calculations.

If the attrition is random, then those who leave the survey are statistically identical to those who continue. The only issue is then the size of the sample, but not whether it is representative of the target population. If there is non-random attrition (i.e. those who leave the survey differ along some dimensions from those who stay) then as time goes on the remaining respondents become less and less representative of the original target population. However, even in the face of non-random attrition, it is still possible to generalize results to the original target population by using the appropriate longitudinal weights. For example, if people with lower income tend to leave the survey, then those with lower income who remain in the survey must have more weight placed on their responses. This is the idea behind the weights provided by Statistics Canada in each cycle of the survey.

Table 4 shows the average characteristics over a number of dimensions of the respondent and non-respondent populations from Cycle 1 to Cycle 2. As indicated above, 22,066 individuals have both student and parent Cycle 1 records, and thus constitute the initial sample for this study. The two columns beneath the "Cycle 2" heading represent the entire initial Cycle 1 population, either as Cycle 2 leavers (6.5\% of the Cycle 1 sample) or Cycle 2 participants $(93.5 \%$ of the Cycle 1 sample). These columns provide

\footnotetext{
${ }^{74}$ Because the sample was never topped up to reflect the changing demographics of the Canadian population, the results are generalizable only to the initial target population, which was youth aged 15 years who were living in Canada in 2000.
} 
information about the average characteristics of both the Cycle 2 leavers and Cycle 2 participants, over dimensions such as gender, family income, reading score and family structure. Each observation is weighted using Cycle 1 weights, since the entire Cycle 1 population is represented here.

Table A-4. Weighted Average Characteristics of the YITS Population Cycles 1 - 2.

\begin{tabular}{lcccc}
\hline & $\begin{array}{c}\text { Cycle 2 } \\
\text { weights) }\end{array}$ & Cycle 2 & (C1 weights) & $\begin{array}{c}\text { Cycle 2 } \\
\text { weights) }\end{array}$ \\
\hline Observations & C1 sample & Leavers & Participant & C2 sample \\
Male & 22,066 & 1,427 & 20,639 & 20,639 \\
& 0.50 & 0.50 & 0.50 & 0.50 \\
Family income & $(0.50)$ & $(0.50)$ & $(0.50)$ & $(0.50)$ \\
& 71,364 & 66,206 & 71,728 & 71,804 \\
Reading score & $(69,797)$ & $(98,091)$ & $(67,342)$ & $(67,259)$ \\
& 532 & 497 & 534 & 534 \\
Intact family & $(96)$ & $(101)$ & $(95)$ & $(94)$ \\
& 0.71 & 0.54 & 0.72 & 0.72 \\
Immigrant & $(0.45)$ & $(0.50)$ & $(0.45)$ & $(0.45)$ \\
& 0.10 & 0.13 & 0.10 & 0.10 \\
Parental & $(0.30)$ & $(0.34)$ & $(0.30)$ & $(0.30)$ \\
education & 2.88 & 2.74 & 2.88 & 2.89 \\
Hope university & $(0.90)$ & $(0.96)$ & $(0.90)$ & $(0.90)$ \\
& 0.65 & 0.60 & 0.65 & 0.65 \\
& $(0.48)$ & $(0.49)$ & $(0.48)$ & $(0.48)$ \\
\hline
\end{tabular}

Source: Youth in Transition Survey, author`s calculations. Standard deviations are in parenthesis.

It is clear that the average characteristics of the two groups differ substantially. For example, while $72 \%$ of the students who participated in the Cycle 2 survey reported (in Cycle 1) being from an intact family, only $54 \%$ of the students who did not participate in Cycle 2 reported (in Cycle 1) coming from an intact family. In addition, students who participated in the Cycle 2 survey had an average reading score of 534 (measured at age 15). This compares to an average reading score for "leavers" (those who did not participate in Cycle 2) of just 497 . Table 4 documents a number of other characteristics over which these two groups differ.

However, the population of leavers after cycle 1 (ie those who did not participate in Cycle 2) is moderate, at only $6.5 \%$ of the Cycle 1 sample, so that the average characteristics of survey participants from Cycle 1 to Cycle 2 is not substantially impacted. In addition, the weights assigned by Statistics Canada reflect the changing characteristics of the remaining population, so that a comparison of Cycle 1 respondents (applying Cycle 1 weights) and Cycle 2 respondents (applying Cycle 2 weights) indicates very little change in characteristics over the first two cycles. This is shown in the first and last data columns of Figure 4 (as well as in the first two data columns of Figure 3). 
Comparisons between leavers and participants from each cycle are provided across the rows of Table 5. ${ }^{75}$ Across all cycles, those who choose to no longer participate in the survey are statistically different from those who continue. However, as was the case when considering attrition between Cycles 1 and 2, individual weights are readjusted to reflect the changing characteristics of the remaining population. Thus, if the average characteristics of the weighted Cycle 1 sample are compared to the average characteristics of the weighted Cycle 6 population, as shown in the last two columns of Table 5 (also documented in Table 3), it is clear that the longitudinal weighting has done its job well. On average, those who have participated through all six cycles are slightly different than the initial population. Even with correctional weighting, the Cycle six sample has a higher proportion of intact families, as reported in Cycle 1, than the initial sample. Those who remain in the survey until Cycle 6 tend to have come from wealthier families (by only about \$2000). There are slightly fewer immigrants in the Cycle 6 group than in the initial sample; and the reading scores of those who remain in the survey through to the end are slightly higher than the average score of the initial sample. However, these differences are small and sometimes statistically insignificant, suggesting that analysis can be carried out using all six cycles of the survey.

\footnotetext{
${ }^{75}$ While the number of leavers is steady from cycle to cycle, especially after Cycle 1, these represent an increasingly large fraction of the remaining population. Between Cycles 5 and 6 , for example, 2,831 respondents left the survey, representing almost $25 \%$ of the Cycle 5 respondent population.
} 
Table A-5. Average Characteristics of the YITS Sample, from Cycle1 to Cycle 6, with Weights

\begin{tabular}{|c|c|c|c|c|c|c|c|c|c|c|c|c|c|}
\hline \multirow[b]{2}{*}{ Observations } & \multirow{2}{*}{$\begin{array}{c}\text { Cycle 1 } \\
\text { (C1 weights) } \\
\text { C1 sample } \\
22,066\end{array}$} & \multicolumn{2}{|c|}{$\begin{array}{c}\text { Cycle 2 } \\
\text { (C1 weights) }\end{array}$} & \multicolumn{2}{|c|}{$\begin{array}{c}\text { Cycle } 3 \\
\text { (C2 weights) }\end{array}$} & \multicolumn{2}{|c|}{$\begin{array}{c}\text { Cycle } 4 \\
\text { (C3 weights) }\end{array}$} & \multicolumn{2}{|c|}{$\begin{array}{c}\text { Cycle 5 } \\
\text { (C4 weights) }\end{array}$} & \multicolumn{2}{|c|}{$\begin{array}{c}\text { Cycle 6 } \\
\text { (C5 weights) }\end{array}$} & \multirow{2}{*}{$\begin{array}{c}\text { Cycle 6 } \\
\text { (C6 weights) } \\
\text { Final Pop. } \\
8,570\end{array}$} & \multirow{2}{*}{$\begin{array}{c}\text { Cycle 1 } \\
\text { (C1 weights) } \\
\text { C1 sample } \\
22,066\end{array}$} \\
\hline & & $\begin{array}{c}\text { Leavers } \\
1427\end{array}$ & $\begin{array}{l}\text { Stayer } \\
\mathbf{2 0 , 6 3 9}\end{array}$ & $\begin{array}{c}\text { Leavers } \\
\mathbf{3 , 0 5 5} \\
\end{array}$ & $\begin{array}{l}\text { Stayer } \\
17,584\end{array}$ & $\begin{array}{c}\text { Leavers } \\
\mathbf{2 , 9 2 7} \\
\end{array}$ & $\begin{array}{c}\text { Stayer } \\
\mathbf{1 4 , 6 5 7} \\
\end{array}$ & $\begin{array}{c}\text { Leavers } \\
\mathbf{3 , 2 5 6} \\
\end{array}$ & $\begin{array}{l}\text { Stayer } \\
11,401 \\
\end{array}$ & $\begin{array}{c}\text { Leavers } \\
\mathbf{2 , 8 3 1}\end{array}$ & $\begin{array}{c}\text { Stayer } \\
\mathbf{8 , 5 7 0}\end{array}$ & & \\
\hline Male & $\begin{array}{c}0.50 \\
(0.50)\end{array}$ & $\begin{array}{c}0.50 \\
(0.50)\end{array}$ & $\begin{array}{c}0.50 \\
(0.50)\end{array}$ & $\begin{array}{c}0.51 \\
(0.50)\end{array}$ & $\begin{array}{c}0.49 \\
(0.50)\end{array}$ & $\begin{array}{c}0.50 \\
(0.50)\end{array}$ & $\begin{array}{c}0.50 \\
(0.50)\end{array}$ & $\begin{array}{c}0.49 \\
(0.50)\end{array}$ & $\begin{array}{c}0.50 \\
(0.50)\end{array}$ & $\begin{array}{c}0.50 \\
(0.50)\end{array}$ & $\begin{array}{c}0.51 \\
(0.50)\end{array}$ & $\begin{array}{c}0.52 \\
(0.50)\end{array}$ & $\begin{array}{c}0.50 \\
(0.50)\end{array}$ \\
\hline Family income & $\begin{array}{c}71,364 \\
(69,797)\end{array}$ & $\begin{array}{c}66,206 \\
(98,091)\end{array}$ & $\begin{array}{c}71,728 \\
(67,342)\end{array}$ & $\begin{array}{c}66,728 \\
(58,325)\end{array}$ & $\begin{array}{c}72,727 \\
(68,721)\end{array}$ & $\begin{array}{c}66,350 \\
(48,291)\end{array}$ & $\begin{array}{c}73,046 \\
(69,597)\end{array}$ & $\begin{array}{c}69,288 \\
(52,662)\end{array}$ & $\begin{array}{c}73,296 \\
(70,850)\end{array}$ & $\begin{array}{c}66,635 \\
(40,383)\end{array}$ & $\begin{array}{c}74,679 \\
(74,967)\end{array}$ & $\begin{array}{c}73,512 \\
(69,936)\end{array}$ & $\begin{array}{c}71,364 \\
(69,797)\end{array}$ \\
\hline Reading score & $\begin{array}{l}532 \\
(96)\end{array}$ & $\begin{array}{c}497 \\
(101)\end{array}$ & $\begin{array}{l}534 \\
(95)\end{array}$ & $\begin{array}{l}509 \\
(96)\end{array}$ & $\begin{array}{l}539 \\
(93)\end{array}$ & $\begin{array}{l}512 \\
(95)\end{array}$ & $\begin{array}{l}539 \\
(94)\end{array}$ & $\begin{array}{l}519 \\
(93)\end{array}$ & $\begin{array}{l}539 \\
(95)\end{array}$ & $\begin{array}{l}514 \\
(93)\end{array}$ & $\begin{array}{l}542 \\
(96)\end{array}$ & $\begin{array}{l}535 \\
(97)\end{array}$ & $\begin{array}{l}532 \\
(96)\end{array}$ \\
\hline Grade age 15 & $\begin{array}{c}3.08 \\
(1.10)\end{array}$ & $\begin{array}{c}2.75 \\
(1.18)\end{array}$ & $\begin{array}{c}3.10 \\
(1.09)\end{array}$ & $\begin{array}{c}2.82 \\
(1.12)\end{array}$ & $\begin{array}{c}3.15 \\
(1.08)\end{array}$ & $\begin{array}{c}2.90 \\
(1.10)\end{array}$ & $\begin{array}{c}3.16 \\
(1.08)\end{array}$ & $\begin{array}{c}3.02 \\
(1.07)\end{array}$ & $\begin{array}{c}3.15 \\
(1.10)\end{array}$ & $\begin{array}{c}2.95 \\
(1.11)\end{array}$ & $\begin{array}{c}3.17 \\
(1.10)\end{array}$ & $\begin{array}{c}3.11 \\
(1.10)\end{array}$ & $\begin{array}{c}3.08 \\
(1.10)\end{array}$ \\
\hline Intact family & $\begin{array}{c}0.71 \\
(0.45)\end{array}$ & $\begin{array}{c}0.54 \\
(0.50)\end{array}$ & $\begin{array}{c}0.72 \\
(0.45)\end{array}$ & $\begin{array}{c}0.61 \\
(0.49)\end{array}$ & $\begin{array}{c}0.74 \\
(0.44)\end{array}$ & $\begin{array}{c}0.67 \\
(0.47)\end{array}$ & $\begin{array}{c}0.74 \\
(0.44)\end{array}$ & $\begin{array}{c}0.70 \\
(0.46)\end{array}$ & $\begin{array}{c}0.74 \\
(0.44)\end{array}$ & $\begin{array}{c}0.70 \\
(0.46)\end{array}$ & $\begin{array}{c}0.74 \\
(0.44)\end{array}$ & $\begin{array}{c}0.74 \\
(0.44)\end{array}$ & $\begin{array}{c}0.71 \\
(0.45)\end{array}$ \\
\hline Immigrant & $\begin{array}{c}0.10 \\
(0.30)\end{array}$ & $\begin{array}{c}0.13 \\
(0.34)\end{array}$ & $\begin{array}{c}0.10 \\
(0.30)\end{array}$ & $\begin{array}{c}0.12 \\
(0.32)\end{array}$ & $\begin{array}{c}0.10 \\
(0.30)\end{array}$ & $\begin{array}{c}0.12 \\
(0.32)\end{array}$ & $\begin{array}{c}0.09 \\
(0.29)\end{array}$ & $\begin{array}{c}0.12 \\
(0.32)\end{array}$ & $\begin{array}{c}0.09 \\
(0.28)\end{array}$ & $\begin{array}{c}0.11 \\
(0.31)\end{array}$ & $\begin{array}{c}0.09 \\
(0.28)\end{array}$ & $\begin{array}{c}0.09 \\
(0.28)\end{array}$ & $\begin{array}{c}0.10 \\
(0.30)\end{array}$ \\
\hline Parental ed. & $\begin{array}{c}2.88 \\
(0.90)\end{array}$ & $\begin{array}{c}2.74 \\
(0.96)\end{array}$ & $\begin{array}{c}2.88 \\
(0.90)\end{array}$ & $\begin{array}{c}2.74 \\
(0.94)\end{array}$ & $\begin{array}{c}2.91 \\
(0.89)\end{array}$ & $\begin{array}{c}2.77 \\
(0.90)\end{array}$ & $\begin{array}{c}2.92 \\
(0.89)\end{array}$ & $\begin{array}{c}2.81 \\
(0.91)\end{array}$ & $\begin{array}{c}2.94 \\
(0.88)\end{array}$ & $\begin{array}{c}2.80 \\
(0.88)\end{array}$ & $\begin{array}{c}2.96 \\
(0.87)\end{array}$ & $\begin{array}{c}2.94 \\
(0.87)\end{array}$ & $\begin{array}{c}2.88 \\
(0.90)\end{array}$ \\
\hline Hope univ. & $\begin{array}{c}0.65 \\
(0.48)\end{array}$ & $\begin{array}{c}0.60 \\
(0.49)\end{array}$ & $\begin{array}{c}0.65 \\
(0.48)\end{array}$ & $\begin{array}{c}0.62 \\
(0.49)\end{array}$ & $\begin{array}{c}0.66 \\
(0.47)\end{array}$ & $\begin{array}{c}0.59 \\
(0.49)\end{array}$ & $\begin{array}{c}0.66 \\
(0.47)\end{array}$ & $\begin{array}{c}0.62 \\
(0.49)\end{array}$ & $\begin{array}{c}0.66 \\
(0.47)\end{array}$ & $\begin{array}{c}0.59 \\
(0.49)\end{array}$ & $\begin{array}{c}0.67 \\
(0.47)\end{array}$ & $\begin{array}{c}0.65 \\
(0.48)\end{array}$ & $\begin{array}{c}0.65 \\
(0.48)\end{array}$ \\
\hline
\end{tabular}

Source: Youth in Transition Survey, author's calculations. Standard deviations are shown in parenthesis. 
Appendix 3.B: Construction of the Outcome Variable "Highest Education Taken"

The outcome variable "highest education taken" was constructed for both Cycle 3 and Cycle 6. In both cases, the variable was constructed using two derived variables from the YITS, HEDLD3 (HEDLD6 for Cycle 6) and HLPSD3 (HLPSD6 for Cycle 6).

HEDLD3(6): Highest education taken as of Dec. 2003 (2009).

$1=$ Education below high school completion.

$2=$ High School graduation .

HLPSD3: Highest level of post-secondary education taken

$2=$ Attestation of vocational specialisation

$3=$ Private business school or training institute diploma or certificate

4 = Registered apprenticeship program

$5=$ College or CÉGEP program

6 = University transfer program at a college or CÉGEP (for credits, university transfer diploma or associate`s degree)

7 = College post-diploma or grad level program (college diploma or higher needed first)

$8=$ University diploma or certificate below Bachelor`s degree

$9=$ Bachelor`s degree

$10=$ First professional degree (eg. law, dentistry, medicine)

$11=$ Graduate-level diploma or certificate above Bachelor`s, below Master`s .

$12=$ Master`s degree

$13=\mathrm{Ph} . \mathrm{D}$. degree

20 = Diploma, certificate or licence from a professional association (e.g. accounting, banking, insurance)

$23=$ Other level of post-secondary education

The dependant variable, highest education taken as of Cycle 3 (Cycle 6), is constructed as outlined in table B-1: 
Table B-1. Construction of the dependant variable "highest education taken".

\begin{tabular}{|l|l|l|}
\hline Highest education taken & Category name & Defined by \\
\hline $\begin{array}{l}\text { Less than high school graduation by age 19 } \\
\text { (age 25) }\end{array}$ & "Less HS" & HEDLD3(6) $=1$ \\
\hline High school graduation by age 19 (age 25) & "HS grad" & HEDLD3(6) $=2$ \\
\hline At least some college by age 19 (age 25) & "College" & $0<$ HLPSD3(6) $<9$ \\
\hline At least some university by age 19 (age 25) & "University" & $9<=$ HLPSD3(6)<23 \\
\hline
\end{tabular}

Source: Youth in Transition Survey, author`s illustration.

Individuals who reported a highest post-secondary education of "other" (HLPSD3(6)=23) are dropped from the sample, as it is unclear what sort of PSE this response represents. The number of respondents who give "other" as their highest post-secondary education taken is very small (32 observations, unweighted). They are disproportionately from PEI and Manitoba, are all Canadian born and are disproportionately rural dwellers.

There are a few categories that were difficult to assigned to college versus university, for example HLPSD3=8, a university diploma or certificate below a BA. In the end, this was assigned to mean at least some college. However, only a very small number of individuals responded to the post-secondary education questions with this answer, so whether they are assigned to "at least some university" or "at least some college" has no effect on the outcome of the statistical analysis. Category 20, "diploma, certificate or license from a professional association as in accounting, banking or insurance" is also unclear. In some cases a university undergraduate degree is required (e.g., Chartered Professional Accountant, Engineering Associations), but in others only work experience and a short training period may be necessary (Certified Personal Trainer). In this paper, educational category 20 is assigned to "more than a BA". 


\section{Appendix 3.C: Examining the Subsample with Less Than a High School Diploma}

The main focus of this research is on the decision to pursue post-secondary education or not. In order for researchers to "observe" this decision in the data, the student needs to have completed high school. Those who have dropped out, or who not yet finished high school, are not in a position to participate in PSE, so they are excluded from the main analysis. ${ }^{76}$ This appendix examines the characteristics of these students.

Students who report their highest education taken as less than a high school diploma are either still finishing high school, or have left high school prior to graduation. Table C-1 shows the frequency of both continuers and leavers in the sample (as well as high school graduates, for reference), in both Cycle 3 and Cycle 6. Continuers made up $4.7 \%$ of the sample in Cycle 3, with leavers making up slightly more of the sample, at 5.0\%. Most of those who were high school continuers in Cycle 3 had graduated by Cycle 6 (81.8\%), with only a small fraction (2.2\%) still in high school by the end of the survey. By contrast, those who reported being high school leavers in Cycle 3 tended to remain leavers, with only $38 \%$ finishing high school by the final cycle (age 25 ).

Table C-1. High School Status as of Cycles 3 and 6.

\begin{tabular}{llll}
\hline & \multicolumn{3}{c}{ Cycle 6 high school status } \\
\hline Cycle 3 HS status: & $\begin{array}{l}\text { HS graduate } \\
\text { (C6) }\end{array}$ & $\begin{array}{l}\text { HS continuer } \\
\mathbf{( C 6 )}\end{array}$ & $\begin{array}{l}\text { HS leaver } \\
(\mathbf{C 6})\end{array}$ \\
& $(96.0 \%)$ & $\mathbf{( 0 . 3 \% )}$ & $(3.7 \%)$ \\
HS graduate $(90.3 \%)$ & 100.0 & 0.0 & 0.0 \\
HS continuer $(4.7 \%)$ & 81.8 & 2.2 & 16.0 \\
HS leaver $(5.0 \%)$ & 38.0 & 3.8 & 58.2 \\
\hline
\end{tabular}

Source: Youth in Transition Survey, author`s calculations.

Table C-2 provides descriptive statistics for all three subsamples - high school graduates, high school continuers, and high school dropouts as of age 19, Cycle 3. While the high school graduate group is comprised of equal numbers of boys and girls, both high school continuers and high school leavers are made up of substantially more boys than girls. High school continuers, for instance, are two thirds boys. Compared to respondents who have received their high school diploma, non-graduates (both high school leavers and continuers) have lower reading and learning skills, are far more disengaged, and have lower levels of self-esteem and self-efficacy. Their parents tend to be less educated, and they are less likely to come from an intact family.

\footnotetext{
${ }^{76}$ In a small number of cases students who drop out of high school can attend university or college without finishing high school. Of the YITS students who had not graduated from high school as of the final cycle (age 25), only $7.5 \%$ were still in high school, leaving $92.5 \%$ as dropouts who had not returned to high school. However, within this group $17.9 \%$ reported having participated in at least some college, and $3.4 \%$ in at least some university.
} 
However, non-graduates are not a homogeneous group. Continuers are distinct from leavers in a number of ways. First, 11 percent of the continuer group are immigrants, compared to only 6 percent in the leavers group, and 9 percent among graduates. It is notable that high school leavers have the lowest fraction of immigrants. Moreover, leavers have substantially higher reading scores than continuers. Given the lower cognitive skills (and overall academic performance) of high school continuers, it is of note that they have, on average, higher educational aspirations than high school dropouts. Notably, continuers have the highest fraction of boys of any of the three groups, at 67 percent.

Table C-2. Descriptive Statistics for Cycle 3 High School Graduates, Continuers, and Leavers

\begin{tabular}{lllllll}
\hline & \multicolumn{2}{c}{ HS grad (7,953) } & \multicolumn{2}{c}{ HS continuer } & \multicolumn{2}{c}{ HS leaver (314) } \\
& \multicolumn{2}{c}{ (248) } & & \\
\hline Mean & Std. dev. & Mean & Std. dev. & Mean & Std. dev. \\
Urban & 0.50 & 0.50 & 0.67 & 0.47 & 0.61 & 0.49 \\
Immigrant & 0.79 & 0.40 & 0.77 & 0.42 & 0.74 & 0.44 \\
Family income & 0.09 & 0.29 & 0.11 & 0.32 & 0.06 & 0.23 \\
Intact & 11.06 & 0.61 & 10.83 & 0.64 & 10.73 & 0.56 \\
Parental education: & 0.76 & 0.43 & 0.51 & 0.50 & 0.46 & 0.50 \\
$\quad$ Less than HS & 0.04 & 0.20 & 0.08 & 0.26 & 0.16 & 0.37 \\
$\quad$ HS only & 0.27 & 0.44 & 0.36 & 0.48 & 0.33 & 0.47 \\
$\quad$ College & 0.37 & 0.48 & 0.42 & 0.50 & 0.41 & 0.49 \\
$\quad$ University & 0.32 & 0.47 & 0.14 & 0.35 & 0.11 & 0.31 \\
Student aspirations: & & & & & & \\
$\quad$ < university degree & 0.29 & 0.45 & 0.57 & 0.50 & 0.69 & 0.46 \\
$\quad$ University degree & 0.31 & 0.46 & 0.27 & 0.44 & 0.17 & 0.38 \\
$\quad$ Graduate degree & 0.40 & 0.49 & 0.17 & 0.37 & 0.14 & 0.35 \\
Parental hopes-univ. & 0.68 & 0.47 & 0.42 & 0.49 & 0.36 & 0.48 \\
Grade at age 17 & 3.24 & 0.92 & 2.16 & 0.86 & 2.21 & 0.90 \\
Reading score & 0.19 & 0.99 & -0.72 & 1.03 & -0.57 & 0.91 \\
Disengagement & -0.07 & 0.96 & 0.71 & 1.03 & 0.84 & 1.34 \\
Learning skills & 0.11 & 0.92 & -0.99 & 1.22 & -0.99 & 1.15 \\
Perceptions & 0.05 & 0.93 & -0.67 & 1.28 & -0.60 & 1.24 \\
Self-esteem & 0.08 & 0.98 & -0.11 & 1.00 & -0.28 & 0.95 \\
Fatalism & -0.01 & 0.98 & 0.17 & 1.07 & 0.21 & 0.94 \\
Self-efficacy & 0.10 & 0.98 & -0.35 & 1.18 & -0.63 & 0.97 \\
\hline Source: Yout & & & & & \\
\hline
\end{tabular}

Source: Youth in Transition Survey, author`s calculations.

The role of gender in determining high school status (as of Cycle 3) is unclear. There are substantially more boys in both non-graduate groups. However, Table C-2 indicates that boys have lower levels of reading and learning skills, as well as aspirations, factors that are generally associated with high school leaving and graduation delay. The extent to which gender is, on its own, an important determinant of high school completion is examined using regression analysis. 
The model is estimated using a multinomial logit regression, where the outcome variable, $\mathrm{Y}_{\mathrm{i}}$ is high school status as of Cycle 3 (age 19). ${ }^{77}$ This categorical variable takes on the values

$Y_{i}\left\{\begin{array}{l}=1 \text { for high school leavers } \\ =2 \text { for high school continuers } \\ =3 \text { for high school graduates }\end{array}\right.$

The vector of explanatory variables is described by $x_{i}$, and includes variables discussed in Table C-2. The regression takes the form of maximum likelihood estimation, where the likelihood function is written,

$$
L^{i}=\prod_{j=0}^{J} \operatorname{prob}\left(Y_{i}=j \mid x_{i}\right)^{I\left(Y_{i}=j\right)}
$$

Table C-3 shows the marginal effects on high school status for each variable. ${ }^{78}$ These take the form of conditional probabilities of being in each of the three possible categories for high school status - high school leaver, high school continuer and high school graduate. The results from Table C-3 indicate the variables that are important in determining high school status. Grade in the last year of schooling taken appears to be an important determinant of high school status. A student with a grade of $<60$ in their last year of schooling is 4 percentage points more likely to be a high school leaver than a student with a grade in the 70s (the reference group), and 7 percentage points more likely to be a high school continuer, by age 19. Reading and learning skills are also significant determinants of high school status. Notably, gender has no direct role to play in determining high school completion. Once factors such as reading skills, non-cognitive skills (such as disengagement, perceptions and learning skills) and aspirations are taken into account, gender is not a significant determinant of high school status.

The roles of various sociodemographic factors are of interest. Family status stands out as being key determinant of high school completion, with students from intact families being 5.2 percentage points more likely to complete high school than students from any other family configuration. Immigrant status also stands out among the many background variables considered. Students who were not born in Canada are 4.8

77 Multinomial logit regressions are a series of binomial logit regressions. In this case, the base (or reference) group is high school graduates. First a logit model is estimated using graduates versus continuer, then using graduate versus leaver.

${ }^{78}$ These are post-estimation results. The multinomial logit estimation returns a set of parameter estimates, one for each binomial logit, which are in the form of log odds. These are then used to derive the marginal effects post-estimation. The coefficient estimates are available on request. 
percentage points more likely than Canadian born students to be high school continuers by age 19. Recall that this is the marginal effect of immigrant status, holding all else constant. Thus, the over-representation of immigrants in the high school continuer category is not due to lower skills or aspirations, as these factors are included in the regression analysis.

Finally, a number of provincial controls were found to be significant and substantial in the size of their effect. Being from Nova Scotia, for example, is associated with a decreases in the likelihood of high school completion by age 19 of 5.7 percentage points, vis-à-vis the reference group of Ontario. Students from Manitoba are 6 percentage points more likely to be high school leavers, again vis-à-vis students from Ontario. This suggests that there are province-specific characteristics, which are linked to the likelihood of high school graduation, that have been excluded from the analysis. These might include factors such as labour market effects (the opportunity to leave school and work in the fisheries), and demographic factors (Aboriginal populations). 
Table C-3. Marginal Effects on High School Status at Age 19 (Cycle 3)

\begin{tabular}{|c|c|c|c|}
\hline & Prob. (HS leaver) & Prob. (HS continuer) & Prob. (HS graduate) \\
\hline \multicolumn{4}{|l|}{ Grade in senior yr HS: } \\
\hline \multirow[t]{2}{*}{$<\mathbf{6 0}$} & $0.039 *$ & $0.070 * * *$ & $-0.110 * * *$ \\
\hline & $(0.023)$ & $(0.028)$ & $(0.033)$ \\
\hline \multirow[t]{2}{*}{ In the $60 \mathrm{~s}$} & 0.000 & $0.024 * *$ & -0.024 \\
\hline & $(0.012)$ & $(0.012)$ & $(0.016)$ \\
\hline in the $70 \mathrm{~s}$ & reference & & \\
\hline \multirow{2}{*}{ in the $80 \mathrm{~s}$} & $-0.035 * * *$ & -0.004 & $0.039 * * *$ \\
\hline & $(0.008)$ & $(0.012)$ & $(0.013)$ \\
\hline \multirow[t]{2}{*}{ in the $90 \mathrm{~s}$} & $-0.038 * * *$ & $-0.021 * *$ & $0.058 * * *$ \\
\hline & $(0.009)$ & $(0.009)$ & $(0.012)$ \\
\hline \multirow{2}{*}{ Reading score } & $-0.007 *$ & $-0.019 * * *$ & $0.026 * * *$ \\
\hline & $(0.004)$ & $(0.007)$ & $(0.008)$ \\
\hline \multirow[t]{2}{*}{ Disengagement } & 0.007 & $0.009 *$ & $-0.015^{* *}$ \\
\hline & $(0.006)$ & $(0.005)$ & $(0.007)$ \\
\hline \multirow[t]{2}{*}{ Learning Skills } & $-0.011 * * *$ & $-0.011 * *$ & $0.022 * * *$ \\
\hline & $(0.004)$ & $(0.005)$ & $(0.006)$ \\
\hline \multirow[t]{2}{*}{ Perceptions } & $-0.011 * *$ & -0.003 & $0.014 * *$ \\
\hline & $(0.005)$ & $(0.005)$ & $(0.006)$ \\
\hline \multirow[t]{2}{*}{ Self-esteem } & -0.005 & 0.001 & 0.004 \\
\hline & $(0.006)$ & $(0.007)$ & $(0.008)$ \\
\hline \multirow[t]{2}{*}{ Fatalism } & $-0.013 * *$ & -0.006 & $0.019 * *$ \\
\hline & $(0.007)$ & $(0.007)$ & $(0.009)$ \\
\hline \multirow[t]{2}{*}{ Self-efficacy } & -0.005 & -0.003 & 0.008 \\
\hline & $(0.004)$ & $(0.005)$ & $(0.006)$ \\
\hline \multirow[t]{2}{*}{ Nova Scotia } & $0.047 * *$ & 0.010 & $-0.057 * * *$ \\
\hline & $(0.021)$ & $(0.014)$ & $(0.022)$ \\
\hline \multirow{2}{*}{ Manitoba } & $0.060 * * *$ & $-0.021 * *$ & $-0.039 * *$ \\
\hline & $(0.019)$ & $(0.009)$ & $(0.019)$ \\
\hline \multirow[t]{2}{*}{ Alberta } & $0.031 * *$ & 0.000 & $-0.030 *$ \\
\hline & $(0.014)$ & $(0.011)$ & $(0.017)$ \\
\hline \multirow[t]{2}{*}{ Male } & -0.003 & -0.007 & 0.009 \\
\hline & $(0.010)$ & $(0.010)$ & $(0.012)$ \\
\hline \multirow[t]{2}{*}{ Urban } & 0.011 & 0.006 & -0.017 \\
\hline & $(0.007)$ & $(0.010)$ & $(0.010)$ \\
\hline \multirow[t]{2}{*}{ Immigrant } & -0.011 & $0.048^{*}$ & -0.037 \\
\hline & $(0.023)$ & $(0.025)$ & $(0.030)$ \\
\hline \multirow[t]{2}{*}{ Family income } & -0.009 & 0.003 & 0.005 \\
\hline & $(0.008)$ & $(0.007)$ & $(0.011)$ \\
\hline Intact & $-0.026 * * *$ & $-0.026 * *$ & $0.052 * * *$ \\
\hline & $(0.010)$ & $(0.013)$ & $(0.015)$ \\
\hline Less than univ. & reference & & \\
\hline Undergrad univ. degree & $-0.019^{* *}$ & 0.006 & 0.013 \\
\hline & $(0.009)$ & $(0.012)$ & $(0.014)$ \\
\hline Grad univ. degree & -0.012 & 0.000 & 0.013 \\
\hline & $(0.010)$ & $(0.013)$ & $(0.014)$ \\
\hline Parental education: & & & \\
\hline Less than HS & $0.029 *$ & -0.003 & -0.026 \\
\hline & $(0.018)$ & $(0.014)$ & $(0.020)$ \\
\hline HS only & 0.003 & 0.002 & -0.005 \\
\hline & $(0.009)$ & $(0.012)$ & $(0.012)$ \\
\hline College & & & \\
\hline University & -0.010 & -0.009 & 0.019 \\
\hline & $(0.010)$ & $(0.011)$ & $(0.014)$ \\
\hline Parental hopes (univ.) & $-0.016^{* *}$ & -0.004 & $0.020^{*}$ \\
\hline & $(0.008)$ & $(0.010)$ & $(0.011)$ \\
\hline
\end{tabular}

Source: Youth in Transition Survey, author`s calculations. 


\section{Thesis Conclusions}

In all three essays, gender gaps in academic outcomes are observed: in primary school rankings; in overall grade in senior high school; and in participation in postsecondary education. In the literature, these gaps have been attributed to gender-based differences in skills, particularly non-cognitive skills. In each of these essays, then, non-cognitive skills have been measured and included in the analysis. In the first essay, gender gaps in attention related skills and impulse control skills were identified, with boys lagging girls considerably in these skills. This gap explained some, but not all, of the difference in class ranking by gender. In the last two chapters, boys were shown to lag girls over skills related to conscientiousness and persistence. Again, these skills contributed to explaining a portion of the gap in academic outcomes.

Why do boys lag girls over this important skills dimension? While there are likely biological and social factors at work (Bertrand and Pan, 2013), the evidence provided in these essays suggest that the institution of school itself may contribute to this gap. In the first essay, which examines non-cognitive skills in early primary school, there is a considerable difference between teacher and parental assessments of skills, suggesting the possibility that the school environment exacerbates pre-existing differences in skills between boys and girls. Researchers have pointed to factors such as the increasing emphasis on early literacy, the decline in recess and physical education in schools, and the feminization of early education, to explain the negative impact the school environment appears to have on non-cognitive skills development in boys (Tyre, 2008). Others such as Lai (2010) suggest that the highly test-oriented education system may lie behind the lower non-cognitive skills of boys observed in later education, as documented in the second and third chapters.

In each of these essays, there is also a direct role for gender in explaining the various outcomes. If the significant role for gender is not an artifact of omitted variable bias, then what explains the significance of gender in these analyses? Some researchers point to unconscious biases in grading by teachers which favours girls over boys (Lavy, 2008; Cornwell, Mustard and Van Parys, 2013). This research gives some support to the unconscious bias hypothesis. Other researchers point to the lack of male educators, from whom boys appear to better able to learn, as a potential cause for the differences in outcomes by gender (Dee, 2006). Neither of the datasets used in these essays is suitable for verifying this claim. However, the role that teacher gender plays in determining academic outcomes is deserving of further study.

In the second and third essays, student aspirations for university education were discussed. Boys lagged girls considerably over aspirations, which explained a substantial fraction of the gender gap in participation in PSE. We know very little about the 
formation of aspirations. It is possible that the early gaps in non-cognitive skills, exacerbated by institutional factors within schools, lay the foundations for these later-life gaps in educational aspirations. Fortin et al. (2015) suggest that his may be the case. In addition, aspirations may also be influenced by unconscious teacher bias, or by the ability of boys to learn from female teachers. There is clearly a need to identify the factors influencing the evolution of aspirations.

From the perspective of education policy, these essays suggest a number of areas that require remediation: the gap in non-cognitive skills that opens early between boys and girls, and that appears to persist throughout formal schooling; the institutional factors that appear to exacerbate this gap, at least during the early years; and the possibility of unconscious bias within the classroom, from early primary to the senior year of high school. There is also a clear need to examine the effects of all of these on the formation of educational aspirations. 